$$
\begin{aligned}
& \text { Universidade de São Paulo } \\
& \text { Departamento de Geografia }
\end{aligned}
$$

FORMAÇÃO DE CARBONATOS E ARGILO-MINERAIS EM SOLOS SÓDICOS DO PANTANAL SUL-MATO-GROSSENSE

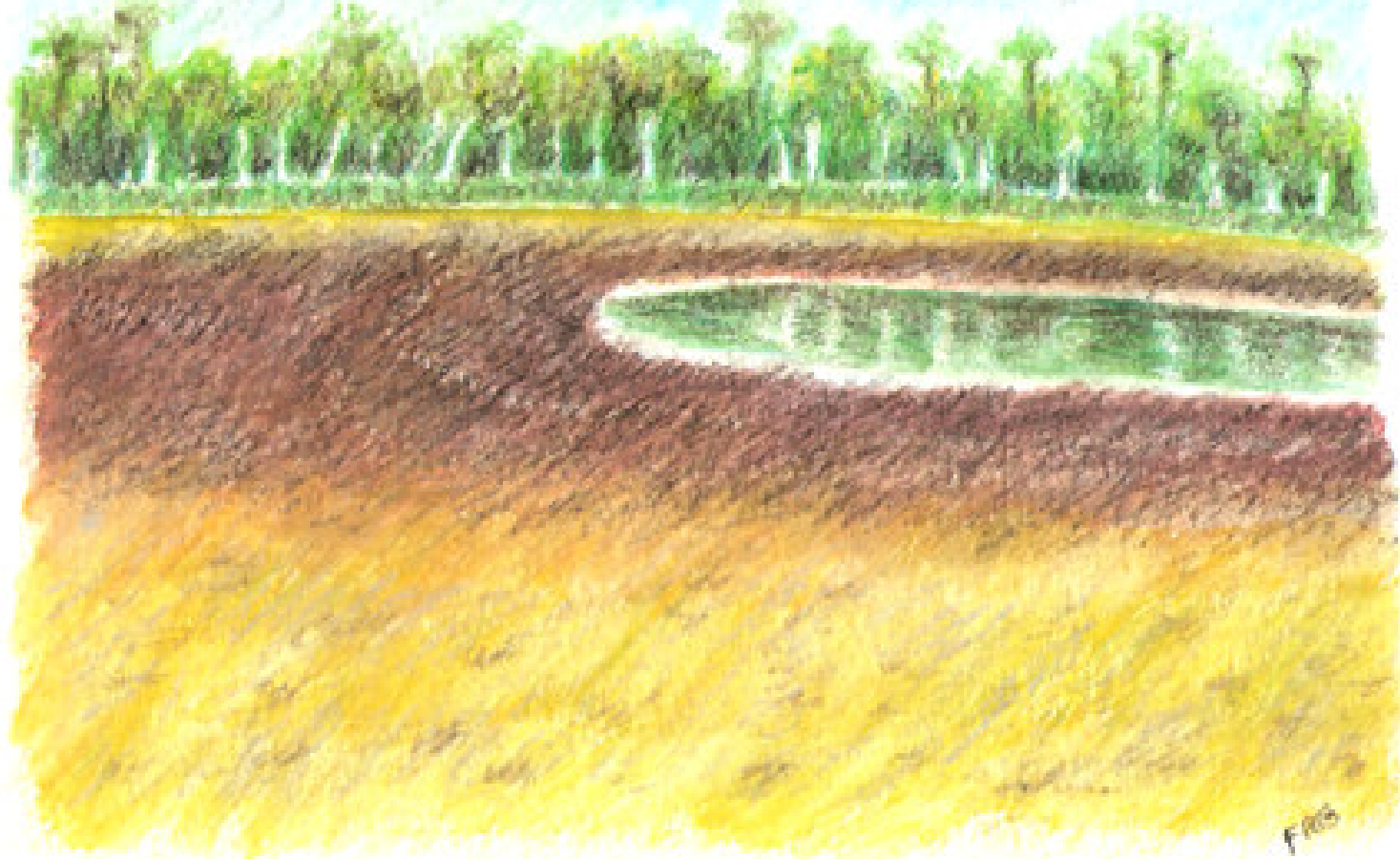

Sheila Aparecida Correia Furquim

Tese de Doutorado 


\section{FORMAÇÃO DE CARBONATOS E ARGILO-MINERAIS EM SOLOS SÓDICOS DO PANTANAL SUL-MATO-GROSSENSE}

\section{SHEILA APARECIDA CORREIA FURQUIM}

\section{Orientador:}

Prof. Dr. José Pereira de Queiroz Neto

Tese apresentada ao Departamento de Geografia da Faculdade de Filosofia, Letras e Ciências Humanas da Universidade de São Paulo, para obtenção do título de Doutor em Geografia Física. 
Ao Fernando e ao Felipe 


\section{APRESENTAÇÃO}

O presente trabalho inseriu-se no projeto de colaboração Capes-Cofecub ( $\left.\mathrm{n}^{\mathrm{o}} 412 / 03\right)$, formado por pesquisadores brasileiros e franceses da Universidade de São Paulo (USP), Universidade Federal do Mato Grosso do Sul (UFMS), "Université Paul Sabatier", "Institut de Recherche pour le Développement (IRD)" e "Université de Provence". Este projeto, conhecido como Projeto Pantanal, teve a duração de 4 anos (2003-2006) e apresentou como temática central o funcionamento hidrológico, físico e biogeoquímico do pantanal da Nhecolândia (Mato Grosso do Sul). Esta tese contou ainda com uma importante colaboração científica com a "University of CaliforniaRiverside (UCR)", firmada entre a presente autora e o Prof. Dr. Robert C. Graham, entre os anos de 2003 e 2005.

O texto apresentado a seguir foi organizado em 6 capítulos. Os capítulos 3, 4 e 5 foram estruturados exatamente como artigos científicos, sendo que cada um deles discorre sobre um conjunto coerente de resultados. A introdução geral (capítulo 1) e a conclusão geral (capítulo 6) foram escritas com a finalidade de conectar os capítulos 3,4 e 5 entre si, aos principais objetivos da tese e às conclusões mais importantes. A inclusão de um capítulo de revisão detalhada sobre o meio físico da região em que se insere a área de estudo (capítulo 2) foge, de certa forma, à estrutura geral adotada, mas foi necessária para fornecer ao leitor subsídios para uma melhor compreensão das interpretações dos resultados. 


\section{AGRADECIMENTOS}

Ao Prof. Dr. José Pereira de Queiroz Neto por orientar este trabalho com grande dedicação e sabedoria e por respeitar as minhas iniciativas no decorrer destes anos.

Ao Prof. Dr. Robert C. Graham, da "University of California-Riverside (UCR)" e ao Dr. Laurent Barbiéro, do "Institut de Recherche pour la Développement (IRD)", pela co-orientação e grande apoio material.

Ao Prof. Dr. Pablo Vidal-Torrado, da ESALQ/USP, e ao Prof. Dr. Arnaldo Sakamoto, da UFMS, pelas sugestões e apoio material.

Ao Prof. Dr. J.B. Dixon, da “Texas A\&M University”, ao Prof. Dr. Chris Amrhein, da "University of California-Riverside (UCR)", à Prof ${ }^{\mathrm{a}}$. Dr ${ }^{\mathrm{a}}$. Monique Fort, da Université Paris-VII, à Prof ${ }^{\mathrm{a}}$. Dr ${ }^{\mathrm{a}}$. Nádia do Nascimento, da UNESP-Rio Claro, ao Prof. Dr. Daniel Atêncio, do Instituto de Geociências/USP, à Prof ${ }^{\mathrm{a}}$. Dr ${ }^{\mathrm{a}}$. Lucy Gomes Sant'Anna, da USP/Leste, ao Prof. Dr. João Bertoldo de Oliveira, do IAC-Campinas e à Prof ${ }^{\mathrm{a}}$. Dr ${ }^{\mathrm{a}}$. Célia Regina Montes, do CENA/USP pelas discussões e preciosas sugestões.

Ao Dr. Douglas Ming e ao Dr. Richard Morris, ambos da NASA-Houston, e ao Prof. Dr. Vincent Vallés, da "Université de Provence", por fornecer informações valiosas a respeito da área de estudo.

À Prof ${ }^{a}$. Dr ${ }^{\mathrm{a}}$. Rosely Pacheco Dias Ferreira, à Prof ${ }^{\mathrm{a}}$. Dr ${ }^{\mathrm{a}}$ Déborah de Oliveira, à Prof ${ }^{\mathrm{a}}$. $\operatorname{Dr}^{\mathrm{a}}$. Sônia Furian, e à $\operatorname{Prof}^{\mathrm{a}}$. Dr ${ }^{\mathrm{a}}$. Sidneide Manfredini pela amizade e o apoio constante e irrestrito.

Aos técnicos de nível superior Paul Sternberg, da "University of California-Riverside (UCR)", Marcos Pinheiro, da Geografia/USP, e Luís Silva, da ESALQ/USP, pela grande assistência nas análises laboratoriais.

Aos funcionários da Fazenda Nhumirim, da Embrapa-Pantanal, e aos seguintes alunos e ex-alunos de graduação e pós-graduação da UFMS: Ary Tavares Rezende Filho, Mauro Henrique Soares da Silva, Vitor Matheus Bacani, Frederico dos Santos Gradella, Kleber Renan de Souza Santos, Lenise Silva, Jaqueline Aparecida Pontes Viana e Camila Franciele da Silva Malone pelo apoio fundamental nos trabalhos de campo. 
À Coordenação de Aprimoramento de Pessoal de Nível Superior-CAPES, pelo fornecimento da bolsa de estudo em nível de doutorado, ao Projeto Capes-Cofecub 412/03 pelo apoio financeiro, à Secretaria Estadual de Meio Ambiente de Mato Grosso do Sul, pelo constante apoio institucional, ao Laboratório de Pedologia do Departamento de Geografia/USP e ao "Soil Mineralogy Laboratory", da University of California-Riverside (UCR)", pelo usos de suas dependências e pelo apoio material.

Ao Paul Sternberg, Daniel Hirmas, Susan Akers, Joan Breiner e Nicole pela convivência agradável no laboratório "Soil Mineralogy" da UCR e pelas discussões interessantes a respeito de solos, Brasil, EUA, Alemanha, presidente Bush, etc...

À Suely Teodoro de Souza, Lia Teodoro Martins e João Vítor Teodoro Martins por gentilmente cederem sua casa para que me hospedasse em Piracicaba e por serem os primeiros a testemunharem um momento muito especial na minha vida.

À Nanette Pratini, Letitia Pepper, Eliana Pacheco, Rosana Dias Aranha, David Trostli, Gustavo Armani, Ana Galetti, Déborah de Oliveira, Cintia Gomes da Fontes Peruzzin, Marcelo Peruzzin, Lúcia Regina Machado da Rocha, Silvia Mitiko Nishida, Sandra Cordellini, Roberta Ribeiro Costa, Amanda Mangeon, Ricardo Junqueira, Francisco e Maricleud Figueiredo, Leonardo Djajarahardja, Jardel Moreira, Tânia Matsuo, Rodrigo Jungmann, Mariana e Rodrigo Krugner, Giuliano e Edilene Marchi, Pablo Viana, Sérgio e Sheila Solter, Nelson e Susana Lozano, Valéria Rogick Barragán e Bruce Pepper, amigos que me proporcionaram momentos de alegria e descontração e que, muitas vezes, desempenharam o papel da minha própria família.

Aos meus pais Laércio Furquim e Terezinha Correia Furquim, aos meus irmãos Tânia Aparecida Correia Furquim e Laércio Furquim Júnior, aos meus sogros Diego Gomes Rodrigues e Judith Ribeiro Gomes e aos meus cunhados Pedro Gonzalez, Gabriela Leirias Barbosa, Idevan Aparecido Martins Vila, Elisabeth Gomes Martins e Denise Ribeiro Gomes, pela constante apoio e paciência. Aos meus sobrinhos Lia Morena Leirias Barbosa Correia Furquim, Caetano Leirias Barbosa Correia Furquim, Thiago Gomes Martins e Ederson Gomes Martins, por trazerem alegria à minha vida.

À Sônia Maria Vieira, por cuidar da nossa casa e tratar o meu filho com carinho.

Ao meu grande amor Fernando Ribeiro Gomes, pela inesgotável paciência, imensurável ajuda e grande carinho em todos os momentos. E ao meu bebê Felipe Furquim Gomes, por ser a maior alegria e orgulho da minha vida. 


\section{RESUMO}

Uma característica de destaque da Nhecolândia, uma sub-região do Pantanal Sul-MatoGrossense, é a presença de lagoas doces (baías) e salgadas (salinas) com uma grande variabilidade química entre si. Apesar da presença de sal nas salinas ser historicamente atribuída a processos passados, estudos recentes sugerem que as águas salgadas estão sendo originadas atualmente devido à concentração por evaporação. $\mathrm{O}$ perfil químico das águas salinas estaria sendo originado principalmente pelo controle de elementos $\left(\mathrm{Ca}^{2+}, \mathrm{Mg}^{2+} \mathrm{e}\right.$ $\mathrm{Si}(\mathrm{OH})_{4}$ ) durante a concentração das águas, com o conseqüente envolvimento destes íons em dois processos: a formação de carbonatos e de silicatos magnesianos. Estudos preliminares em solos de salinas sugerem que a ocorrência de nódulos esbranquiçados e a presença de um horizonte enriquecido em argila podem evidenciar estes dois processos. Neste tipo de ambiente, carbonatos como calcita e dolomita são comumente neoformados, mas há divergências na literatura quanto ao mecanismo de origem autigênica dos silicatos magnesianos.

Baseando-se no exposto acima, foram definidos os seguintes objetivos para a presente pesquisa: 1) ampliar o conhecimento sobre os solos associados às salinas através de uma caracterização baseada em dados de campo e laboratório dos solos presentes no entorno de uma lagoa salina representativa da Nhecolândia (lagoa do Meio); 2) identificar os processos envolvidos no controle do $\mathrm{Ca}^{2+}, \mathrm{Mg}^{2+}$ e $\mathrm{Si}(\mathrm{OH})_{4}$ nas águas salinas, através do estudo das relações entre as fases líquidas (águas superficiais e subsuperficiais) e sólidas (minerais) presentes nos solos do entorno da lagoa do Meio; e 3) identificar os mecanismos específicos de gênese dos minerais autigênicos possivelmente presentes nos solos do entorno da lagoa do Meio.

As amostras de solo foram coletadas ao longo de uma topossequência nos arredores da lagoa do Meio e submetidas à análise granulométrica, análises químicas (ICP-MS, pH, CE, carbono total, carbonato de cálcio equivalente, bases trocáveis e testes de imersão em água, ácido e bases) e análises mineralógicas (DRX, MET-EDS). Amostras de água superficiais e subsuperficiais foram coletadas em um transecto que abarca a topossequência estudada e então encaminhadas às análises de pH, Eh, CE, temperatura, titulação com $\mathrm{HCl}$, cromatografia de íons, EAA e ICP-MS.

Os solos dos arredores da salina do Meio caracterizam-se pela textura areia a franco-arenosa, pela ausência de estrutura e, de maneira geral, por altos valores de pH, CE, CTC e saturação em $\mathrm{Na}^{+}$. O pH fortemente alcalino e o domínio de $\mathrm{Na}^{+}$no complexo de troca desencadeiam a atuação do processo de solonização e dos seguintes processos específicos associados: migração de matéria orgânica perfil abaixo, precipitação de carbonatos (calcita, dolomita e nahcolita) em nódulos, solubilização/precipitação de sílica amorfa e formação autigênica de minerais de argila do grupo das esmectitas e micas. Diferentes esmectitas estão presentes ao longo da topossequência: a) na zona raramente atingida pelas variações sazonais do nível d'água da salina, a esmectita é do tipo ferribeidelita, possui um grau de interestratificação com mica e vermiculita e apresenta teores de $\mathrm{Fe}^{3+}$ similares às micas identificadas no mesmo 
solo. Estas características sugerem que o mineral do tipo ferribeidelita é originado pela transformação de micas enriquecidas em $\mathrm{Fe}^{3+}$, sendo a vermiculita provavelmente uma fase intermediária nesta transformação; b) na zona de maior variação sazonal do nível d'água da salina, as esmectitas são classificadas como do tipo saponita e estevensita. Os baixos teores de elementos terras-raras nas amostras enriquecidas nestes minerais, o controle do $\mathrm{Mg}^{2+}$ e do $\mathrm{Si}(\mathrm{OH})_{4}$ nas águas próximas à lagoa do Meio, a saturação das águas do entorno da lagoa em relação a saponita e estevensita e a presença destas esmectitas magnesianas nos locais onde são esperadas máximas taxas de evaporação, provam que estes minerais estão se originando por precipitação química diretamente da coluna d'água da lagoa salina. Já as micas presentes nos solos estudados são do tipo ilita, glauconita e mica glauconítica, possuem interestratificação com camadas de esmectitas e parecem estar associadas a materiais amorfos. Experimentos de síntese disponíveis na literatura mostram que águas semelhantes às associadas à lagoa do Meio são ideais para a cristalização de micas a partir da precipitação inicial de hidróxidos amorfos. Desta forma, as evidências obtidas sugerem que estas micas são neoformadas a partir da precipitação inicial de amorfos e posterior cristalização.

Os resultados obtidos certamente ampliaram o conhecimento sobre os solos presentes no entorno de lagoas salinas, uma vez os estudos disponíveis na literatura são baseados quase que exclusivamente em dados de campo. Mostrou-se que o controle do $\mathrm{Ca}^{2+}$ das águas mais salinas está sendo realizado pela formação de calcita e dolomita em nódulos, enquanto o controle do $\mathrm{Mg}^{2+}$ e do $\mathrm{Si}(\mathrm{OH})_{4}$ está ocorrendo pela formação de esmectitas magnesianas do tipo saponita e estevensita. Estes processos são provavelmente os responsáveis pela alta variabilidade entre as águas doces das baías/vazantes e as salgadas das salinas/arredores, conforme hipótese lançada em literatura. Assim, o presente trabalho fornece fortes evidências de que a presença de sal nas águas das lagoas salinas da Nhecolândia é atual ou, ao menos, tem contribuição de processos atuais. Por fim, mostrou-se ser possível a formação conjunta de ilita, glauconita e mica glauconítica e de esmectitas do tipo saponita e estevensita pelo mecanismo de precipitação diretamente das águas ou soluções em ambientes sujeitos a concentração evaporativa.

Palavras-Chave: lagoas salinas, concentração das águas, carbonatos, Mg-esmectitas, saponita, estevensita, Fe-micas, ilita, glauconita, mica glauconítica. 


\section{ABSTRACT \\ Minerals formation in a modern saline-alkaline lake of Pantanal wetland, Brasil.}

A distinctive feature of Nhecolândia, a sub-region of the Pantanal wetland, is the presence in close proximity of freshwater and saline lakes with a huge chemical variability. The salt has been generally attributed to Pleistocene processes, but recent studies have suggested that saline waters arise from present-day concentration of freshwater by evaporation. The chemical profile of saline waters would be originated by chemical control of $\mathrm{Ca}^{2+}, \mathrm{Mg}^{2+}$, and $\mathrm{Si}(\mathrm{OH})_{4}$ as the water becomes more saline. Two processes would be responsible for this control: formation of carbonates and formation of Mg-silicates. The presence of whitish nodules and clayey horizons in soils associated to the saline lakes would be evidences of these processes. In saline-alkaline environments, carbonates such as calcite and dolomite are commonly formed by chemical precipitation, but the mechanisms responsible for $\mathrm{Mg}$ silicates genesis are still under debate.

The objectives of this research are: a) increasing the general knowledge about soils associated to Pantanal saline lakes through a detailed characterization of the soils located around a representative saline lake of Nhecolândia ("Salina do Meio"); b) identifying the processes involved in $\mathrm{Ca}^{2+}, \mathrm{Mg}^{2+}$ and $\mathrm{Si}(\mathrm{OH})_{4}$ control from saline waters, through the study of relationships between waters and minerals present in the soils around "Salina do Meio"; c) identifying the specific mechanisms of authigenic genesis of the minerals possibly found around "Salina do Meio".

Soils were sampling along a toposequence and submitted to physical (particle-size), chemical (ICP-MS, pH, EC, total carbon, inorganic carbonate, exchangeable bases, and soaking in $\mathrm{H}_{2} \mathrm{O}$, $\mathrm{HCl} 1 \mathrm{~N}$, and $\mathrm{NaOH} 4 \mathrm{M}$ ), and mineralogical analyses (XRD and TEM-EDS). Water was collected along a transect involving the lake and submitted to $\mathrm{pH}, \mathrm{Eh}, \mathrm{EC}$, temperature, titration with $\mathrm{HCl}$, ion chromatography, and ICP-MS analyses.

The studied soils are sandy, structureless, and present, in general, high values of $\mathrm{pH}, \mathrm{CE}$, CEC, and $\mathrm{Na}^{+}$saturation. Prevailing of $\mathrm{Na}^{+}$in the waters and exchangeable sites and dominance of extremely high $\mathrm{pH}$ strongly suggest the general action of solonization in these soils and its influence on the following processes: organic matter translocation toward deeper horizons, precipitation of carbonates (calcite, dolomite, and nahcolite) in nodules, precipitation of amorphous silica, and authigenic formation of smectites and micas. Different authigenic smectites occur along the toposequence: a) in the zone hardly reached by the lake level variation, the smectite is classified as ferribeidellite-type, present an interstratification with mica and vermiculite, and has similar amounts of $\mathrm{Fe}^{3+}$ than the Fe-mica present in the soils. These characteristics suggest that this ferribeidellite-type mineral originates from transformation of Fe-mica and that vermiculite may be an intermediate phase in this transformation; b) in the zone of seasonal lake level variation, the smectites are classified as saponite- and stevensite-type minerals. Low REE amounts in the samples enriched in saponite and stevensite, geochemical control of $\mathrm{Mg}^{2+}$ and $\mathrm{Si}(\mathrm{OH})_{4}$, saturation with respect to $\mathrm{Mg}$ - 
smectite in the more saline waters, and presence of $\mathrm{Mg}$-smectite where the maximum of evaporation is expected, prove that saponite- and stevensite-like minerals originate by chemical precipitation from the water column of the saline lake. The micas present in the studied soils are classified as illite-, glauconite- and glauconitic mica-type minerals. They present $20 \%$ or less smectite layers and seem to be associated to amorphous materials. Synthesis of micas available in the literature shows that water conditions similar to the study area allow for dioctahedral mica crystallization from initial precipitation of amorphous hydroxides. Therefore, it suggests that micas of study area are neoformed.

The results of this dissertation contributed to a better understanding about the soils associated to Nhecolândia saline lakes, since most of the published researches are based on field data. The control of $\mathrm{Ca}^{2+}$ from more saline waters occurs by formation of calcite and dolomite in nodules, while the control of $\mathrm{Mg}^{2+}$ and $\mathrm{Si}(\mathrm{OH})_{4}$ occur by formation of $\mathrm{Mg}$-smectites classified as saponite- and stevensite-type. These processes are probably responsible for the chemical variability between freshwater and saline lakes, as supposed in a previous research. Therefore, the present work gives strong evidences about the current origin of Nhecolândia salt water. Also, it showed the possibility of genesis of illite, glauconita, glauconitic mica, saponite, and stevensite minerals through direct precipitation of waters or soil solutions under concentration by evaporation.

Keywords: saline lakes, concentration of water, carbonates, Mg-smectites, saponite, stevensite, Fe-micas, illite, glauconite, and glauconitic mica. 


\section{ÍNDICE}

Apresentação

$\begin{array}{ll}\text { Agradecimentos } & \text { II }\end{array}$

Resumo IV

$\begin{array}{lll}\text { Abstract } & \text { VI }\end{array}$

Capítulo 1 - Introdução Geral 1

1.1 - Introdução Geral 2

1.2 - Referências Bibliográficas $\quad 8$

$\begin{array}{ll}\text { Capítulo 2 - Caracterização da Área de Estudo } & 11\end{array}$

2.1 - Clima 12

2.2 - Caracterização hidrológica e química das águas $\quad 14$

2.2.1 - Regime hidrológico no Pantanal $\quad 14$

2.2.2 - Regime hidrológico na sub-região da Nhecolândia 17

2.2.3 - Caracterização química das águas da sub-região da Nhecolândia 21

2.3 - Geologia e Geomorfologia 26

$2.4-$ Solos 30

2.4.1 - Principais ordens/subordens de solos no Pantanal e na Nhecolândia 30

2.4.2 - Relações entre solos e unidade da paisagem na Nhecolândia 37

2.5 - Meio Biótico 44

2.5.1 - Fitogeografia 44

2.5.2 - Fitoplâncton - algas $\quad 47$

2.6 - Referências Bibliográficas $\quad 48$

Capítulo 3 - Solos e Processos Pedogenéticos no Entorno da Salina do Meio 51

Resumo $\quad 52$

Abstract $\quad 53$

3.1 - Introdução $\quad 54$

3.2 - Materiais e Métodos $\quad 55$

3.2.1 - Trabalhos de campo $\quad 55$

3.2.2 - Análises de solo em laboratório $\quad 57$

3.2.3 - Análises de água em laboratório $\quad 61$

3.3 - Resultados 61

3.3.1 - Descrição morfológica dos solos $\quad 61$

3.3.2 - Propriedades físicas e químicas do solo 67

3.3.3 - Identificação e semi-quantificação dos minerais $\quad 71$

3.3.4 - Caracterização mineralógica da caulinita 76

3.3.5 - Identificação mineralógica dos nódulos $\quad 80$

3.3.6 - Química da água $\quad 80$ 
3.4 - Discussão dos Resultados $\quad 84$

3.4.1 - Representatividade das águas e dos solos na Baixa Nhecolândia $\quad 84$

3.4.2 - A solonização e suas condições propiciadoras $\quad 86$

3.4.3 - Processos pedogenéticos fundamentais associados à solonização $\quad 87$

3.4.4 - Classificação dos solos $\quad 94$

3.5 - Conclusões 94

3.6 - Referências Bibliográficas $\quad 95$

Capítulo 4 - Mineralogia e Gênese de Esmectitas Presentes nos Solos do Entorno 99 da Salina do Meio

$\begin{array}{ll}\text { Resumo } & 100\end{array}$

$\begin{array}{ll}\text { Abstract } & 101\end{array}$

4.1 - Introdução 102

4.2 - Materiais e Métodos $\quad 103$

4.2.1 - Análises de solo 103

4.2.2 - Análises de água 106

$\begin{array}{ll}4.3 \text { - Resultados } & 107\end{array}$

$\begin{array}{ll}\text { 4.3.1 - Caracterização das esmectitas por DRX } & 107\end{array}$

4.3.2 - Caracterização química das esmectitas 107

4.3.3 - Elementos terras raras (ETR) na composição mineral 116

4.3.4 - Química da água 116

4.4 - Discussão dos Resultados $\quad 116$

4.4.1 - Identificação das esmectitas $\quad 116$

4.4.2 - Gênese dos minerais do tipo ferribeidelita 121

4.4.3 - Gênese dos minerais do tipo saponita e estevensita 123

4.5 - Conclusões 126

$\begin{array}{ll}4.6 \text { - Referências Bibliográficas } & 126\end{array}$

Capítulo 5 - Mineralogia e Gênese de Micas nos Solos do Entorno da Salina do 129 Meio

$\begin{array}{ll}\text { Resumo } & 130\end{array}$

$\begin{array}{ll}\text { Abstract } & 131\end{array}$

5.1 - Introdução 132

5.2 - Materiais e Métodos 133

5.2.1 - Análises de solo $\quad 133$

5.2.2 - Análises de água 136

$\begin{array}{ll}5.3 \text { - Resultados } & 137\end{array}$

$\begin{array}{ll}\text { 5.3.1 - Caracterização das micas por DRX } & 137\end{array}$

5.3.2 - Caracterização química das micas $\quad 141$

$\begin{array}{ll}\text { 5.3.3 - Morfologia dos cristais de mica } & 146\end{array}$

5.3.4 - Características da água $\quad 149$

5.4 - Discussão dos Resultados 152 
5.4.1 - Caracterização por DRX

5.4.2 - Classificação das micas

5.4.3 - Origem dos minerais

5.5 - Conclusões 162

5.6 - Referências Bibliográficas 163

Capítulo 6 - Conclusões Gerais $\quad 166$

6.1 - Conclusões Gerais 167

6.1.1 - Aprofundamento do conhecimento dos solos 167

6.1.2 - Controle de íons, formação de minerais e gênese das águas salinas 167

6.1.3 - Mecanismos de gênese dos minerais 169

$\begin{array}{ll}6.2 \text { - Referências Bibliográficas } & 170\end{array}$

$\begin{array}{ll}\text { Anexos } & 171\end{array}$

Anexo 1 - Descrição detalhada dos métodos mineralógicos e das análises estatística e manométrica

Anexo 2 - Organização da cobertura pedológica nas Topossequências 2 e 3

Anexo 3 - Curvas de DRX submetidas a diferentes tratamentos 
Capítulo 1

INTRODUÇÃO GERAL 


\section{1 - Introdução Geral}

O Pantanal Sul-Mato-Grossense, localizado na porção central da América do Sul, é internacionalmente conhecido como uma das maiores áreas úmidas do mundo, com cerca de $200.000 \mathrm{~km}^{2}$ (Scott, 1991; Por, 1995) (Figura 1.1). O conceito de áreas úmidas ou wetlands, como é denominado na língua inglesa, envolve como características gerais a presença permanente ou temporária, porém recorrente, de águas superficiais rasas, a ocorrência de solos sujeitos a saturação prolongada e a presença de flora e fauna adaptadas às condições úmidas contínuas ou cíclicas (Maltby, 1991; Dennison \& Berry, 1993; Mitsch \& Gosselink, 1993; Moore, 2001).

Scott (1991), ao descrever as principais áreas úmidas da América Latina, caracteriza o Pantanal Sul-Mato-Grossense como uma grande planície aluvionar ainda em formação, parcialmente atingida por inundações sazonais. Trata-se de uma área com altitudes entre 100 e 200 metros e declividades extremamente baixas (de 0,03 a 0,5 $\mathrm{m} / \mathrm{km}$ ), o que condiciona um lento escoamento das águas (Alvarenga et al., 1984; Silva, 1986; Garcia, 1991). O rio Paraguai e seus afluentes transportam e depositam sedimentos predominantemente arenosos na planície principalmente durante as cheias, período em que as águas atingem inúmeras zonas deprimidas e, em geral, coalescemse em extensos corpos d'água intermitentes (Carvalho, 1986; Garcia, 1991; Del'Arco et al., 1982). As águas que alimentam as inundações, assim como os sedimentos por elas transportados, são em boa parte provenientes das cabeceiras de drenagem localizadas nas serras e chapadas com altitudes entre 200 e 900 metros que circundam o Pantanal (Adámoli, 1986). As altas taxas de evapotranspiração na própria planície superam os seus índices pluviométricos, caracterizando uma deficiência hídrica anual superior a $300 \mathrm{~mm}$ (Alfonsi \& Camargo, 1986).

A Nhecolândia é uma sub-região localizada na porção sul do Pantanal (Figura 1.1), em um macro-cone aluvial muito arenoso formado pelo rio Taquari e seus defluentes. É delimitada ao norte/noroeste pelo próprio rio Taquari, ao sul/sudoeste pelo rio Negro e, a leste, pela Serra de Maracaju (Queiroz Neto et al., 1997; Fernandes et al., 1999). A característica de destaque da Nhecolândia é a presença de milhares de lagoas de água doce (baías) e salgada (salinas) associadas a outros elementos geomorfológicos típicos da paisagem, localmente denominados vazantes e cordilheiras (Figura 1.2). 


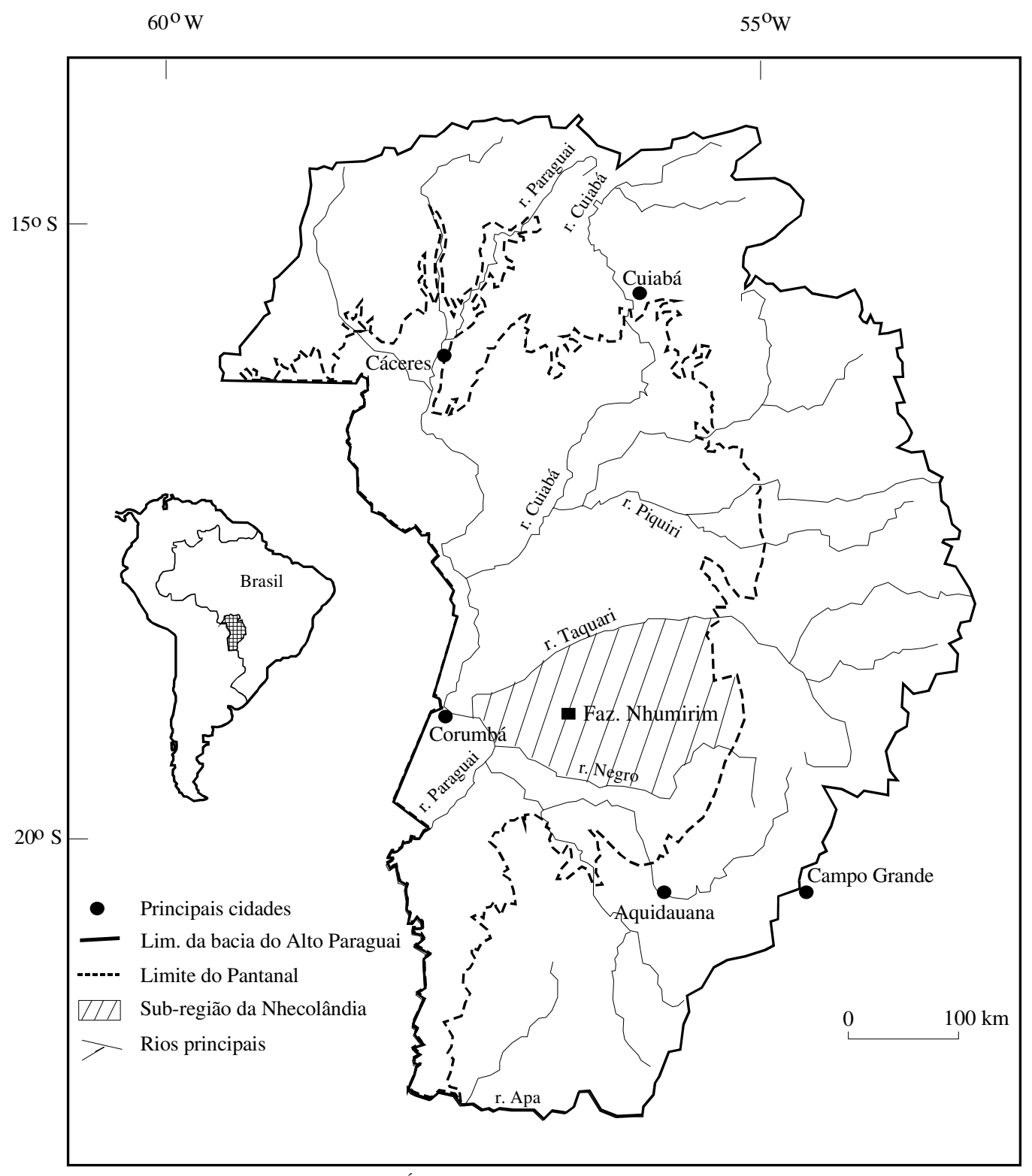

Fonte: adaptado a partir de Agência Nacional de Águas - ANA.

Figura 1.1 - Localização do Pantanal, da sub-região da Nhecolândia e da fazenda onde se situa a lagoa salina estudada (Fazenda Nhumirim). 


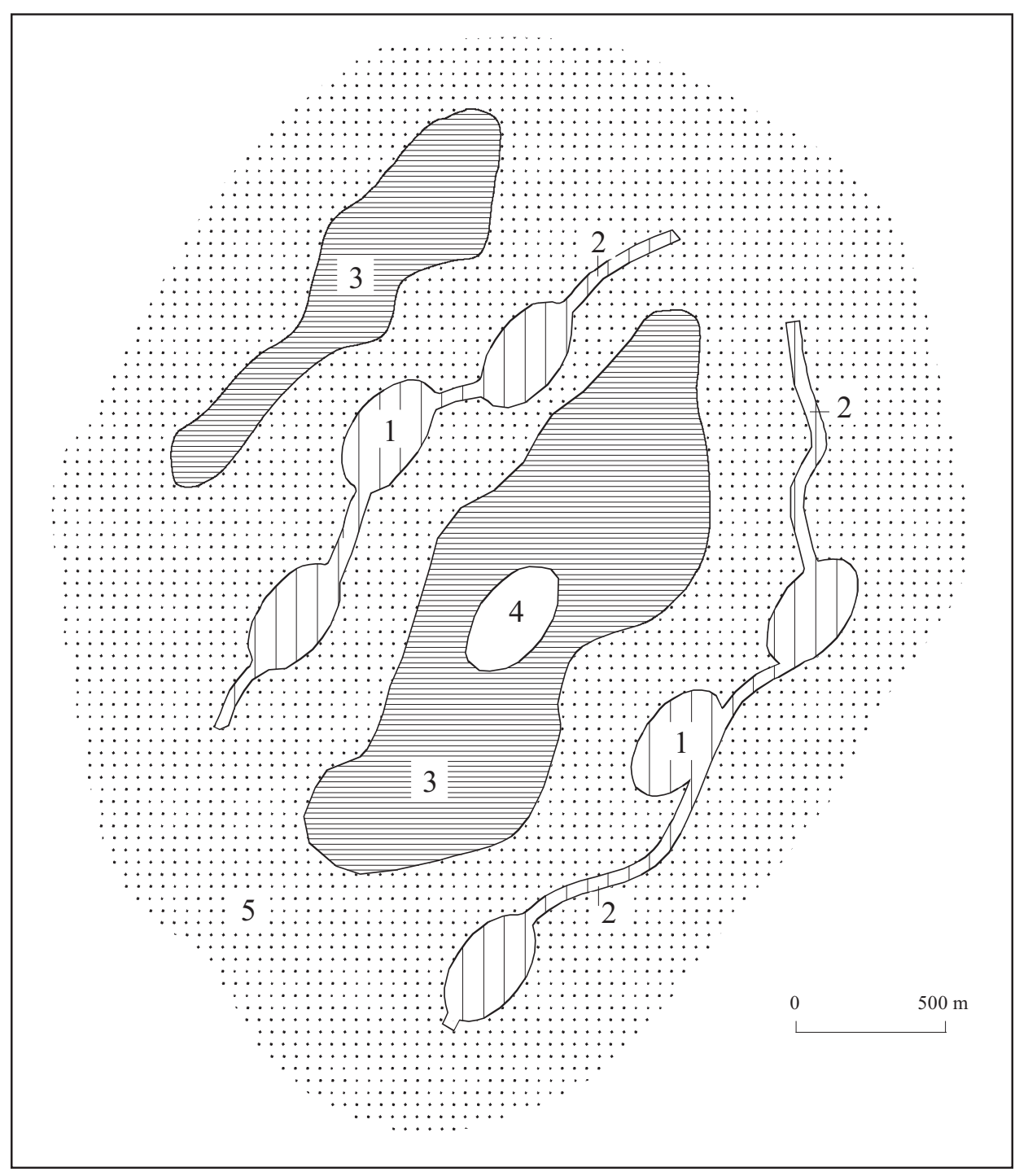

Figura 1.2 - Esquema de distribuição dos principais elementos típicos da paisagem da Nhecolândia: 1-baías; 2-vazantes; 3-cordilheiras; 4-lagoas salinas; 5-campos dominados por vegetação herbácea. 
As vazantes são cursos d'água intermitentes por onde escoam as águas das cheias; podem atingir muitos quilômetros de extensão e 10 a 30 metros de largura. As baías são depressões localizadas no interior das vazantes, coalescentes no período de máxima cheia, mas secas na estiagem; possuem diferentes formas e tamanhos e atingem, em geral, 2 metros de profundidade. Tanto as vazantes quanto as baías são fracamente mineralizadas e recobertas principalmente por vegetação herbácea. As cordilheiras constituem elevações estreitas (200 a 300 metros) e alongadas adjacentes às vazantes, apenas 2 a 3 metros mais altas que o entorno e recobertas por Cerradão. As lagoas salinas são depressões localizadas no interior das cordilheiras, arredondadas ou alongadas, com diâmetros entre 500 e 1000 metros e profundidades entre 2 a 3 metros; são lagoas fortemente mineralizadas, permanentemente com água, mas com nível d'água sazonalmente variável devido às oscilações do lençol freático (Queiroz Neto et al., 1997, Fernandes et al. 1999; Barbiéro et al., 2002). As cordilheiras e as salinas geralmente não são atingidas pelas águas superficiais das cheias.

A origem das salinas tem sido geralmente relacionada à ocorrência de climas áridos durante o Pleistoceno, mas os processos responsáveis pela sua gênese são controvertidos. Para Tricart (1982), as salinas correspondiam a "sebkhas" associadas a dunas eólicas. Já segundo Ab’Saber (1988), teria ocorrido a migração de cursos d'água e a formação de depressões por isolamento de meandros, com posterior acúmulo de sal.

Entretanto, análises químicas de águas superficiais e subsuperficiais da Nhecolândia, efetuadas por Barbiéro et al. (2002), sugerem que as águas salinas estão sendo originadas nos dias atuais. Foi encontrada uma alta variabilidade geoquímica entre os diferentes ambientes estudados, pois enquanto as águas das baías e vazantes apresentam $\mathrm{pH}$ entre 7 e 8 e condutividade elétrica mínima de 0,015 dS/m, as águas das salinas chegam a atingir pH 10 e condutividade elétrica máxima de $68 \mathrm{dS} / \mathrm{m}$. Apesar destas diferenças, os autores mostraram que todas as águas pertencem à uma mesma família geoquímica, que parece estar evoluindo por concentração, em função de altas taxas de evaporação, na direção da alcalinidade. Segundo estes autores, as mudanças nas características químicas da água devem-se provavelmente ao desencadeamento dos dois eventos que parecem controlar quimicamente o $\mathrm{Ca}^{2+}, \mathrm{Mg}^{2+}$ 
e $\mathrm{Si}(\mathrm{OH})_{4}$ das águas e das soluções dos solos, na medida em que a concentração torna-se maior: a formação de calcita ou calcita magnesiana e a formação de algum silicato magnesiano (estevensita, sepiolita, Mg-montmorillonita).

Estudos preliminares de algumas topossequências, baseados principalmente em levantamentos de campo e em poucas análises laboratoriais, também mostraram uma variabilidade na morfologia dos solos associados aos diferentes elementos da paisagem da Nhecolândia (Queiroz Neto et al., 1997; Sakamoto, 1997; Fernandes et al., 1999; Barbiéro et al., 2000). Das bordas das cordilheiras até as baías ocorrem solos $\operatorname{arenosos}(20$ a $30 \mathrm{~g} / \mathrm{kg}$ de argila), bem selecionados e ácidos $(\mathrm{pH}<5)$, classificados pelos autores como Areias Quartzosas (atualmente Neossolos Quartzarênicos - Embrapa, 2006). Nas proximidades das lagoas salinas a Areia Quartzosa é substituída por solos com sinais de hidromorfia, não classificados, compostos por horizontes arenosos (20 a $30 \mathrm{~g} / \mathrm{kg}$ de argila) escurecidos em subsuperfície e com presença de nódulos esbranquiçados, sobrepostos a um horizonte esverdeado (5Y 6/4), mais argiloso (90 g/kg de argila) e alcalino ( $\mathrm{pH}>8$ ), que se estende por baixo da lagoa salina.

A especificidade dos solos encontrados nos arredores das salinas está muito provavelmente ligada às características das águas associadas a estas lagoas. Os ciclos sazonais de umedecimento e ressecamento da salina e as oscilações do lençol freático do seu entorno mantém os solos parcial ou totalmente submersos na época das cheias e parcial ou totalmente expostos ao ar na época das secas. Desta forma, é de se esperar que estas águas alcalinas e mineralizadas influenciem os processos aí atuantes. A ocorrência de nódulos esbranquiçados e o significativo enriquecimento em argila do horizonte esverdeado já foram apontados por Barbiéro et al. (2000) como possíveis evidências da precipitação de calcita ou calcita magnesiana e da formação de silicatos magnesianos (estevensita, sepiolita, Mg-montmorillonita), processos previstos pela análise regional das químicas das águas (Barbiéro et al., 2002).

A formação de minerais em solos e sedimentos a partir de águas em concentração pode ocorrer, de maneira geral, através de dois processos: precipitação química direta das águas concentradas (processo de neoformação) e transformação devido à incorporação de íons na estrutura cristalina de minerais pré-existentes. A precipitação de carbonatos não magnesianos e/ou magnesianos, acompanhada pela formação 
autigênica $^{1}$ de silicatos magnesianos, são processos que integram a evolução geoquímica de grande parte das águas de lagos continentais submetidas a condições crescentes de salinidade (Gac et al., 1977; Eugster \& Hardie, 1978; Eugster \& Jones, 1979; Velde, 1985; Jones, 1986; Buch \& Rose, 1996). A gênese destes minerais através de precipitação inorgânica direta de soluções concentradas é amplamente aceita na literatura (Gac et al., 1977; Fullerton et al., 1987; Gonzalez, 1989; Buch \& Rose, 1996; Hem \& Lind, 1996; Raí \& Absar, 1996; Garcia Ruiz, 1998). Quanto aos silicatos magnesianos, os possíveis processos responsáveis por sua formação em ambientes sujeitos à evaporação ainda não são consenso. De acordo com Jones (1986), a transformação de minerais pré-existentes parece ser mais freqüente nestes ambientes devido à alta disponibilidade de partículas que funcionam como base para reação, tais como os argilo-minerais. As únicas fases que se originariam pela nucleação direta a partir de águas ricas em sílica, segundo este último autor, seriam a sepiolita (Mg-silicato) e a magadita (Na-silicato). Eugster \& Hardie (1978) também citam estes dois minerais como possivelmente originados por este processo, mas acrescentam o talco entre os Mg-silicatos. Entretanto, contrariando as posições de Eugster \& Hardie (1978) e Jones (1986), a origem de outros silicatos magnesianos também vem sendo atribuída à precipitação química de águas em processo de concentração, incluindo-se a paligorsquita, estevensita e saponita (Tettenhorst \& Moore, 1978; Velde, 1985; Darragi \& Tardy, 1987; Torres Ruiz et al., 1994).

Diante do que foi exposto, torna-se importante estabelecer como objetivos da presente pesquisa:

- Ampliar o conhecimento sobre os solos associados às lagoas salinas através de uma caracterização baseada em dados de campo e laboratório dos solos presentes no entorno de uma lagoa salina representativa da Nhecolândia (lagoa do Meio);

- Identificar os processos envolvidos no controle do $\mathrm{Ca}^{2+}, \mathrm{Mg}^{2+}$ e $\mathrm{Si}(\mathrm{OH})_{4}$ nas águas, através do estudo das relações entre as fases líquidas (águas superficiais e subsuperficiais) e sólidas (minerais) presentes nos solos do entorno da lagoa do Meio;

\footnotetext{
${ }^{1}$ No presente trabalho, o termo autigênese engloba a formação de minerais tanto por neoformação quanto por transformação de minerais já existentes (Jeans et al., 1984).
} 
- Identificar os mecanismos específicos de gênese dos minerais autigênicos possivelmente presentes nos solos do entorno da lagoa do Meio.

Os resultados aqui obtidos contribuirão para aprofundar o conhecimento a respeito das características e dos processos atuantes nos solos do entorno das lagoas salinas da Nhecolândia, uma vez que os trabalhos elaborados até o momento são baseados fundamentalmente em dados de campo.

Além disto, poderá ainda auxiliar no esclarecimento sobre a origem atual ou pretérita dos processos relacionados à salinidade na Nhecolândia, já que o controle do $\mathrm{Ca}^{2+}$, $\mathrm{Mg}^{2+}$ e $\mathrm{Si}(\mathrm{OH})_{4}$ pela formação de fases minerais no entorno das lagoas salinas pode explicar a variabilidade geoquímica das águas superficiais e subsuperficiais associadas às baías e salinas.

E, por fim, pode-se contribuir para a elucidação da origem de silicatos magnesianos. Grande parte dos solos e sedimentos da Nhecolândia, material de origem dos solos associados às lagoas salinas, possui teores muito baixos de argila. Este fato representa uma grande vantagem para o estudo da gênese dos silicatos magnesianos eventualmente presentes nos solos, pois favorece a hipótese da neoformação, já que a disponibilidade de partículas que funcionam como base para transformação de minerais é baixa.

\section{2 - Referências Bibliográficas}

Ab'Saber, A.N. (1988) O Pantanal Mato-Grossense e a Teoria dos Refúgios. Revista Brasileira de Geografia, 50, p 9-57.

Adámoli, J. (1986) A dinâmica das inundações no Pantanal. Pp: 51-61 in: Anais do $1^{\circ}$ Simpósio sobre Recursos Naturais e Sócio-Econômicos do Pantanal, 27 de novembro a 4 de dezembro de 1984, Corumbá (MS).

Agência Nacional de Águas (ANA). Endereço eletrônico: www.ana.gov.br. Acesso em 20/04/2006.

Alfonsi, R.R. \& Camargo, M.B.P. (1986) Condições Climáticas para a Região do Pantanal Matogrossense. Pp. 29-42 in: Anais do $1^{\circ}$ Simpósio sobre Recursos Naturais e Sócio-Econômicos do Pantanal, 27 de novembro a 4 de dezembro de 1984, Corumbá (MS), p. 29-42.

Alvarenga, S.M.; Brasil, A.E.; Pinheiro, R.; Kux, H.J.H. (1984) Estudo Geomorfológico Aplicado à Bacia do Alto Rio Paraguai e Pantanais Matogrossenses. Boletim Técnico Projeto RADAMBRASILSérie Geomorfologia, 1, 187.

Barbiéro, L.; Queiroz Neto, J.P.; Sakamoto, A.Y. (2000) Características Geoquímicas dos Solos Relacionadas à Organização Pedológica e à Circulação da Água (Fazenda Nhumirim: Embrapa CPAP, Nhecolândia, MS). Pp. 90-100 in: Anais do $3^{\circ}$ Simpósio sobre Recursos Naturais e SócioEconômicos do Pantanal, Corumbá (MS). 
Barbiéro, L. Queiroz Neto, J.P. Ciornei, G. Sakamoto, A.Y. Capellari, B. Fernandes, E. Valles, V., (2002) Geochemistry of water and ground water in the Nhecolândia, Pantanal of Mato Grosso, Brazil: variability and associated processes. Wetlands, 22, 528-540.

Buch, M.W \& Rose, D. (1996) Mineralogy and geochemistry of the sediments of the Etosha Pan region in northern Namibia: a reconstruction of the depositional environment. Journal of African Earth Sciences, 22, 355-378.

Carvalho, N.O. (1986) Hidrologia da Bacia do Alto Paraguai. Pp. 43-49 in: Anais do $1^{o}$ Simpósio sobre Recursos Naturais e Sócio-Econômicos do Pantanal, 27 de novembro a 4 de dezembro de 1984, Corumbá (MS).

Darragi, F. \& Tardy, Y. (1987) Authigenic trioctahedral smectites controlling pH, alkalinity, silica, and magnesium concentrations in alkaline lakes. Chemical Geology, 63, 59-72.

Del'Arco, J.O.; Silva, R.H.; Tarapanoff, I.; Freire, F.A.; Pereira, L.G.M.; Souza, S.L.; Luz, D.S.; Palmeira, R.C.B.; Tassinari, C.C.G. (1982) Geologia da Folha SE.21-Corumbá e Parte da Folha SE.20. Pp 25 a 160 in: RADAMBRASIL-Levantamento dos Recursos Naturais. Rio de Janeiro.

Dennison, M.S. \& Berry, J.F. (1993) Wetlands: guide to science, law, and technology. Noyes Publications, Park Ridge (USA). 439 p.

Empresa Brasileira de Pesquisas Agropecuárias - Embrapa (2006) Sistema Brasileiro de Classificação de Solos. $2^{\mathrm{a}}$ edição, Embrapa Solos, Rio de Janeiro. 306 p.

Eugster, H.P. \& Hardie, L.A. (1978) Saline Lakes. Pp. 237-294 in: Lakes: chemistry, geology and physics (A. Lerman, ed.). Springer-Verlag, Berlin.

Eugster, H.P. \& Jones, B.F. (1979) Behavior of major solutes during closed-basin brine evolution. American Journal of Science, 279, 609-281.

Fernandes, E.; Sakamoto, A.Y.; Queiroz Neto, J.P.; Lucati, H.M.; Capellari, B (1999) Le "Pantanal da Nhecolândia" Mato Grosso: Cadre Physique et Dynamique Hydrologique. Geografia Fisica $e$ Dinamica Quaternaria, 22, 13-21.

Fullerton, M.K.; Shafer, M.M.; Armstrong, D.E. (1987) Calcium carbonate precipitation in Lake Michigan. Pp A-22 in: 30th Conference on Great Lakes Research Programs, 30, International Association for Great Lakes Research Programs-IAGLR.

Gac, J.Y., Droubi, A., Fritz, B., Tardy,Y. (1977). Geochemical behavior of silica and magnesium during the evaporation of waters in Chad. Chemical Geology, 19, 215-228.

Garcia, E.A.C. (1991) Zoneamento Agroecológico e Sócioeconômico da Bacia Hidrográfica Brasileira do rio Paraguai: uma abordagem numérica preliminar. Embrapa Pantanal, 65p.

Garcia Ruiz, J.M. (1998) Carbonate precipitation into alkaline silica-rich environments. Geology (boulder), 26, 843-846.

Gonzalez, L.A. (1989) Inorganic calcium carbonate precipitation; controls on mineralogy, morphology and trace elemental composition. Ph.D Dissertation. Univ. of Michigan, Ann Arbor, USA, 193 p.

Hem, J.D. \& Lind, C.J. (1996) Chemical processes in manganese oxide and carbonate precipitation in Pinal Creek, Arizona, U.S. Geological Survey Report, WRI 94-4015, 1095-1099.

Jeans, C.V.; Mitchell, J.G.; Scherer, M.; Fisher, M.J. (1994) Origin of the Permo-Triassic clay mica assemblage. Clay Minerals, 29, 575-589.

Jones, B.F. (1986). Clay mineral diagenesis in lacustrine sediments. Pp. 291-300 in: Studies in Diagenesis (F.A. Mumpton, ed.). US Geolological Survey Bulletin, 1578.

Maltby, E. (1991) Wetlands and their values. Pp. 85-114 in: Wetlands: a global perspective (C.M. Finlayson \& M.E. Moser, eds.). Facts on File, New York.

Mitsch, W.J. \& Gosselink, J.G. (1993) Wetlands. Von Nostrand Reinhold Co., 722 p.

Moore, P.D. (2001) Wetlands. Facts on File, New York, 200 p. 
Por, F.D. (1995) The Pantanal of Mato Grosso (Brazil) - World's Largest Wetlands. Klumer Academic Publishers, $122 \mathrm{p}$.

Queiroz Neto, J.P.; Sakamoto, A.Y.; Lucati, H.M.; Fernandes, E.; Capellari, B. (1997) Solos de Cordilheiras, Baías e Lagoas salinas na Área do Leque (Pantanal da Nhecolândia, MS). Pp. 16-20 in: Anais da VIII Semana de Estudos de Geografia do CEUL-UFMS. Três Lagoas, MS

Raí, V. \& Absar, A. (1996) Sub-lacustrine hydrotermal activity in Kuchanan and Sargot saline lakes, District Nagaur, Rajasthan. Special Publication Series-Geological Survey of India, 45, 361-366.

Sakamoto, A. Y. (1997) Dinâmica hídrica em uma lagoa salina e seu entorno no Pantanal da Nhecolândia: contribuição ao estudo das relações entre o meio físico e a ocupação, Fazenda São Miguel Firme, MS. Tese de Doutorado defendida no Departamento de Geografia da Faculdade de Filosofia, Letras e Ciências Humanas da Universidade de São Paulo. 183 p.

Scott, D.A. (1991) Latin America and the Caribbean. Pp. 85-114 in: Wetlands: a global perspective (C.M. Finlayson \& M.E. Moser, eds.). Facts on File, New York.

Silva, T.C. (1986) Contribuição da Geomorfologia para o Conhecimento e Valorização do Pantanal. Pp: 77-90 in: Anais do $1^{\circ}$ Simpósio sobre Recursos Naturais e Sócio-Econômicos do Pantanal, 27 de novembro a 4 de dezembro de 1984, Corumbá (MS).

Tettenhorst, R. \& Moore, G.E. (1978) Stevensite oolites from the green river formation of Central Utah. Journal of Sedimentary Petrology, 48, 587-594.

Torres Ruiz, J., López-Galindo, A., González-López, J.M., Delgado, A. (1994) Geochemistry of Spanish sepiolite-palygorskite deposits: genetic considerations based on trace elements and isotopes. Chemical Geology, 112, 221-245.

Tricart, J. (1982) El Pantanal: Un ejemplo del impacto de la Geomorfología sobre el medio ambiente. Geografia, 7, 37-50.

Velde, B. (1985) Clay Minerals: a physico-chemical explanation of their occurrence. Developments in Sedimentology, 40. Elsevier, 427 p. 
Capítulo 2

\section{CARACTERIZAÇÃO DA ÁREA DE ESTUDO}




\section{2 - CARACTERIZAÇÃo DA ÁREA DE ESTUDO}

\section{1 - Clima}

De acordo com a classificação de Köppen, o Pantanal Sul-Mato-Grossense possui clima do tipo Aw, caracterizado pela presença de temperaturas médias mensais superiores a $18^{\circ} \mathrm{C}$ e pela nítida definição de um período seco no inverno (Alvarenga et al., 1984; Garcia, 1991; Por, 1995).

O domínio de altas temperaturas deve-se à localização da região na faixa tropical (entre $16^{\circ}$ e $22^{\circ} \mathrm{S}$ ) e à sua distância de aproximadamente $1500 \mathrm{~km}$ do oceano Atlântico, estando portanto sujeita ao efeito da continentalidade (Tarifa, 1986). As médias anuais de temperatura calculadas por este autor para o Pantanal e arredores estão entre 22,4 e $25,6^{\circ} \mathrm{C}$, sendo outubro o mês mais quente nas estações de menores latitudes (Cuiabá e Cáceres), dezembro o mês mais quente nas estações de maiores latitudes (Corumbá, Aquidauana e Campo Grande) e julho o mês mais frio nas 5 estações meteorológicas consultadas (Figura 2.1). As menores temperaturas médias anuais $\left(25,1 ; 23,9\right.$ e $\left.22,4^{\circ} \mathrm{C}\right)$ são registradas em Corumbá, Aquidauana e Campo Grande, respectivamente, já que estas estações localizam-se em maiores latitudes e estão sujeitas a maior atuação dos sistemas extratropicais (Figura 2.1).

Para a Fazenda Nhumirim, Soriano (1996) obteve uma temperatura média anual de $25,5^{\circ} \mathrm{C}$, valor semelhante àquele encontrado por Tarifa (1986) em Corumbá. A média das temperaturas máximas na Fazenda Nhumirim é de $31,5^{\circ} \mathrm{C}$, sendo que de janeiro a setembro as máximas absolutas ultrapassam $40^{\circ} \mathrm{C}$. Já a média anual das temperaturas mínimas é de $20,3^{\circ} \mathrm{C}$, com mínimas absolutas próximas o $0^{\circ} \mathrm{C}$ nos meses de maio a agosto (Soriano, 1996).

As médias pluviométricas anuais para o Pantanal estão entre 850 e 1100 mm, nitidamente inferiores àquelas registradas nas regiões altas circundantes, que variam entre 1100 e 1800 mm (Alvarenga et al., 1984, Alfonsi \& Camargo, 1986). Na planície, as chuvas ocorrem em um padrão de manchas ou ilhas de distribuição espacialmente aleatória, o que poder ser um indicativo da maior atuação de processos convectivos em sua geração (Tarifa, 1986). A análise realizada por Alfonsi \& Camargo (1986), baseada em 4 estações meteorológicas (Cáceres, Corumbá, Aquidauana e Porto Murtinho) (Figura 2.1), mostra que o período de maior concentra- 


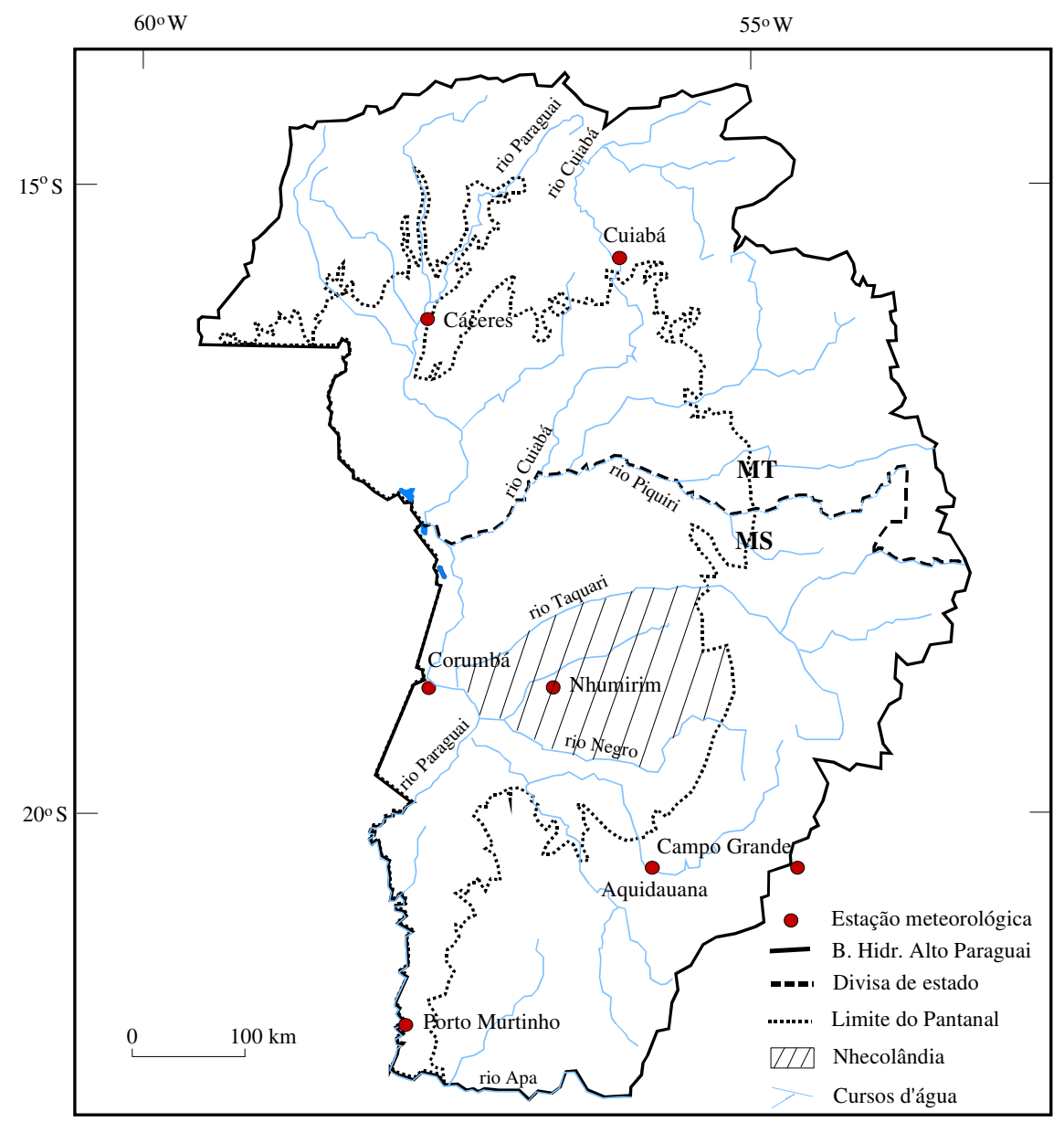

Fonte: adaptado a partir da Agência Nacional de Águas (ANA) e Alfonsi \& Camargo (1986)

Figura 2.1 - Localização das estações meteorológicas situadas no Pantanal e arredores.
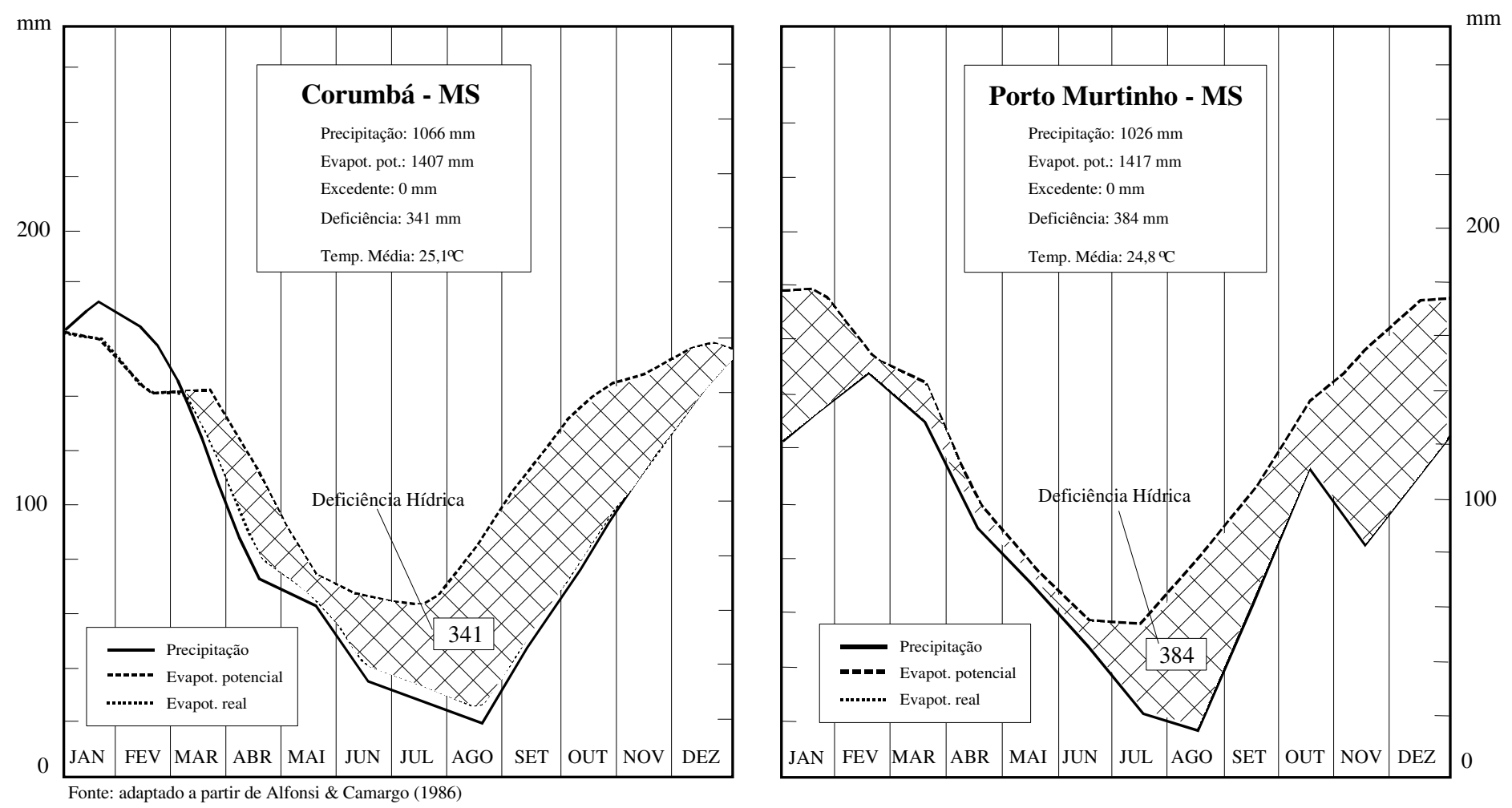

Figura 2.2 - Exemplos de balanço hídrico em duas estações meteorológicas do Pantanal. 
ção pluviométrica no Pantanal e arredores ocorre entre os meses de dezembro a março, com médias mensais entre 113 e 217 mm, enquanto o período de maior estiagem ocorre de junho a agosto, com médias mensais entre 7 e $51 \mathrm{~mm}$.

Para a Fazenda Nhumirim, Soriano (1996) calculou uma média pluviomérica anual de $1182,5 \mathrm{~mm}$, ligeiramente superior às médias apontadas para todo o Pantanal. Janeiro foi o mês mais chuvoso, com 229,7 mm distribuídos em 13 dias de chuva. No período de junho a agosto foram registrados apenas $6 \%$ da precipitação anual em 6 dias de chuva.

Deve-se destacar que o Pantanal apresenta uma deficiência hídrica anual superior a $300 \mathrm{~mm}$ (Figura 2.2), já que apresenta altos valores de evapotranspiração potencial anual, superiores a $1400 \mathrm{~mm}$ em toda a planície, e médias pluviométricas anuais próximas ou inferiores a $1100 \mathrm{~mm}$ (Alfonsi \& Camargo, 1986). Na Fazenda Nhumirim, Soriano (1996) calculou uma deficiência hídrica de 331,0 mm, correspondente ao período entre fevereiro e novembro, sendo entretanto mais pronunciada de agosto a outubro.

\section{2 - Caracterização Hidrológica e Química das Águas}

\subsection{1 - $\underline{\text { Regime hidrológico no Pantanal }}$}

A Bacia do Alto Paraguai ocupa terras paraguaias, bolivianas e, em grande maioria, brasileiras. O rio Paraguai nasce na Chapada dos Parecis (MT, Brasil), percorre planaltos e serras até aproximadamente a localidade de Barra do Bugres e, então, passa a correr pela planície pantaneira. Sua confluência com o rio Apa marca o limite sul tanto do Pantanal quanto da própria Bacia do Alto Paraguai (Figura 2.3a). Daí em diante flui em seu curso médio e inferior até desembocar no rio Paraná que, por sua vez, deságua no rio da Prata (Carvalho, 1986).

Quarenta por cento da Bacia do Alto Paraguai são ocupados pelas terras baixas e planas correspondentes ao Pantanal. Como comentado no Capítulo 1, esta planície caracteriza-se por um sistema hidrológico submetido a inundações periódicas, as quais são determinadas principalmente pelo regime sazonal de oferta hídrica característico da região e pelo lento escoamento das águas superficiais e subsuperficiais, condicio- 

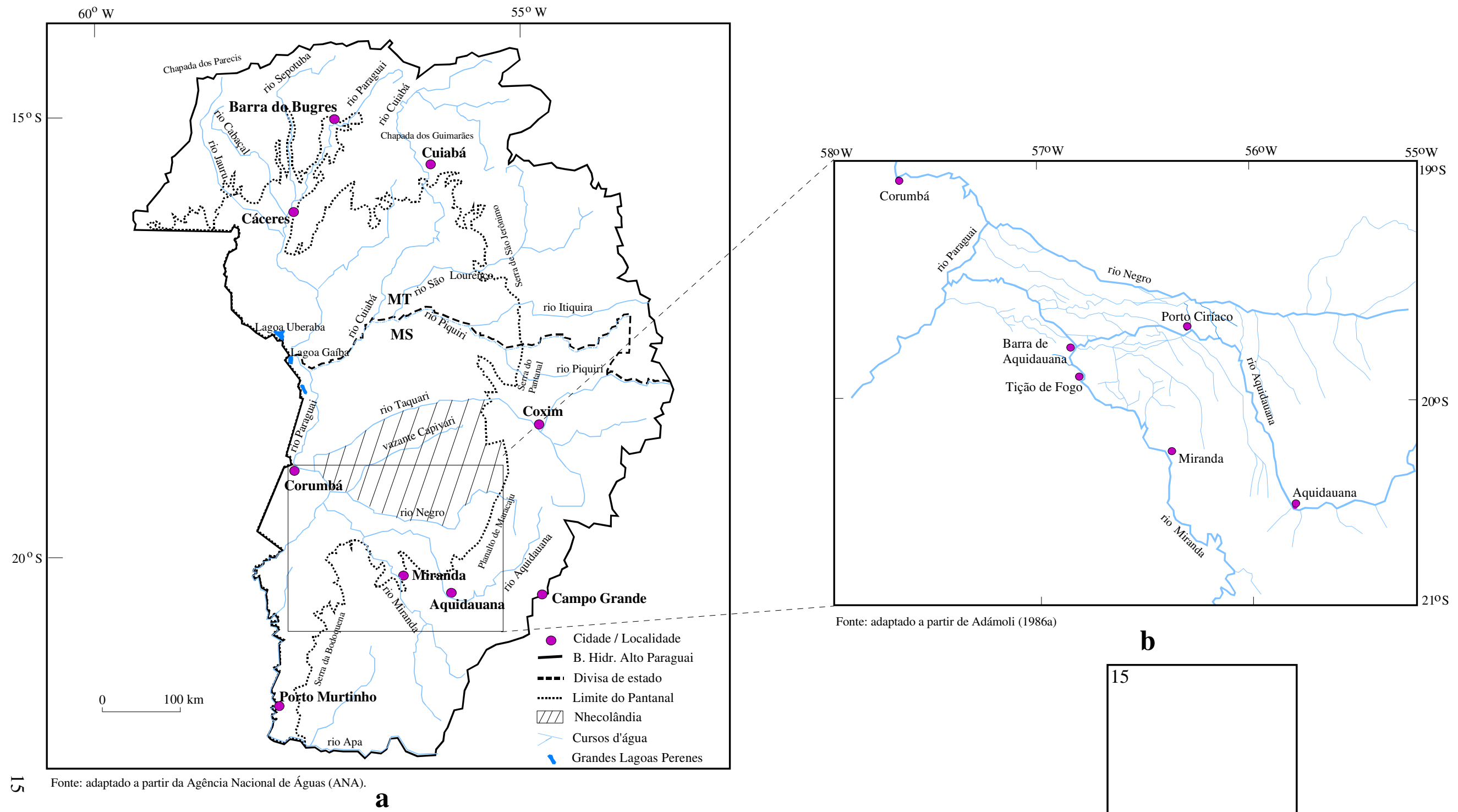

Figura 2.3 - Localização dos principais elementos hidrográficos do Pantanal: a) principais cursos d'água e grandes lagoas perenes; b) sistema natural de vertedouros entre os rios Miranda e Aquidauana. 
nado pelo baixo gradiente topográfico (de 0,3 a $0,5 \mathrm{~m} / \mathrm{km}$ na direção $\mathrm{E}-\mathrm{W}$ e de 0,03 a 0,15 m /km na direção N-S) (Silva, 1986; Garcia, 1991).

As inundações no rio Paraguai são alimentadas, em geral, pelas águas da rede de drenagem provenientes das terras altas circundantes. Desta forma, ocorre uma defasagem temporal nas inundações entre várias localidades (Figura 2.3a): em Cáceres, situada ao norte, as inundações coincidem com meses que possuem altos índices pluviométricos (janeiro a março), mas a onda de inundação só alcançará Corumbá 2 a 3 meses depois (final de abril para maio), podendo demorar ainda 2 meses ou mais para alcançar as proximidades de Porto Murtinho, localidade situada ao sul, onde ocorrerá em plena época de estiagem (junho para julho) (Carvalho, 1986; Garcia, 1991).

As diversas unidades hidrográficas presentes na totalidade ou apenas em parte da planície pantaneira são afetadas pela dinâmica das inundações, destacando-se entre estes os rios, as grandes lagoas perenes, as pequenas lagoas de água doce (baías), as pequenas lagoas de água salgada (salinas) e as vazantes.

Os rios da planície pantaneira são os cursos d'água permanentes cujas nascentes situam-se principalmente nas terras altas circundantes, sendo os mais importantes os rios Sepotuba, Cabaçal e Jauru, afluentes da margem direita do rio Paraguai, e os rios Cuiabá (com seus afluentes São Lourenço e Piquiri), Taquari, Negro, Miranda (com seu afluente Aquidauana) e Apa, tributários da margem esquerda do rio Paraguai (Figura 2.3a). Os baixos cursos destes rios geralmente são anastomosados (rios Taquari e Negro) e possuem muitos meandros abandonados, reabastecidos pelos transbordamentos periódicos dos canais principais (Carvalho, 1986).

As grandes lagoas perenes, tais como as lagoas Uberaba e Gaíba (Figura 2.3a), situam-se principalmente na porção noroeste do Pantanal, possuem água doce e apresentam dimensões da ordem de dezenas de $\mathrm{km}^{2}$ na estiagem e até centenas de $\mathrm{km}^{2}$ nas épocas das cheias, sendo alimentadas neste período por cursos d'água perenes e/ou intermitentes (Carvalho, 1986).

As lagoas salinas e baías, já definidas no Capítulo 1, estão presentes apenas na porção S-SW da Nhecolândia. Fernandes (2005), ao mapear e caracterizar esta área 
através de imagens de satélite, identificou 25.190 lagoas na época das cheias, sendo 21.164 (84\%) baías e 4.026 salinas (16\%). Estas lagoas são geralmente pequenas, com tamanho predominante entre 7.199 a $127.801 \mathrm{~m}^{2}$. Maiores detalhes do funcionamento hídrico e químico destas pequenas lagoas serão dados nos próximos itens (2.2.2 e 2.2.3).

Por fim, as vazantes ou cursos d'água intermitentes, já definidas no Capítulo 1, são abundantes em toda a Nhecolândia. Entre as principais pode-se citar a do Corixinho, Almoço e Capivari (Figura 2.4) (Carvalho, 1986; Por, 1995). Adámoli (1986a) verificou que alguns destes cursos d'água temporários são, na verdade, defluentes de rios permanentes que se espraiam em várias direções na época das cheias, podendo retornar ao rio de onde se originaram ou nunca retornar, indo alimentar, neste caso, outros cursos d'água. Este fenômeno explica o fato de determinados picos de vazão nos cursos superiores dos rios permanentes serem superiores aos do trecho pantaneiro destes mesmos rios, a jusante. $\mathrm{O}$ autor identificou, desta forma, um verdadeiro sistema natural de vertedouros responsável pelo escoamento do excesso de água que não pode ser conduzido pelas calhas dos rios principais. Os vertedouros do rio Miranda, no trecho entre Miranda e Tição de Fogo, por exemplo, seriam capturados pelo rio Aquidauana e retornariam ao rio Miranda em Barra de Aquidauana (Figura 2.3b).

\subsection{2 - $\underline{\text { Regime hidrológico na sub-região da Nhecolândia }}$}

Assim como constatado em diversos locais da planície pantaneira, também ocorrem defasagens temporais entre as inundações em diferentes localidades da Nhecolândia. Em sua porção E-NE e nos terços superior e médio dos rios Taquari e Negro, as inundações ocorrem, de maneira geral, entre novembro e abril (Queiroz Neto et al., 1998), enquanto que na porção terminal do leque (S-SW) e no terço inferior dos rios Taquari e Negro, as cheias ocorrem geralmente entre fevereiro e julho, mas não ocupam necessariamente este período inteiro em todas localidades (Sakamoto, 1997; Queiroz Neto et al., 1998). Durante as inundações, o tamanho e a densidade das baías e salinas, exclusivas da porção S-SW da Nhecolândia, aumentam substancialmente e as vazantes locais passam a ser cursos d’água contínuos (Queiroz Neto et al., 1998).

Enquanto o nível d'água das baías parece sofrer contribuições tanto de fluxos superficiais quanto de subsuperficiais, as lagoas salinas seriam quase que exclusivamente abastecidas por fluxo subterrâneo. Leão (1996), ao realizar um estudo 


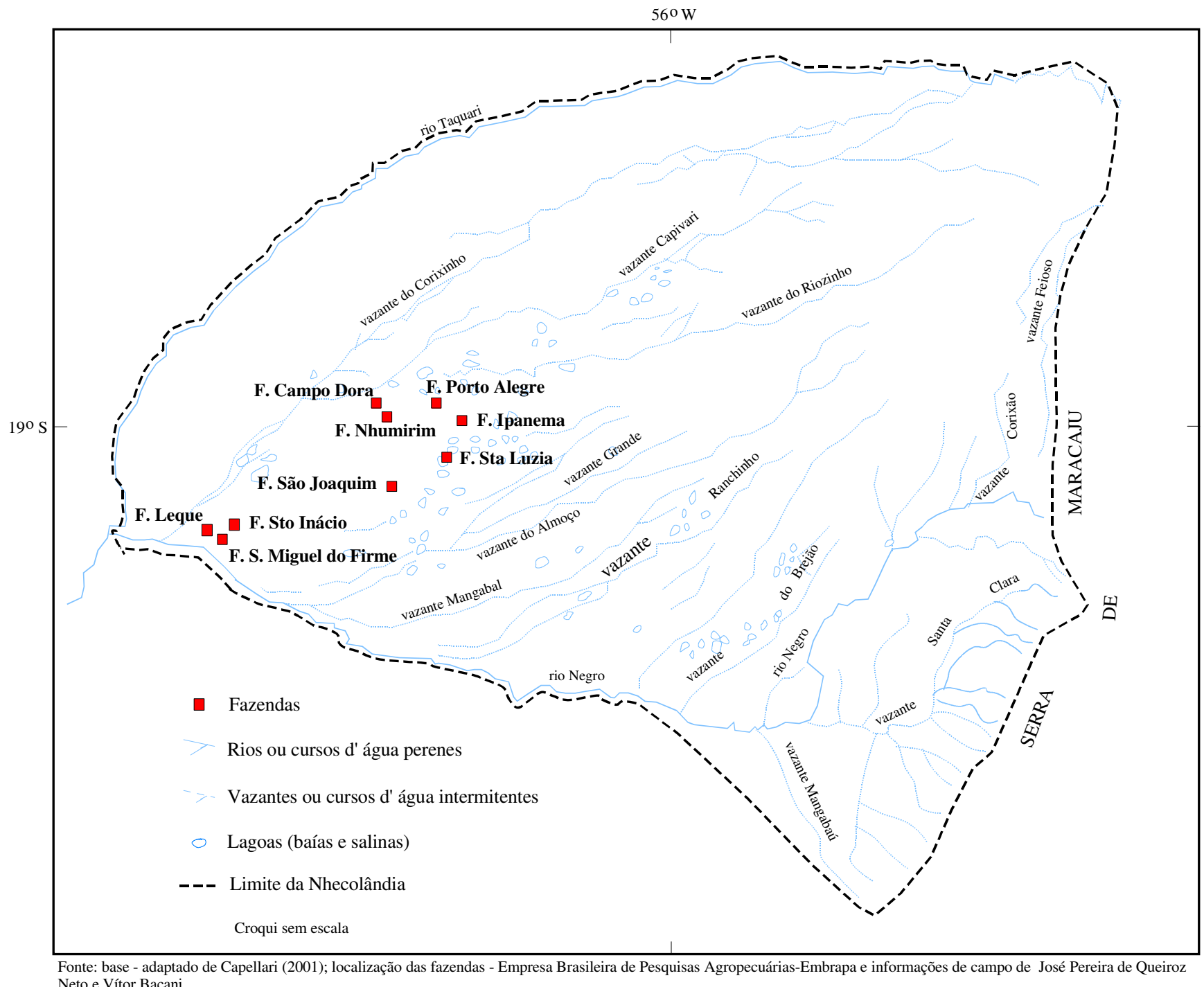

Figura 2.4 - Hidrografia e localização aproximada das fazendas na sub-região da Nhecolândia 
regional das águas subterrâneas no Pantanal, já havia sugerido que o abastecimento de lagoas que raramente secam na parte sul da Nhecolândia seria feito pelo lençol freático. Este fato foi corroborado por monitoramentos piezométricos ao longo do sistema baía-cordilheira-salina em duas localidades da porção S-SW da Nhecolândia: Fazenda São Miguel do Firme (Sakamoto, 1997) e Fazenda Nhumirim (Bacani, 2004) (Figura 2.4). Estes estudos mostraram que as salinas mantiveram-se com água durante a grande maioria do tempo (F. São Miguel Firme) ou por todo o tempo monitorado (F. Nhumirim) e constataram que a oscilação dos níveis d'água das salinas deveu-se essencialmente ao comportamento do lençol freático. A posição de abrigo em que as depressões que formam as salinas encontram-se no interior das cordilheiras seria a principal responsável pelo pouco ou nenhum aporte de águas superficiais das inundações.

Sakamoto (1997) observou ainda que o lençol freático era contínuo no eixo vazantecordilheira-salina e notou que, durante grande parte do ano, havia um leve mergulho do lençol freático no sentido vazante-salina, sendo a primeira possivelmente responsável pelo abastecimento de água da segunda. A hipótese do abastecimento da lagoa salina por águas subsuperficiais provenientes das baías ou vazantes foi também adotada por Fernandes (2000), pois durante um levantamento pedológico na porção SSW da Nhecolândia constatou que as profundidades dos lençóis freáticos nas tradagens apresentavam um caimento em direção às salinas.

O monitoramento efetuado por Bacani (2004) abarcou especificamente uma vertente voltada para a salina do Meio, lagoa estudada na presente tese. Durante o período de recarga (cheia), o nível mais alto do lençol freático ocorreu na vazante enquanto o mais baixo ocorreu na cordilheira (Figura 2.5). No período de descarga (seca) a situação inverteu-se, sendo que o nível mais alto do lençol foi registrado na cordilheira e o mais baixo na vertente da salina (Figura 2.5). Desta forma, apesar da confirmação da existência de um lençol freático contínuo entre vazante, cordilheira e salina, é possível que o fluxo no sentido da salina ocorra apenas no período de descarga ou seca, sendo a cordilheira o local de onde parte a fonte de alimentação e não a vazante.

Bacani (2004) verificou, ainda, uma correspondência entre as oscilações do nível dos piezômetros, o nível da salina do Meio e as precipitações. Assim, no período mais 

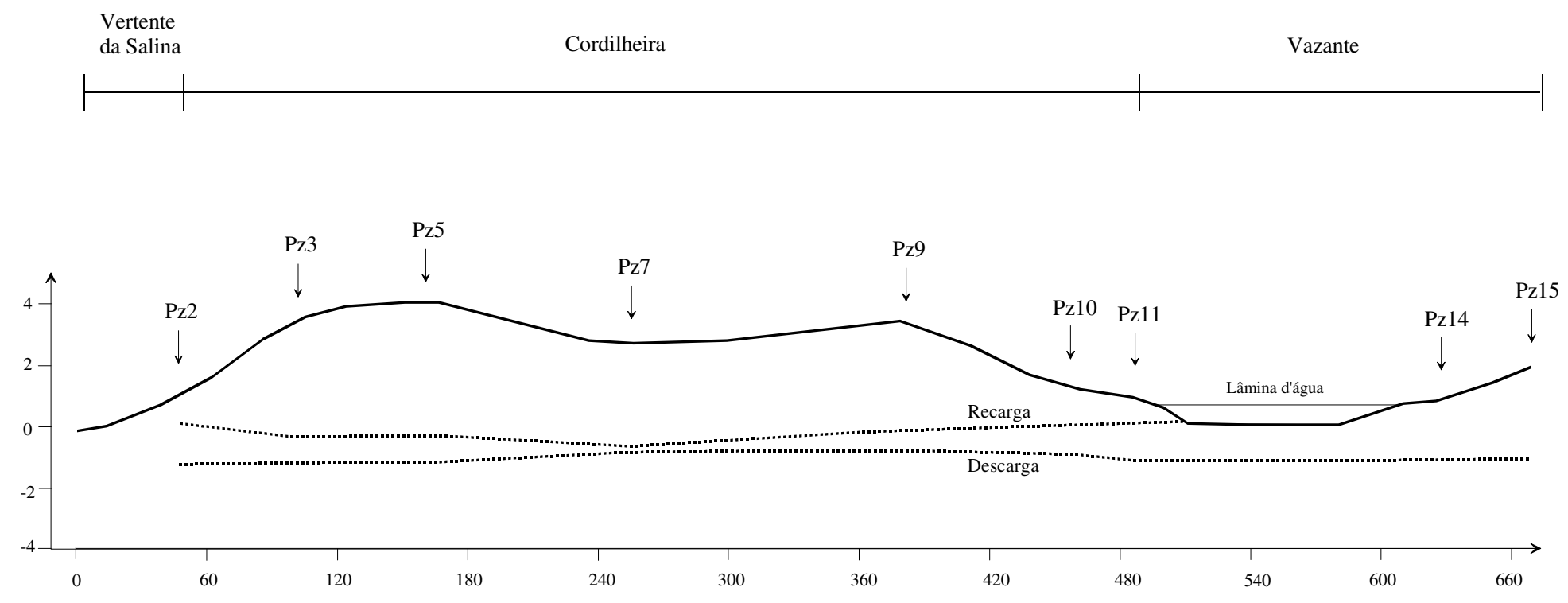

\begin{tabular}{|c|c|c|c|c|}
\hline \multirow{2}{*}{ Piezômetro } & 0 & 30 & 60 & \\
\hline & \multicolumn{4}{|c|}{ Escala Horizontal } \\
\hline ... Lençol freático & 0 & 2 & 4 & \\
\hline
\end{tabular}

Figura 2.5 - Nível do lençol freático nos períodos de recarga e descarga - Fazenda Nhumirim 
chuvoso (dezembro a março) os níveis dos piezômetros e da salina subiram, enquanto no período seco (abril a setembro) os níveis baixaram progressivamente. Destaca-se que na Fazenda Nhumirim, em específico, as inundações ocorrem principalmente de fevereiro a março, quando há o extravasamento dos lençóis freáticos para a superfície (Soriano et al., 1997). Desta forma, as cheias na Fazenda Nhumirim parecem ter grande contribuição das precipitações locais, diferente do que ocorre no rio Paraguai, cujas águas das inundações são majoritariamente provenientes das terras altas dos arredores.

No período medido por Bacani (2004), o nível do espelho d'água da salina do Meio, medido através de uma régua, oscilou o máximo de $70 \mathrm{~cm}$ em profundidade. Em 2001, o maior valor foi de $125 \mathrm{~cm}$ em janeiro e o menor de $75 \mathrm{~cm}$ em setembro, e em 2002, um ano excepcionalmente seco, chegou a aproximadamente $120 \mathrm{~cm}$ em março e $50 \mathrm{~cm}$ em outubro (Figura 2.6). Apesar de não terem sido feitas medidas específicas da área ocupada pelo espelho d'água durante as variações sazonais de disponibilidade de água, observações de campo permitiram notar que, no período de máxima cheia, o espelho d'água expande-se até cerca de 25 metros de distância da cordilheira, situando na borda de uma estreita faixa de gramíneas que antecede o Cerradão, enquanto no período da máxima seca, recua para o centro da depressão, a cerca de 100 metros da cordilheira, deixando uma extensa área de areia exposta na superfície.

\subsection{3 - Caracterização química das águas da sub-região da Nhecolândia}

O primeiro a analisar as propriedades químicas das lagoas da porção S-SW da Nhecolândia foi provavelmente Cunha (1942), através de amostragem em 8 salinas na época das cheias. Seus resultados apontaram a presença de águas alcalinas, com $\mathrm{pH}$ entre 8 e 10, com altas concentrações de $\mathrm{HCO}_{3}{ }^{-}, \mathrm{Cl}^{-}$e $\mathrm{Na}^{+}$(Tabela 2.1).

Brum \& Sousa (1985) realizaram um estudo em escala mais abrangente, já que amostraram 20 salinas e 17 baías, todas na época de seca. O objetivo foi medir a concentração de 10 cátions, a fim de avaliar sua disponibilidade para o gado criado em pastagens extensivas da região. Verificou-se que as concentrações médias de $\mathrm{Ca}^{2+}$, $\mathrm{Mg}^{2+}, \mathrm{Fe}, \mathrm{Mn}$ são superiores nas baías, enquanto que as de $\mathrm{Na}^{+}$e $\mathrm{K}^{+}$são superiores nas salinas (Tabela 2.1). Assim como já haviam intuído os fazendeiros da região, os autores concluíram que as salinas contribuem significativamente com a complementa- 


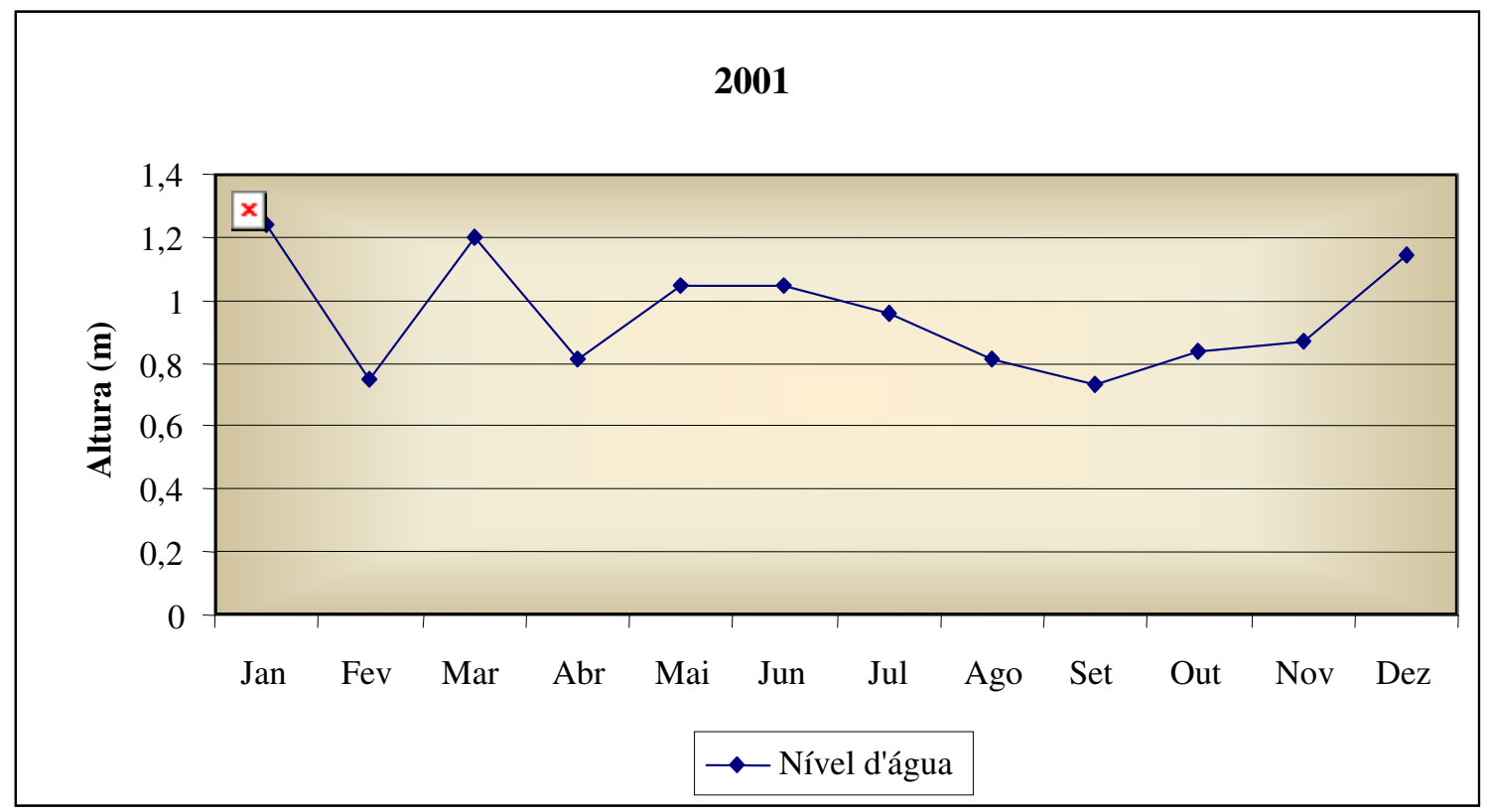

Fonte: Bacani (2004)

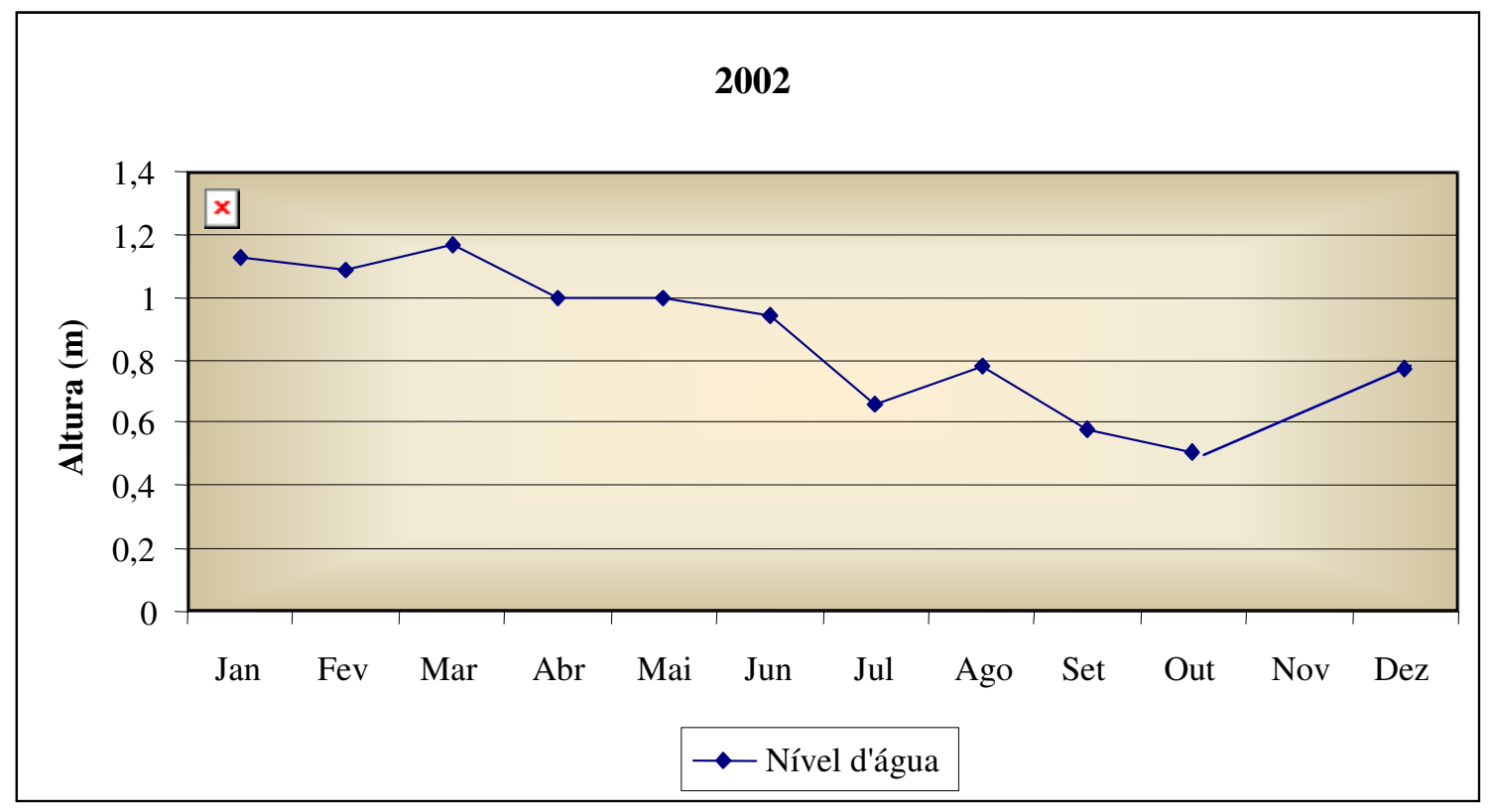

Fonte: Bacani (2004)

Figura 2.6 - Comportamento mensal do nível d'água superficial da salina do Meio 
Tabela 2.1 - Resultados selecionados das análises químicas das águas da Nhecolândia, apresentados em bibliografia*

\begin{tabular}{|c|c|c|c|}
\hline \multirow{2}{*}{ Íons } & \multirow{2}{*}{$\begin{array}{l}\text { Cunha }(\mathbf{1 9 4 2}) \\
\text { Salinas }(\mathrm{mg} / \mathrm{L})\end{array}$} & \multicolumn{2}{|c|}{ Brum \& Sousa (1985) } \\
\hline & & Salinas (mg/L) & Baías (mg/L) \\
\hline $\mathrm{Fe}$ & 8 a 10 & $0,64 \pm 0,86$ & $1,17 \pm 1,35$ \\
\hline $\mathrm{Al}^{3+}$ & 0 a 1 & ------------ & ------------ \\
\hline Mn & --------- & $0,10 \pm 0,00$ & $0,37 \pm 0,23$ \\
\hline $\mathrm{Ca}^{2+}$ & 7 a 14 & $1,54 \pm 1,49$ & $3,02 \pm 2,37$ \\
\hline $\mathrm{Mg}^{2+}$ & 2 a 6 & $0,70 \pm 0,71$ & $1,45 \pm 1,36$ \\
\hline $\mathrm{Na}^{+}$ & 1660 a 1679 & $484,00 \pm 347,12$ & $11,35 \pm 0,13$ \\
\hline $\mathrm{K}^{+}$ & 186 a 192 & $213,90 \pm 101,18$ & $11,53 \pm 8,38$ \\
\hline $\mathrm{Cl}^{-}$ & 1242 & ------------- & -------- \\
\hline $\mathrm{SO}_{4}{ }^{2-}$ & 44 a 46 & ------------- & ------------- \\
\hline $\mathrm{SiO}_{4}^{3-}$ & 150 a 160 & ----------- & ------------- \\
\hline $\mathrm{HCO}_{3}^{-}$ & 2003 & ------------- & ------------- \\
\hline $\mathrm{CO}_{3}{ }^{2-}$ & 287 & ------------- & ------------- \\
\hline
\end{tabular}

ção de sal para o gado, especialmente do $\mathrm{K}^{+}, \mathrm{Fe}$ e $\mathrm{Na}^{+}$, já que fornecem respectivamente $9,27 \%, 16,64 \%$ e $209,73 \%$ das necessidades diárias destes elementos. As baías, por sua vez, contribuem principalmente no complemento do Fe, fornecendo $30,42 \%$ das necessidades diárias.

Dados de um número ainda maior de amostras de águas da Nhecolândia foram obtidos recentemente. O trabalho de Barbiéro et al. (2002), já citado no Capítulo 1, envolveu águas superficiais de 5 rios, 41 baías e salinas e 7 vazantes, além de águas subsuperficiais de 12 piezômetros; os meses da amostragem não foram especificados. Os resultados permitiram aos autores levantar a hipótese de que as águas mais mineralizadas (de alguns piezômetros e salinas) estão sendo originadas atualmente pela concentração das águas pouco mineralizadas (baías, vazantes e rios), devido às altas taxas de evapotranspiração ${ }^{1}$.

Estes autores mostram que as águas menos mineralizadas (baías, vazantes, rios) apresentam $\mathrm{pH}$ menor que 8,0 e maiores teores de $\mathrm{CO}_{3}{ }^{2-} / \mathrm{Cl}^{-}$e $\mathrm{Na}^{+} / \mathrm{K}^{+}$, enquanto as mais mineralizadas (salinas, piezômetros) apresentam $\mathrm{pH}$ maior que 9,0 e maiores teores de $\mathrm{CO}_{3}{ }^{2-}$ e $\mathrm{Na}^{+}$. Os dados de Cunha (1942) e Brum \& Sousa (1985) (Tabela 2.1) também apresentam uma predominância isolada de $\mathrm{Na}^{+}$nas salinas e $\mathrm{Na}^{+} \mathrm{e} \mathrm{K}^{+}$

\footnotetext{
1 Apesar deste trabalho já ter sido comentado no Capítulo 1, maiores detalhes serão fornecidos neste item devido à sua importância na interpretação dos dados da presente tese.
} 
nas baías, mas Cunha (1942) mostra maiores concentrações de $\mathrm{HCO}_{3}{ }^{-}$e $\mathrm{Cl}^{-}$do que $\mathrm{CO}_{3}{ }^{2-}$ nas salinas.

As principais diferenças entre águas mais e menos mineralizadas podem ser em grande maioria explicadas, segundo Barbiéro et al. (2002), por processos associados à concentração das águas por evaporação, envolvendo a conservação de alguns elementos em solução e a supersaturação e conseqüente controle de outros no decorrer da concentração. Os diagramas de concentração reproduzidos na Figura 2.7 mostram como isto ocorreria. $\mathrm{O}$ fator de concentração das águas, no eixo $\mathrm{x}$, foi estimado pela concentração do $\mathrm{Na}^{+}$, acreditando-se ser este um elemento conservativo. A linha contínua representa hipoteticamente a evolução dos teores de sódio durante a concentração e a linha tracejada é a simulação da evolução do que está sendo representado no eixo y. Assim, notou-se que $\mathrm{pH}$ e $\mathrm{CO}_{3}{ }^{2-}$ (alcalinidade) são conservativos, pois acompanham de maneira geral o aumento da concentração/mineralização das águas, aumentando proporcionalmente às molalidades do sódio. Potássio, $\mathrm{SO}_{4}{ }^{2-}$ e $\mathrm{Cl}^{-}$também têm aumento geral com a concentração, apesar de haver um suave decréscimo das molalidades entre 10 e $100 \mathrm{meq} / \mathrm{L}$ de sódio no caso do primeiro elemento e a partir de 5-10 meq/L de sódio para os dois últimos elementos. Tanto $\mathrm{Ca}^{2+}$ quanto $\mathrm{Mg}^{2+}$ aumentam com o fator de concentração até a molalidade 1-5 meq/L do sódio, e a partir daí diminuem brutalmente. Por fim, as molalidades de $\mathrm{Si}(\mathrm{OH})_{4}$ são controladas nas proximidades da concentração de 1 meq/L de sódio, aumentando suavemente em águas mais mineralizadas.

A partir destes resultados, os autores destacam o comportamento das molalidades do $\mathrm{Ca}^{2+}, \mathrm{Mg}^{2+}$ e $\mathrm{Si}(\mathrm{OH})_{4}$, pois sua nítida diminuição se comparadas às do sódio indica que estes íons tornam-se supersaturados e são controlados em algum ponto do processo de concentração das águas. Como já citado no Capítulo 1, a precipitação de carbonatos ou Mg-carbonatos e a formação de silicatos magnesianos são apontados como possíveis responsáveis pelo controle destes elementos, que parece estar ocorrendo em águas mais mineralizadas. São destacados também o $\mathrm{SO}_{4}{ }^{2-} \mathrm{e} \mathrm{Cl}^{-}$, cujas molalidades diminuem levemente em águas não muito mineralizadas, mas voltam a subir em águas mais mineralizadas. Este comportamento seria explicado não por processos associados à concentração, mas sim pela possível formação de hidróxidos 

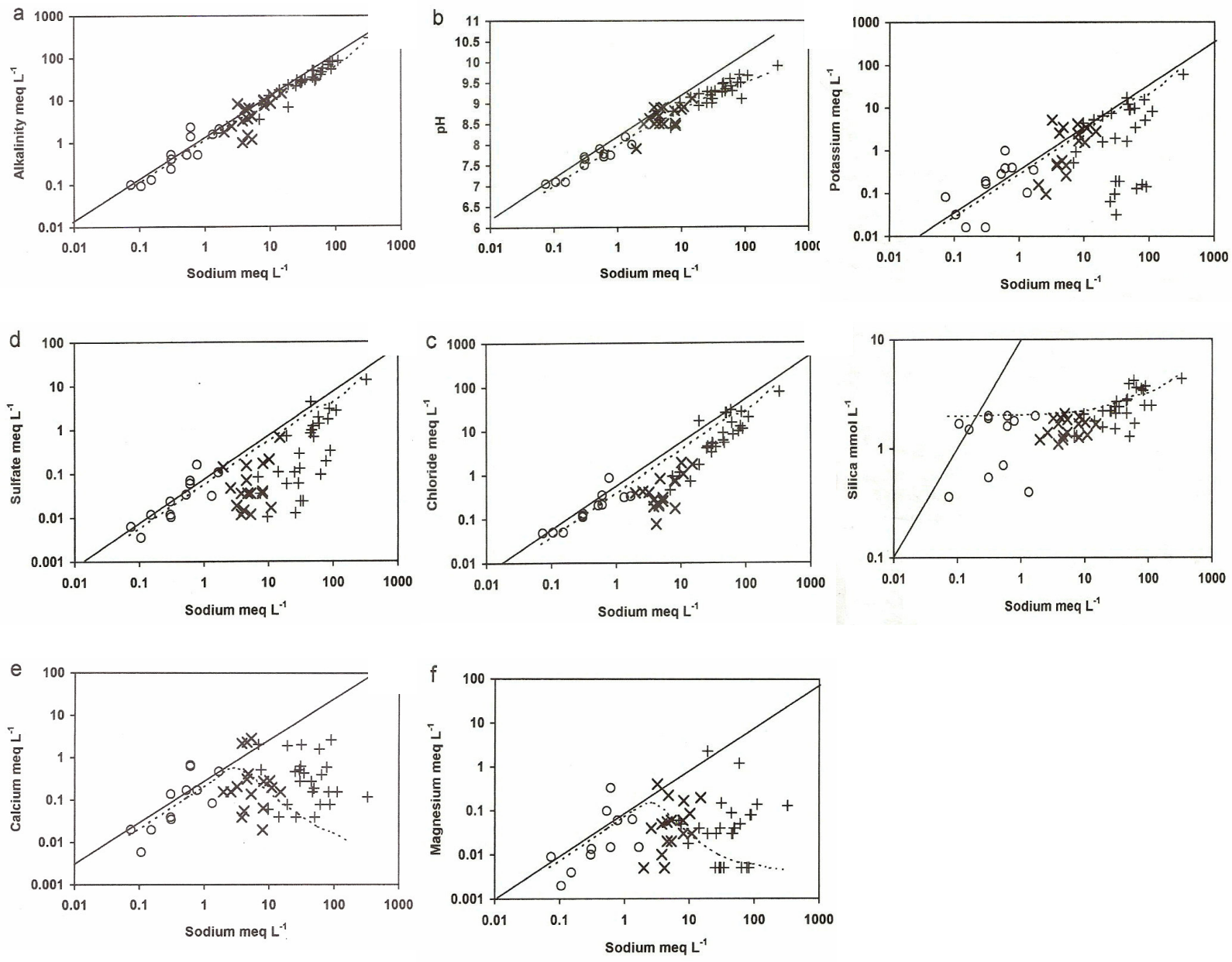

Fonte: Barbiéro et al. (2002)

Figura 2.7 - Seleção de diagramas de concentração das águas da Nhecolândia. Linha contínua: evolução dos teores de $\mathrm{Na}^{+}$; linha tracejada: simulação; ○: rios e vazantes; $\mathrm{x}$ : baías; +: lençol freático e salinas.

Calcite-solution equilibrium

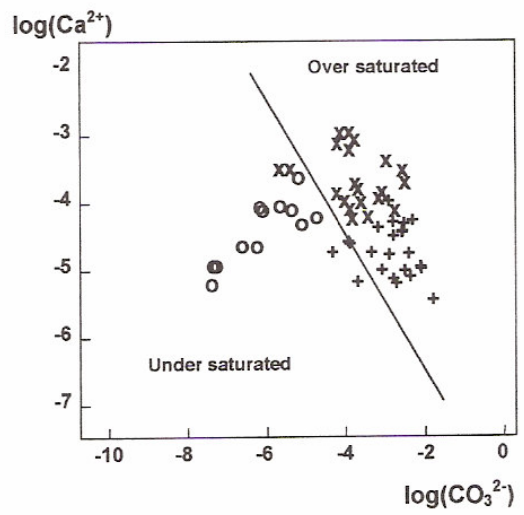

Magnesite-solution equilibrium

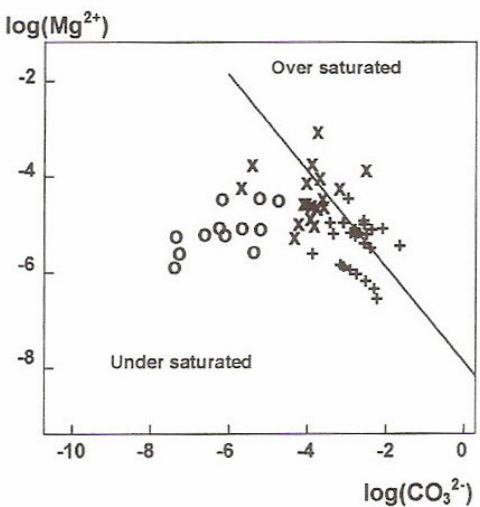

Magnesian silicate-solution equilibrium

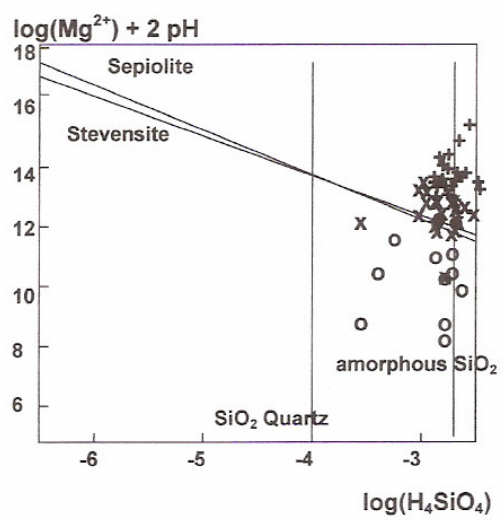

Fonte: Barbiéro et al. (2002)

Figura 2.8 - Seleção de diagramas de equilíbrio. o: rios e vazantes; x: baías; + : lençol freático e salinas. 
férricos-ferrosos em ambiente de oxi-redução, sendo que o $\mathrm{SO}_{4}{ }^{2-} \mathrm{e}^{-} \mathrm{Cl}^{-}$substituiriam o $\mathrm{OH}^{-}$.

Diagramas de equilíbrio apresentados pelos autores (Figura 2.8) sustentam a hipótese de controle do $\mathrm{Ca}^{2+}, \mathrm{Mg}^{2+}$ e $\mathrm{Si}(\mathrm{OH})_{4}$ já que indicam: a) que as águas mais mineralizadas (salinas e de alguns piezômetros) estão em equilíbrio ou suavemente supersaturadas em relação à calcita $\left(\mathrm{CaCO}_{3}\right)$ e magnesita $\left(\mathrm{MgCO}_{3}\right)$; b) que a maioria das águas estão supersaturadas em relação ao quartzo e em equilíbrio com sílica amorfa, mostrando ser possível sua presença no sistema e; c) o equilíbrio com a estevensita ou sepiolita (Mg-silicatos) é atingido.

\section{3 - Geologia e Geomorfologia}

A formação do Pantanal Sul-Mato-Grossense está relacionada à gradual subsidência tectônica decorrente do soerguimento do geossinclínio andino durante o Cenozóico, formando na borda leste da Cordilheira dos Andes o conjunto de terrenos deprimidos composto pela Depressão do Rio Paraguai, pelos Pampas Argentinos e pela Depressão do Chaco (Del'Arco et al., 1982; Por, 1995). Os abatimentos ocorreram no contato entre rochas cristalinas pré-cambrianas e rochas sedimentares mesozóicas da Bacia do Paraná (Silva, 1986).

Com a abertura da Depressão do Rio Paraguai, iniciou-se a deposição de sedimentos fluviais, lacustres e flúvio-lacustres, processo que possivelmente se iniciou no PlioPleistoceno e até o momento não cessou (Del'Arco et al., 1982). Estas formações sedimentares recebem o nome de Formação Pantanal, sendo composta pela alternância de camadas e/ou pacotes arenosos, síltico-argilosos e argilosos, inconsolidados ou semi-consolidados, com espessura máxima de 500 metros, depositados possivelmente de acordo com oscilações climáticas (Del'Arco et al., 1982; Godoi Filho, 1986) (Figura 2.9).

Grande parte da superfície cujo embasamento é constituído pelos sedimentos da Formação Pantanal configura uma unidade geomorfológica denominada Planícies e Pantanais (Franco \& Pinheiro, 1982). Como citado no Capítulo 1, trata-se de uma extensa área caracterizada por altitudes entre 100 e 200 metros, com uma topografia quase plana e parcialmente sujeita a inundações periódicas. Vários autores dividiram 


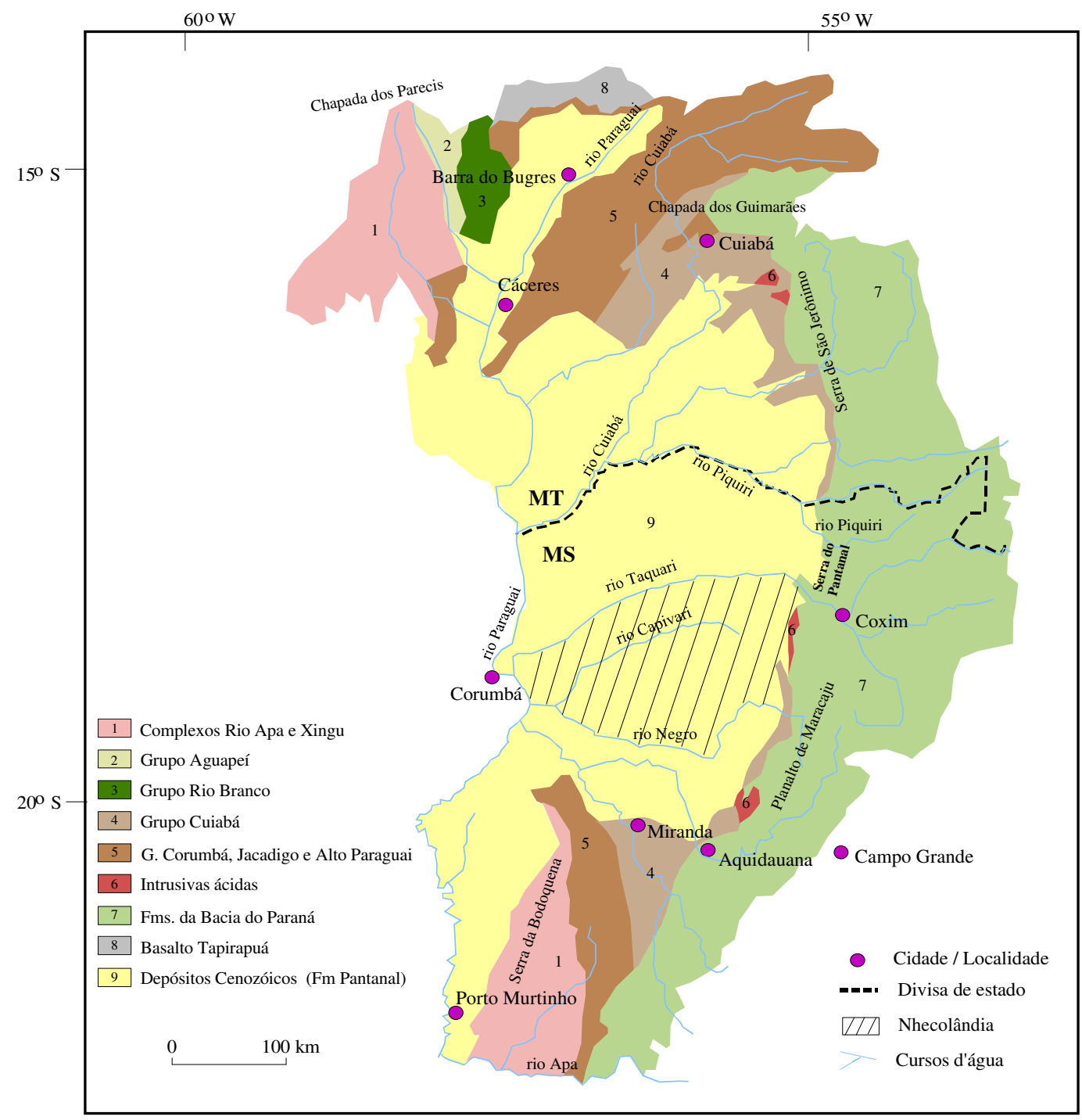

Fonte: adaptação a partir de Godoi Filho (1986) e Agência Nacional de Águas (ANA).

Figura 2.9 - Mapa geológico simplificado do Pantanal e arredores.

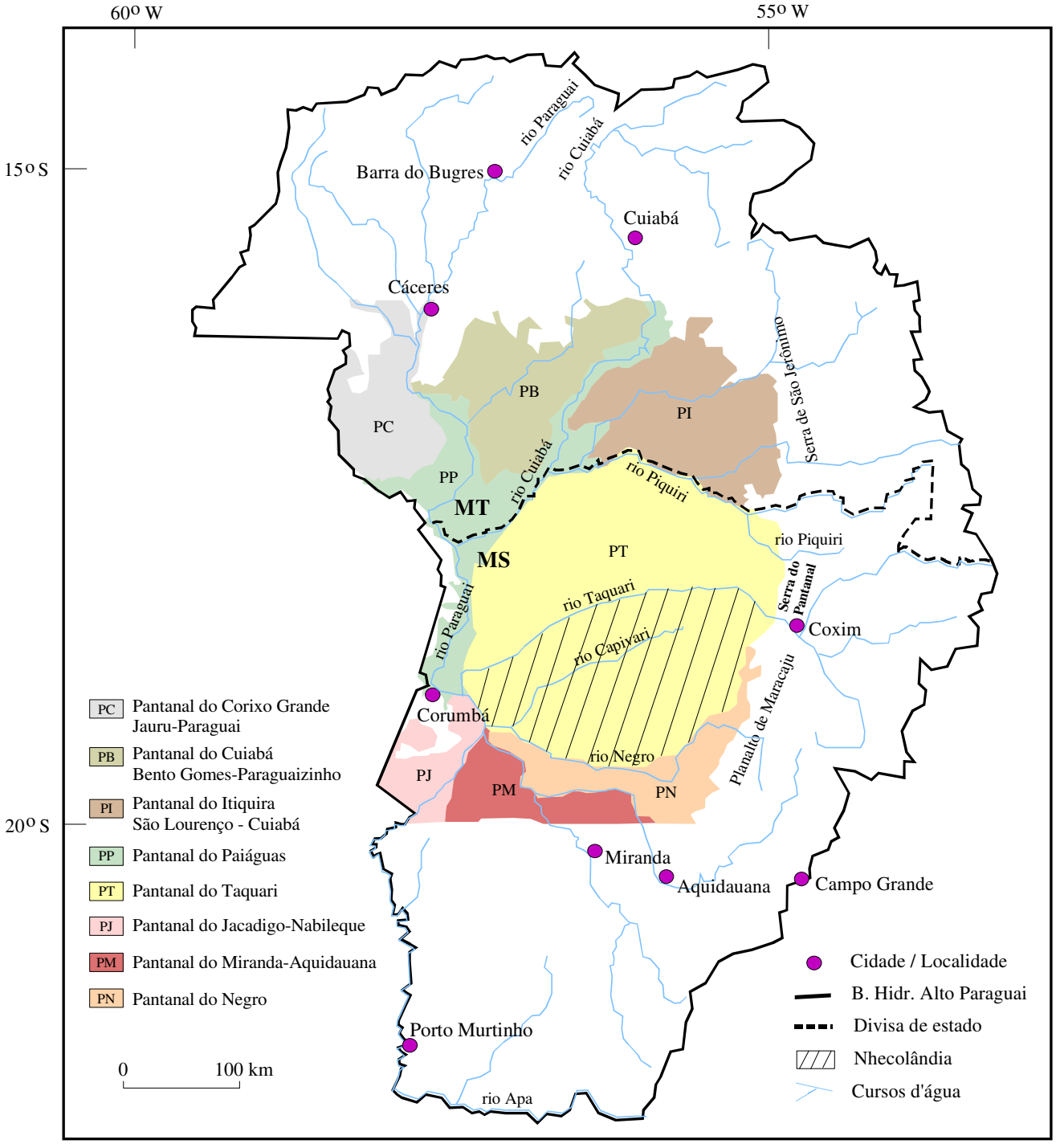

Fonte: adaptado a partir de Franco \& Pinheiro (1982) e Agência Nacional de Águas (ANA)

Figura 2.10 - As sub-divisões do Pantanal conforme Relatório do Radambrasil 
esta unidade geomorfológica em subunidades, principalmente em função da dinâmica de inundação e das características fisiográficas específicas de cada área (Franco \& Pinheiro, 1982; Por, 1995). No projeto Radambrasil, Franco \& Pinheiro (1982) propõem a divisão destas planícies e pantanais em 8 compartimentos geomorfológicos, correspondentes a sistemas fluviais formados por bacias dos principais afluentes do rio Paraguai (Figura 2.10).

Dos compartimentos delimitados por estes autores, destaca-se o denominado Pantanal do Taquari, que corresponde a um macro leque aluvial, com uma área de cerca de $50.000 \mathrm{~m}^{2}$, provavelmente formado durante a última fase semi-árida pleistocênica, quando havia o predomínio de processos torrenciais (Del'Arco et al., 1982; Silva, 1986). Limita-se ao norte e noroeste pelos rios Piquiri e Cuiabá, a oeste e sul pelo rio Negro e a leste pelas serras e planaltos de Maracaju e do Pantanal (Figura 2.10). A sub-região da Nhecolândia corresponde à porção centro-sul do Pantanal do Taquari, entre os rios Taquari e Negro (Figura 2.10).

A Formação Pantanal na Nhecolândia é composta por 95\% de sedimentos arenosos finos, apresentando teores muito baixos de argila (Cunha, 1980). As áreas-fonte destes sedimentos localizam-se essencialmente no Planalto de Maracaju, de onde são provenientes grande parte das nascentes dos cursos d'água que banham a região. De acordo com Del Arco et al. (1982), este planalto pode ser dividido em 2 grandes áreas $^{2}$ : a leste, engloba uma superfície pediplanada e amplos interflúvios de topo plano, sendo sustentado por sedimentos da Unidade Edafoestratigráfica DetríticoLaterítica e da Formação Bauru e por rochas eruptivas da Formação Serra Geral (Tabela 2.2); a oeste, nas bordas da planície pantaneira, abrange uma frente de cuesta, sustentada por rochas do Pré-Cambriano Superior (Grupo Cuiabá), e o seu reverso, composto por sedimentos das Formações Furnas, Ponta Grossa, Aquidauana e Botucatu (Tabela 2.2) (Del'Arco et al., 1982; Franco \& Pinheiro, 1982). Há, portanto, uma grande diversidade de litologias que constituem as áreas-fonte dos sedimentos da Nhecolândia, mas destaca-se que os sedimentos arenosos da Bacia do Paraná (Forma-

\footnotetext{
${ }^{2}$ As unidades geológicas descritas por Del Arco et al. (1982) e detalhadas na Tabela 2.2 não correspondem diretamente às unidades apresentadas no mapa geológico da Figura 2.9, já que este é uma representação simplificada. A correlação entre as unidades de Del' Arco et al. (1982) e as apresentadas na Figura 2.9 pode ser vista na Tabela 2.2.
} 
Tabela 2.2 - Características das Formações Geológicas das áreas-fonte da Nhecolândia

\begin{tabular}{|c|c|c|c|}
\hline Formações & Idade & Litologias & $\begin{array}{c}\text { Correspondência na } \\
\text { Figura } 2.9\end{array}$ \\
\hline & $\begin{array}{l}\text { Pré-Cambriano } \\
\text { Superior }\end{array}$ & $\begin{array}{l}\text { Filitos, xistos, metarenitos, } \\
\text { metarcóseos, } \\
\text { metaparaconglomerados, } \\
\text { quartzitos, mármores. }\end{array}$ & Grupo Cuiabá \\
\hline $\begin{array}{l}\text { Granito } \\
\text { Coxim }\end{array}$ & $\begin{array}{l}\text { Paleoz: } \\
\text { Cambro- } \\
\text { Ordoviciano }\end{array}$ & $\begin{array}{l}\text { Granito róseo, de granulação } \\
\text { média a grossa }\end{array}$ & Intrusivas Ácidas \\
\hline Furnas & $\begin{array}{l}\text { Paleoz: } \\
\text { Siluriano }\end{array}$ & $\begin{array}{l}\text { Arenitos grosseiros, } \\
\text { dominantemente quartzosos, } \\
\text { com níveis conglomeráticos. }\end{array}$ & $\begin{array}{l}\text { Fms. da Bacia do } \\
\text { Paraná }\end{array}$ \\
\hline Ponta Grossa & $\begin{array}{l}\text { Paleoz: } \\
\text { Devoniano }\end{array}$ & $\begin{array}{l}\text { Intercalação de siltitos, } \\
\text { arenitos e folhelhos. }\end{array}$ & $\begin{array}{l}\text { Fms. da Bacia do } \\
\text { Paraná }\end{array}$ \\
\hline Aquidauana & $\begin{array}{l}\text { Paleoz: } \\
\text { Carbonífero- } \\
\text { Permiano }\end{array}$ & $\begin{array}{l}\text { Arenitos, siltitos, argilitos, } \\
\text { folhelhos, conglomerado } \\
\text { basal. }\end{array}$ & $\begin{array}{l}\text { Fms. da Bacia do } \\
\text { Paraná }\end{array}$ \\
\hline Botucatu & $\begin{array}{l}\text { Mesoz: } \\
\text { Triássico- } \\
\text { Jurássico }\end{array}$ & $\begin{array}{l}\text { Arenitos bem selecionados } \\
\text { com lentes conglomerá- } \\
\text { ticas. }\end{array}$ & $\begin{array}{l}\text { Fms. da Bacia do } \\
\text { Paraná }\end{array}$ \\
\hline Serra Geral & $\begin{array}{l}\text { Mesoz: } \\
\text { Jurássico- } \\
\text { Cretáceo }\end{array}$ & $\begin{array}{l}\text { Basaltos finos a afaníticos, } \\
\text { amigdalóides no topo. }\end{array}$ & \\
\hline Bauru & $\begin{array}{l}\text { Mesoz: } \\
\text { Cretáceo }\end{array}$ & $\begin{array}{l}\text { Arenitos vermelhos a róseos, } \\
\text { mal classificados, ás vezes } \\
\text { calcíferos. }\end{array}$ & $\begin{array}{l}\text { Fms. da Bacia do } \\
\text { Paraná }\end{array}$ \\
\hline $\begin{array}{l}\text { Cobertura } \\
\text { Detrítico- } \\
\text { Laterítica }\end{array}$ & $\begin{array}{l}\text { Cenoz: } \\
\text { Terciária- } \\
\text { Quaternária }\end{array}$ & $\begin{array}{l}\text { Areias e argilas concrecio- } \\
\text { nárias, laterita e solos } \\
\text { ferruginosos }\end{array}$ & \\
\hline
\end{tabular}

Fonte: adaptação a partir de Del'Arco et al. (1982). 
ções Bauru, Furnas, Aquidauana e Botucatu) são fortemente predominantes em área (Del'Arco et al., 1982), como pode ser observado na Figura 2.9.

Fernandes et al. (1999) e Fernandes (2000) subdividiram a Nhecolândia em 6 compartimentos fisiográficos, principalmente a partir de características geomorfológicas e hidrográficas interpretadas em imagens de satélite (Figura 2.11). A partir desta compartimentação foi possível verificar que os sistemas compostos por lagoa salina-cordilheira e baía-vazante estão presentes apenas no compartimento que possui as menores altitudes (80 a 120 metros) e que ocupa a porção S-SW da Nhecolândia, denominado pelos autores de Baixa Nhecolândia. Os autores citados, confirmando a hipótese de Queiroz Neto et al. (1998), mostram que as águas que chegam nestas áreas são provenientes essencialmente da então chamada Alta Nhecolândia, ou seja, da porção com as maiores altitudes (120 a 160 m) situada no NNE da Nhecolândia, e vão desaguar na planície de inundação do Rio Negro.

A morfologia em escala de detalhe de vazantes, baías, cordilheiras e salinas da Baixa Nhecolândia foi mostrada a partir de levantamentos topográficos realizados na Fazenda São Miguel do Firme (Figura 2.4) por Sakamoto et al. (1996), Sakamoto (1997) e Capellari (2001). A principal conclusão destes estudos revela que as lagoas salinas são depressões que estão sempre em situação topográfica rebaixada em relação às cordilheiras, vazantes e baías. As diferenças de altitude são métricas, como mostra Capellari (2001): enquanto as salinas apresentam profundidades entre 1,46 e 3,81 metros em relação ao entorno, as baías tem profundidade entre 0,29 e 2,20 metros e as vazantes entre 0,10 e 0,55 metro (Tabela 2.3). Os baixos níveis topográficos das salinas podem então ser os responsáveis pelo afloramento do lençol subterrâneo durante todo o ano, mantendo estas lagoas permanentemente com água por longos períodos.

\section{4 - Solos}

\subsection{1 - Principais ordens/subordens de solos no Pantanal e na Nhecolândia}

De acordo o mapeamento do Projeto Radambrasil, em escala 1:1.000.000, as principais ordens/subordens de solos da planície pantaneira são as Lateritas Hidromórficas ao norte, Podzóis Hidromórficos ao centro e sul (incluindo a Nheco- 


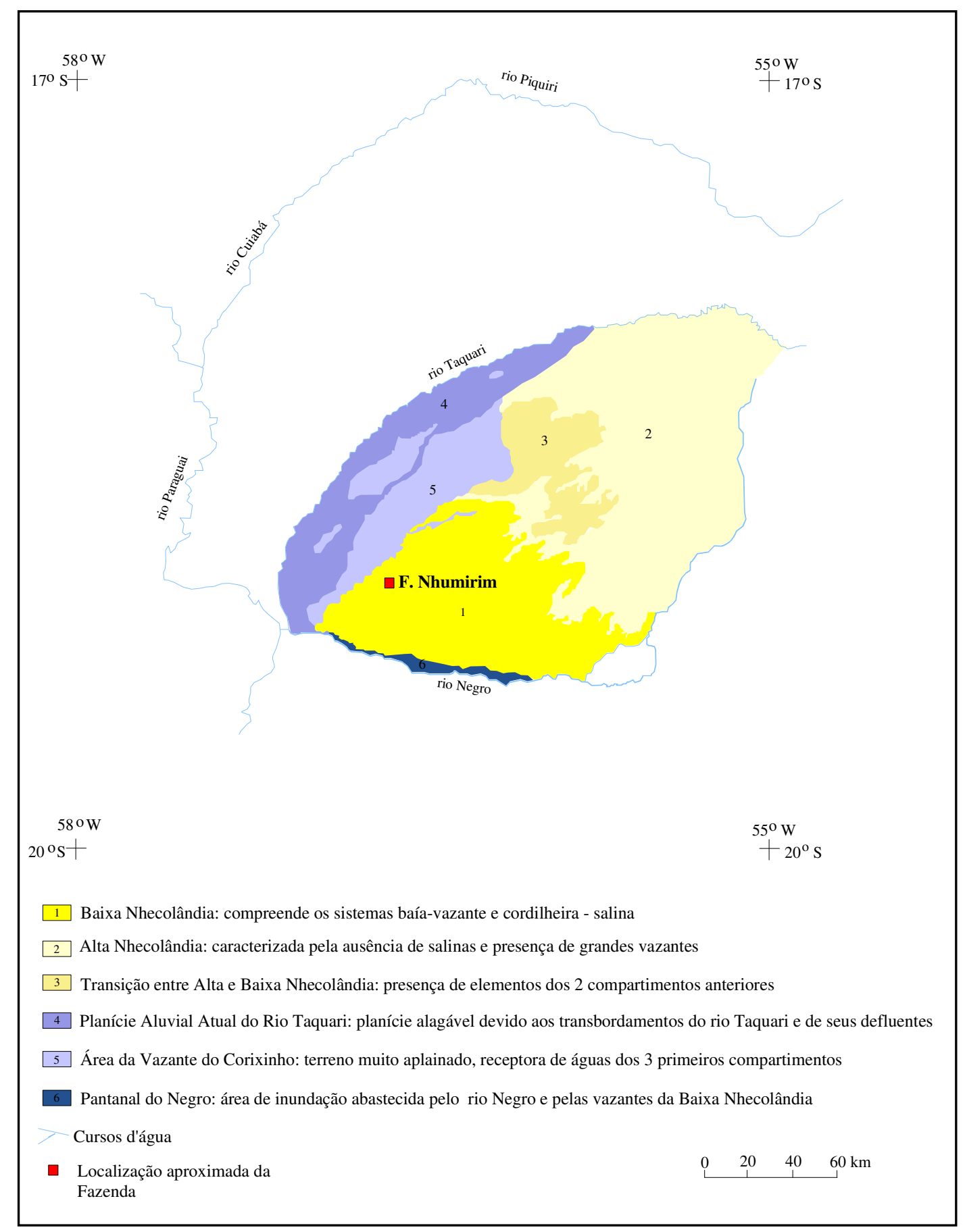

Fonte: adaptado a partir de Fernandes et al. (1999) e Fernandes (2000)

Figura 2.11 - Compartimentos fisiográficos da Nhecolândia 
Tabela 2.3 - Profundidade de baías, salinas e vazantes em 5 perfis topográficos na Fazenda São Miguel do Firme.

\begin{tabular}{|c|c|}
\hline Corpos d'água & Profundidade (m) \\
\hline \multicolumn{2}{|c|}{ Perfil 1} \\
\hline Salina 1 & 3,81 \\
\hline Salina 2 & 2,64 \\
\hline Baía 1 & 2,20 \\
\hline \multicolumn{2}{|c|}{ Perfil 2} \\
\hline Salina 3 & 2,75 \\
\hline Vazante 1 & 0,82 \\
\hline Vazante 2 & 0,55 \\
\hline \multicolumn{2}{|c|}{ Perfil 3} \\
\hline Salina 4 & 1,61 \\
\hline Baía 2 & 0,29 \\
\hline Baía 3 & 0,58 \\
\hline \multicolumn{2}{|c|}{ Perfil 4} \\
\hline Vazante 3 & 0,38 \\
\hline Vazante 4 & 0,19 \\
\hline \multicolumn{2}{|c|}{ Perfil 5} \\
\hline Salina 5 & 1,46 \\
\hline
\end{tabular}


lândia), Solonetz-Solodizados ao sul e Gleis Pouco Húmicos nas adjacências do rio Paraguai e seus afluentes (Orioli et al., 1982) (Figura 2.12).

As Lateritas Hidromórficas (atualmente Plintossolos - Embrapa, 2006) são solos bem diferenciados, imperfeitamente ou mal drenados, caracterizados por apresentar expressiva quantidade de plintita, formação que ocorre em mosqueados avermelhados ou nódulos, originada pela segregação do ferro, com conseqüente mobilização, transporte e concentração final de seus compostos (Embrapa, 2006). No Pantanal, estes solos apresentam a sequiência de horizontes A, Btpl (B textural plíntico) e C; o horizonte A é geralmente moderado ou chernozêmico e arenoso e o Btp apresenta estrutura maciça, granular ou em blocos subangulares e textura média a muito argilosa (Orioli et al., 1982). O levantamento do Radambrasil (Orioli et al., 1982) não reconhece esta ordem na Nhecolândia (Figura 2.12), mas o mapeamento preliminar de Cunha (1981) aponta sua existência em uma estreita faixa próxima ao limite leste desta sub-região (Figura 2.13).

Os Podzóis Hidromórficos (atualmente Espodossolos - Embrapa, 2006) são solos minerais bem diferenciados, imperfeitamente ou mal drenados, geralmente ácidos, com presença do horizonte B espódico, o qual apresenta acumulação iluvial de matéria orgânica $(\mathrm{Bh})$ e/ou de complexos formados por matéria-orgânica e sesquióxidos de ferro e alumínio (Bir ou atualmente Bs) (Embrapa, 2006). Estes solos, dominantemente arenosos quando ocorrem sobre o leque do rio Taquari, possuem seqüência de horizontes A, E, B espódico e C; o horizonte A é geralmente do tipo moderado, o B espódico caracteriza-se pelas colorações bruno-escuras, avermelhadas ou amareladas, evidenciando um acúmulo de matéria-orgânica, óxidos de ferro ou alumínio, e o C, em geral, apresenta mosqueamentos típicos de deficiência hídrica (Orioli et al., 1982). Tanto para Radambrasil (Orioli et al., 1982) quanto para Cunha (1981) esta é a classe dominante na Nhecolândia, sendo que para o primeiro autor ocorre ao norte, ao sul e ao centro (Figura 2.12) e, para o segundo, principalmente ao norte e ao centro desta sub-região (Figura 2.13).

A classe Solonetz-Solodizado (atualmente Planossolos - Embrapa, 2006) compreende solos minerais imperfeitamente ou mal drenados, com saturação em sódio superior a $15 \%$ (sódicos), condutividade elétrica inferior a $4 \mathrm{dS} / \mathrm{m}$ e presença de horizonte $\mathrm{E}$ 


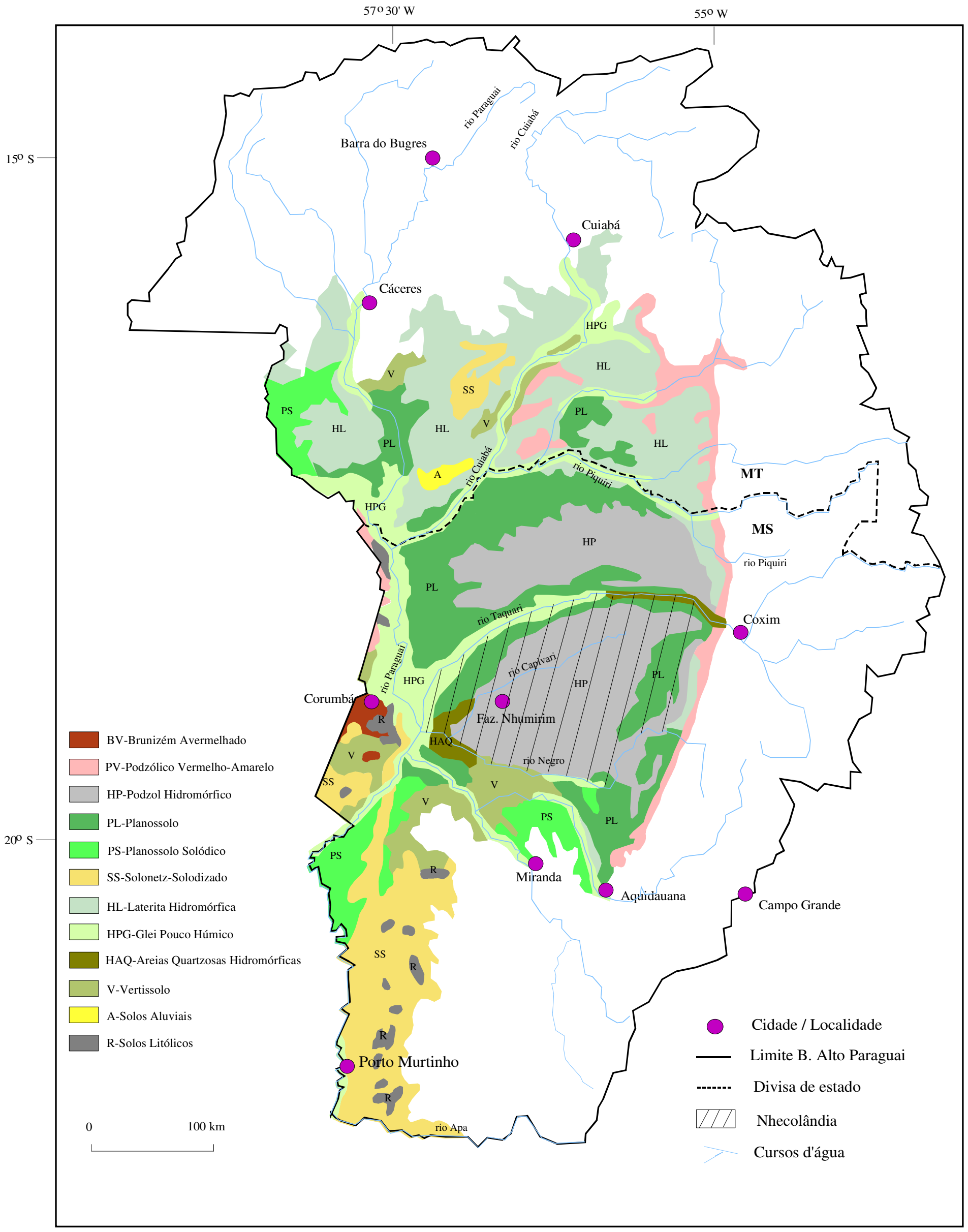

Fonte: adaptado a partir de Orioli et al. (1982), Amaral Filho (1986) e Agência Nacional de Águas (ANA).

Figura 2.12 - Mapa pedológico do Pantanal. 


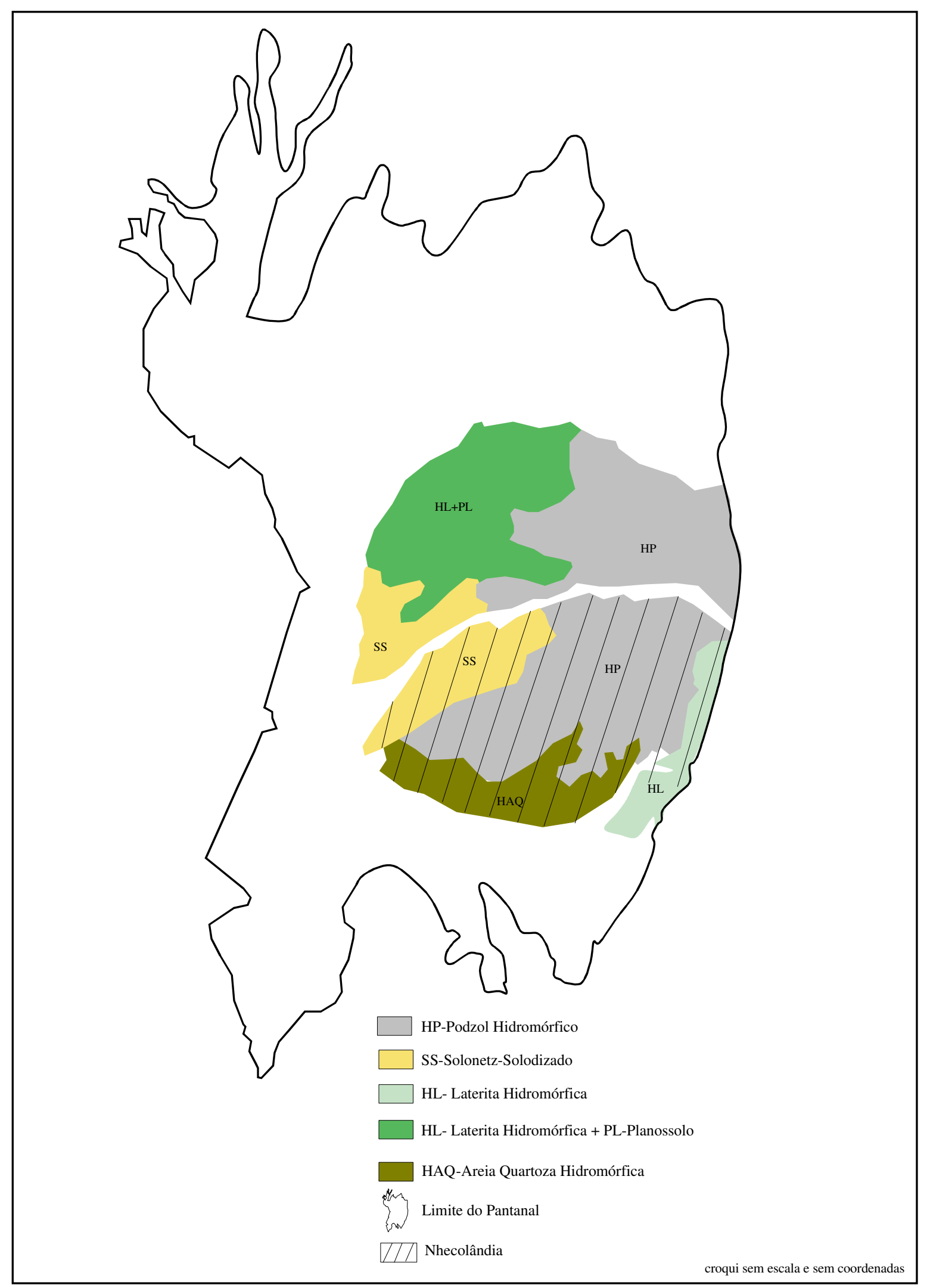

Fonte: adaptado a partir de Cunha (1981)

Figura 2.13 - Croqui de solos do leque do Taquari 
$\left(\mathrm{A}_{2}\right)$ sobrejacente ao horizonte B plânico, que se caracteriza por ser adensado, pelos teores elevados de argila dispersa e pela retenção temporária de um lençol de água suspenso (Embrapa, 2006). A classe geral hoje intitulada Planossolos engloba a definição dos antigos Solonetz-Solodizados, sendo reconhecida por serem solos imperfeitamente ou mal drenados, com presença de horizonte E e B plânico, podendo ou não ter horizonte cálcico, caráter carbonático, fragipã, duripã, propriedade sódica, solódica, caráter salino ou sálico. De acordo com Radambrasil (Orioli et al., 1982), os Solonetz-Solodizados e Planossolos no Pantanal, diferenciados na época do mapeamento principalmente pelo caráter solódico ou sódico do primeiro, apresentam seqüência de horizontes $\mathrm{A}, \mathrm{E}, \mathrm{Bt}$ e $\mathrm{C}$, sendo o A do tipo moderado, E arenoso, com estrutura colunar ou em blocos subangulares fortemente desenvolvida, hidromorfismo acentuado e textura franco-argilo-arenosa a argilosa. No mapeamento do Radambrasil, os Planossolos (associados a poucos Solonetz-Solodizados) estão presentes na Nhecolândia em faixas que acompanham os rios Taquari e parte do Negro (Figura 2.12). Mas conforme o levantamento preliminar de Cunha (1981) apenas os SolonetzSolodizados ocorrem, localizando-se também em faixa adjacente à parte do rio Taquari (Figura 2.13).

Os solos Gleis Pouco Húmicos (atualmente Gleissolos - Embrapa, 2006) são solos minerais hidromórficos, mal e muito mal drenados, com presença de horizonte gleizado (g), que se caracteriza pela redução de ferro devido à presença de água estagnada, evidenciada por cores neutras e/ou por mosqueamentos de cores vivas (Embrapa, 2006). Possuem seqüência de horizontes A e Cg e classes texturais muito variadas. Conforme Radambrasil (Orioli et al., 1982), estão associados às planícies aluviais presentes em todo o Pantanal, incluindo as dos rios Taquari e Negro, limites da Nhecolândia (Figura 2.12). Cunha (1981) não mapeou estes solos na Nhecolândia (Figura 2.13).

Deve-se destacar ainda as Areias Quartzosas Hidromórficas (atualmente Neossolos Quartzarênicos - Embrapa, 2006) que, apesar de terem sido mapeadas em poucas e pequenas manchas por Radambrasil (Orioli et al., 1982) (Figura 2.12), sua presença é apontada por Cunha (1981) em uma grande área na porção sul da Nhecolândia (Figura 2.13). Trata-se de solos geralmente profundos, imperfeitamente a mal drenados, com 
textura areia ou areia franca e pouco desenvolvidos, sendo compostos por um horizonte A sobreposto ao C.

Mapas esquemáticos para todo o Pantanal, organizados por Amaral Filho (1986) a partir de informações do Radambrasil (Orioli et al., 1982), mostram a distribuição da granulometria dos horizontes superficiais e subsuperficiais (Figura 2.14). Nota-se que na Nhecolândia a totalidade dos horizontes superficiais e a maioria dos horizontes subsuperficiais são arenosos. Faixas adjacentes ao rio Taquari e parte do rio Negro apresentam horizonte subsuperfical de textura média, associados principalmente a Planossolos e, secundariamente, a Solonetz-Solodizados (Figura 2.12).

É interessante ainda verificar o mapa de distribuição dos teores de $\mathrm{Na}^{+}$no complexo sortivo (Figura 2.15) no Pantanal, organizado pelo mesmo autor. Segundo ele, a grande maioria dos solos da Nhecolândia seria não-sódica e não-solódica (em maioria Podzóis Hidromórficos), com exceção de faixas que acompanham os rio Taquari e parte do rio Negro, que possuiriam solos dominantes não-sódicos e não-solódicos (Planossolos), mas com solos subdominantes sódicos (Solonetz-Solodizado).

\subsection{2 - Relações entre solos e unidades da paisagem da sub-região da Nhecolândia.}

Cunha (1980) é um dos pioneiros no estudo analítico dos solos presentes nas diferentes unidades da paisagem da Baixa Nhecolândia. Deste trabalho, destacam-se os resultados dos solos das cordilheiras e das vazantes/campo limpo em áreas topograficamente mais altas (Fazendas São Joaquim, Santa Luzia e Porto Alegre) e das cordilheiras em borda de planície (Fazenda Leque), ou seja, das áreas rebaixadas próximas ao contato com as planícies de inundação dos principais rios da Nhecolândia As fazendas citadas neste sub-item estão localizadas na Figura 2.4.

Nas áreas topograficamente mais elevadas, os solos das cordilheiras apresentam perfis com seqüência de horizontes $A_{1}, A_{2}(E), B h, B_{2}$ e $B^{2} r_{3}(P e r f i l ~ 1)$ ou $A_{1}, B, A_{2}(E)$, Bir $_{1}$ e C (Perfil 2), e os solos das vazantes a sequência $A_{1}, A_{2}(E)$ e Bir (Perfil 3). Apesar do autor não tê-los classificado diretamente, a presença dos horizontes Bh e Bir possivelmente indica que são Espodossolos (antigos Podzóis), a classe dominante na Nhecolândia. A partir da Tabela 2.4, nota-se que os perfis 1, 2 e 3 representam solos de textura areia ( $\leq 5 \%$ de argila) e com baixa soma de bases, sendo os cátions $\mathrm{Ca}^{2+}$ e $\mathrm{Mg}^{2+}$ dominantes. Os solos das cordilheiras (perfis 1 e 2 ) são em 


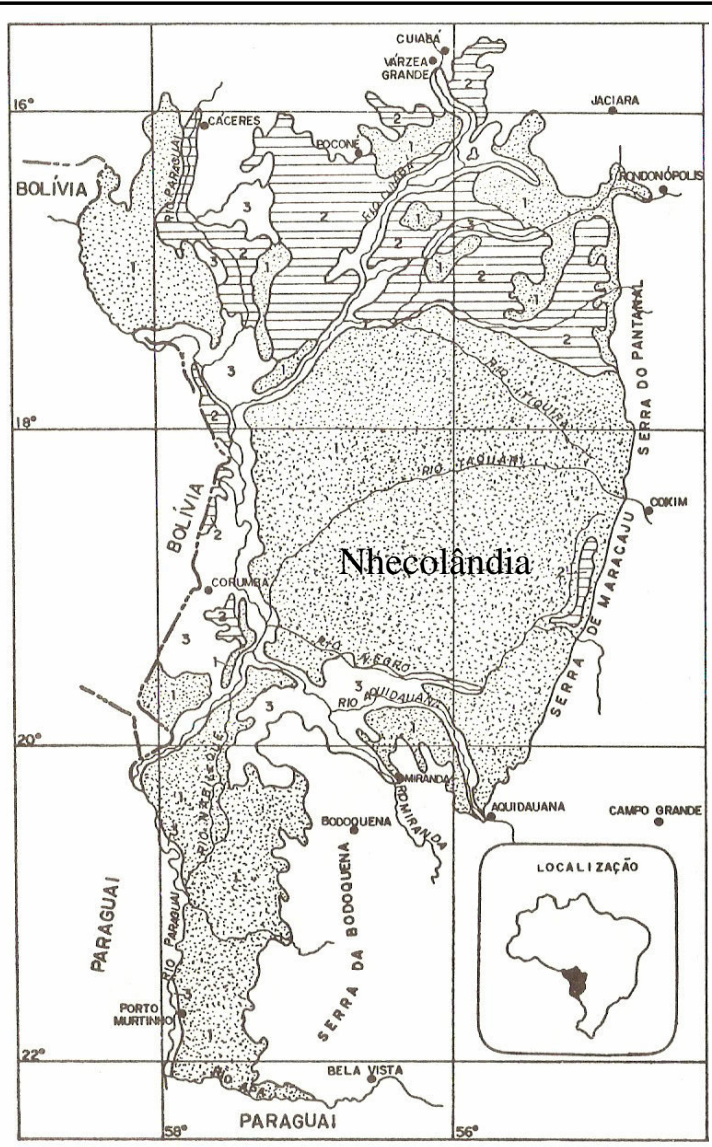

A

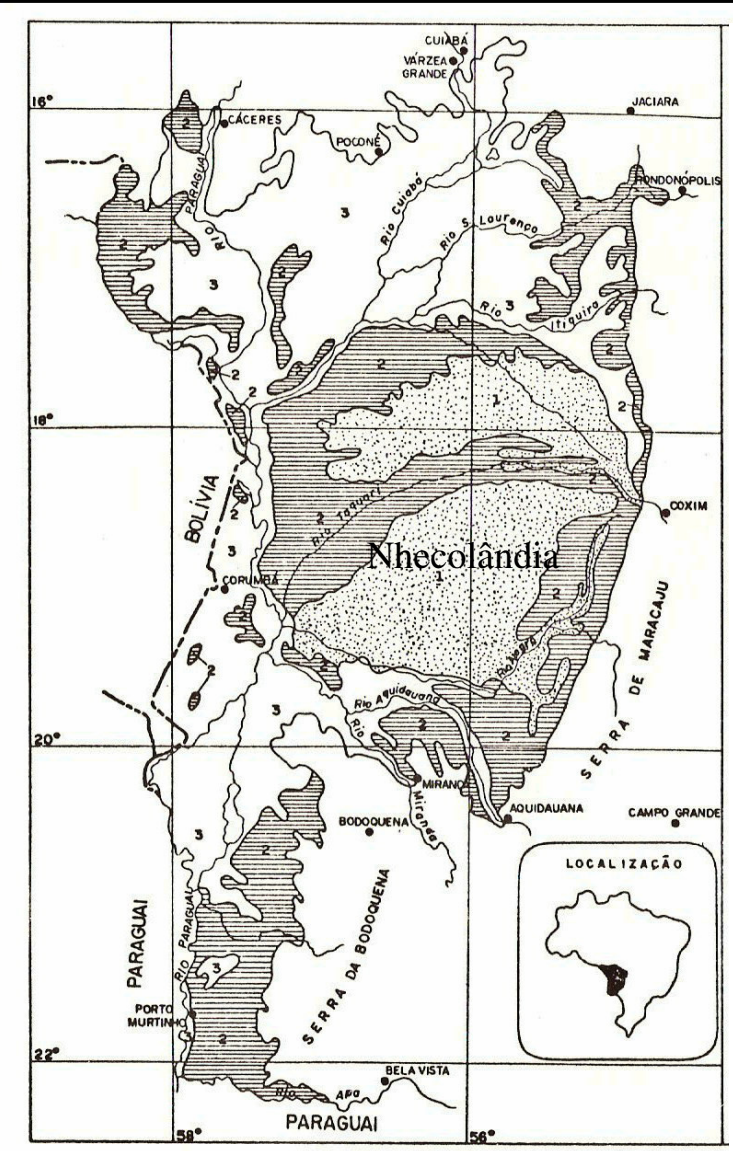

B

17 Textura arenosa- classes com teores de argila $<15 \%$ (areia e areia franca)

E琶目 Textura média - classes com teores de argila entre 15 e 35\%

3 Textura argilosa - classes com teores de argila entre 35 e $60 \%$

Fonte: Amaral Filho (1986)

Figura 2.14 - Distribuição da granulometria dos horizontes superficiais (A) e sub-superficiais (B) dos solos do Pantanal 


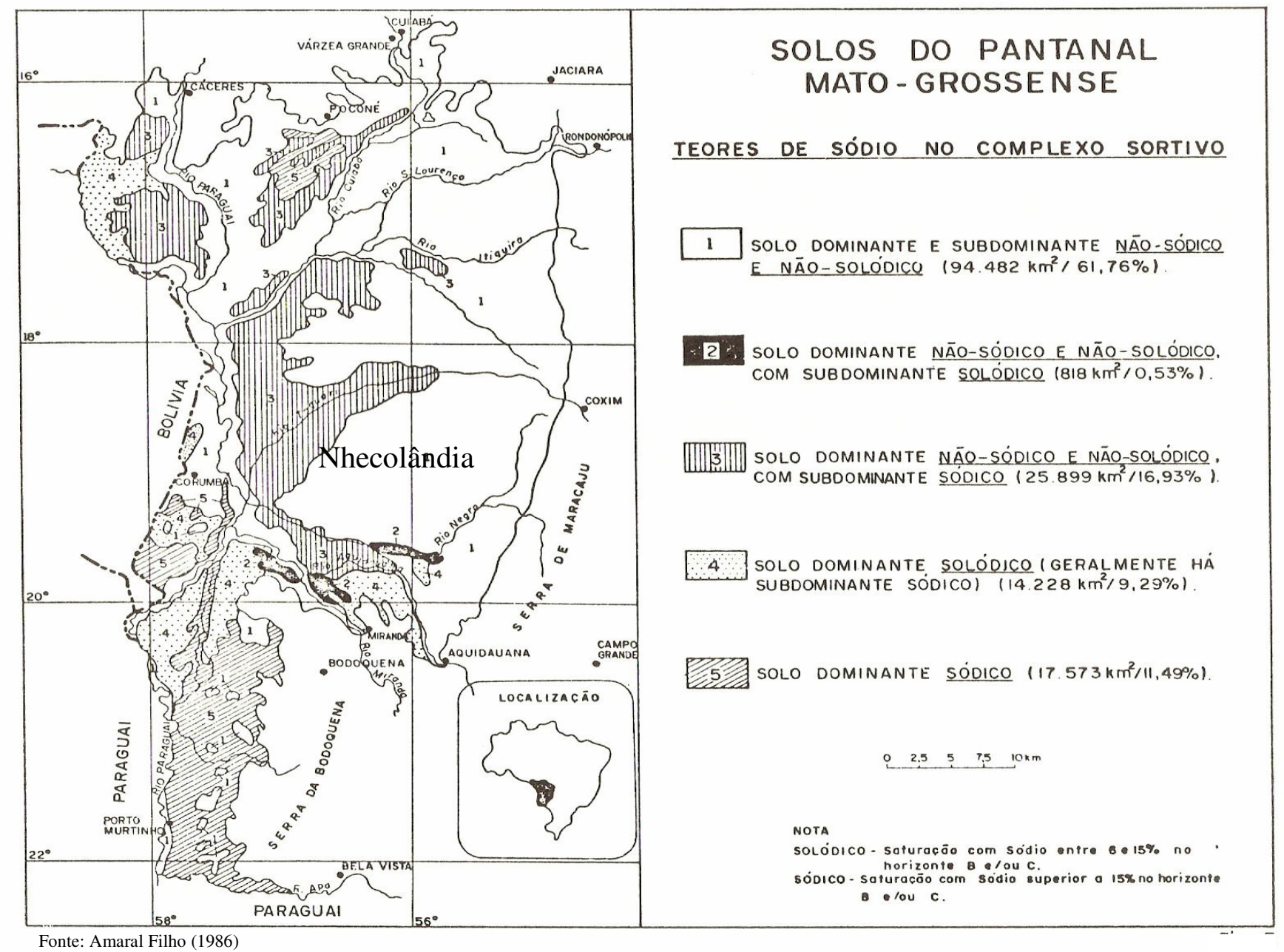

Figura 2.15 - Distribuição dos teores de $\mathrm{Na}^{+}$trocável nos solos do Pantanal 
Tabela 2.4 - Resultados de análises físicas e químicas de solos de cordilheiras e vazantes

\begin{tabular}{|c|c|c|c|c|c|c|c|c|c|c|c|}
\hline Solos & $\begin{array}{c}\text { Gra } \\
\text { Areia }\end{array}$ & $\begin{array}{l}\text { lom., } \\
\text { Silte }\end{array}$ & $\begin{array}{c}\text { g/kg } \\
\text { Arg. }\end{array}$ & $\begin{array}{c}\mathbf{p H} \\
\mathrm{H}_{2} \mathrm{O}\end{array}$ & $\begin{array}{c}\mathrm{C} \\
\mathrm{g} / \mathrm{kg}\end{array}$ & $\mathrm{Ca}^{2+}$ & $\mathbf{M g}^{2+}$ & $\begin{array}{c}\mathbf{K}^{+} \\
\mathrm{cmol}_{\mathrm{c}} / \mathrm{kg}\end{array}$ & $\mathrm{Na}^{+}$ & CTC & $\begin{array}{l}\mathbf{V} \\
\%\end{array}$ \\
\hline \multicolumn{12}{|c|}{ Perfil 1 - Cordilheira de áreas mais elevadas - Faz. São Joaquim e Sta Luzia } \\
\hline $\mathrm{A}_{11}$ & 870 & 80 & 50 & 5,6 & 6,0 & 2,4 & 0,6 & 0,21 & 0,01 & 5,1 & 66 \\
\hline $\mathrm{A}_{12}$ & 880 & 70 & 50 & 5,8 & 2,8 & 1,6 & 0,2 & 0,10 & 0,01 & 2,9 & 66 \\
\hline $\mathrm{A}_{2}$ & 900 & 60 & 40 & 5,9 & 1,0 & 0,8 & 0,2 & 0,06 & 0,02 & 1,7 & 65 \\
\hline $\mathrm{Bh}$ & 890 & 70 & 40 & 6,3 & 5,0 & \multicolumn{2}{|c|}{0,6} & 0,08 & 0,02 & 1,1 & 64 \\
\hline $\mathrm{Bir}_{2}$ & 910 & 60 & 30 & 6,9 & 0,4 & \multicolumn{2}{|c|}{0,4} & 0,04 & 0,02 & 0,7 & 71 \\
\hline $\mathrm{Bir}_{3}$ & 890 & 80 & 30 & 6,6 & 0,2 & \multicolumn{2}{|c|}{0,4} & 0,03 & 0,01 & 0,6 & 67 \\
\hline $\mathrm{C}$ & 920 & 50 & 30 & 6,8 & 0,2 & \multicolumn{2}{|c|}{0,4} & 0,03 & 0,02 & 1,0 & 50 \\
\hline
\end{tabular}

Perfil 2 - Cordilheira em áreas mais elevadas - Faz. Porto Alegre

$\begin{array}{llllllllllll}\mathrm{A}_{11} & 910 & 80 & 10 & 5,9 & 2,0 & 0,7 & 0,4 & 0,09 & 0,04 & 2,0 & 61 \\ \mathrm{~A}_{12} & 890 & 90 & 10 & 5,6 & 0,8 & 0,4 & 0,2 & 0,04 & 0,03 & 1,5 & 45 \\ \mathrm{~B} & 920 & 70 & 20 & 5,5 & 0,1 & 0,3 & 0,1 & 0,03 & 0,05 & 0,8 & 63 \\ \mathrm{~A}_{2} & 900 & 80 & 20 & 5,6 & 0,1 & 0,2 & 0,2 & 0,03 & 0,03 & 1,1 & 42 \\ \mathrm{Bir}_{21} & 900 & 90 & 20 & 5,4 & 0,1 & 0,2 & 0,2 & 0,03 & 0,03 & 0,9 & 49 \\ \mathrm{Bir}_{22} & 910 & 80 & 20 & 5,8 & 0,1 & 0,2 & 0,1 & 0,03 & 0,03 & 1,0 & 40 \\ \mathrm{Bir}_{23} & 900 & 90 & 10 & 5,8 & 0,1 & 0,3 & 0,1 & 0,03 & 0,03 & 0,5 & 82\end{array}$

Perfil 3 - Vazante/Campo Limpo em áreas mais elevadas - Faz. Porto Alegre

$\begin{array}{lccccccccccc}\mathrm{A}_{11} & 910 & 80 & 5 & 6,3 & 3,0 & 0,2 & 0,06 & 0,09 & 0,05 & 1,0 & 43 \\ \mathrm{~A}_{12} & 910 & 90 & 6 & 7,0 & 2,0 & 0,2 & 0,02 & 0,02 & 0,02 & 0,9 & 30 \\ \mathrm{~A}_{21} & 910 & 90 & 3 & 7,2 & 0,2 & 0,2 & 0,04 & 0,03 & 0,03 & 0,6 & 50 \\ \mathrm{~A}_{22} & 870 & 120 & 2 & 7,2 & 0,2 & 0,2 & 0,08 & 0,03 & 0,03 & 0,4 & 100 \\ \mathrm{Bir} & 900 & 90 & 2 & 6,9 & 0,2 & 0,4 & 0,25 & 0,07 & 0,02 & 0,8 & 86\end{array}$

Perfil 4 - Cordilheira de borda de planície - Faz. Leque

\begin{tabular}{llllllllllll}
$\mathrm{A}_{11}$ & 900 & 70 & 30 & 7,2 & 3,9 & 2,7 & 0,3 & 0,18 & 0,01 & 3,2 & 100 \\
$\mathrm{~A}_{12}$ & 900 & 70 & 30 & 7,3 & 2,4 & 1,4 & 0,4 & 0,08 & 0,01 & 1,9 & 100 \\
$\mathrm{~A}_{2}$ & 910 & 60 & 30 & 7,7 & 0,5 & 0,7 & 0,4 & 0,11 & 0,05 & 1,3 & 100 \\
$\mathrm{~A}_{2} / \mathrm{B}_{1}$ & 890 & 70 & 40 & 9,0 & 0,7 & 3,0 & 0,6 & 0,10 & 0,40 & 4,1 & 100 \\
$\mathrm{Bca}_{21}$ & 850 & 80 & 70 & 9,1 & 0,8 & 3,4 & 1,2 & 0,19 & 0,85 & 5,6 & 100 \\
$\mathrm{Bca}_{22}$ & 850 & 80 & 70 & 9,2 & 0,7 & 3,6 & 0,8 & 0,24 & 0,89 & 5,5 & 100 \\
$\mathrm{Cca}$ & 910 & 40 & 50 & 9,5 & 0,3 & 1,7 & 0,2 & 0,42 & 0,66 & 3,0 & 100 \\
\hline
\end{tabular}

Fonte: Cunha (1980). 
geral mais espessos, mais ácidos e, nos horizontes $\mathrm{A}_{1}$ e $\mathrm{A}_{2}$, possuem maior capacidade de troca catiônica (T) e maior saturação por bases (V) que os solos da vazante/campo limpo (exemplo no Perfil 3). Desta forma, estes últimos solos são descritos pelo autor como extremamente lixiviados, com pouquíssimos nutrientes disponíveis para as plantas. Destaca-se no perfil 1 (Tabela 2.4), que o horizonte Bh apresenta teores de carbono 5 vezes maiores que o horizonte sobrejacente, concordando com seu caráter espódico. Entretanto, pelos dados analíticos apresentados pelo autor, não é evidente a acumulação de matéria orgânica e sesquióxidos de ferro ou alumínio no horizonte Bir dos perfis 1,2 e 3, apesar dele ressaltar que a classificação deste horizonte no campo é nítida.

Nas áreas topograficamente mais rebaixadas, ou bordas de planície, os solos mostraram-se nitidamente enriquecidos em bases e muitos apresentaram alto $\mathrm{pH}$ e alta salinidade, apesar de não terem sido relacionados pelo autor às lagoas salinas em parte alguma. Os dados do perfil 4 da Tabela 2.4 são referentes ao solo de uma cordilheira localizada nestas áreas rebaixadas. $O$ perfil apresenta uma sequiência de horizontes $A_{1}$, $\mathrm{A}_{2}(\mathrm{E}), \mathrm{AB}, \mathrm{Bca}$ e Cca. O sufixo ca, atualmente substituído por $\mathrm{k}$, refere-se à acumulação de carbonatos no horizonte, mas a quantidade de carbonatos e a descrição morfológica de campo não foram apresentadas no texto. Destacam-se os valores de pH moderado a fortemente alcalino na maioria do perfil e a saturação em $\mathrm{Na}^{+}$superior a $15 \%$ no horizonte $B$. Os solos das bordas de planície também não foram classificados diretamente pelo autor, mas as características citadas levam a interpretálos como Planossolos, com caráter sódico (antigos Solonetz-Solodizados).

Descrições morfológicas de solos de lagoas salinas, cordilheiras, baías e vazantes de várias fazendas da Baixa Nhecolândia têm sido apresentadas nos últimos 10 anos por pesquisadores associados ao Projeto Pantanal. Tais trabalhos, apesar de poucos serem acompanhados por análises físicas e químicas, são bastante úteis na medida em que permitem estabelecer padrões morfológicos dos solos da Baixa Nhecolândia nas diferentes unidades da paisagem aí presentes.

Desta forma, foi possível notar que os perfis de solos dos arredores das 5 lagoas salinas (Faz. São Miguel do Firme, Faz. Santo Ignácio e Faz. Nhumirim: salinas da 
Ponta, do Oito e do Meio) e de 1 lagoa salitrada ${ }^{3}$ (Faz. Campo Dora) na Baixa Nhecolândia (Figura 2.4), estudadas por Sakamoto (1997), Barbiéro et al. (2000), Fernandes (2000), Silva et al. (2003), Silva \& Sakamoto (2003) e Silva et al. (2004), apresentaram as seguintes características em comum: a) presença de horizontes superficiais com cores escuras (ex: 10YR 3/2) ou claras (ex: 10YR 7/3), variáveis conforme a presença ou não de vegetação em superfície, muito arenosos; b) presença de horizontes subsuperficiais escurecidos, brunados ou acinzentados (ex: 2,5YR 3/2; 10YR 3/2), areno-argilosos e com presença de nódulos ou concreções esbranquiçados, esverdeados ou pretos, interpretados como de acúmulo de matéria orgânica; e c) presença de horizonte subsuperficial esverdeado (ex: 5Y 5/3, 5Y 4/1), argilo-arenoso, endurecido e muitas vezes impenetrável com o trado, sendo chamado neste caso de laje. Como já ressaltado no Capítulo 1, algumas análises físicas e químicas deste horizonte esverdeado, realizadas no entorno da salina do Meio da Faz. Nhumirim (Barbiéro et al., 2000) e da salina da Faz. São Miguel do Firme (Sakamoto, 1997), mostraram que ele apresenta nitidamente maiores teores de argila $(90 \mathrm{~g} / \mathrm{kg}), \mathrm{de} \mathrm{pH}(>$ 8) e de saturação em bases (com grande participação de $\mathrm{K}^{+}$e $\mathrm{Na}^{+}$), que os outros horizontes do perfil ${ }^{4}$. Trata-se, portanto, de um horizonte alcalino e rico em sais.

Outros elementos estão presentes nas descrições dos solos de apenas algumas das salinas e salitrada (Figura 2.4): presença de volumes verticais escuros (com aparência de linhas) no horizonte arenoso (superficial ou subjacente) de alguns perfis, interpretadas como de migração de matéria-orgânica para o horizonte escuro subjacente (salina da faz. São Miguel do Firme-Sakamoto, 1997; salitrada da faz Campo Dora-Silva et al., 2003; salina da Faz. Sto Inácio-Silva et al., 2004); e presença de um horizonte cinza muito-escuro ou preto (ex: 10YR 3/1, 10YR 2/1), pouco denso e argiloso, presente nas áreas deprimidas do centro da depressão, onde a água permanece em superfície durante grande parte do tempo (Salina da Ponta-Faz Nhumirim e Lagoa Salitrada da Faz. Campo Dora-Silva \& Sakamoto, 2003).

Cabe destacar ainda que medidas piezométricas efetuadas no entorno da salina do Meio mostram que os solos aí presentes estão ao menos parcialmente saturados por água durante todo o ano. $\mathrm{Na}$ época das cheias, o lençol freático encontra-se

\footnotetext{
${ }^{3}$ Algumas das lagoas da Baixa Nhecolândia são chamadas de salitradas por possuem valores de $\mathrm{pH}$ intermediários entre salinas e baías.
} 
aproximadamente no nível dos horizontes de superfície, enquanto que na época da estiagem, o nível abaixa até aproximadamente o topo do horizonte esverdeado (Barbiéro et al., 2006). Ressalta-se, contudo, que nas cheias o lençol freático aflora em superfície nos locais mais deprimidos e permanece a aproximadamente 1 metro da superfície nas proximidades da cordilheira.

Sakamoto (1997) e Fernandes (2000) classificaram os solos das salinas da Faz. São Miguel do Firme e do Oito (Faz. Nhumirim) principalmente por características descritas em campo. Devido à presença de um horizonte subsuperficial escurecido, interpretado como rico em matéria-orgânica, denominado pelos autores de Bh ou Bhs (quando da presença significativa de concreções), e à presença de volumes verticais (linhas), que seriam indicativos de migração de matéria-orgânica, estes solos foram chamados de Podzóis Hidromórficos (Espodossolos - Embrapa, 2006).

Nas vazantes e baías da Baixa Nhecolândia, estudadas principalmente nas fazendas São Miguel do Firme (Sakamoto, 1997) e Ipanema (Fernandes, 2000) (Figura 2.4), a sequiência de horizontes inclui, em maioria, horizontes superficiais denominados de A, com cores muito escuras (10YR 2/1 ou 2/2) ou brunas (10YR 5/3 ou 5/4), arenosos, seguido de um horizonte subsuperficial denominado $\mathrm{C}$, mais claro que o sobrejacente (10YR 5/3, 10YR 6/4, 10YR 7/3), também arenoso, com evidências de hidromorfia e onde o nível do lençol freático foi geralmente encontrado durante as tradagens (Sakamoto, 1997; Fernandes, 2000). A sequência de horizontes A-C, com ausência do horizonte supostamente rico em matéria orgânica e do horizonte esverdeado, junto ao caráter extremamente arenoso destes solos, conduziram à classificação em Areias Quartzosas (Neossolos Quartzarênicos - Embrapa, 2006).

Entretanto, exceção deve ser feita à vazante (banhado) próxima à lagoa do Meio (Faz. Nhumirim), salina que está sendo estudada na presente tese, onde Rezende Filho et al. (2003) encontrou os horizontes subsuperficiais orgânico e esverdeado em perfil semelhante aos das lagoas salinas. Estes horizontes estavam sempre associados às áreas de maior salinidade dentro da vazante, conforme medições realizadas com o aparelho EM-38, que obtém dados de condutividade elétrica de forma indireta por indução de ondas eletromagnéticas.

\footnotetext{
${ }^{4}$ Os dados não são reproduzidos aqui por terem sido, em parte, representados originalmente apenas em figuras.
} 
Por fim, nas cordilheiras os solos parecem variar quanto à presença ou não de horizontes escuros, supostamente de acúmulo de matéria orgânica, e do horizonte esverdeado associado à presença de maior salinidade. As topossequências estudadas por Sakamoto (1997; Faz. São Miguel do Firme), Fernandes (2000; Faz NhumirimSalina do Oito), Silva et al. (2003; Faz. Campo Dora-Salitrada) e Silva \& Sakamoto (2003; Faz. Nhumirim-Salina da Ponta, Salitrada, Salina do Oito) (Figura 2.4), as quais envolveram lagoas salinas ou salitradas e as vertentes adjacentes das cordilheiras circundantes, geralmente revelaram presença de horizonte escuro interpretado como rico em matéria-orgânica e horizonte esverdeado (ou laje) nas cordilheiras, ambos subjacentes a horizontes arenosos e espessos. Já as vertentes das cordilheiras adjacentes às vazantes, estudadas por Sakamoto (1997; Faz. São Miguel do Firme) e Fernandes (2000; Faz. Ipanema) apresentam solos profundos e arenosos, com presença ou não de horizontes escurecidos interpretados como de acúmulo de matéria-orgânica. O horizonte esverdeado, associado às áreas de maiores salinidades, não foi encontrado nestas localidades.

Da mesma forma que nas salinas, os horizontes subsuperficiais escuros presentes nas cordilheiras, interpretados como enriquecidos em matéria-orgânica, foram chamados por Sakamoto (1997) e Fernandes (2000) de Bh ou Bhs e os solos com a sua presença foram então conseqüentemente classificados como Podzóis Hidromórficos (Espodossolos - Embrapa, 2006). Desta forma, receberam a mesma classificação dos solos das cordilheiras estudadas por Cunha (1980). Já os perfis arenosos, geralmente com seqüência de horizontes A-C, foram classificados como Areias Quartzosas (Neossolos Quartzarênicos - Embrapa, 2006).

\section{5 - Meio Biótico}

\subsection{1 - Fitogeografia}

De acordo com Adámoli (1986b), a diversidade fitogeográfica do Pantanal só pode ser compreendida através de um enfoque continental, uma vez que ali ocorre a convergência de quatro províncias fitogeográficas da América do Sul: 1) Província da Amazônia, presente principalmente no noroeste do Pantanal e em florestas galerias do rio Paraguai e seus afluentes Sepotuba, Cabaçal e Jauru; 2) Província Chaquenha, localizada principalmente na margem direita do rio Paraguai, marcando o limite oeste do Pantanal; 3) Província do Cerrado, situada principalmente na porção central e leste 
do Pantanal, onde predominam solos arenosos desenvolvidos a partir dos sedimentos quaternários que formam os leques aluviais presentes na planície; e 4) Província Atlântica ou Paranaense (Florestas Meridionais), presente no sul e sudeste do Pantanal, onde há presença de solos argilosos e alternância de campos inundáveis e capões de mata.

A província do cerrado é predominante em área no Pantanal e engloba grande parte da Nhecolândia. O cerrado do Mato Grosso do Sul e Mato Grosso pode ser definido como uma vegetação xeromórfica, com aspecto fisionômico variando de arbórea densa a gramíneo-lenhosa. Sua vegetação lenhosa apresenta casca grossa e rugosa, órgãos de reserva subterrânea profundos e folhas desenvolvidas, com estômatos permanentemente abertos, protegidos por pelos. A composição florística é bem heterogênea, mas as espécies se repetem com muita freqüência nas mais diversas localidades (Loureiro et al., 1982).

A diversidade fisionômica do cerrado é caracterizada pela presença de vários estágios sucessionais, definidos em geral conforme o porte e proporção de espécies herbáceas, arbustos e árvores. Coutinho (1990) classifica estes estágios sucessionais em campos (limpo e sujo), campo-cerrado, cerrado sensu stricto, cerradão e floresta estacional tropical (semi-distrófica e eutrófica), sendo que todos eles estão presentes no Pantanal (Por, 1995).

Na Nhecolândia, os diversos estágios sucessionais do cerrado estão associados às diferentes unidades da paisagem aí presentes. Desta forma, ocorrem mudanças fisionômicas em curtos espaços, o que dificulta o mapeamento em escalas médias e pequenas. Fernandes (2000), ao utilizar imagens de satélite, fotos-aéreas e controle de campo, constatou que nas baías e fundo das vazantes, que constituem depressões, dominam os campos com vegetação herbácea na ausência de água em superfície, ou vegetação aquática na presença de água em superfície. Em níveis topográficos intermediários, entre o fundo das vazantes e as cordilheiras, predominam os campos dominados por vegetação herbácea. Na transição deste nível intermediário para as cordilheiras encontram-se os campos cerrados e cerrados. E, finalmente, nas cordilheiras e outras elevações do terreno há cerradão (Figura 2.16). Em geral, não há vegetação nos arredores imediatos das lagoas salinas. O limite do solo nu do entorno 


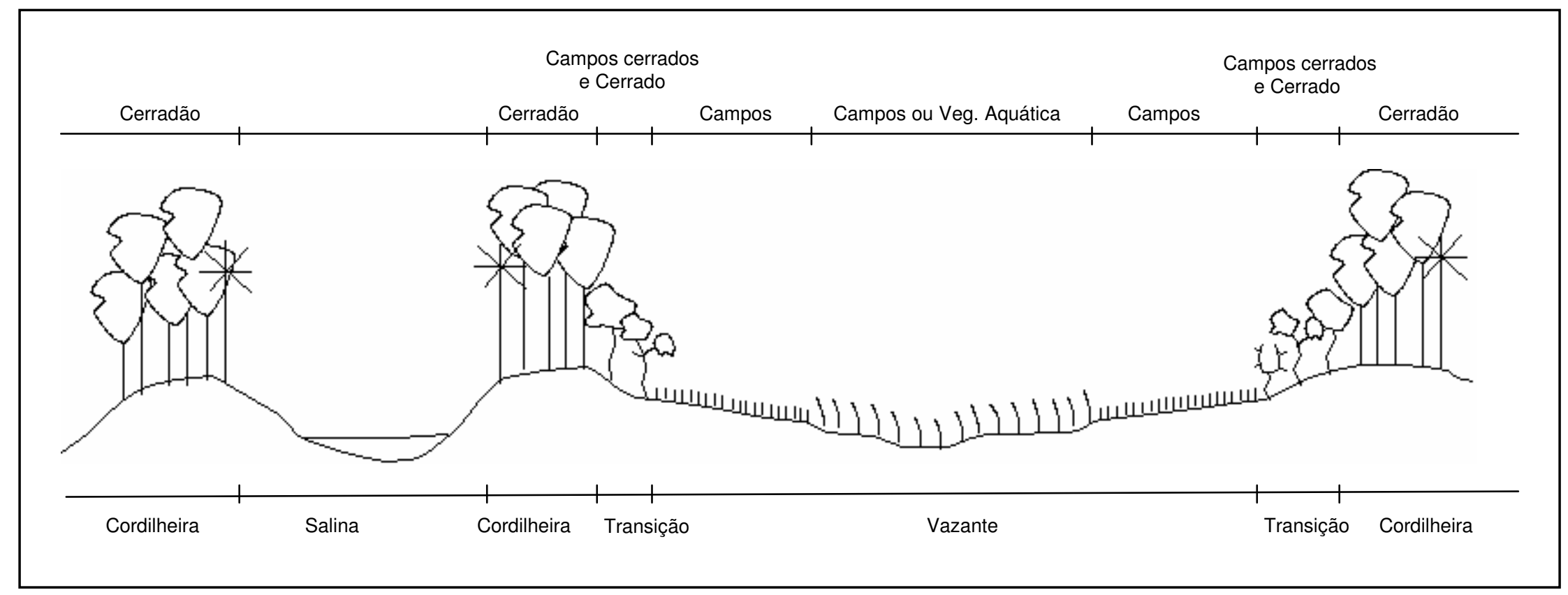

Fonte: baseado em descrição de Fernandes (2000)

Figura 2.16 - Modelo da distribuição dos estágios sucessionais do cerrado na Baixa Nhecolândia. 
das salinas com o cerradão da cordilheira normalmente se faz por uma faixa de gramíneas, palmeiras (carandás) e bromeliáceas (caraguatás).

\subsection{2 - Fitoplâncton - algas}

As algas constituem grande parte da vida microscópica aquática flutuante, conhecida como fitoplâncton, e está presente nos mais variados ambientes terrestres e aquáticos, incluindo águas doces, salobras, salinas e hipersalinas (Hoehne, 1979; Campbell et al., 1999). Por serem parte essencial da produção primária em meios aquáticos, podem ter uma influência determinante nos ciclos dos elementos químicos. Desta forma, o reconhecimento das espécies e o posterior conhecimento dos processos de troca de elementos (retirada, liberação e estocagem) com o ambiente através de seus mecanismos fisiológicos é de fundamental importância para o estabelecimento de um balanço hidro-biogeoquímico.

Na Nhecolândia, as pesquisas a respeito da vida aquática existente nas salinas e salitradas estão na fase de reconhecimento dos gêneros e espécies. Mourão (1989) e Mourão et al. (1988) notaram que a associação entre pH elevado e a presença da forma não ionizável da amônia nestas lagoas são fatores limitantes à ocorrência de peixes, plantas, zooplâncton e macrófitas. Ocorre, entretanto, uma grande variedade de algas microscópicas.

Santos et al. (2004a) e Santos et al. (2004b) apresentam um inventário dos gêneros presentes em três lagoas salinas (Faz. Sto Inácio e Faz. Nhumirim: do Meio e da Reserva) e uma salitrada (Faz. Campo Dora) da Baixa Nhecolândia. Foram identificados 53 gêneros de algas, distribuídos em 6 divisões taxonômicas. O grupo Cyanophyta foi predominante nas lagoas salinas enquanto o Chlorophyta foi o mais comum na salitrada. Os gêneros Frustulia sp (Chrysophyta-Diatomáceas), grande liberador de $\mathrm{O}_{2}$ na água, e Spirulina sp (Cyanophyta) foram comuns a todas as lagoas, sendo, portanto, organismos indiferentes às mudanças de $\mathrm{pH}$ e concentração de sais. $\mathrm{O}$ gênero Anabaenophisis sp (Cyanophyta) foi comum às 3 salinas, podendo ser um bom indicador deste tipo de ambiente. Destaca-se ainda que o gênero Nostoc sp (Cyanophyta) foi predominante na Salina do Meio, sendo que estas algas atuam na fixação de nitrogênio. 


\section{6 - Referências Bibliográficas}

Adámoli, J. (1986a) A dinâmica das inundações no Pantanal. Pp. 51-61in: Anais do $1^{\circ}$ Simpósio sobre Recursos Naturais e Sócio-Econômicos do Pantanal, 27 de novembro a 4 de dezembro de 1984, Corumbá (MS).

Adámoli, J. (1986b) Fitogeografia do Pantanal. Pp.105-106 in: Anais do $1^{o}$ Simpósio sobre Recursos Naturais e Sócio-Econômicos do Pantanal, 27 de novembro a 4 de dezembro de 1984, Corumbá (MS).

Agência Nacional de Águas (ANA). Endereço eletrônico: www.ana.gov.br. Acesso em 20/04/2006

Alfonsi, R.R. \& Camargo, M.B.P. (1986) Condições Climáticas para a Região do Pantanal Matogrossense. Pp. 29-42 in: Anais do $1^{\circ}$ Simpósio sobre Recursos Naturais e Sócio-Econômicos do Pantanal, 27 de novembro a 4 de dezembro de 1984, Corumbá (MS).

Alvarenga, S.M.; Brasil, A.E.; Pinheiro, R.; Kux, H.J.H. (1984) Estudo Geomorfológico Aplicado à Bacia do Alto Rio Paraguai e Pantanais Matogrossenses. Boletim Técnico Projeto RadambrasilSérie Geomorfologia, 1, 187.

Amaral Filho, Z.P. (1986) Solos do Pantanal Matogrossense. Pp. 91-103 in: Anais do $1^{o}$ Simpósio sobre Recursos Naturais e Sócio-Econômicos do Pantanal, 27 de novembro a 4 de dezembro de 1984, Corumbá (MS).

Bacani, V. M. (2004) Comportamento Piezométrico do Entorno da Lagoa Salina do Meio: Fazenda Nhumirim/ Embrapa/CPAP no Pantanal da Nhecolândia. Monografia apresentada ao curso de Licenciatura Plena e Bacharelado em Geografia da Universidade Federal de Mato Grosso do Sul UFMS, Três Lagoas, 48 p.

Barbiéro, L.; Queiroz Neto, J.P.; Sakamoto, A.Y. (2000) Características Geoquímicas dos Solos Relacionadas à Organização Pedológica e à Circulação da Água (Fazenda Nhumirim: Embrapa CPAP, Nhecolândia, MS). Pp. 90-100 in: Anais do $3^{\circ}$ Simpósio sobre Recursos Naturais e SócioEconômicos do Pantanal, Corumbá (MS).

Barbiéro, L.; Furian, S.; Queiroz Neto, J.P.; Ciornei, G.; Sakamoto, A.Y.; Capellari, B.; Fernandes, E.; Valles, V. (2002) Geochemistry of water and ground water in the Nhecolândia, Pantanal of Mato Grosso, Brazil: variability and Associated processes. Wetlands, 22, 528-540.

Barbiéro L.; Furquim, S.A.C.; Vallès, V.; Furian, S.; Sakamoto, A. (2006) Natural Arsenic in Groundwater and Alkaline Lakes at the Upper Paraguay Basin, Pantanal, Brazil. In: Arsenic in Soil and Groundwater Environments: Biogeochemical Interactions (P. Bhattacharya, A.B. Mukherjee, R.H. Loeppert, R.H., eds), Elsevier Book Series.

Brum, P.A.R \& Sousa, J.C. (1985) Níveis de Nutrientes minerais para gado, em lagoas ("baías" e "salinas") no Pantanal Sul-matogrossense. Pesquisa Agropecuária Brasileira, 20, 1451-1454.

Campbell, N.A.; Reece, J.B.; Mitchell, L.G. (1999) Biology. Addison Wesley Longman, Inc., 1175 p.

Capellari, B. (2001) Sensoriamento Remoto Aplicado ao Estudo da Dinâmica Hidrológica da região da Nhecolândia, Pantanal Matogrossense, MS. Dissertação de Mestrado, FFLCH, USP.100 p.

Carvalho, N.O. (1986) Hidrologia da Bacia do Alto Paraguai. Pp. $43-49$ in: Anais do $1^{\circ}$ Simpósio sobre Recursos Naturais e Sócio-Econômicos do Pantanal, 27 de novembro a 4 de dezembro de 1984, Corumbá (MS).

Coutinho, A.C. (1990) Segmentação e classificação de imagens Landsat-TM para o mapeamento dos usos da terra na região de Campinas. Dissertação de Mestrado, Depto de Ecologia, Instituto de Biociências, USP.

Cunha, N.G. (1980) Considerações sobre os solos da sub-região da Nhecolândia, Pantanal MatoGrossense. Circular Técnica Embrapa, 1, 1-45.

Cunha, J. (1942) Cobre do Jauru e lagoas alcalinas do Pantanal (Mato Grosso). Boletim do Laboratório de Produção Mineral, 6, 1-43.

Cunha, N.G. (1981) Classificação e Fertilidade de Solos da Planície Sedimentar do rio Taquari, Pantanal Matogrossense. Circular Técnica Embrapa, 4, 1-55. 
Del'Arco, J.O.; Silva, R.H.; Tarapanoff, I.; Freire, F.A.; Pereira, L.G.M.; Souza, S.L.; Luz, D.S.; Palmeira, R.C.B.; Tassinari, C.C.G. (1982) Geologia da Folha SE.21 Corumbá e Parte da Folha SE.20. Pp. 25 a 160 in RADAMBRASIL-Levantamento dos Recursos Naturais. Rio de Janeiro.

Empresa Brasileira de Pesquisas Agropecuárias - Embrapa (2006) Sistema Brasileiro de Classificação de Solos. $2^{\mathrm{a}}$ edição. Embrapa Solos, Rio de Janeiro, 306p.

Empresa Brasileira de Pesquisas Agropecuárias - Embrapa. Endereço eletrônico: www.embrapa.br. Acesso em 20/04/2006.

Fernandes, E.; Sakamoto, A.Y.; Queiroz Neto, J.P.; Lucati, H.M.; Capellari, B (1999) Le "Pantanal da Nhecolândia" Mato Grosso: Cadre Physique et Dynamique Hydrologique. Geografia Fisica $e$ Dinamica Quaternaria, 22, 13-21.

Fernandes, E. (2000) Caracterização dos Elementos do Meio Físico e da Dinâmica da Nhecolândia (Pantanal Sulmatogrossense). Dissertação de Mestrado. Departamento de Geografia, Faculdade de Filosofia, Letras e Ciências Humanas, Universidade de São Paulo, 130 p.

Fernandes, E. (2005) Análise espacial dos meios ácidos e alcalinos e suas relações com a estrutura e organização dos elementos da paisagem regional da Baixa Nhecolândia-Pantanal de Mato Grosso do Sul. Relatório de Qualificação de Tese de Doutoramento. FFLCH, Depto de Geografia-USP, São Paulo, 138 p.

Franco, M.S.M. \& Pinheiro, R. (1982) Geomorfologia da Folha SE.21 Corumbá e Parte da Folha SE.20. Pp. 161-224 in: RADAMBRASIL-Levantamento dos Recursos Naturais. Rio de Janeiro.

Garcia, E.A.C. (1991) Zoneamento Agroecológico e Sócioeconômico da Bacia Hidrográfica Brasileira do rio Paraguai: uma abordagem numérica preliminar. Embrapa Pantanal, 65p.

Godoi Filho, J.D. (1986) Aspectos Geológicos do Pantanal Mato-Grossense e de sua Área de Influência. Pp. 63-76 in: Anais do $1^{\circ}$ Simpósio sobre Recursos Naturais e Sócio-Econômicos do Pantanal, 27 de novembro a 4 de dezembro de 1984, Corumbá (MS).

Hoehne, F.C. (1979) Plantas Aquáticas. Instituto de Botânica, São Paulo, 168 p.

Leão, M.I. (1996) O Comportamento das Águas Subterrâneas no Pantanal. Pp: 18-19 in: Resumos do II Simpósio sobre Recursos Naturais e Sócio-Econômicos do Pantanal-Manejo e Conservação, 18 a 22 de novembro de 1996, Corumbá, MS. Embrapa Pantanal e UFMS.

Loureiro, R.L.; Lima, J.P.S; Fonzar, B.C.; Oliveira Filho, L.C. (1982) Vegetação da Folha SE.21 Corumbá e Parte da Folha SE.20: As regiões fitoecológicas, sua natureza e seus recursos econômicos. Pp 329-372 in: RADAMBRASIL-Levantamento dos Recursos Naturais. Rio de Janeiro.

Mourão, G.M.; ISHII, I.H.; Campos, Z.M.S. (1988) Alguns fatores limnológicos relacionados com a ictiofauna de baías e salinas do Pantanal da Nhecolândia, MS, Brasil. Acta Limnológica Brasileira, 2, 181-198.

Mourão, G.M. (1989) Limnologia comparativa de três lagoas (duas baías e uma salina) do Pantanal da Nhecolândia, MS. Dissertação de Mestrado, Universidade Federal de São Carlos-UFSCAR, $135 \mathrm{p}$.

Orioli, A.L.; Amaral Filho, Z.P.; Oliveira, A.B. (1982) Pedologia: levantamento exploratório de solos da Folha SE.21 Corumbá e Parte da Folha SE.20: As regiões fitoecológicas, sua natureza e seus recursos econômicos. Pp. 225-328 in: RADAMBRASIL-Levantamento dos Recursos Naturais. Rio de Janeiro.

Por, F.D. (1995) The Pantanal of Mato Grosso (Brazil) - World's Largest Wetlands. Klumer Academic Publishers, 122p.

Queiroz Neto, J.P.; Lucati, H.M.; Capellari, B.; Fernandes, E.; Sakamoto, A.Y.; Botelho, R.G.M. (1998) Nhecolândia: exemplo de regime hidrológico do leque aluvial do Taquari (MS). Pp. 379-386 in: Anais do II Simpósio Nacional de Geomorfologia. Novembro de 1998, Florianópolis-SC.

Rezende Filho, A.T.; Sakamoto, A.; Barbiéro, L; Furian, S. (2003) Variabilidade de salinidade ao redor de uma lagoa na Fazenda Nhumirim no Pantanal da Nhecolândia. Pp.174-177 in: XII Encontro SulMatogrossense de Geografia, Três Lagoas, MS. Trabalho completo. 
Sakamoto, A.Y.; Queiroz Neto, J.P.; Fernandes, E. e Lucati, H.M. (1996) Topografia de Lagoas Salinas e seus Entornos no Pantanal da Nhecolândia, MS. Pp. 40 in: Resumos do II Simpósio sobre Recursos Naturais e Sócio-Econômicos do Pantanal - Manejo e Conservação. 18 a 22 de novembro de 1996, Corumbá, MS. Embrapa Pantanal e UFMS.

Sakamoto, A. Y. (1997) Dinâmica hídrica em uma lagoa salina e seu entorno no Pantanal da Nhecolândia: contribuição ao estudo das relações entre o meio físico e a ocupação, Fazenda São Miguel Firme, MS. Tese de Doutorado defendida no Departamento de Geografia da Faculdade de Filosofia, Letras e Ciências Humanas da Universidade de São Paulo. 183 p.

Santos, K.R.S; Sakamoto, A., José Neto, M.; Barbiéro, L.; Queiroz Neto, J.P. (2004a) Ficoflora do Pantanal da Nhecolândia, MS, Brasil: um levantamento preliminar em três lagoas salinas e uma salitrada. In: IV Simpósio sobre Recursos naturais e Sócio-Econômicos do Pantanal, Corumbá, 23 a 26 de Novembro de 2004. Trabalho completo.

Santos, K.R.S; Sakamoto, A., José Neto, M.; (2004b) Ficoflora da lagoa salina Santo Inácio e lagoa salina do Meio (Nhumirim), região do Pantanal da Nhecolândia-MS; dados preliminares. In: XIII Encontro Estadual de Geografia. Aquidauana, MS. Trabalho completo.

Silva, M.H.S. \& Sakamoto, A. (2003) Perfis pedomorfológicos do Pantanal da Nhecolândia-MS: Um estudo comparativo. Pp.544-552 in: XII Encontro Sul-Matogrossense de Geografia, Três Lagoas, MS. Trabalho completo.

Silva, M.H.S.; Bacani, V. Sakamoto, A.; Queiroz Neto, J.P.; Barbiéro, L. (2003) Morfologia e pH do solo da lagoa Salitrada, Pantanal da Nhecolândia, MS. In: XXIX Congresso Brasileiro de Ciência do Solo, 13 a 18 de julho de 2003, Ribeirão Preto, São Paulo. Trabalho completo.

Silva, M.H.S.; Bacani, V.M.; Sakamoto, A. (2004) Caracterização do solo de uma lagoa salina na área da fazenda Santo Inácio, Pantanal da Nhecolândia, MS. In: XIII Encontro Estadual de Geografia. Aquidauana, MS. Trabalho completo.

Silva, T.C. (1986) Contribuição da Geomorfologia para o Conhecimento e Valorização do Pantanal. Pp. 77-90 in: Anais do $1^{o}$ Simpósio sobre Recursos Naturais e Sócio-Econômicos do Pantanal, 27 de novembro a 4 de dezembro de 1984, Corumbá (MS).

Soriano, B.M.A. (1996) Caracterização Climática da Sub-região da Nhecolândia, Pantanal-MS. Pp. 52 in: Resumos do II Simpósio sobre Recursos Naturais e Sócio-Econômicos do Pantanal-Manejo e Conservação. 18 a 22 de novembro Corumbá (MS).

Soriano, B.M.A.; Oliveira, H.; Catto, J.B.; Comastri Filho, J.A.; Galdino, S.; Salis, S.M. (1997) Plano de utilização da fazenda Nhumirim, Corumbá, MS. Embrapa Pantanal. Documento 21, 71p.

Tarifa, J.R. (1986) O Sistema Climático do Pantanal: da compreensão do sistema à definição de prioridades de pesquisa climatológica. Pp. 9-27 in: Anais do $1^{o}$ Simpósio sobre Recursos Naturais e Sócio-Econômicos do Pantanal, 27 de novembro a 4 de dezembro de 1984, Corumbá (MS). 
Capítulo 3

\section{SOLOS E PROCESSOS PEDOGENÉTICOS NO ENTORNO DA SALINA DO MEIO}




\section{3 - SOLOS E PROCESSOS PEDOGENÉTICOS NO ENTORNO DA SALINA DO MEIO}

\section{Resumo}

Estudos a respeito dos solos associados às lagoas salinas da Baixa Nhecolândia não fazem referências detalhadas aos processos pedogenéticos responsáveis pela sua gênese. $\mathrm{O}$ objetivo deste capítulo é descrever os solos do entorno de uma lagoa salina representativa e identificar os principais processos atuantes na diferenciação de seus horizontes.

As amostras de solo foram coletadas ao longo de uma topossequência e então encaminhadas para análise granulométrica, análises químicas $(\mathrm{pH}, \mathrm{CE}$, carbono total, carbonatos, bases trocáveis e testes de imersão em água, ácido e bases) e análises mineralógicas (DRX, METEDS). As águas superficiais da lagoa e as águas subterrâneas do seu entorno foram coletadas e submetidas à titulação com $\mathrm{HCl}$ e à análises de ICP-MS e cromatografia de íons.

A dominância do $\mathrm{Na}^{+}$nas águas e no complexo de troca, a presença de $\mathrm{pH}$ fortemente alcalino e a ocorrência de condições ambientais específicas fortemente sugerem a atuação da solonização nos solos do entorno da lagoa salina e a sua influência na ocorrência dos seguintes processos: a) acúmulo de matéria-orgânica nos horizontes 2 e 3, proveniente da decomposição de restos vegetais do cerradão, gramíneas e algas, e translocação de matéria orgânica no horizonte 4 subjacente, até principalmente o topo do horizonte 5 , facilitada pela dispersão de colóides em meio enriquecido em $\mathrm{Na}^{+}$; b) Precipitação de carbonatos (calcita, dolomita e nahcolita) em nódulos, principalmente no horizonte 5, devido ao aumento da salinidade das soluções; c) Solubilização de sílica, desencadeada principalmente pelo pH fortemente alcalino e pela ocorrência de altas temperaturas, e precipitação de sílica amorfa no horizonte 6, facilitada pela alta atividade da $\mathrm{Si}(\mathrm{OH})_{4}$ e pela maior presença de argila; e d) formação autigênica de argilo-minerais, a ser tratada detalhadamente nos capítulos subseqüentes desta tese.

A comparação dos dados obtidos com os da literatura mostram que as águas e os solos associados à lagoa salina estudada são representativos da Baixa Nhecolândia. Desta forma, é provável que a solonização e os processos a ela associados, tais como identificados no presente trabalho, sejam os principais responsáveis pela gênese dos solos do entorno das lagoas salinas presentes nesta sub-região do Pantanal Sul-Mato-Grossense.

Palavras-chave: processos pedogenéticos, solos sódicos, translocação de matéria orgânica, nódulos carbonáticos, duripan. 
Abstract

Soils and pedogenetic processes around salina do Meio.

Researches involving soils around saline lakes of Nhecolândia have never considered the pedogenetic processes involved in their formation. The objective of this chapter is to describe the soils around a saline lake of Nhecolândia and then identifying the main processes responsible for its horizonation.

Soils were sampling along a toposequence and submitted to physical (particle-size), chemical ( $\mathrm{pH}$, EC, total carbon, inorganic carbonate, exchangeable bases, and soaking in $\mathrm{H}_{2} \mathrm{O}, 1 \mathrm{~N} \mathrm{HCl}$, and $4 \mathrm{M} \mathrm{NaOH}$ ), and mineralogical analyses (XRD and TEM-EDS). Water was collected along a transect involving the lake and submitted to titration with $\mathrm{HCl}$, ion chromatography, and ICP-MS analyses.

Prevailing of $\mathrm{Na}^{+}$in the waters and exchangeable sites, dominance of extremely high $\mathrm{pH}$, and occurrence of special environmental conditions strongly suggest the general action of solonization in the soils around the saline lake and its influence on the following processes: a) organic matter accumulation in horizons 2 and 3 due to forest, grass, and algae decay and organic matter translocation through horizon 4 , toward horizon 5 , triggered by colloidal dispersion caused by high $\mathrm{Na}^{+}$saturation in exchangeable sites; b) Precipitation of carbonates (calcite, dolomite, and nahcolite) in nodules, mainly concentrated in horizon 5, due to the increasing of solution salinity; c) Silica solubilization promoted by extremely alkaline $\mathrm{pH}$ and precipitation of amorphous silica in horizon 6, eased by high $\mathrm{Si}(\mathrm{OH})_{4}$ activity and higher amounts of clay; and d) authigenic formation of clay minerals, separately considered in the next 2 chapters of this dissertation.

Comparison with literature data shows that soils and waters associated to the studied saline lake are representative of Nhecolândia. Then, solonization and the associated pedogenic processes identified are probably the main responsible for genesis of soils located around Pantanal saline lakes.

Keywords: pedogenic processes; Sodic soils, Solonetz, organic matter translocation, carbonatic nodules, duripan. 


\section{1 - Introdução}

O entorno imediato de lagos salinos é comumente ocupado por sedimentos atuais inconsolidados (Jones \& Weir, 1983; Darragy \& Tardy, 1987) ou por solos halomórficos (Heck \& Mermut, 1992; Kohut \& Dudas, 1994). A diferenciação entre solos e outras formações superficiais é feita principalmente pela proposição de que os solos devem ser capazes de sustentar plantas com raízes em um ambiente natural e/ou mostrar evidências de diferenciação de horizontes devido a processos pedogenéticos (Soil Survey Staff, 2006).

De acordo com a teoria elaborada por Simonson (1959), amplamente utilizada na literatura atual, a formação de qualquer tipo de solo ocorre pela atuação de processos fundamentais de adições, perdas, translocações e transformações de matéria. A combinação dos processos fundamentais dá origem a processos gerais, operantes em determinadas condições ambientais e responsáveis pela gênese de determinadas classes de solos (Fanning \& Fanning, 1989). Entre tais processos, pode-se citar a podzolização e a solonização, respectivamente responsáveis pela formação de Espodossolos e de solos com alto teor de sódio no complexo de troca, tais como Planossolos ou Gleissolos Sódicos.

Os arredores das lagoas salinas presentes na Baixa Nhecolândia são, em grande maioria, desprovidos de vegetação. Entretanto, a presença de atributos morfológicos característicos tem permitido que seus materiais sejam tratados como solos (Embrapa, 1997; Sakamoto, 1997; Barbiéro et al., 2000; Fernandes, 2000; Silva \& Sakamoto, 2003; Silva et al., 2004), apesar de não haver até o momento trabalhos que façam referências detalhadas aos processos pedogenéticos responsáveis pela sua gênese. Sakamoto (1997) e Fernandes (2000) apenas sugerem indiretamente a dominância do processo geral de podzolização nos solos associados às salinas ao classificarem os perfis estudados como Podzóis Hidromórficos ${ }^{1}$, classe dominante na Nhecolândia.

O objetivo deste capítulo é descrever detalhadamente os solos do entorno da lagoa do Meio e identificar os principais processos fundamentais e gerais responsáveis pela diferenciação de horizontes. Pretende-se, assim, fornecer elementos para o melhor entendimento da gênese dos solos associados às lagoas salinas da Baixa Nhecolândia.

\footnotetext{
${ }^{1}$ Atualmente Espodossolos, conforme Embrapa (2006).
} 


\section{2 - Materiais e Métodos}

\subsection{1 - Trabalhos de campo}

Levantamento e coleta de solos

O presente trabalho foi realizado em uma lagoa salina situada na sub-região da Nhecolândia, localmente conhecida como salina do Meio (1858’31'’S e 56 38'48’W), localizada na Fazenda Nhumirim (Figura 1.1, p. 3), propriedade da Embrapa Pantanal. A salina do Meio (Figura 3.1) foi selecionada para este trabalho por ter sido alvo de estudos hidrológicos e de levantamentos pedológicos preliminares anteriores a esta pesquisa, por possuir valores de $\mathrm{pH}(9,64)$ e condutividade elétrica $(12,74 \mathrm{dS} / \mathrm{m})$ representativos da Baixa Nhecolândia e por situar-se em uma área de fácil acesso.

Foram realizados 4 trabalhos de campo em um total de 25 dias, todos no período da seca (setembro/outubro), quando as lagoas estão com o nível d'água baixo e os solos do entorno estão com grande exposição. O levantamento do solo foi feito em 3 topossequências transversais à salina do Meio (T1, T2 e T3), situadas entre o nível d'água superficial da lagoa na época dos levantamentos e a borda da cordilheira. Utilizou-se a metodologia da Análise Estrutural da Cobertura Pedológica, que consiste em estudar as características morfológicas, a distribuição lateral/vertical e o arranjo geométrico das estruturas pedológicas através da descrição dos solos em tradagens e trincheiras localizadas ao longo de transectos (Boulet, 1992; Ruellan \& Dosso, 1993). As descrições morfológicas dos solos foram feitas de acordo com Lemos \& Santos (1996) e os levantamentos topográficos dos transectos foram realizados a partir do uso de teodolito, marca Topochaix.

A Topossequência 1 (T1) foi escolhida para a coleta de todas as amostras de solo por estar localizada no eixo do monitoramento piezométrico efetuado no local desde 1998. Amostras foram coletadas ao longo de 5 pedons (P1 a P5) e então encaminhadas para as análises laboratoriais.

\section{Coleta de água}

A coleta de amostras de água foi feita no corpo d'água da salina do Meio e em 15 piezômetros (Pz1 a Pz15) e 13 coletores (G0 a G12) de água subterrânea, na época da 

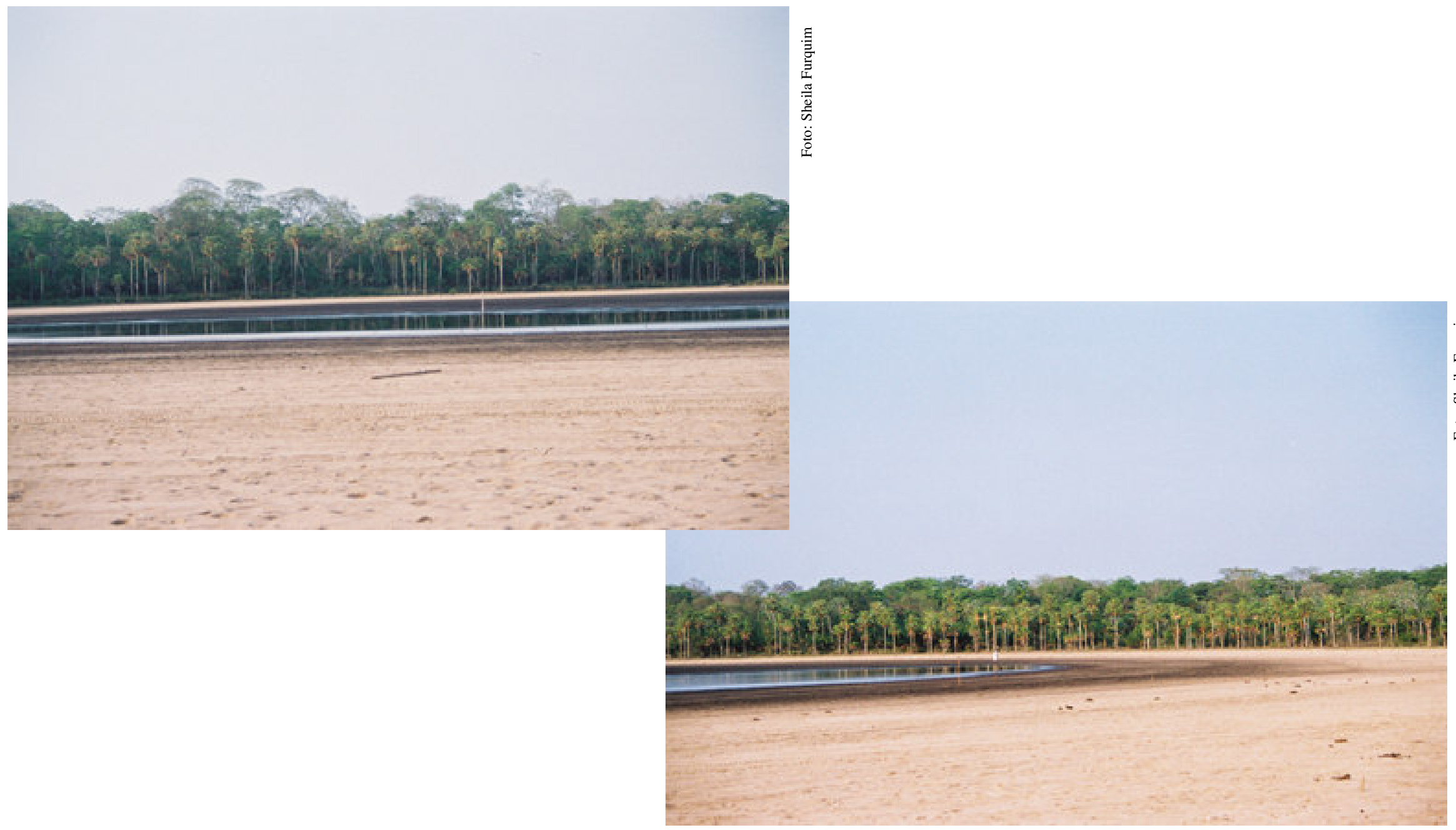

Figura 3.1 - Visões gerais da salina do Meio, em outubro de 2002. Nota-se o baixo nível do espelho d'água no centro da depressão e a cordilheira coberta por Cerradão no entorno. 
seca. A localização dos piezômetros e coletores inclui a Topossequência 1 (T1) e a cordilheira e baía adjacentes, sendo que apenas Pz2, G0 e G1 estão situados ao longo de T1. Os coletores, compostos por potes de polietileno embalados em tecido sintético, foram inseridos a diferentes profundidades de furos de trado e as amostras foram obtidas através de um tubo de $1 \mathrm{~mm}$ de diâmetro, que conectava o pote coletor ao topo do furo. Todas as amostras foram coletadas em duplicata e submetidas a leituras de campo de $\mathrm{pH}$ (instrumento Sentix 41). As que foram encaminhadas para análises de laboratório passaram por um filtro do tipo seringa, composto por membrana de acetato-celulose com abertura de $0,2 \mu \mathrm{m}$, e então guardadas em potes de polietileno previamente lavados com ácido.

\subsection{2 - Análises de solo em laboratório}

A seguir serão dadas informações sucintas a respeito dos métodos analíticos utilizados no presente capítulo, mas maiores detalhamentos podem ser vistos no Anexo 1. A maioria das análises foi feita com 20 amostras, 4 de cada um dos 5 pedons selecionados, mas algumas das medidas envolveram um número maior ou menor de amostras. A Tabela 3.1 mostra quais das amostras coletadas em campo foram utilizadas em cada uma das análises laboratoriais.

\section{Análises físicas e químicas}

A análise granulométrica foi feita a partir do método da pipeta (USDA, 1996), utilizando-se os seguintes intervalos de tamanho das partículas: 5 frações de areia areia muito grossa $(1 \mathrm{a} 2 \mathrm{~mm})$, areia grossa $(0,5 \mathrm{a} 1 \mathrm{~mm})$, areia média $(0,25$ a 0,5$)$, areia fina $(0,125$ a $0,25 \mathrm{~mm})$ e areia muito fina $(0,125$ a $0,05 \mathrm{~mm}) ; 2$ frações de silte silte grosso $(0,02$ a $0,05 \mathrm{~mm})$ e silte fino $(0,02$ a $0,002 \mathrm{~mm})$; e 2 frações de argila argila grossa $(0,002$ a $0,0002 \mathrm{~mm})$ e argila fina $(<0,0002 \mathrm{~mm})$. Os valores apresentados correspondem a médias de duplicatas.

$\mathrm{O}$ pH foi medido em uma suspensão obtida pela relação solo/água de 1:1 (USDA, 1996), em um instrumento modelo Accumet-25 e um combinado de eletrodos Accumet-13620287, com referência Prata-Cloreto de Prata, ambos da marca Fisher Scientific. A condutividade elétrica (CE) foi medida no extrato da pasta saturada (USDA, 1996), utilizando-se um aparelho Horiba, modelo C-173. A determinação do carbono orgânico $(\mathrm{CO})$ foi feita pela subtração entre teores de carbono total e carbono inorgânico, sendo este último derivado do total de carbonato de cálcio equivalente nos 
Tabela 3.1 - Amostras selecionadas para diferentes análises de solos incluídas no Capítulo 3

\begin{tabular}{|c|c|c|c|c|c|c|}
\hline $\begin{array}{l}\text { Profundidade } \\
\text { (cm) }\end{array}$ & Horizonte & $\begin{array}{c}\text { Análises } \\
\text { Granulom. }\end{array}$ & pH & $\begin{array}{c}\text { Outras Anal. } \\
\text { Químicas }{ }^{2}\end{array}$ & DRX $^{3}$ & MET $^{4}$ \\
\hline \multicolumn{7}{|c|}{ PEDON 1} \\
\hline $0-40$ & 1 & $\mathrm{X}$ & $X$ & $X$ & $X$ & ----------- \\
\hline $120-130$ & 1 & ----------- & $\mathrm{X}$ & ----------- & ----------. & ---------- \\
\hline $200-210$ & 3 & ------------ & $\mathrm{X}$ & ------------ & ----------.- & ------------ \\
\hline 230 & 3 & $X$ & $\mathrm{X}$ & $X$ & $X$ & ------------ \\
\hline $250-270$ & 5 & $X$ & $\mathrm{X}$ & $X$ & $\mathrm{X}$ & ----------- \\
\hline 350 & 6 & $X$ & $\mathrm{X}$ & $X$ & $\mathrm{X}$ & $\mathrm{X}$ \\
\hline \multicolumn{7}{|c|}{ PEDON 2} \\
\hline $0-40$ & 1 & $X$ & $\mathrm{X}$ & $X$ & $\mathrm{X}$ & ---------- \\
\hline 80 & 4 & $X$ & $X$ & $X$ & $\mathrm{X}$ & ----------- \\
\hline $110-145$ & 5 & $\mathrm{X}$ & $\mathrm{X}$ & $\mathrm{X}$ & $\mathrm{X}$ & ----------- \\
\hline $145-158$ & 5 & -------- & $\mathrm{X}$ & -------- & ----. & ------------ \\
\hline $168-175$ & 6 & $X$ & $\mathrm{X}$ & $X$ & $X$ & ----------- \\
\hline $185-200$ & 6 & --------- & $\mathrm{X}$ & ----------- & $---\cdot$ & ----------- \\
\hline \multicolumn{7}{|c|}{ PEDON 3} \\
\hline $0-6$ & 1 & $X$ & $\mathrm{X}$ & $\mathrm{X}$ & $\mathrm{X}$ & ---------- \\
\hline $6-12$ & 3 & ---- & $\mathrm{X}$ & -------- & ----.. & ------------ \\
\hline $12-65$ & 4 & $X$ & $\mathrm{X}$ & $\mathrm{X}$ & $\mathrm{X}$ & ---------- \\
\hline $68-73$ & 5 & $\mathrm{X}$ & $\mathrm{X}$ & $X$ & $\mathrm{X}$ & ----------- \\
\hline $78-85$ & 6 & $X$ & $\mathrm{X}$ & $X$ & $\mathrm{X}$ & ------------ \\
\hline $91+$ & 6 & ----------- & $\mathrm{X}$ & ---------- & ----------- & ---------- \\
\hline \multicolumn{7}{|c|}{ PEDON 4} \\
\hline $0-5$ & 2 & $\mathrm{X}$ & $\mathrm{X}$ & $\mathrm{X}$ & $\mathrm{X}$ & ------------ \\
\hline $13-15$ & 3 & ---- & $\mathrm{X}$ & ------ & ---- & ---------- \\
\hline $30-40$ & 4 & $X$ & $\mathrm{X}$ & $X$ & $\mathrm{X}$ & ------------ \\
\hline $55-70$ & 5 & ----.. & $\mathrm{X}$ & -------- & ----- & ----------- \\
\hline $70-80$ & 5 & $\mathrm{X}$ & $\mathrm{X}$ & $X$ & $X$ & ----------- \\
\hline 100 & 6 & $X$ & $X$ & $X$ & $\mathrm{X}$ & ----------- \\
\hline \multicolumn{7}{|c|}{ PEDON 5} \\
\hline $0-5$ & 2 & $X$ & $\mathrm{X}$ & $X$ & $\mathrm{X}$ & ----------- \\
\hline $5-20$ & 3 & -------- & $\mathrm{X}$ & & ----. & ------------ \\
\hline $20-40$ & 4 & $X$ & $\mathrm{X}$ & $\mathrm{X}$ & $\mathrm{X}$ & ---------- \\
\hline 60 & 5 & -------- & $\mathrm{X}$ & -------- & ---... & ------------ \\
\hline 70 & 5 & $\mathrm{X}$ & $\mathrm{X}$ & $\mathrm{X}$ & $\mathrm{X}$ & ----------- \\
\hline 90 & 6 & $X$ & $\mathrm{X}$ & $X$ & $X$ & $X$ \\
\hline
\end{tabular}

1 - Granulom=granulométricas; 2 - Outras Análises Químicas= condutividade elétrica, carbono total, análise manométrica, bases trocáveis, acidez trocável, acidez potencial, imersão em água, ácido e bases; 3 DRX=Difração de Raios-x; 4 - MET=Microscópio Eletrônico de Transmissão

$\mathrm{X}$ - Amostras analisadas; ------- - Amostras não selecionadas para esta análise. 
solos. O carbono total foi obtido por combustão seca (Nelson \& Sommers, 2001) em um instrumento da marca Thermo Electron Corporation, modelo Flash EA 1112. Os teores de carbonato de cálcio equivalente, tanto do solo total quanto de nódulos, foram determinados pelo método manométrico (Nelson, 1982), através de um manômetro da marca Dwyer, de modelo digital e série 477. Tanto o carbono total quanto o carbonato equivalente foram medidos em 3 repetições, sendo utilizado os valores das médias. A conversão de carbonato equivalente em carbono inorgânico foi feita pela multiplicação por 0,120 (informação verbal do Prof. Dr. Chris Amrhein, "University of California-Riverside").

Cálcio e $\mathrm{Mg}^{2+}$ trocáveis foram obtidos através da resina trocadora de íons, segundo método descrito por Raij (2001), e os extratos foram lidos por espectrofotometria de absorção atômica, através de espectrofotômetro da marca Perkin Elmer, modelo 1100B. Sódio e $\mathrm{K}^{+}$trocáveis foram extraídos com solução de Melisch 1, constituída por uma mistura de $\mathrm{HCl} \mathrm{0,05} \mathrm{M} \mathrm{e}_{2} \mathrm{SO}_{4} 0,0125 \mathrm{M}$, e determinados por fotômetro de chama (Silva, 1999), da marca Corning, modelo 400. A acidez trocável $\left(\mathrm{Al}^{3+}\right)$ foi determinada em extrato de $\mathrm{KCl} 1 \mathrm{M}, \mathrm{pH} 5,5$ (Cantarella et al., 2001) e a acidez

potencial $\left(\mathrm{Al}^{3+}+\mathrm{H}^{+}\right)$em extrato de $\mathrm{Ca}\left(\mathrm{CH}_{3} \mathrm{COO}\right)_{2} 1 \mathrm{M}$, pH 7,0, sendo ambas determinadas por titulação.

Amostras do horizonte esverdeado endurecido (identificado aqui como horizonte 6) dos 5 pedons foram submetidas à imersão em água, ácido e bases a fim de verificar se o horizonte atinge os critérios para classificação em duripan ou fragipan (Araújo Filho, 2004; Soil Survey Staff, 2006). Torrões de 2 a 5 cm de diâmetro e com peso entre 35 a $70 \mathrm{~g}$ foram submetidos à imersão em água por 8 horas e à imersão em $\mathrm{HCl}$ $1 \mathrm{~N}, \mathrm{NaOH} 1 \mathrm{M}$ e $\mathrm{NaOH} 4 \mathrm{M}$ por 12 dias (Araújo Filho, 2004). Decorrido o devido tempo, verificou-se a porcentagem de volume pulverizada por estimativa visual.

\section{Análises Mineralógicas}

Amostras de solo total e amostras de nódulos foram esboroadas e passadas em um peneira de 100 mesh, dispostas de modo aleatório em um suporte metálico e examinadas por Difração de Raios X (DRX), a fim de detectar o espaço $d_{060}$ e identificar minerais carbonáticos. 
Todas as amostras de solo total foram então fracionadas em silte fino, argila grossa e argila fina por sedimentação e centrifugação, após a destruição da matéria orgânica com $\mathrm{NaOCl}$ (pH 9,5) (Anderson, 1963).

As amostras fracionadas de silte fino, argila grossa e argila fina passaram então por uma preparação para as análises de DRX. As amostras das 3 frações sofreram 5 diferentes tratamentos: saturação com $\mathrm{Mg}^{2+}$ e posterior confecção de lâmina, solvatação com etileno glicol (EG) das lâminas saturadas com $\mathrm{Mg}^{2+}$, saturação com $\mathrm{K}^{+}$e posterior confecção de lâmina e aquecimento das lâminas saturadas com $\mathrm{K}^{+} \mathrm{a}$ temperaturas de $350^{\circ} \mathrm{C}$ e $550^{\circ} \mathrm{C}$. As lâminas de vidro foram orientadas através do espalhamento em uma só direção de pastas de argilas e do gotejamento da solução contendo silte fino (Theisen \& Harward, 1962). Os tratamentos facilitam a diferenciação entre os diferentes minerais enquanto a orientação das lâminas possibilita a detecção do espaço $d_{00 l}$ e a conseqüente identificação de filossilicatos. Amostras não orientadas foram dispostas em suporte metálico a fim de detectar o espaço $d_{060}$ e identificar o caráter dioctaédrico ou trioctaédrico dos minerais. As lâminas e os suportes metálicos foram então submetidos à DRX. Utilizou-se um Difratômetro Siemens D-500, com radiação $\mathrm{K}_{\alpha}$ e alvo de cobre $(\mathrm{Cu})$, sendo as amostras rodadas a uma taxa de $0,02^{\circ} 2 \theta$ por etapa, a cada 1 segundo.

Indícios de origem autigênica na assembléia mineral da argila fina levaram a maiores detalhamentos dos principais minerais presentes nesta fração (caulinita, esmectita e mica). Nestes detalhamentos, incluem-se estimativas semi-quantitativas (em \%) da concentração de cada mineral em cada uma das amostras de argila fina, feitas de acordo com a proporção de área dos picos de DRX em padrões de EG (Biscaye, 1965). Além disto, foram feitas caracterizações mineralógicas específicas para cada um dos três minerais citados. Entretanto, apenas a caracterização mineralógica da caulinita será considerada no presente capítulo, enquanto a caracterização da esmectita e da mica será feita detalhadamente em capítulos separados (4 e 5, respectivamente), uma vez que a localização destes dois minerais parece estar de acordo com a dinâmica atual da lagoa salina e arredores.

O índice de cristalinidade (IC) da caulinita foi calculado nas amostras, medindo-se a largura do pico $d_{001}(0,72 \mathrm{~nm})$ na metade da altura do pico (Moore \& Reynolds, 1997). Duas amostras selecionadas de fração argila fina foram ainda submetidas à análise pelo Microscópio Eletrônico de Transmissão (MET), tipo FEI-Philips CM300, 
acoplado ao Espectrômetro tipo Dispersão em Energia (EDS), modelo Phoenix. A composição química de 6 cristais individuais de caulinita, obtida com uma acurácia de 1-3\%, foi utilizada para o cálculo das fórmulas químicas, que foi feito de acordo com Moore \& Reynolds (1997). Dados de Espectrometria Mossbauer revelaram que os conteúdos de $\mathrm{Fe}^{2+}$ são iguais ou inferiores a $8 \%$ nas amostras (informação verbal do Dr. Richard Morris, NASA) e, por isto, apenas o $\mathrm{Fe}^{3+}$ foi incluído nas fórmulas.

\subsection{3 - Análises da água em laboratório}

A alcalinidade total foi determinada por titulação com $\mathrm{HCl}$ (Gran, 1952), a quantificação dos ânions foi realizada por Cromatografia de Íons (Dionex, ED50GP50) e a quantificação dos cátions por Espectrometria de Plasma Acoplada a Detector de Massas (ICP-MS) (Perkin-Elmer, Elan 6000). As análises foram comparadas a materiais de referência padrão (Bmoos-01, SLRS4 e SRM1640). A acurácia para a maioria das análises dos elementos maiores foi menor que $2 \%$ para amostras sem diluição e dentro de $10 \%$ para amostras que passaram pela diluição máxima (500 vezes).

Os diagramas de concentração do $\mathrm{Ca}^{2+}, \mathrm{Mg}^{2+}$ e $\mathrm{Si}(\mathrm{OH})_{4}$ foram construídos mantendo o $\mathrm{Na}^{+}$como o equivalente ao fator de concentração, já que este é provavelmente um elemento conservativo.

\section{3 - Resultados}

\subsection{1 - Descrição morfológica dos solos}

As 3 topossequências (T1, T2 e T3) levantadas ao redor da lagoa do Meio possuem características morfológicas e seqüência vertical e lateral de horizontes muito semelhantes. Desta forma, será apresentada neste item apenas a descrição macromorfológica da Topossequência 1, incluída no eixo de coleta de água e onde foram coletadas as amostras para todas as análises físicas, químicas e mineralógicas efetuadas no presente trabalho. As representações gráficas de T2 e T3 podem, contudo, ser visualizadas no Anexo 2.

Para acompanhar a descrição a seguir, sugere-se a visualização da organização bidimensional da cobertura pedológica de T1 na Figura 3.2, de fotos dos solos na Figura 3.3, e das principais características morfológicas dos horizontes identificados nos Pedons 1 a 5 (P1 a P5) na Tabela 3.2. 


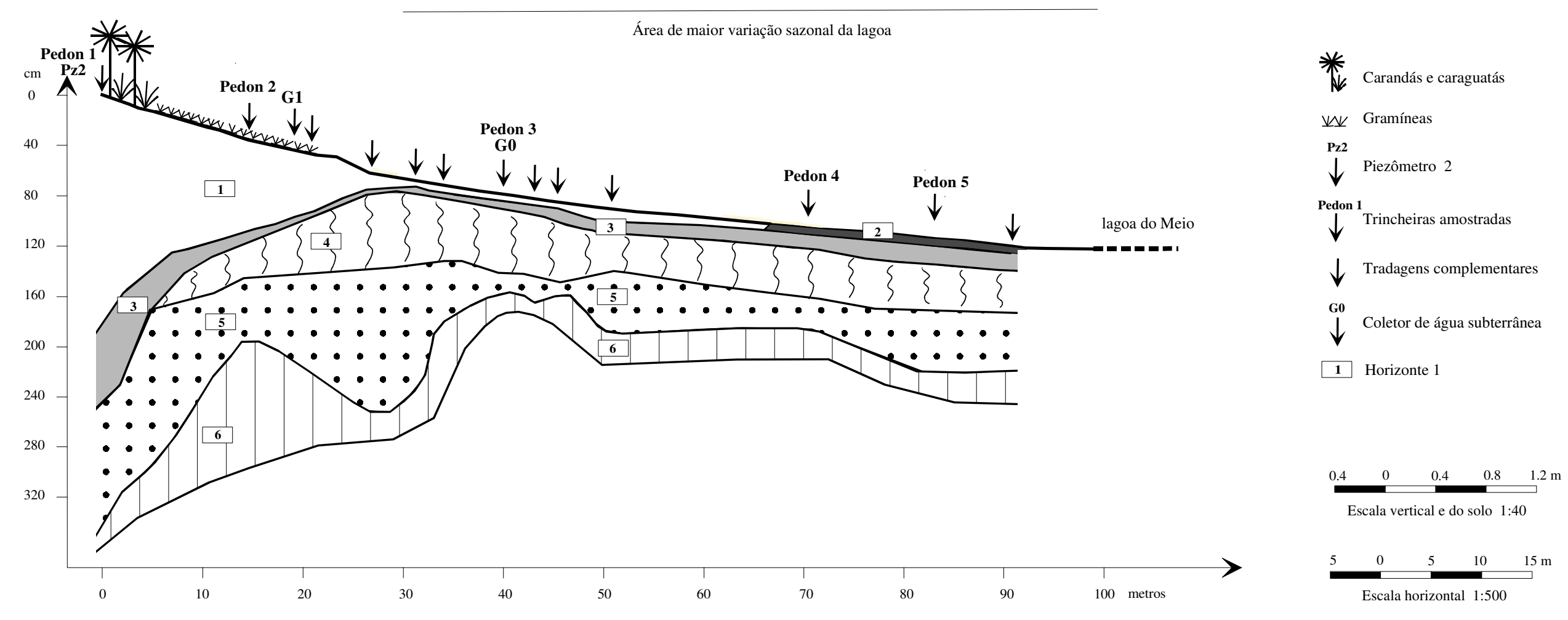

Figura 3.2 - Organização da cobertura pedológica ao longo da Topossequência 1. 


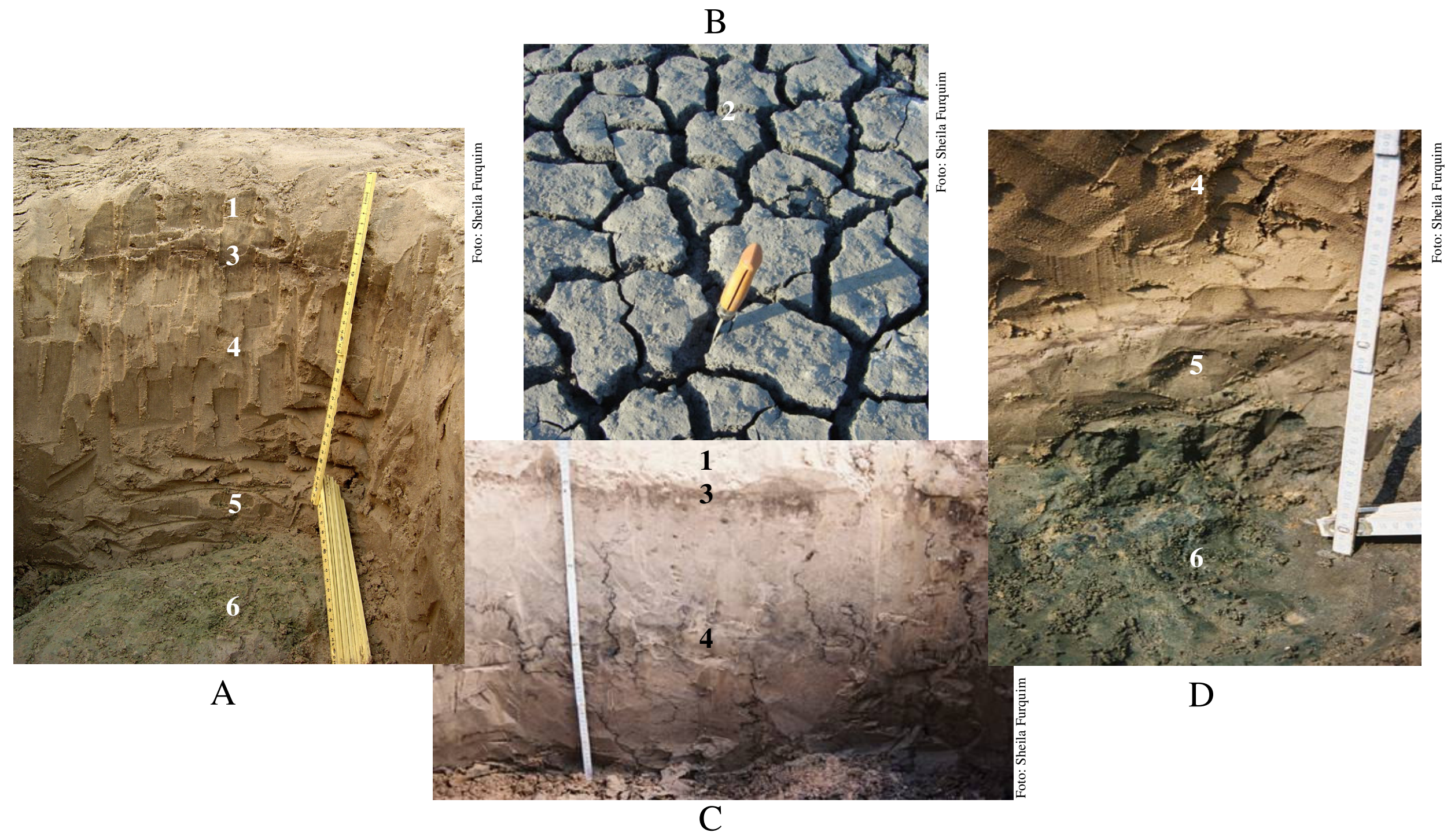

Figura 3.3 - A) Visão geral do solo no Pedon 4; B) Visão aérea do horizonte 2, nas proximidades do Pedon 5; C) Detalhe dos horizontes 1, 3 e 4 no Pedon 3; C); D) Detalhe dos horizontes 5 e 6 no Pedon 3. 
Tabela 3.2 - Características morfológicas dos solos da Topossequência 1

\begin{tabular}{|c|c|c|c|c|c|c|c|c|c|}
\hline Horiz. $^{1}$ & Profund. $^{2}$ & $\begin{array}{c}\text { Cor Mat. }{ }^{3} \\
\text { (Seca) }\end{array}$ & Textura & Estrutura $^{4}$ & Porosidade $^{5}$ & Consistência $^{6}$ & $\begin{array}{l}\text { Volumes ou } \\
\text { nódulos }\end{array}$ & $\begin{array}{l}\text { Cor - volumes } \\
\text { e/ou nódulos }\end{array}$ & Transição $^{8}$ \\
\hline \multicolumn{10}{|c|}{ PEDON 1} \\
\hline 1 & $0-190$ & $10 \mathrm{YR} 6 / 3$ & Areia & Grãos simples & Int, mp-p, ab & Sol; sol; npl, npj & $\mathrm{N}$, ar, mm, r-co & $2,5 \mathrm{Y} 7 / 1$ & Clara, ond \\
\hline 3 & $190-250$ & 10YR 5/1 & Areia franca & Maciça & Int/Tub: mp-m, co & $\mathrm{M} ; \mathrm{fr} ; \mathrm{lpl}, \mathrm{lpj}$ & 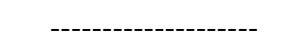 & --------------- & Gradual, ond \\
\hline 5 & $250-350$ & $10 Y R 5 / 3$ & Areia franca & Maciça - sub & Int/Tub: p-m, co & Ld; f; lpl, lpj & $\mathrm{N}, \mathrm{ar} / \mathrm{o}, \mathrm{mm}-\mathrm{cm}, \mathrm{co}-\mathrm{ab}$ & $5 Y 5 / 4$ & Clara, ond \\
\hline 6 & $350-360+$ & $2.5 \mathrm{Y} 6 / 2$ & Franco arenoso & Maciça & Tub, mp-m, co & Md; f; pl e pj & $\mathrm{N}$, ar, mm-cm, r-co & $5 Y 5 / 4 ; 2,5 Y 2 / 1$ & --------------- \\
\hline \multicolumn{10}{|c|}{ PEDON 2} \\
\hline 1 & $0-70$ & $10 Y R 7 / 3$ & Areia & Grãos simples & Int, mp-p, ab & Sol; sol; npl, npj & 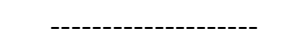 & --------------- & $\mathrm{Cl}$, ond, interd \\
\hline 3 & $70-75$ & $10 \mathrm{YR} 4 / 2$ & Areia franca & Maciça - sub & Int/Tub: mp-m, co & M; fr; npl, npj & -------------------' & -------------- & $\mathrm{Cl}$, ond, interd \\
\hline 4 & $75-110$ & $2,5 \mathrm{Y} 6 / 2$ & Areia & Grãos Simples & Int, mp-p, ab & Sol; sol; npl, npj & $\mathrm{V}$, along, mp-m, co-ab & $10 Y R$ 4/2 & Gradual, plana \\
\hline 5 & $110-160$ & $2,5 Y 6 / 2$ & Areia & Maciça & Int/Tub: p-m, co & Ld; f; npl, npj & $\mathrm{N}$, ar/o, mm, r-co & $5 Y 5 / 2$ & Abrupta, ond \\
\hline 6 & $160-250+$ & $5 Y 5 / 2$ & Franco arenoso & Maciça & Tub, mp-m, co & Md; f; pl e pj & $\mathrm{N}$, ar, mm-cm, r-co & $5 Y 5 / 4 ; 2,5 Y 2 / 1$ & -------------- \\
\hline \multicolumn{10}{|c|}{ PEDON 3} \\
\hline 1 & $0-6$ & $10 \mathrm{YR} 6 / 3$ & Areia & Grãos simples & Int, mp-p, ab & Sol; sol; npl, npj & $\mathrm{V}$, ar, co & $2,5 \mathrm{Y} \quad 7 / 2$ & $\mathrm{Cl}$, ond, interd \\
\hline 3 & $6-12$ & $10 \mathrm{YR} 5 / 3$ & Areia & Maciça & Int/Tub: mp-m, r-co & $\mathrm{M} ; \mathrm{fr} ; \mathrm{npl}, \mathrm{npj}$ & $\mathrm{V}, \mathrm{ar}, \mathrm{mm}-\mathrm{cm}, \mathrm{ab}$ & 10YR 3/1 & $\mathrm{Cl}$, ond, interd \\
\hline 4 & $12-65$ & $2,5 \mathrm{Y} 6 / 2$ & Areia & Grãos simples & Int, mp-p, ab & Sol; sol; npl, npj & $\mathrm{V}$, along, mp-m, co-ab & 10YR 3/1 & Gradual, plana \\
\hline 5 & $65-78$ & $2,5 Y 5 / 1$ & Areia franca & Maciça - sub & Int/Tub: $p$, co & Ld; f; npl, npj & $\mathrm{N}, \mathrm{ar} / \mathrm{o}, \mathrm{mm}-\mathrm{cm}, \mathrm{ab}$ & $5 Y 5 / 4$ & Clara, plana \\
\hline 6 & $78-91+$ & $5 Y 5 / 2$ & Franco arenoso & Maciça & Tub, mp-m, co & Md; mf; lpl e lpj & $\mathrm{N}, \mathrm{ar}, \mathrm{mm}-\mathrm{cm}, \mathrm{co-ab}$ & $5 Y 5 / 4 ; 2,5 Y 2 / 1$ & ------------ \\
\hline \multicolumn{10}{|c|}{ PEDON 4} \\
\hline 2 & $0-5$ & 10YR 4/1 & Areia & Grãos simples & Int, mp-p, ab & Sol; sol; npl, npj & 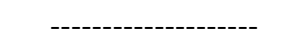 & --------------- & Clara, ond \\
\hline 3 & $5-15$ & $2,5 \mathrm{Y} 5 / 2$ & Areia & Maciça & Int/Tub: mp-m, r-co & M; fr; npl, npj & $\mathrm{V}, \mathrm{ar}, \mathrm{mm}-\mathrm{cm}, \mathrm{ab}$ & $10 Y R 3 / 2$ & $\mathrm{Cl}$, ond, interd \\
\hline 4 & $15-55$ & $2,5 \mathrm{Y} 6 / 2$ & Areia & Grãos simples & Int, mp-p, ab & Sol; sol; npl, npj & $\mathrm{V}$, along, mp-m, r-co & $2,55 / 2$ & Gradual, plana \\
\hline 5 & $55-80$ & $2,5 \mathrm{Y} 6 / 2$ & Areia & Maciça & Int/Tub: $p$, co & Ld; f; npl, npj & $\mathrm{N}$, ar/o, mm-cm, co & $5 \mathrm{Y} 6 / 2$ & Abrupta, ond \\
\hline 6 & $80-100+$ & $5 Y 6 / 1$ & Franco arenoso & Maciça & Tub, mp-m, co & Ed; ef; lpl, lpj & $\mathrm{N}$, ar, $\mathrm{mm}-\mathrm{cm}$, co & $5 Y 5 / 4 ; 2,5 Y 2 / 1$ & ---------------- \\
\hline \multicolumn{10}{|c|}{ PEDON 5} \\
\hline 2 & $0-5$ & 10YR 4/1 & Areia franca & Prism - sub & Tub: mp-m, ab & Ld; f; mpl, mpj & 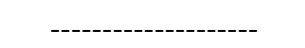 & -------------- & Clara, ond \\
\hline 3 & $5-20$ & $10 \mathrm{YR} 4 / 2$ & Areia & Maciça & Int/Tub: mp-m, r-co & $\mathrm{M} ; \mathrm{fr} ; \mathrm{npl}, \mathrm{npj}$ & --------------------- & --------------- & $\mathrm{Cl}$, ond, interd \\
\hline 4 & $20-40$ & $2,5 \mathrm{Y} 6 / 2$ & Areia & Grãos simples & Int, mp-p, ab & Sol; sol; npl, npj & $\mathrm{V}$, along, mp-m, r-co & -------------- & Clara, plana \\
\hline 5 & $40-90$ & $2,5 Y 5 / 1$ & Areia franca & Maciça - sub & Int/Tub, $p$, co & Ld; f; lpl, lpj & $\mathrm{N}, \mathrm{ar} / \mathrm{o}, \mathrm{mm}-\mathrm{cm}, \mathrm{co}$ & $5 Y 5 / 1$ & Clara, ond \\
\hline 6 & $90-95+$ & $5 Y 5 / 1$ & Franco arenoso & Maciça & Tub, mp-m, co & Ed; ef; lpl, lpj & $\mathrm{N}, \mathrm{ar}, \mathrm{mm}-\mathrm{cm}, \mathrm{co}-\mathrm{ab}$ & $5 Y 5 / 4 ; 2,5 Y 2 / 1$ & ---------------- \\
\hline
\end{tabular}

1 - Horiz=horizonte; 2 - Profund.=profundidade; 3 - Cor Mat.= cor da matriz; 4 - Sub=subestrutura em blocos subangulares; 5 - Int=intersticial intergrãos; Tub=tubular; mp=muito pequeno; p=pequeno; $\mathrm{m}=$ médio; $\mathrm{ab}=\mathrm{abundante} ; \mathrm{co}=\mathrm{comum} ; \mathrm{r}=$ raro. Quando há porosidade intersticial e tubular (Int/Tub), as características descritas referem-se à da porosidade tubular; $\mathbf{6}$ - sol=solta; $\mathrm{m}=\mathrm{macio}$; ld=ligeiramente duro; $\mathrm{md}=$ muito duro; ed=extremamente duro; fr=friável; f=firme; $\mathrm{mf}=$ muito firme; ef=extremamente firme; npl=não plástico; lpl=ligeiramente plástico; pl=plástico; mpl=muito plástico; npj=não pegajoso; lpj=ligeiramente pegajoso; $\mathrm{p}=$ pegajoso; $\mathrm{mpj}=$ muito pegajoso; 7 - N=nódulos; $\mathrm{V}=$ volumes; along=alongados; $\mathrm{ar}=$ arredondados; $\mathrm{o}=\mathrm{ovais}$; $\mathrm{mm}=\mathrm{milimétricos;} \mathrm{cm}=\mathrm{centimétricos,}$ $\mathrm{mp}=$ muito pequeno; $\mathrm{p}=$ pequeno; $\mathrm{m}=$ édio; $\mathrm{r}=\mathrm{raro}$; co=comum; ab=abundante;. 8 - Cl=clara; ond=ondulada; interg=interdigitada. 
1) O horizonte 1 estende-se lateralmente do terço superior até o final do terço médio, apresenta espessura entre 6 e $190 \mathrm{~cm}$ e torna-se gradativamente menos espesso no sentido cordilheira-lagoa salina. Caracteriza-se pelo matiz 10YR e pelo domínio de cores claras. É extremamente arenoso, apresenta-se em grãos simples e possui poros intersticiais intergrãos, muito pequenos a pequenos, abundantes. No trecho onde há vegetação (P1 e P2), há raízes fasciculadas com diâmetro <1 a $3 \mathrm{~mm}$, comuns a abundantes. Em P1 foram ainda encontrados nódulos esbranquiçados, arredondados, milimétricos, raros a comuns. A transição vertical para o horizonte 3 é clara e ondulada, em alguns casos com algumas finas interdigitações.

2) $\mathrm{O}$ horizonte 2 substitui lateralmente o horizonte 1 e estende-se por todo o terço inferior. Possui pequena espessura, sendo de no máximo $5 \mathrm{~cm}$. Caracteriza-se pelo matiz 10YR, mas possui cores bem mais escuras que o horizonte 1 devido à maior presença de matéria orgânica. Não há cobertura vegetal sobre este horizonte, mas é possível reconhecer restos de algas provenientes do espelho d'água da lagoa salina, em vários estágios de decomposição. No Pedon 4, apresenta textura areia, grãos simples e poros intersticiais intergrãos, muito pequenos a pequenos, abundantes, mas no Pedon 5, já a poucos metros do nível d'água superficial da salina, passa a ter textura areia franca, estrutura prismática e porosidade tubular, muito pequena a média, abundante. A transição vertical para o horizonte 3 é clara e ondulada.

3) O Horizonte 3 estende-se lateralmente por toda a topossequência. Sua espessura varia de 5 a $60 \mathrm{~cm}$, sendo significativamente maior na borda da cordilheira (P1). Caracteriza-se principalmente pelo matiz 10YR e pelo domínio de cores bruno e bruno-escuras, aparentemente devido à maior presença de matéria orgânica. Em alguns pedons ocorrem volumes ainda mais escuros que a matriz, arredondados, milimétricos a centimétricos e abundantes. Não é possível, entretanto, reconhecer restos vegetais em decomposição, como no horizonte 2. A textura é areia ou areia franca, é maciço, mas com presença de subestrutura em blocos subangulares em alguns pedons. A porosidade é tanto tubular, muito pequena a média e rara a comum, quanto intersticial, muito pequena a pequena e comum. A transição para o horizonte 5 é gradual e ondulada e para o horizonte 4 é clara, ondulada e com interdigitações.

4) O Horizonte 4 ocorre desde parte do terço superior até o fim do terço inferior, com espessuras entre 20 e $53 \mathrm{~cm}$. Este horizonte apresenta uma matriz com matiz 2,5Y e 
com tonalidades claras, associada a volumes com matiz geralmente $10 \mathrm{YR} \mathrm{e}$ tonalidades escuras, forma alongada, espessuras entre $<1$ e $3 \mathrm{~mm}$, quantidade rara a abundante e disposição vertical a partir do horizonte 3 sobrejacente. Estas linhas verticais muitas vezes coalescem-se em profundidade, formando volumes irregulares e com maiores tamanhos (até $10 \mathrm{~cm}$ no eixo maior) e originando, em geral, uma contínua camada horizontal, com espessura máxima observada de $2 \mathrm{~cm}$, exatamente no limite com o horizonte 5 subjacente.

A matriz apresenta textura areia e ausência de estrutura (grãos simples). A porosidade é principalmente intersticial intergrãos, muito pequena a pequena, abundante. Em algumas amostras foram observados nódulos cinzento-claros (2,5Y 7/1), pretos (10YR 2/1) ou oliva (5Y 5/4, semelhante ao horizonte 6), arredondados, milimétricos, raros e duros. A transição para o horizonte 5 é gradual ou clara e plana.

5) O horizonte 5 está presente em toda a extensão lateral da topossequência, apresentando espessuras entre 13 e $100 \mathrm{~cm}$. Caracteriza-se principalmente pelo matiz $2,5 \mathrm{Y}$, havendo uma variação de cores com diferentes combinações de bruno e cinza. A textura dominante é areia ou areia franca, mas geralmente com maior presença de argila do que o horizonte sobrejacente. É maciço, mas apresenta subestrutura em blocos subangulares. Há tanto poros intersticiais, muito pequenos a pequenos e comuns, quanto poros tubulares, pequenos a médios, comuns.

No limite inferior, há nódulos principalmente esverdeados (semelhantes ao horizonte 7 subjacente), arredondados ou ovais, com tamanhos entre $1 \mathrm{~mm} \mathrm{e} 7 \mathrm{~cm}$ no eixo maior, raros a abundantes e duros. A transição para o horizonte 6 é clara ou abrupta e principalmente ondulada.

6) O horizonte 6 está presente em toda a extensão lateral da topossequência. O matiz dominante é o $5 \mathrm{Y}$ e as cores são sempre esverdeadas. Caracteriza-se pela textura franco arenosa, sendo nitidamente mais argiloso que os horizontes sobrejacentes. Verificou-se, entretanto, cores verdes mais claras e menor quantidade de argila com o aumento de sua profundidade. É maciço e apresenta porosidade tubular, muito pequena a média, comum, havendo também uma quantidade média de planos estruturais com direção vertical dominante. No interior dos poros e dos planos estruturais foi observada cerosidade contínua, comum a moderada. Uma de suas características mais marcantes é a consistência muito dura e firme no terço superior 
(P1 e P2) e muito a extremamente dura e muito a extremamente firme nos terços médio e inferior (P3, P4 e P5).

Ressalta-se a presença de nódulos: a) esverdeados, arredondados, com diâmetro entre 1 e $3 \mathrm{~mm}$, comuns a abundantes, firmes e extremamente duros, muito semelhantes aos do horizonte sobrejacente e; b) próximos ao preto, arredondados, com tamanhos entre $<1 \mathrm{~mm}$ a $>1 \mathrm{~cm}$ no eixo maior, raros a comuns.

\subsection{2 - Propriedades físicas e químicas dos solos}

A granulometria dos solos está exposta na Tabela 3.3. Os horizontes apresentam entre 700 e $961 \mathrm{~g} / \mathrm{kg}$ de areia total, com maiores quantidades nos horizontes mais superficiais (1, 2, 3 e 4). A areia fina e a areia muito fina são fortemente dominantes, perfazendo juntas quase a totalidade da fração areia. Os teores de argila total, por sua

vez, estão entre 28 e 190 g/kg, com maiores concentrações nos horizontes mais profundos (5 e 6). Destacam-se, entretanto, quantidades significativas de argila total no horizonte 3 de P1 e no horizonte 2 de P5. A argila grossa é dominante na grande maioria das amostras.

$\mathrm{O}$ pH $\left(\mathrm{H}_{2} \mathrm{O}\right)$ varia de 5,40 a 11,03, mas 93\% dos valores são maiores que 8,5, sendo então fortemente alcalinos (Figura 3.4, Tabela 3.4). Os valores tendem a ser maiores com o aumento da profundidade, sendo que os mais altos estão invariavelmente no horizonte 5 ou 6 . Os valores mais baixos são encontrados no horizonte 1 de P1 e P2, os dois pontos mais próximos da cordilheira.

Os valores de condutividade elétrica (CE) estão entre 0 e $43 \mathrm{dS} / \mathrm{m}$, sendo geralmente superiores nos 3 pedons mais próximos a lagoa salina (P3 a P5) (Tabela 3.4). Já os teores de carbono orgânico (CO) variam de 0 a $22 \mathrm{~g} / \mathrm{kg}$, mas são em geral menores que $2 \mathrm{~g} / \mathrm{kg}$. Não há uma tendência clara de diminuição de CO das menores para maiores profundidades. O horizonte superficial 2 possui os maiores teores de $\mathrm{CO}$ de P4 e P5, mas valores relativamente altos também podem ser encontrados nos horizontes 1, 5 ou 6 de todos os pedons (Tabela 3.4).

A capacidade de troca catiônica (CTC) varia de 4 a $207 \mathrm{cmol}_{\mathcal{C}} / \mathrm{kg}$ e, assim como os valores de $\mathrm{CE}$, tende a ser maior nos 3 pedons mais próximos a lagoa salina (P3 a P5) (Tabela 3.4). Nestes pedons, os valores mais altos estão geralmente nos horizontes superficiais. A saturação em $\mathrm{Na}^{+}$é de 58 a 96\%, sendo este cátion, portanto, fortemente dominante no complexo de troca. Cálcio e $\mathrm{K}^{+}$são os cátions mais abun- 
Tabela 3.3 - Análises granulométricas de amostras de solos na Topossequência 1

\begin{tabular}{|c|c|c|c|c|c|c|c|c|c|c|c|c|c|c|}
\hline \multirow[t]{2}{*}{ Horiz. $^{1}$} & \multirow[t]{2}{*}{$\mathbf{p H}$} & \multirow{2}{*}{$\begin{array}{c}\mathbf{C E}^{2} \\
\mathrm{dS} / . \mathrm{m}\end{array}$} & \multicolumn{6}{|c|}{ Areia g/kg } & \multicolumn{3}{|c|}{ Silte $\mathrm{g} / \mathrm{kg}$} & \multicolumn{3}{|c|}{ Argila g/kg } \\
\hline & & & m.g. ${ }^{3}$ & grossa & med. $^{4}$ & fina & m. f. ${ }^{5}$ & total & grossa & fina & total & grossa & fina & total \\
\hline \multicolumn{15}{|c|}{ PEDON 1} \\
\hline 1 & 5,40 & 0,35 & 0,1 & 2,9 & 70,3 & 460,2 & 427,0 & 960,5 & 3,1 & 4,5 & 7,6 & 18,7 & 13,2 & 31,9 \\
\hline 3 & 9,91 & 6,79 & 0,0 & 3,4 & 85,2 & 366,3 & 378,8 & 833,7 & 21,5 & 28,0 & 49,4 & 85,7 & 31,1 & 116,9 \\
\hline 5 & 9,60 & 7,19 & 0,0 & 4,4 & 104,5 & 358,9 & 349,5 & 817,3 & 45,8 & 48,9 & 94,7 & 59,5 & 28,5 & 88,0 \\
\hline 6 & 9,51 & 4,65 & 0,0 & 1,9 & 50,7 & 258,8 & 394,5 & 705,9 & 40,2 & 64,8 & 105,0 & 109,1 & 80,1 & 189,1 \\
\hline \multicolumn{15}{|c|}{ PEDON 2} \\
\hline 1 & 8,05 & 0,28 & 0,0 & 2,6 & 90,9 & 460,0 & 402,9 & 956,4 & 8,5 & 5,7 & 14,3 & 28,3 & 1,0 & 29,3 \\
\hline 4 & 9,23 & 0,47 & 0,0 & 3,3 & 91,1 & 482,6 & 383,6 & 960,7 & 5,6 & 4,9 & 10,4 & 17,0 & 11,9 & 28,9 \\
\hline 5 & 10,50 & 11,51 & 0,0 & 4,4 & 94,9 & 435,2 & 364,2 & 898,7 & 29,8 & 15,2 & 45,0 & 48,4 & 7,9 & 56,3 \\
\hline 6 & 11,03 & 14,92 & 0,0 & 3,0 & 80,6 & 339,7 & 304,0 & 727,3 & 36,5 & 82,5 & 119,0 & 124,9 & 28,8 & 153,7 \\
\hline \multicolumn{15}{|c|}{ PEDON 3} \\
\hline 1 & 10,37 & 9,59 & 0,0 & 5,5 & 170,6 & 468,9 & 309,3 & 954,3 & 4,1 & 6,0 & 10,1 & 11,0 & 24,6 & 35,6 \\
\hline 4 & 10,15 & 17,71 & 0,0 & 3,4 & 81,1 & 448,9 & 398,5 & 932,0 & 17,8 & 13,1 & 30,8 & 17,1 & 20,1 & 37,2 \\
\hline 5 & 10,24 & 19,20 & 0,0 & 3,4 & 81,1 & 408,6 & 363,5 & 856,5 & 29,3 & 49,2 & 78,5 & 40,2 & 24,8 & 65,0 \\
\hline 6 & 10,63 & 17,73 & 0,0 & 1,7 & 54,2 & 367,8 & 319,1 & 742,8 & 57,0 & 67,7 & 124,7 & 89,2 & 43,3 & 132,5 \\
\hline \multicolumn{15}{|c|}{ PEDON 4} \\
\hline 2 & 10,32 & 30,32 & 0,1 & 3,5 & 141,6 & 417,1 & 383,9 & 946,1 & 10,2 & 7,6 & 17,8 & 20,6 & 15,4 & 36,0 \\
\hline 4 & 10,12 & 11,43 & 0,0 & 2,8 & 69,3 & 404,2 & 426,2 & 902,5 & 26,6 & 29,4 & 55,9 & 33,5 & 8,1 & 41,6 \\
\hline 5 & 10,80 & 13,30 & 0,1 & 3,4 & 75,1 & 393,4 & 410,2 & 882,2 & 40,2 & 27,8 & 67,9 & 34,2 & 15,7 & 49,9 \\
\hline 6 & 10,39 & 11,42 & 1,0 & 18,9 & 149,4 & 330,2 & 283,7 & 783,2 & 38,8 & 62,4 & 101,2 & 81,2 & 34,4 & 115,6 \\
\hline \multicolumn{15}{|c|}{ PEDON 5} \\
\hline 2 & 10,22 & 43,01 & 0,0 & 5,3 & 125,4 & 354,2 & 337,9 & 822,7 & 33,4 & 58,4 & 91,8 & 62,9 & 22,5 & 85,4 \\
\hline 4 & 10,38 & 9,82 & 0,08 & 2,5 & 67,6 & 378,4 & 453,0 & 902,2 & 31,8 & 32,1 & 63,9 & 19,0 & 14,9 & 33,9 \\
\hline 5 & 10,81 & 13,93 & 0,01 & 1,9 & 56,7 & 373,7 & 370,4 & 802,8 & 45,1 & 76,9 & 121,9 & 56,8 & 18,6 & 75,3 \\
\hline 6 & 10,58 & 13,18 & 0,47 & 51,6 & 128,7 & 289,0 & 288,4 & 762,3 & 55,5 & 82,7 & 138,2 & 76,5 & 22,9 & 99,5 \\
\hline
\end{tabular}

1 - Horiz: horizonte; 2 - CE: condutividade elétrica; 3 - m,g,: muito grossa; 4 - med,: média; 5 - m,f,: muito fina, 


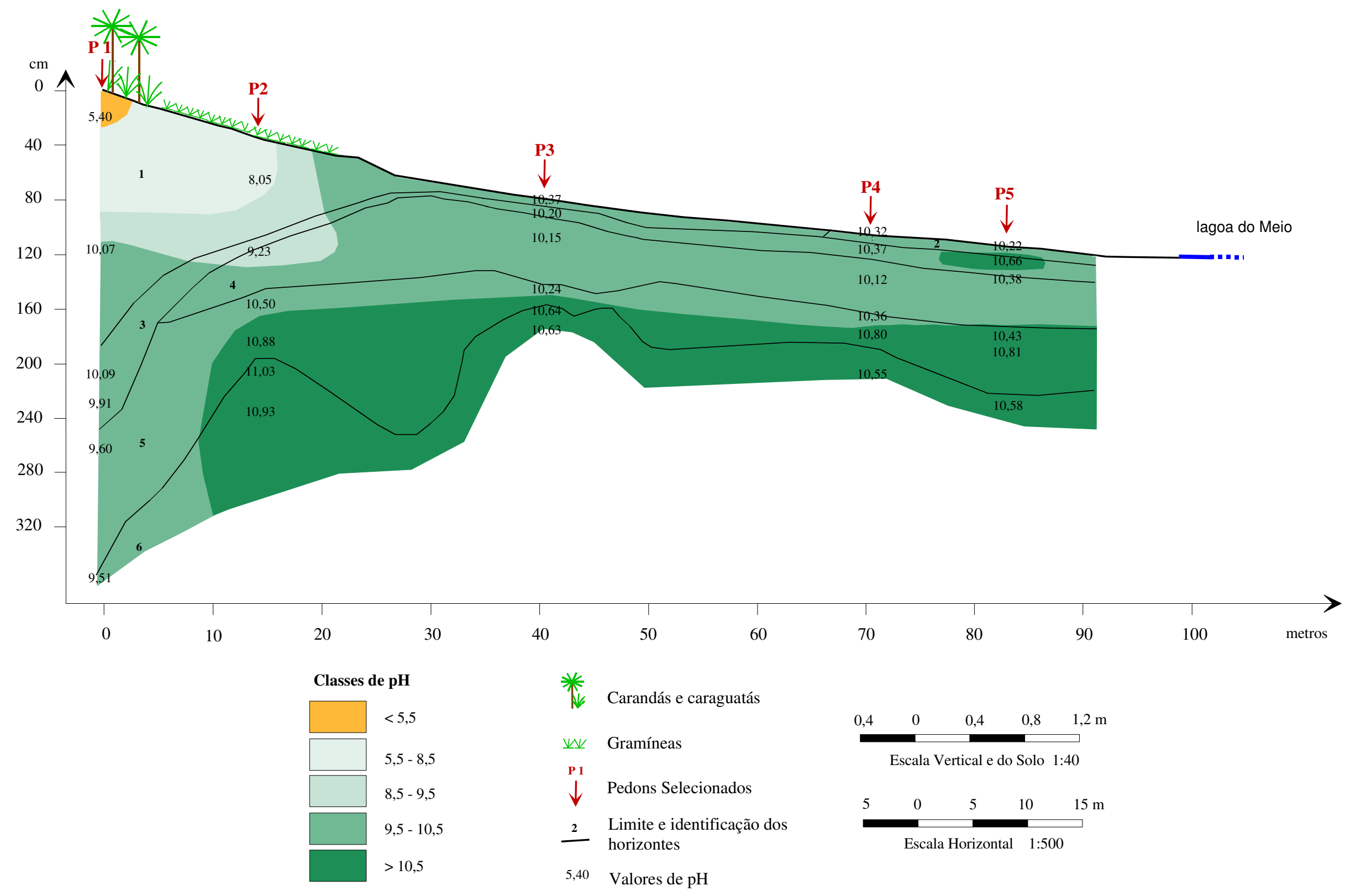

Figura 3.4 - Valores de pH ao longo da Topossequência 1 
Tabela 3.4 - Propriedades químicas de amostras de solo da Topossequência 1.

\begin{tabular}{|c|c|c|c|c|c|c|c|c|c|c|c|c|}
\hline Hor. $^{1}$ & $\begin{array}{c}\mathbf{p H} \\
\left(\mathbf{H}_{2} \mathbf{O}\right)\end{array}$ & $\begin{array}{c}\mathbf{E C} \\
\left.\text { (p.sat. }^{2}\right)\end{array}$ & $\begin{array}{l}\text { Carbono } \\
\text { Orgânico }\end{array}$ & $\mathrm{Ca}^{2+}$ & $\mathrm{Mg}^{2+}$ & $\mathbf{K}^{+}$ & $\mathbf{N a}^{+}$ & $\mathrm{Al}^{3+}$ & $\mathbf{H}^{+}+\mathrm{Al}^{3+}$ & CTC & $\mathbf{V}$ & $100 \mathrm{Na} / \mathrm{CTC}$ \\
\hline & & $\mathrm{dS} / \mathrm{m}$ & $\mathrm{g} / \mathrm{Kg}$ & \multicolumn{7}{|c|}{--------------------------------cmol $/ \mathrm{Kg}$ (----------------------------- } & \multicolumn{2}{|c|}{---------"\%--------- } \\
\hline \multicolumn{13}{|c|}{ PEDON 1} \\
\hline 1 & 5,40 & 0,35 & 8,5 & 0,20 & 0,00 & 0,03 & 3,20 & 0,19 & 1,81 & 5,43 & 63,16 & 58,93 \\
\hline 3 & 9,91 & 6,79 & 0,8 & 0,60 & 0,10 & 1,13 & 23,00 & 0,00 & 0,00 & 24,83 & 100,00 & 92,62 \\
\hline 5 & 9,60 & 7,19 & 0,5 & 1,30 & 0,30 & 2,79 & 41,00 & 0,00 & 0,00 & 45,39 & 100,00 & 90,32 \\
\hline 6 & 9,51 & 4,65 & 0,5 & 2,70 & 0,50 & 3,76 & 36,00 & 0,00 & 0,00 & 42,96 & 100,00 & 83,79 \\
\hline \multicolumn{13}{|c|}{ PEDON 2} \\
\hline 1 & 8,05 & 0,28 & 0,0 & 0,20 & 0,10 & 0,12 & 4,80 & 0,00 & 0,68 & 5,90 & 88,47 & 81,35 \\
\hline 4 & 9,23 & 0,47 & 0,0 & 0,10 & 0,00 & 0,14 & 3,80 & 0,00 & 0,40 & 4,33 & 90,76 & 87,75 \\
\hline 5 & 10,50 & 11,51 & 0,1 & 1,50 & 0,10 & 1,38 & 25,00 & 0,00 & 0,00 & 27,98 & 100,00 & 89,34 \\
\hline 6 & 11,03 & 14,92 & 0,7 & 2,80 & 0,10 & 6,72 & 80,00 & 0,00 & 0,00 & 89,62 & 100,00 & 89,26 \\
\hline \multicolumn{13}{|c|}{ PEDON 3} \\
\hline 1 & 10,37 & 9,59 & 0,8 & 3,60 & 0,20 & 2,90 & 190,00 & 0,00 & 1,60 & 198,30 & 99,19 & 95,81 \\
\hline 4 & 10,15 & 17,71 & 0,1 & 0,80 & 0,10 & 0,97 & 34,00 & 0,00 & 0,00 & 35,87 & 100,00 & 94,78 \\
\hline 5 & 10,24 & 19,20 & 0,8 & 2,30 & 1,00 & 3,22 & 82,00 & 0,00 & 0,00 & 88,52 & 100,00 & 92,63 \\
\hline 6 & 10,63 & 17,73 & 0,5 & 4,70 & 0,30 & 7,26 & 102,00 & 0,00 & 0,00 & 114,26 & 100,00 & 89,27 \\
\hline \multicolumn{13}{|c|}{ PEDON 4} \\
\hline 2 & 10,32 & 30,32 & 3,0 & 9,60 & 1,00 & 1,02 & 41,00 & 0,00 & 0,00 & 52,62 & 100,00 & 77,91 \\
\hline 4 & 10,12 & 11,43 & 0,4 & 5,10 & 1,50 & 0,82 & 29,00 & 0,00 & 0,00 & 36,42 & 100,00 & 79,91 \\
\hline 5 & 10,80 & 13,30 & 1,0 & 1,50 & 1,50 & 1,18 & 37,00 & 0,00 & 0,00 & 41,18 & 100,00 & 89,84 \\
\hline 6 & 10,39 & 11,42 & 0,5 & 5,20 & 0,70 & 2,68 & 50,00 & 0,00 & 0,00 & 58,58 & 100,00 & 85,35 \\
\hline \multicolumn{13}{|c|}{ PEDON 5} \\
\hline 2 & 10,22 & 43,01 & 21,8 & 11,80 & 0,80 & 4,08 & 190,00 & 0,00 & 0,00 & 206,68 & 100,00 & 91,92 \\
\hline 4 & 10,38 & 9,82 & 0,0 & 1,10 & 0,10 & 0,92 & 32,00 & 0,00 & 0,00 & 34,12 & 100,00 & 93,78 \\
\hline 5 & 10,81 & 13,93 & 0,3 & 0,70 & 0,00 & 2,41 & 36,00 & 0,00 & 0,00 & 39,11 & 100,00 & 92,04 \\
\hline 6 & 10,58 & 13,18 & 1,4 & 3,60 & 0,30 & 5,70 & 68,00 & 0,00 & 0,00 & 77,60 & 100,00 & 87,62 \\
\hline
\end{tabular}


dantes após o $\mathrm{Na}^{+}$, mas ambos apresentam valores baixos. Ressalta-se ainda que $\mathrm{Al}^{3+}$ e $\mathrm{Al}^{3+}+\mathrm{H}^{+}$são pouco presentes ou ausentes nas amostras.

Os testes de imersão em água, ácido e bases revelaram que em P1 e P2, 100\% do volume dos torrões pulverizaram em água, 90 a $100 \%$ em $\mathrm{HCl} 1 \mathrm{~N}, 100 \%$ em $\mathrm{NaOH}$ $1 \mathrm{M}$ e 90 a 100\% em NaOH 4M. Em P3, P4 e P5, os torrões pulverizaram em cerca de $10 \%$ do volume em água, 5 a $10 \%$ em $\mathrm{HCl} 1 \mathrm{~N}, 5$ a $10 \%$ em $\mathrm{NaOH} 1 \mathrm{M}$ e 90 a $100 \%$ em NaOH 4M.

\subsection{3 - Identificação e semi-quantificação dos minerais}

Encontrou-se uma clara diferenciação entre as assembléias minerais das diferentes frações granulométricas analisadas, uma vez que há principalmente mica, esmectita e caulinita na argila fina, quartzo e caulinita na argila grossa e quartzo no silte fino (Figuras 3.5, 3.6 e 3.7; Anexo 3). O reconhecimento destes minerais foi feito por: a) mica - presença do valor $d_{001}$ de 0,99 a $1,01 \mathrm{~nm}, d_{002}$ de 0,49 a $0,50 \mathrm{~nm}$ e $d_{003}$ de 0,33 a $0,35 \mathrm{~nm}$ nas amostras saturadas com $\mathrm{Mg}^{2+}$ e $\mathrm{K}^{+}$e nenhuma ou pequena alteração destes números após aquecimento ou impregnação com etileno glicol (EG) (Fanning et al., 1989); b) esmectita - pela presença do valor $d_{001}$ de 1,41 a $1,53 \mathrm{~nm}$ nas amostras saturadas com $\mathrm{Mg}^{2+}$, pela expansão destes picos para o intervalo de 1,70-1,86 nm nas amostras solvatadas com etileno glicol, e pelo colapso do pico saturado com $\mathrm{K}^{+}$para $1,00 \mathrm{~nm}$ após aquecimento a $350^{\circ} \mathrm{C}$ (Reid-Soukup \& Ulery, 2002); c) caulinita - pelos picos $d_{001}$ de 0,71 a $0,72 \mathrm{~nm}$ e $d_{002}$ de $0,35 \mathrm{~nm}$ nas amostras saturadas com $\mathrm{Mg}^{2+}$ e $\mathrm{K}^{+}$, sua permanência em solvatação com etileno glicol e seu desaparecimento após aquecimento a $550^{\circ} \mathrm{C}$; e d) quartzo - pelo presença dos picos $d_{101}$ de $0,33 \mathrm{~nm}$ e $d_{100}$ de $0,42 \mathrm{~nm}$ em todos os tratamentos utilizados.

Uma avaliação inicial da intensidade dos picos primários sugeriu uma maior concentração de cada um dos minerais da fração argila fina em determinados pedons e/ou horizontes da topossequência (Figura 3.5), mas não revelou um padrão importante de distribuição dos minerais das frações argila grossa e silte fino. A semiquantificação dos principais minerais da argila fina, realizada conforme os procedimentos de Biscaye (1965), confirmou as tendências iniciais (Tabela 3.5). A esmectita está presente em todos os horizontes dos pedons mais próximos a cordilheira (P1 e P2) e nos horizontes 1, 2 e 3 dos pedons sujeitos a maior variação do nível d'água da lagoa salina (P3, P4 e P5), mas concentra-se em P1 e P2 e, principal- 


\section{Pedons $\quad \mathrm{P} 1$}

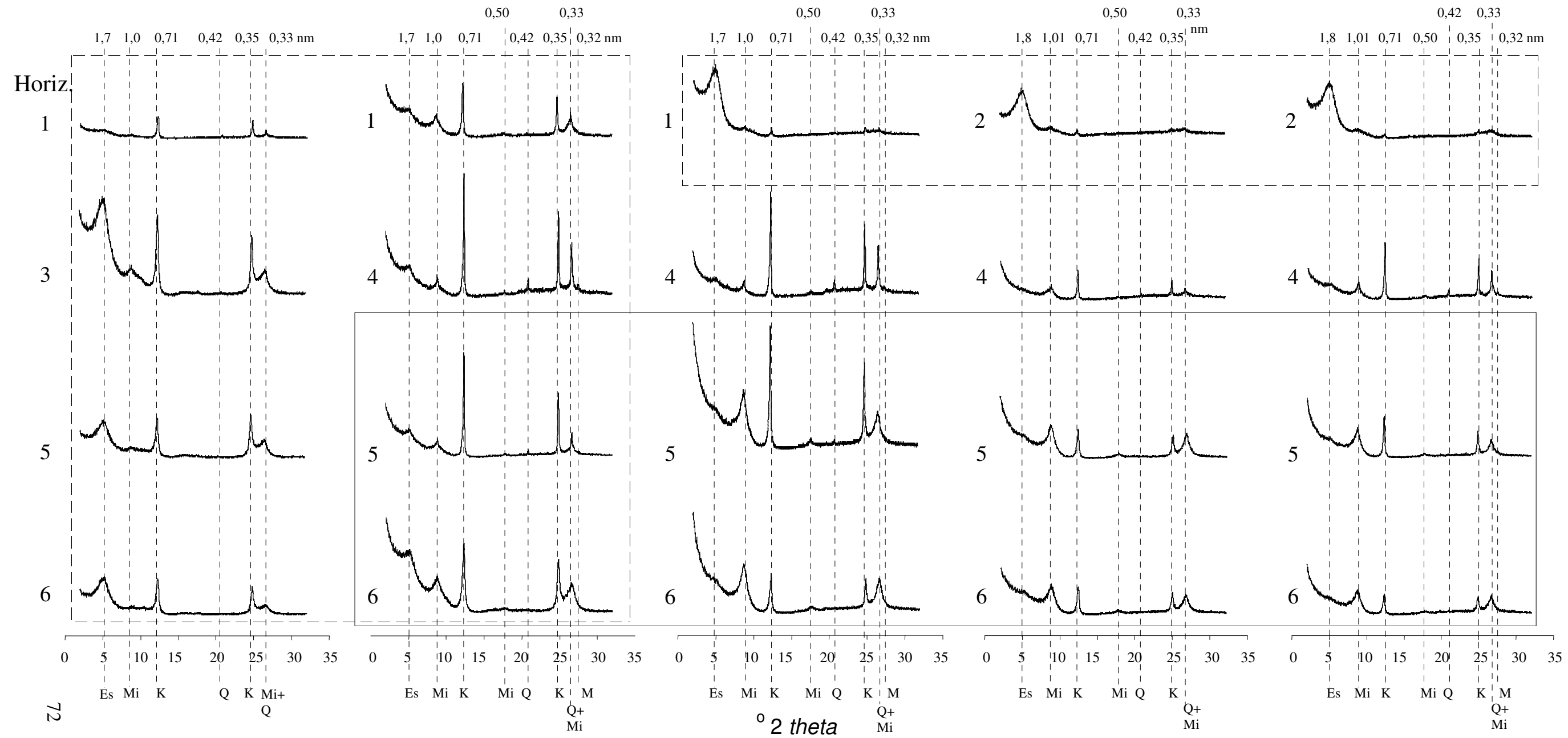

Figura 3.5 - Picos de raio-x relativos à argila fina ao longo da Topossequência 1 (tratados com Etileno Glicol). Polígonos com linha tracejada: maior concentração da esmectita; Polígono com linha cheia: maior concentração da mica. 


\section{Pedons P1}

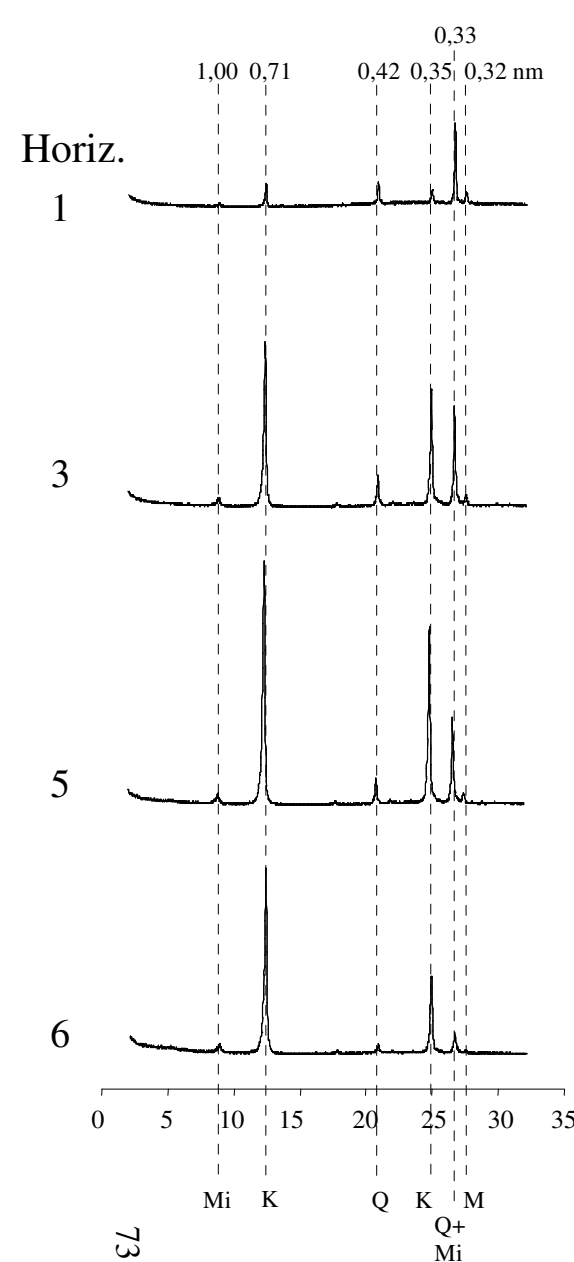

P2

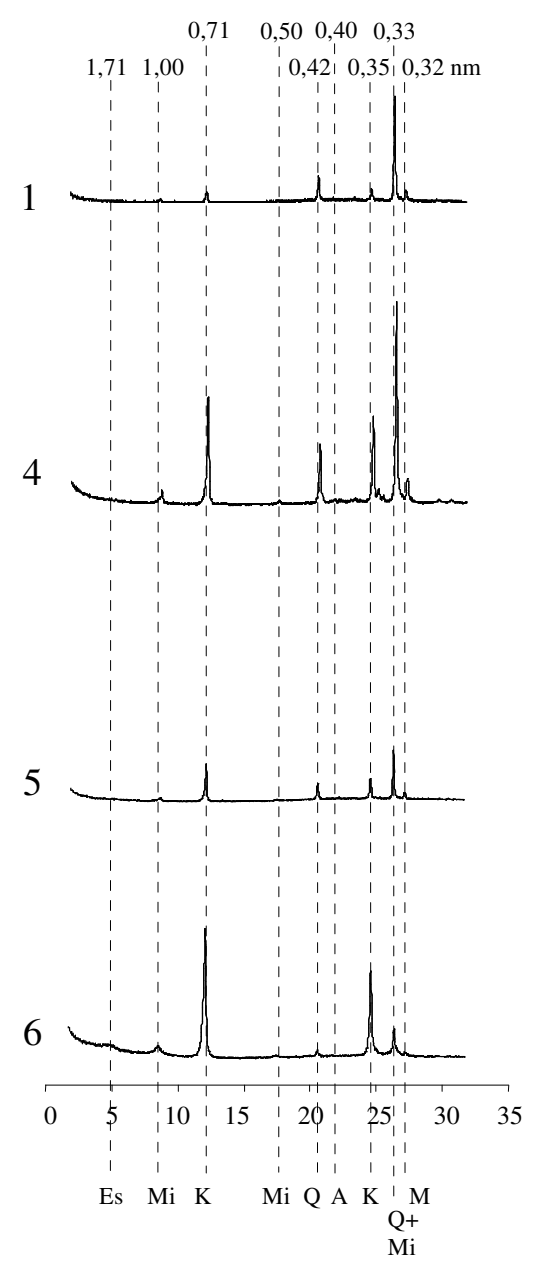

P3

P4

P5

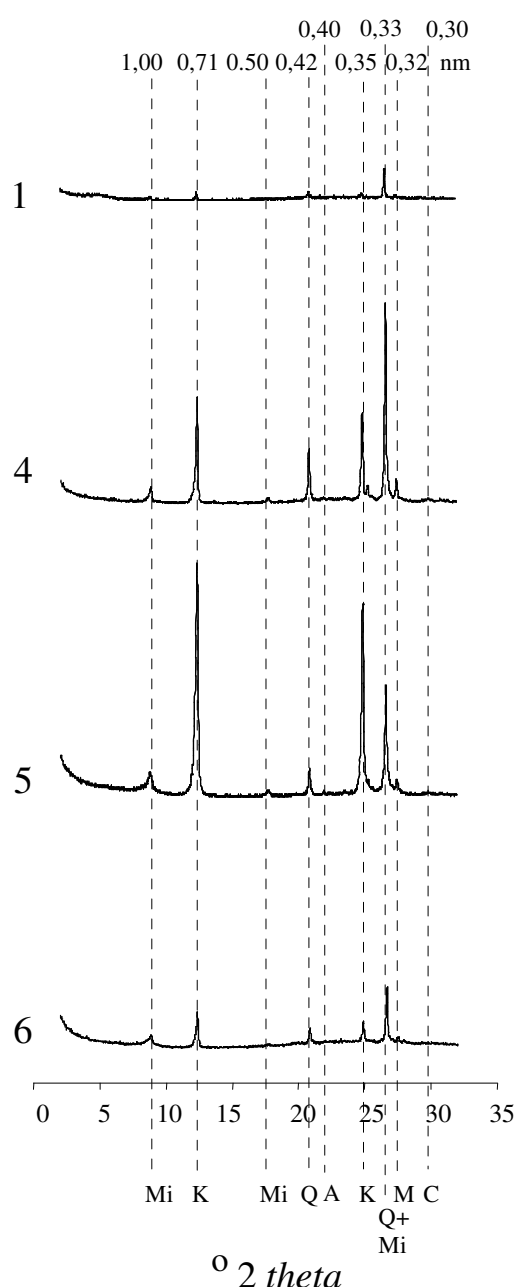

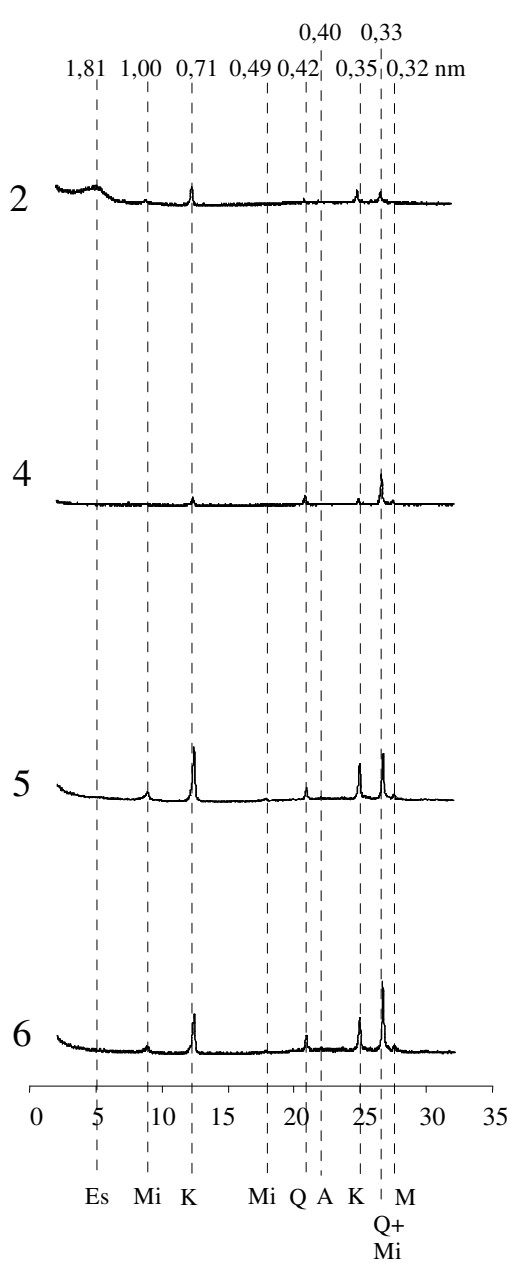

$\begin{array}{lll}0,40 & 0,33\end{array}$

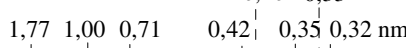

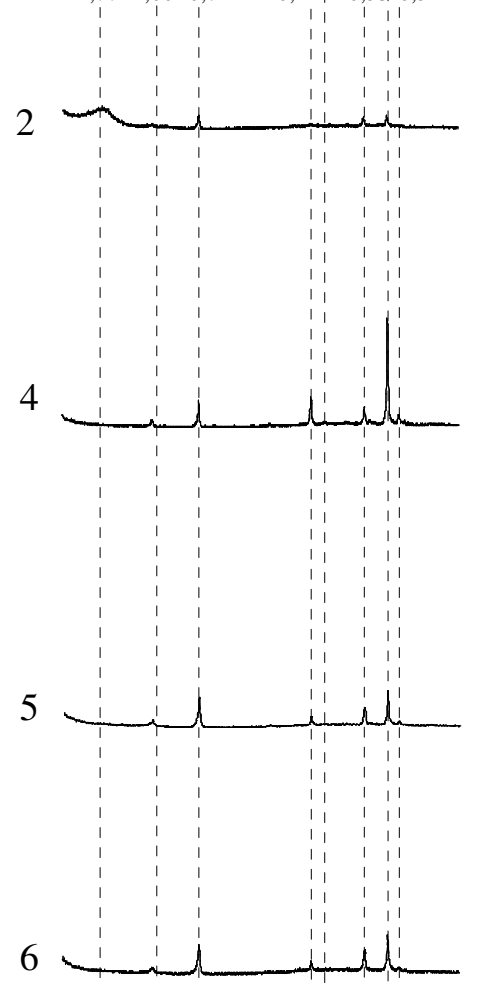

\begin{tabular}{llll:ll:llll}
\hline 0 & 5 & 10 & 15 & 20 & 25 & 30 & 35
\end{tabular}

Es Mi Q A K

Figura 3.6 - Picos de raio-x relativos à argila grossa ao longo da Topossequência 1 (tratados com Etileno Glicol). Os minerais encontrados são principalmente: K - caulinita e Q - quartzo; secundariamente há: Mi - mica, M - microclina, Es - esmectita, A - albita e C - calcita. 
$<$ Cordilheira

Pedons P1

P2

P3

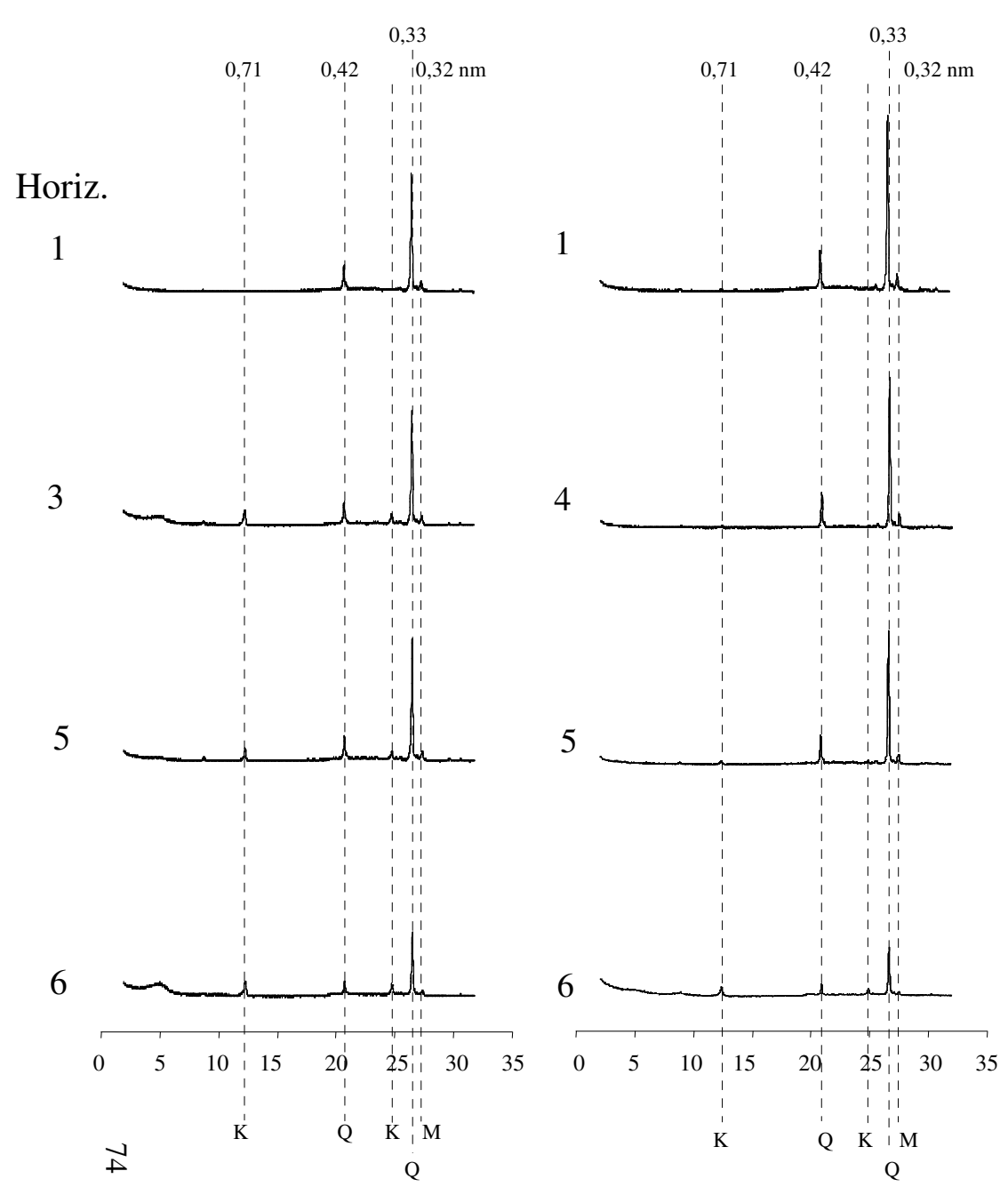

P5

Zona de maior variação sazonal do nível d’água da salina

Salina

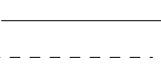

$\mathrm{P} 4$

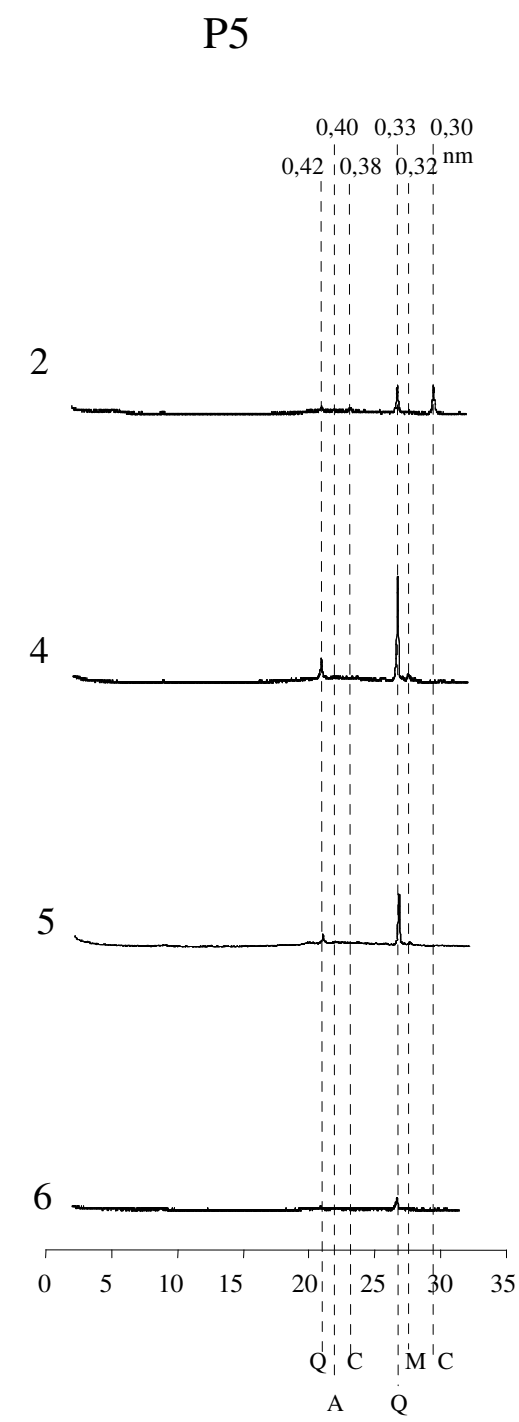

Figura 3.7 - Picos de raio-x relativos ao silte fino ao longo da Topossequência 1 (tratados com Etileno Glicol). O principal mineral encontrado é Q - quartzo; secundariamente há: M - microclina, A - albita, C - calcita e K - caulinita. 
Tabela 3.5 - Semi-quantificação dos principais minerais da argila fina

\begin{tabular}{|c|c|c|c|c|}
\hline Horizontes & Caulinita & Esmectita & $\begin{array}{ll} & \text { Mica }\end{array}$ & Quartzo \\
\hline \multicolumn{5}{|c|}{ PEDON 1} \\
\hline 1 & 50 & 17 & 32 & 0 \\
\hline 3 & 34 & 40 & 26 & 0 \\
\hline 5 & 41 & 34 & 24 & 0 \\
\hline 6 & 49 & 50 & 1 & 0 \\
\hline \multicolumn{5}{|c|}{ PEDON 2} \\
\hline 1 & 36 & 10 & 51 & 3 \\
\hline 4 & 46 & 10 & 26 & 20 \\
\hline 5 & 49 & 11 & 40 & 0 \\
\hline 6 & 35 & 14 & 52 & 0 \\
\hline \multicolumn{5}{|c|}{ PEDON 3} \\
\hline 1 & 5 & 73 & 22 & 0 \\
\hline 4 & 53 & 6 & 23 & 20 \\
\hline 5 & 29 & 0 & 71 & 0 \\
\hline 6 & 15 & 0 & 84 & 1 \\
\hline \multicolumn{5}{|c|}{ PEDON 4} \\
\hline 2 & 5 & 70 & 26 & 0 \\
\hline 4 & 29 & 0 & 71 & 0 \\
\hline 5 & 19 & 0 & 81 & 0 \\
\hline 6 & 21 & 4 & 75 & 0 \\
\hline \multicolumn{5}{|c|}{ PEDON 5} \\
\hline 2 & 4 & 69 & 27 & 0 \\
\hline 4 & 37 & 10 & 47 & 7 \\
\hline 5 & 24 & 0 & 67 & 9 \\
\hline 6 & 16 & 0 & 84 & 0 \\
\hline
\end{tabular}


mente, nos horizontes superficiais de P3, P4 e P5. Ressalta-se que o horizonte superficial de P5 apresenta estrutura prismática, provavelmente devido à presença massiva de esmectita e provavelmente à maior variação do nível da salina neste local. Já a mica e a caulinita estão presentes em toda a topossequência, mas a primeira concentra-se claramente nos horizontes profundos 5 e principalmente 6 , enquanto a segunda concentra-se em todos os horizontes dos pedons mais próximos à cordilheira (P1 e P2).

Vale destacar ainda a presença significativa de calcita no silte fino dos horizontes superficiais de P3, P4 e P5 (Figura 3.7, Anexo 3), situados na zona de maior variação do nível d'água da lagoa salina. A análise manométrica revelou quantidades muito pequenas de carbonato de cálcio equivalente nas amostras totais do solo em questão, com valores entre 1,7 e $31,9 \mathrm{~g} / \mathrm{kg}$ (Tabela 3.6). Entretanto, os dois maiores valores registrados, 31,9 $\mathrm{g} / \mathrm{kg}$ e $12,0 \mathrm{~g} / \mathrm{kg}$, estão justamente situados nos horizontes superficiais de P4 e P5, pedons que apresentam picos pronunciados de calcita.

\subsection{4 - Caracterização mineralógica da caulinita}

Os difratogramas $d_{060}$ das amostras enriquecidas em caulinita (todas de P1 e P2) apresentam picos entre 0,149 e $0,150 \mathrm{~nm}$, o que demonstra seu caráter dioctaédrico (Figura 3.8). Os índices de cristalinidade (IC) são baixos, com valores entre 0,04 e 0,07 mm (Tabela 3.7). A análise estatística ANOVA mostra que não há um padrão de variação significativo de IC de montante a jusante na topossequência $\left(\mathrm{F}_{4,15}=1,1315\right.$; $P=0,3789$ ). Quanto à profundidade, verificou-se uma variação significativa de IC $\left(\mathrm{F}_{3,16}=3,8271 ; P=0,0305\right)$, mas referente apenas a diferenças entre os horizontes 4 e 6 (Tukey test: $P=0,03282$ ).

A Tabela 3.8 apresenta os cálculos das fórmulas químicas de cristais individuais $\left(\mathrm{n}^{\circ} 1\right.$ a 6), obtidos através de dados do MET-EDS. Todas os espécimes apresentam teores de $\mathrm{Si}^{4+}$ no tetraedro superiores a 2,0 átomos por unidade de fórmula, baseados em 14 ânions (apuf/14), não havendo, portanto, substituição isomórfica por $\mathrm{Al}^{3+}$. Alumínio e $\mathrm{Fe}^{3+}$ são os únicos cátions presentes no octaedro, o que confirma o caráter dioctaédrico apontado por DRX. Os teores de $\mathrm{Al}^{3+}$ no octaedro estão entre 1,43 e 1,81 apuf/14, sendo o cátion dominante em todos os cristais. Os teores de $\mathrm{Fe}^{3+}$, por sua vez, variam de 0,08 a 0,25 apuf/14. A carga total está entre 0,00 e - 0,21 , sendo o octaedro 
Tabela 3.6 - Carbonato de cálcio equivalente nas amostras de solo total

\begin{tabular}{ccc}
\hline Pedon & Horizonte & Carbonatos $\mathbf{( g / \mathbf { k g } )}$ \\
\hline 1 & 1 & 1,7 \\
& 3 & 1,8 \\
5 & 2,1 \\
& 6 & 2,4 \\
2 & 1 & 2,3 \\
& 4 & 2,1 \\
& 5 & 3,3 \\
3 & 6 & 7,5 \\
& 1 & 5,0 \\
& 4 & 2,4 \\
4 & 5 & 3,4 \\
& 6 & 4,1 \\
& 2 & 12,0 \\
& 4 & 4,9 \\
5 & 5 & 6,1 \\
& 6 & 4,5 \\
& 2 & 31,9 \\
& 4 & 5,1 \\
& 5 & 4,8 \\
& 6 & 10,3 \\
\hline
\end{tabular}

Tabela 3.7 - Índices de Cristalinidade (IC) da caulinita na argila fina

\begin{tabular}{lcc}
\hline Pedon & Horizonte & IC da caulinita $(\mathbf{m m})$ \\
\hline 1 & 1 & 0,05 \\
& 3 & 0,06 \\
5 & 0,07 \\
& 6 & 0,07 \\
2 & 1 & 0,05 \\
& 4 & 0,05 \\
& 5 & 0,04 \\
3 & 6 & 0,06 \\
& 1 & 0,05 \\
& 4 & 0,05 \\
4 & 5 & 0,05 \\
& 6 & 0,06 \\
& 2 & 0,05 \\
& 4 & 0,04 \\
5 & 5 & 0,07 \\
& 6 & 0,07 \\
& 2 & 0,06 \\
& 4 & 0,05 \\
& 5 & 0,06 \\
& 6 & 0,07 \\
\hline
\end{tabular}




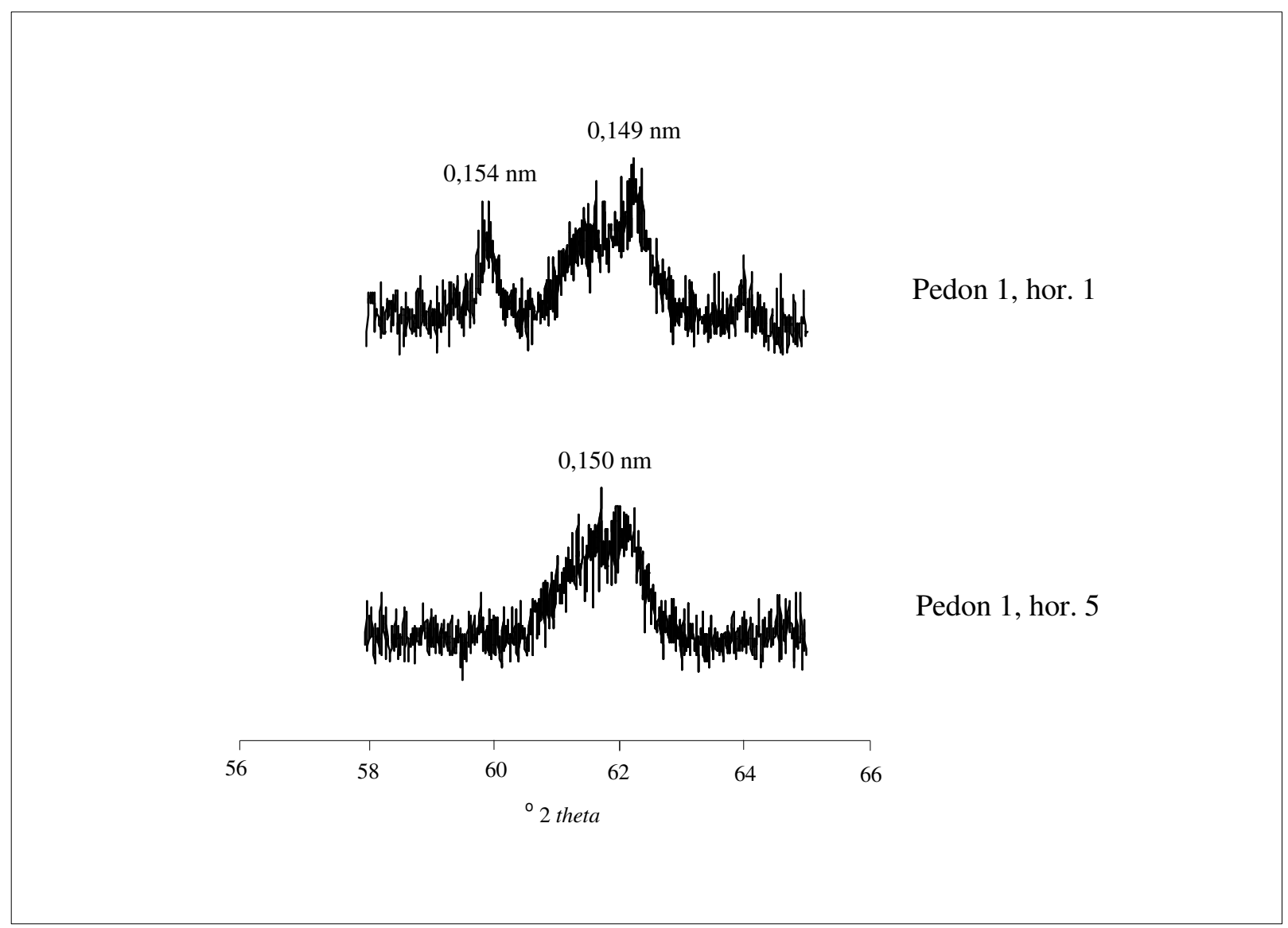

Figura 3.8 - Picos $\mathrm{d}_{060} 0,149$ e $0,150 \mathrm{~nm}$ mostrando o caráter dioctaédrico dos minerais presentes em $\mathrm{P} 1$. O pico $0,154 \mathrm{~nm}$ provavelmente representa o quartzo. 
Tabela 3.8 - Óxidos e fórmulas químicas de cristais individuais de caulinita

\begin{tabular}{|c|c|c|c|c|c|c|}
\hline & \multicolumn{6}{|c|}{ Cristais Individuais } \\
\hline & \multicolumn{3}{|c|}{ Pedon 1 , horizonte 6} & \multicolumn{3}{|c|}{ Pedon 5 , horizonte 6} \\
\hline & 1 & 2 & 3 & 4 & 5 & 6 \\
\hline$\% \mathrm{SiO}_{2}$ & 55,3 & 57,0 & 55,8 & 53,8 & 56,0 & 56,0 \\
\hline$\% \mathrm{Al}_{2} \mathrm{O}_{3}$ & 40,3 & 36,8 & 41,3 & 39,7 & 31,2 & 33,5 \\
\hline$\% \mathrm{Fe}_{2} \mathrm{O}_{3}$ & 4,4 & 6,2 & 2,7 & 5,1 & 8,6 & 7,6 \\
\hline$\% \mathrm{~K}_{2} \mathrm{O}$ & 0,0 & 0,0 & 0,2 & 1,5 & 4,3 & 2,9 \\
\hline $\mathrm{Si}^{4+}$ & 2,07 & 2,14 & 2,08 & 2,04 & 2,18 & 2,16 \\
\hline$\sum$ Tetraedro & 2,07 & 2,14 & 2,08 & 2,04 & 2,18 & 2,16 \\
\hline $\mathrm{Al}^{3+}$ & 1,78 & 1,63 & 1,81 & 1,78 & 1,43 & 1,52 \\
\hline $\mathrm{Fe}^{3+}$ & 0,13 & 0,18 & 0,08 & 0,15 & 0,25 & 0,22 \\
\hline$\sum$ Octaedro & 1,91 & 1,81 & 1,89 & 1,93 & 1,68 & 1,74 \\
\hline $\mathrm{K}^{+}$ & 0,00 & 0,00 & 0,01 & 0,07 & 0,21 & 0,14 \\
\hline Carga Tetraedro & 0,26 & 0,58 & 0,32 & 0,16 & 0,73 & 0,63 \\
\hline Carga Octaedro & $-0,26$ & $-0,58$ & $-0,33$ & $-0,24$ & $-0,94$ & $-0,77$ \\
\hline Carga Total & 0,00 & 0,00 & $-0,01$ & $-0,08$ & $-0,21$ & $-0,14$ \\
\hline Carga Entrecamada & 0,00 & 0,00 & 0,01 & 0,07 & 0,21 & 0,14 \\
\hline
\end{tabular}


totalmente responsável pela sua produção. $\mathrm{O} \mathrm{K}^{+}$é o único cátion presente na entrecamada dos cristais negativamente carregados $\left(n^{0} 3\right.$ a 6$)$.

Imagens obtidas no MET mostram que os cristais de caulinita geralmente apresentam a forma de placas hexagonais, com vértices angulares ou subangulares e laterais lisas, onduladas ou rugosas. Alguns dos cristais, entretanto, apresentam formas irregulares, que parecem preservar apenas algumas das laterais e vértices de um suposto hexágono original (Figura 3.9).

\subsection{5 - Identificação mineralógica dos nódulos}

Os nódulos ocorrem em diferentes profundidades, mas concentram-se principalmente no horizonte 5 (Tabela 3.9). O contato com $\mathrm{HCl}$ mostrou haver efervescência em $81 \%$ dos nódulos amostrados, caracterizando-os como nódulos carbonáticos. A análise manométrica confirma esta ocorrência, revelando teores de carbonato de cálcio equivalente variáveis de 6,7 a 439,6 g/kg nos nódulos que reagiram ao $\mathrm{HCl}$, sendo em geral muito maiores que os teores registrados nas amostras de solo total. Houve uma boa correlação entre o grau de efervescência e os teores de carbonato equivalente, já que reação foi nula para teores de carbonatos inferiores a $6,7 \mathrm{~g} / \mathrm{kg}$, baixa entre $6,7 \mathrm{e}$ $19,9 \mathrm{~g} / \mathrm{kg}$, média entre 58,7 e $86,6 \mathrm{~g} / \mathrm{kg}$ e alta para teores iguais ou superiores a 123,7 $\mathrm{g} / \mathrm{kg}$. Os nódulos com efervescência média a alta são principalmente de coloração preta e esverdeada.

A análise de DRX mostrou picos equivalentes a minerais carbonáticos apenas nos nódulos com efervescência média e alta e com teores de carbonato de cálcio equivalente iguais e superiores a 66,3 g/kg (Figura 3.10). Os principais carbonatos presentes são calcita $\left(\mathrm{CaCO}_{3}\right)$, dolomita $\left(\mathrm{Ca}, \mathrm{Mg}\left(\mathrm{CO}_{3}\right)\right)$ e um bicarbonato de sódio denominado nahcolita $\left(\mathrm{NaHCO}_{3}\right)$, respectivamente identificados pelos picos $d_{060}$ de $0,304 \mathrm{~nm}, 0,288 \mathrm{~nm}$ e 0,294 nm. Destacam-se ainda nos difratogramas vários picos correspondentes ao quartzo.

\subsection{6 - Química da água}

As águas superficiais e subsuperficiais coletadas no corpo d'água da lagoa do Meio e ao longo da Topossequência 1 (Pz2, G1 e G0) apresentam pH alcalino, entre 7,66 e 9,64, e um perfil químico caracterizado pelo predomínio de alcalinidade $\left(\mathrm{HCO}_{3}{ }^{-}\right.$ $\left.+\mathrm{CO}_{3}{ }^{2-}\right)$ e de $\mathrm{Na}^{+}$. Os teores de $\mathrm{Si}(\mathrm{OH})_{4}$ são em maioria altos, com valores entre 3,2 e 97,6 mg/L, havendo um aumento gradativo no sentido da lagoa salina. As concentra- 


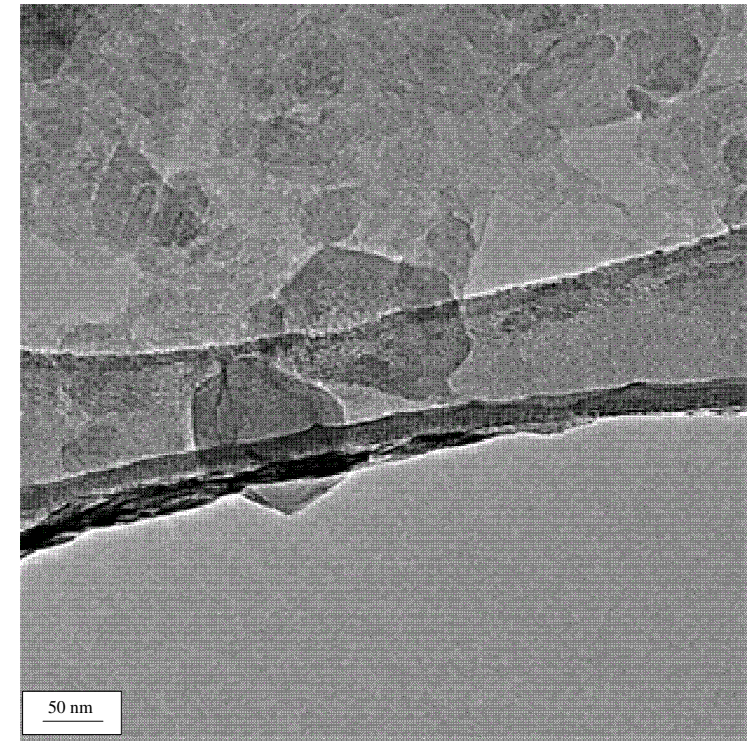

A

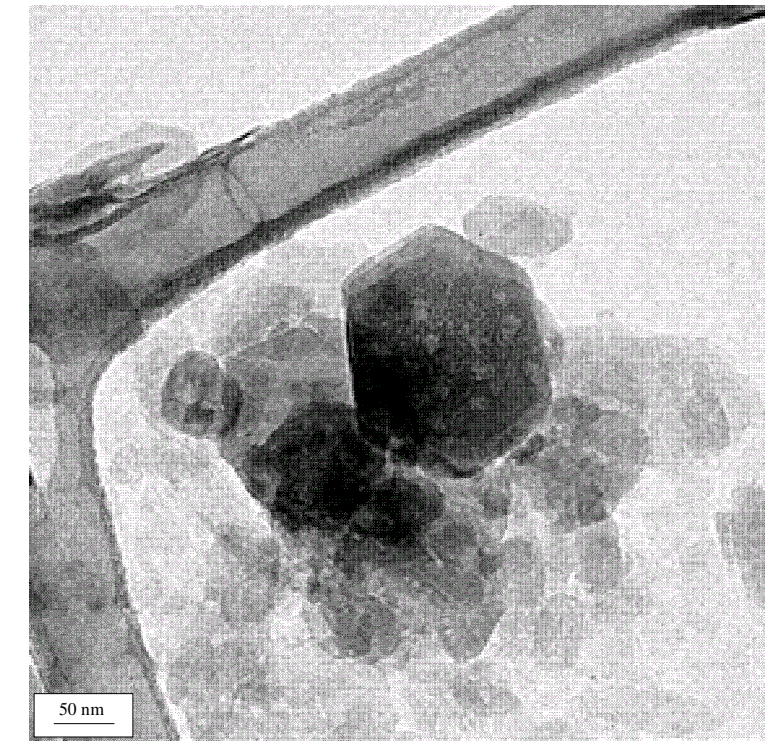

B

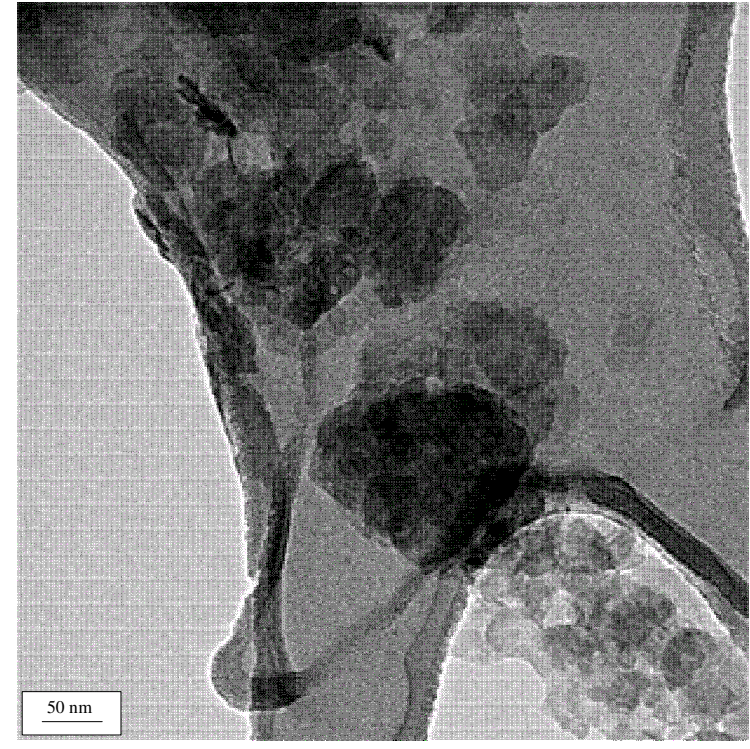

C

Figura 3.9 - Imagens de cristais de caulinita obtidas pelo MET: A) cristal n. 2 de P1, hor. 6; B) cristal n. 3 de P1, hor. 6 ; e C) cristal n. 2 de P5, hor.6 (a numeração dos cristais é a mesma da Tabela 3.8). 
Tabela 3.9 - Características químicas e mineralógicas dos nódulos

\begin{tabular}{|c|c|c|c|c|}
\hline Horizontes & Nódulos & $\begin{array}{c}\text { Efervescência } \\
\text { HCl }\end{array}$ & $\begin{array}{c}\mathrm{CaCO}_{3} \\
\mathrm{~g} / \mathrm{kg}\end{array}$ & $\begin{array}{l}\text { Minerais - } \\
\text { Carbonatos }\end{array}$ \\
\hline & & PEDON 1 & & \\
\hline 1 & 1 & Baixa & 6,7 & ---- \\
\hline 3 & 2 & Alta & 205,3 & Calcita \\
\hline 5 & 3 & Alta & 167,1 & Calcita/Nahcolita \\
\hline 5 & 4 & Não & 1,9 & ----------------- \\
\hline \multirow[t]{2}{*}{5} & 5 & Não & 0,1 & sem medição \\
\hline & & PEDON 2 & & \\
\hline 5 & 6 & Alta & 123,7 & Dolomita/Nahcolita \\
\hline 5 & 7 & Média & 58,7 & sem medição \\
\hline 5 & 8 & Não & 3,7 & 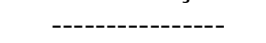 \\
\hline 5 & 9 & Alta & 143,5 & Dolomita \\
\hline 6 & 10 & Alta & 439,6 & Calcita/Dolomita \\
\hline \multirow[t]{2}{*}{6} & 11 & Alta & 159,8 & Dolomita/Nahcolita \\
\hline & & PEDON 3 & & \\
\hline 1 & 12 & Média & 66,3 & Dolomita \\
\hline 5 & 13 & Média & 72,7 & Nahcolita/Dolomita \\
\hline \multirow[t]{2}{*}{5} & 14 & Não & 4,0 & ---------------- \\
\hline & & PEDON 4 & & \\
\hline 4 & 15 & Alta & 169,2 & Calcita \\
\hline 4 & 16 & Baixa & 19,9 & ----------- \\
\hline 5 & 17 & Baixa & 8,1 & sem medição \\
\hline 5 & 18 & Baixa & 6,8 & ------------- \\
\hline \multirow[t]{2}{*}{5} & 19 & Média & 82,3 & Dolomita \\
\hline & & PEDON 5 & & \\
\hline 3 & 20 & Média & 8,66 & Calcita \\
\hline 6 & 21 & Alta & 27,03 & Dolomita \\
\hline
\end{tabular}

Tabela 3.10 - Concentrações de elementos selecionados nas águas superficiais da lagoa do Meio e nas águas subterrâneas dos arredores (cátions com duas repetições).

\begin{tabular}{|c|c|c|c|c|c|c|c|c|c|}
\hline & & \multicolumn{2}{|c|}{ Pz2 } & \multicolumn{2}{|c|}{ G1 } & \multicolumn{2}{|c|}{ G0 } & \multicolumn{2}{|c|}{ lagoa do Meio } \\
\hline $\mathrm{pH}$ & & 7,66 & -------- & 8,66 & ---------- & 9,25 & ---------- & 9,64 & --------- \\
\hline $\mathrm{HCO}_{3}+\mathrm{CO}_{3}{ }^{*}$ & $\mathrm{mEq} / \mathrm{L}$ & 29,73 & -------- & 26,49 & ---------- & 194,08 & ---------- & 67,62 & --------- \\
\hline $\mathrm{Cl}^{-}$ & & 21,58 & -------- & 15,78 & ---------- & 76,17 & ---------- & 66,64 & --------- \\
\hline $\mathrm{SO}_{4}^{2-}$ & $\mathrm{mmol} / \mathrm{L}$ & 0,48 & -------- & 0,43 & ----------- & 1,53 & ----------- & 0,48 & ---------- \\
\hline $\mathrm{Si}(\mathrm{OH})_{4}$ & & 3,2098 & 3,5155 & 36,9463 & 38,6839 & 51,4686 & 52,3721 & 97,6426 & 89,5579 \\
\hline $\mathrm{Al}^{3+}$ & & 0,0007 & 0,0007 & 0,0196 & 0,0594 & 0,0039 & 0,0040 & 0,0514 & 0,0272 \\
\hline $\mathrm{Mg}^{2+}$ & $\mathrm{mg} / \mathrm{L}$ & 1,0813 & 1,1843 & 0,0356 & 0,0372 & 0,2202 & 0,2241 & 2,2365 & 2,0513 \\
\hline $\mathrm{Ca}^{2+}$ & & 6,2313 & 6,8249 & 1,4463 & 1,4720 & 4,2313 & 4,3056 & 8,5382 & 7,8313 \\
\hline $\mathrm{Fe}$ & & 0,0826 & 0,4466 & 0,0319 & 0,0439 & 0,0120 & 0,0342 & 0,0553 & 0,0880 \\
\hline $\mathrm{Na}^{+}$ & & -------- & -------- & 982,2820 & 1028,479 & 5827,8413 & 5930,1401 & --------- & --------- \\
\hline
\end{tabular}



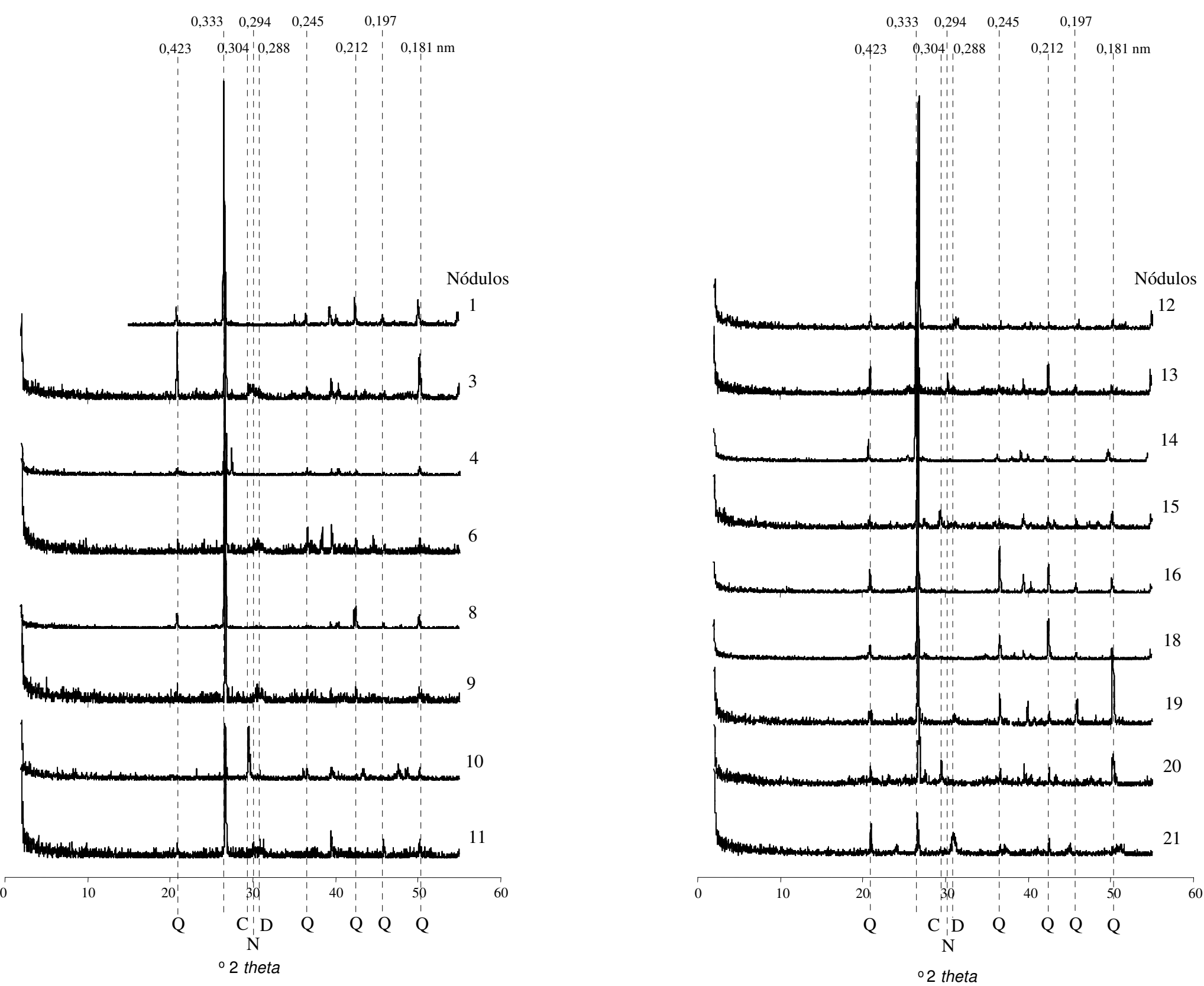

Figura 3.10 - Picos $\mathrm{d}_{060}$ dos nódulos amostrados ao longo da toposequência. Os principais minerais encontrados são: Q - quartzo; C - calcita; N - nahcolita; D - dolomita. A numeração dos nódulos é a mesma da Tabela 3.9. 
ções de $\mathrm{Al}^{3+}$ são baixas, entre 0,0007 a 0,0594 mg/L. Por fim, o $\mathrm{Mg}^{2+}$ e o $\mathrm{Ca}^{2+}$ variam de 0,03 a $2,23 \mathrm{mg} / \mathrm{L}$ e de 1,44 a $8,53 \mathrm{mg} / \mathrm{L}$, respectivamente, e apresentam maiores teores na borda da cordilheira (Pz2) e na própria lagoa do Meio (Tabela 3.10).

Os diagramas de concentração mostram que $\mathrm{Ca}^{2+}, \mathrm{Mg}^{+2}$ e $\mathrm{Si}(\mathrm{OH})_{4}$, sofrem controle com o aumento da concentração das águas, sugerindo a precipitação destes elementos em maiores salinidades (Figura 3.11).

\section{4 - Discussão dos Resultados}

\subsection{1 - Representatividade das águas e dos solos na Baixa Nhecolândia}

Os resultados das análises de águas superficiais da lagoa do Meio e subsuperficiais de seu entorno mostram grande semelhança com os estudos já feitos nas lagoas salinas da Baixa Nhecolândia. Nas águas da lagoa do Meio e arredores dominam a alcalinidade $\left(\mathrm{HCO}_{3}{ }^{-}+\mathrm{CO}_{3}{ }^{2-}\right)$ e $\mathrm{Na}^{+}$, íons já apontados como dominantes nas lagoas salinas por Cunha (1942), Brum \& Sousa (1985) e Barbiéro et al. (2002), conforme já exposto no Capítulo 2. Além disto, o estudo regional de Barbiéro et al. (2002) nas águas da Baixa Nhecolândia, apontou o controle do $\mathrm{Ca}^{2+}, \mathrm{Mg}^{2+}$ e $\mathrm{Si}(\mathrm{OH})_{4}$ com o aumento da salinidade das águas, assim como foi verificado no presente trabalho.

Uma comparação com os dados apresentados no Capítulo 2 mostra que a morfologia dos solos associados à lagoa do Meio é também bastante semelhante à identificada em outras lagoas salinas da Baixa Nhecolândia, sugerindo que os solos do presente trabalho é representativo da região. Os horizontes aqui denominados 1, 5 e 6 correspondem, respectivamente, ao horizonte arenoso superficial, ao horizonte brunado ou acinzentado, areno-argiloso e com nódulos e ao horizonte esverdeado, argilo-arenoso e pouco permeável presentes invariavelmente em todas as salinas estudadas (Sakamoto, 1997; Barbiéro et al., 2000; Fernandes, 2000; Silva \& Sakamoto, 2003; Silva et al., 2004), enquanto os horizontes identificados como 2 e 4 correspondem, respectivamente, ao horizonte preto, argiloso e pouco denso e ao horizonte arenoso com volumes verticais escuros, encontrados em algumas das salinas (Sakamoto, 1997; Silva \& Sakamoto, 2003; Silva et al., 2004).

As poucas análises químicas efetuadas por Sakamoto (1997) e Barbiéro et al. (2000) em solos dos arredores de salinas já haviam apontado para a presença de $\mathrm{pH}$ alcalino e 

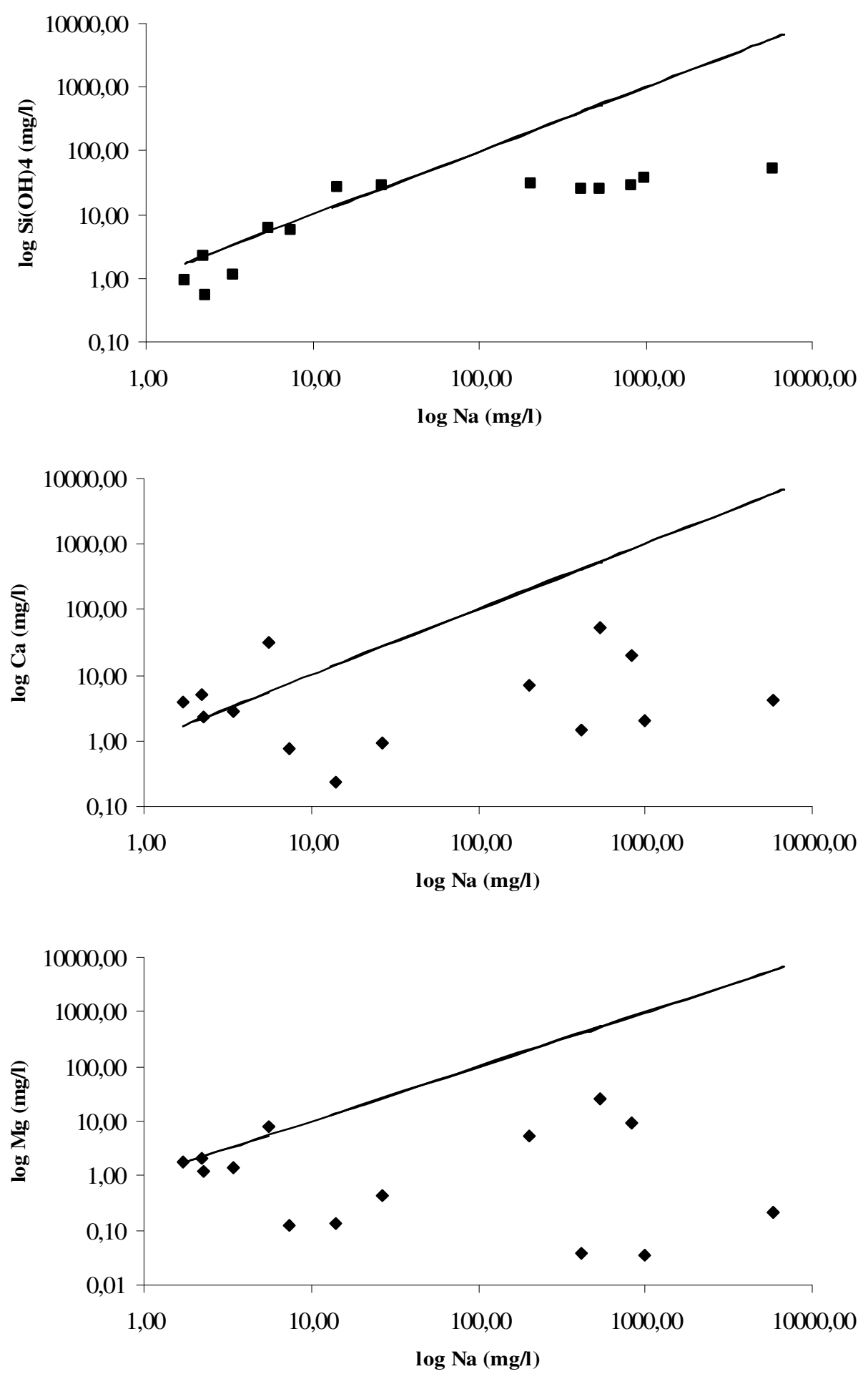

Figura 3.11 - Diagramas de concentração de $\mathrm{Si}(\mathrm{OH})_{4}, \mathrm{Ca}^{2+} \mathrm{e}$ $\mathrm{Mg}^{2+}$. A linha cheia representa o fator de concentração. 
de grande participação de $\mathrm{Na}^{+}$no complexo de troca. Os resultados apresentados no presente trabalho confirmam estas tendências, mostrando $\mathrm{pH}$ principalmente entre 8,5 e 11,0 e saturação em $\mathrm{Na}^{+}$superior a 59\%. Estas características sugerem a presença do processo geral de solonização nos solos da lagoa do Meio e das outras lagoas salinas estudadas na Baixa Nhecolândia.

\subsection{2 - $\underline{\text { A solonização e suas condições propiciadoras }}$}

A solonização inclui uma série de mecanismos que levam ao desenvolvimento de solos sódicos (Fanning \& Fanning, 1989). Em situações clássicas, inicia-se quando

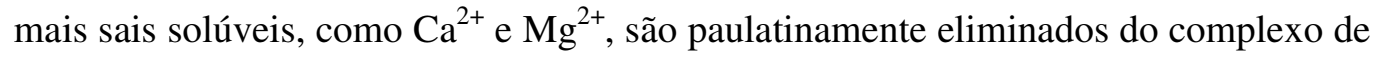
troca por lixiviação ou precipitação de minerais, sendo então substituídos por $\mathrm{Na}^{+}$ (U.S. Salinity Laboratory Staff, 1954). A hidrólise do sódio do complexo de troca ${ }^{1}$ é descrita como um dos principais mecanismos responsáveis pela elevação do $\mathrm{pH}$ a valores fortemente alcalinos (Bohn et al., 1985; Fanning \& Fanning, 1989). Tais condições levam ao desencadeamento de características morfológicas específicas nos solos, tais como estrutura colunar ou prismática no horizonte $\mathrm{B}$, feições indicativas de migração de colóides, horizontes de acumulação de argila, camadas endurecidas e presença de carbonatos e filossilicatos autigênicos (U.S. Salinity Laboratory Staff, 1954; Whittig, 1959; Fehrenbacher et al., 1963).

As principais condições ambientais apontadas na literatura como propiciadoras à instalação da solonização e o desenvolvimento de solos sódicos são: a) índices anuais de precipitação menores que os de evapotranspiração, os quais permitem a concentração das águas e dos íons solubilizados (Bohn et al., 1985); b) abundância temporária de umidade alternada com a existência de períodos secos, responsável pela expansão e contração de minerais de argila expansíveis e o conseqüente desenvolvimento de estrutura prismática ou colunar (Westin, 1953); c) topografia deprimida e alto nível do lençol freático, os quais restringem os fluxos de água nos solos, permitem o aprisionamento da água necessário para altas taxas de evaporação e diminuem a lixiviação (Westin, 1953; U.S. Salinity Laboratory Staff, 1954).

A lagoa do Meio e, de maneira geral, as lagoas salinas da Baixa Nhecolândia, apresentam todas as condições descritas acima, conforme exposto no Capítulo 2. O

${ }^{1} \mathrm{NaX}+\mathrm{H}_{2} \mathrm{O} \quad \mathrm{HX}+\mathrm{NaOH}$, onde $\mathrm{X}$ é o complexo de troca (Fanning \& Fanning, 1989). 
Pantanal Sul-Mato-Grossense caracteriza-se por uma deficiência hídrica anual superior a $300 \mathrm{~mm}$, decorrente de médias pluviométricas próximas ou inferiores a $1100 \mathrm{~mm}$ e valores de evapotranspiração potencial superiores a $1400 \mathrm{~mm}$. As precipitações são fortemente concentradas de dezembro a março, imprimindo uma clara alternância entre períodos úmidos e secos em toda a planície (Alfonsi \& Camargo, 1986). As lagoas salinas são nítidas depressões na paisagem, sempre topograficamente rebaixadas tanto em relação às cordilheiras, quanto às vazantes e baías (Sakamoto et al., 1996; Sakamoto, 1997; Capellari, 2001). Por fim, pelas medidas efetuadas, o lençol freático parece estar alto na maior parte do tempo, permanecendo no nível do horizonte 6 durante a estiagem (Barbiéro et al., 2006).

\subsection{3 - Processos pedogenéticos fundamentais associados à solonização}

As condições ambientais expostas desencadeiam a instalação de processos pedogenéticos fundamentais associados a solonização no entorno da lagoa do Meio e o conseqüente surgimento de características morfológicas específicas. Assim, ocorrem adição e translocação de matéria orgânica e transformações complexas associadas à neoformação de carbonatos, precipitação de sílica amorfa e formação de minerais de argila, conforme exposto a seguir:

\section{Adição e translocação de matéria orgânica}

Os solos sódicos são muitas vezes chamados de "black alkali" devido à acumulação de MO no horizonte superficial e sua migração ao longo do perfil (Westin, 1953; Bohn et al., 1985). A alta saturação em $\mathrm{Na}^{+}$no complexo de troca provoca a dispersão de colóides húmicos e minerais, já que íons monovalentes presentes na dupla camada difusa de um determinado colóide são pouco atraídos pelas superfícies dos colóides adjacentes (Bohn et al., 1985). A MO dispersa dos horizontes superficiais é então facilmente carregada por fluxos no interior da cobertura pedológica.

Cores características, com baixos valores e cromas, evidenciam a ocorrência de matéria orgânica (MO) principalmente nos horizontes 2 e 3 da área de estudo, provavelmente originada da decomposição de restos vegetais do cerradão e gramíneas nas proximidades da cordilheira e de algas provenientes do corpo d'água da lagoa salina na zona onde há maior variação sazonal do seu nível d'água. A presença de

volumes verticais abundantes no horizonte 4 , com origem e mesma coloração do horizonte sobrejacente 3, mostra que a MO está se movendo para maiores 
profundidades. A textura extremamente arenosa, caracterizada por mais de $90 \%$ de areia total, e a porosidade abundante conferem ao horizonte 4 uma alta permeabilidade e possibilitam um movimento vertical retilíneo da MO até o topo do horizonte 5. Ao encontrar um horizonte relativamente menos permeável, caracterizado por teores de argila dispersa entre $20 \%$ e $120 \%$ maiores e por porosidade menos abundante que o horizonte sobrejacente, a migração perfil abaixo diminui e a MO tende a acumular-se em volumes paralelos à transição entre o horizonte 4 e 5, como observado na maioria dos pedons descritos.

Ressalta-se, entretanto, que apesar das evidências morfológicas da presença de MO e de sua translocação perfil abaixo, as amostras analisadas mostram que os teores de carbono orgânico (CO) são em geral bastante baixos em todos os horizontes, sem diferenças significativas entre eles. O único valor relativamente alto de $\mathrm{CO}$ é do horizonte 2 de P5, mas parece ser pontual, uma vez que este pedon provavelmente permanece submerso pela lagoa por um tempo mais longo que os outros, recebendo então maior quantidade de algas. Valores muito baixos de $\mathrm{CO}$ em horizontes que, por análise de campo, pareciam ricos em MO já haviam sido verificados por Cunha (1980), em solo arenoso de uma cordilheira, e Sakamoto (1997), em solo arenoso de uma lagoa salina.

O CO correlaciona-se negativamente aos valores e cromas dos solos (Konen et al., 2003), mas solos arenosos necessitam de menor quantidade de CO para apresentar os mesmos valores ou cromas de solos de textura média ou argilosa. Isto porque a matéria orgânica tende a envolver as partículas de areia e como estas possuem baixa capacidade de espalhamento da luz visível, pequenas quantidades de pigmento são necessárias para escurecer os grãos (Schulze et al., 1993). Este fenômeno deve ser o responsável pela coloração escura dos horizontes arenosos 2 e 3. Junta-se ainda o fato de que, na área de estudo, a matéria orgânica encontra-se dispersa e, portanto, disponível para envolver um número maior de partículas e fornecer baixos valores e cromas em maiores volumes.

\section{Neoformação de carbonatos}

A precipitação de carbonatos tem sido observada em solos salinos ou sódicos, caracterizados por serem freqüentemente submetidos à concentração das soluções devido a altas taxas de evaporação (Fehrenbacher et al., 1963; Mahjoory, 1979; Kohut 
\& Dudas, 1995). Este processo é inclusive apontado como um dos responsáveis pela transformação de solos salinos em sódicos, uma vez que a precipitação de carbonatos de cálcio e magnésio diminui a concentração destes cátions nas soluções, aumentando, portanto, as concentrações de sódio tanto nas soluções quanto no complexo de troca (U.S. Salinity Laboratory Staff, 1954).

Os carbonatos alcalino-terrosos, pouco solúveis, são normalmente os primeiros a se precipitarem no processo de concentração, estando entre estes a calcita e dolomita (Eugster \& Hardie, 1978; Boettinger \& Richardson, 2001). A calcita contém menos de $5 \mathrm{~mol} \%$ de $\mathrm{MgCO}_{3}$ em sua composição, já que a relação $\mathrm{Mg}^{2+} / \mathrm{Ca}^{2+}$ das soluções diluídas que tipicamente lhe dão origem é normalmente baixa $(<1)$. Porém, com a continuidade do processo de precipitação deste mineral, a relação $\mathrm{Mg}^{2+} / \mathrm{Ca}^{2+}$ da água aumenta e, por conseqüência, há um aumento do conteúdo de $\mathrm{Mg}^{2+}$ nas precipitações subsequientes dos carbonatos, originando-se minerais como a dolomita (Eugster \& Hardie, 1978).

Os diagramas de concentração expostos na Figura 3.11 mostram que há uma tendência à diminuição das concentrações de $\mathrm{Ca}^{2+}$ e do $\mathrm{Mg}^{2+}$ com o aumento da salinidade das águas superficiais e subsuperficiais associadas à lagoa do Meio, fato concordante com os resultados do estudo regional efetuado por Barbiéro et al. (2002), conforme já exposto. $\mathrm{O}$ controle destes cátions bivalentes nas águas mais salinas sugere seu envolvimento na precipitação de carbonatos de cálcio e de magnésio nos arredores da lagoa, uma vez que os limites de solubilidade destes minerais são os primeiros a serem excedidos no processo de concentração. A ocorrência de nódulos com até $440 \mathrm{~g} / \mathrm{kg}$ de carbonato de cálcio equivalente e a presença de minerais carbonáticos, identificados principalmente como calcita e dolomita, confirmam plenamente as sugestões fornecidas pela química das águas e atestam a neoformação destes minerais nos solos.

Os nódulos carbonáticos estão presentes ao longo de toda a topossequência, mas concentram-se principalmente no horizonte 5. O lençol freático (L.F.) dos arredores da salina, conforme comentado no Capítulo 2, flutua principalmente entre os horizontes superficiais ( 1 e 2) na estação úmida e o topo do horizonte esverdeado (6) na estação seca (Barbiéro et al., 2006). No processo de rebaixamento do L.F. entre os níveis máximos registrados, as águas devem atingir o horizonte 5 em concentrações ideais para a precipitação de calcita e, posteriormente, dolomita. 
Solubilização e precipitação de sílica amorfa

A consistência seca muito dura a extremamente dura e a consistência úmida muito firme a extremamente firme do horizonte 6 em P3, P4 e P5 remetem à presença de um agente cimentante. Os resultados obtidos nos testes de imersão em ácido e base sugerem que este horizonte encontra-se cimentado por sílica amorfa, uma vez que esta é insolúvel em $\mathrm{HCl} 1 \mathrm{~N}$ (Fanning and Fanning, 1989), mas solúvel em $\mathrm{NaOH}$ concentrado (Kodama \& Ross, 1991). A presença de horizontes cimentados por sílica amorfa, conhecidos como duripans, é comum em solos sujeitos a pequena lixiviação, mas com presença suficiente de água para translocar a sílica ao longo do perfil (Flach et al., 1969), condições alcançadas na área de estudo.

A solubilização da sílica depende de uma série de fatores, destacando-se o $\mathrm{pH}$ e a temperatura do meio (Drees et al., 1989). A concentração de $\mathrm{Si}(\mathrm{OH})_{4}$ em soluções aquosas permanece baixa até $\mathrm{pH}$ 8,5 e aumenta exponencialmente após pH 9 (Krauskopf, 1956). Temperaturas mais altas também favorecem sua solubilização, sendo que um aumento de $15^{\circ}$ para $40^{\circ} \mathrm{C}$ pode ser o suficiente para aumentar o fator de concentração em 2 a 3 unidades (Hamrouni \& Dhahbi, 2001). De fato, as condições vigentes nos solos do entorno da lagoa do Meio são favoráveis para a solubilização da sílica, já que o pH é fortemente alcalino na maioria da topossequência e, como já explicitado no Capítulo 2, as temperaturas máximas absolutas ultrapassam $40^{\circ} \mathrm{C}$ na Fazenda Nhumirim entre janeiro e setembro (Soriano, 1996).

A precipitação de sílica, por outro lado, parece ser controlada principalmente pela sua atividade e pH (Chadwick et al., 1987a). Para a precipitação de compostos amorfos ou mal cristalizados como opala-A e opala-CT são necessárias, respectivamente, concentrações $>20 \mathrm{mg} / \mathrm{L}$ e $>60 \mathrm{mg} / \mathrm{L}$ de $\mathrm{Si}(\mathrm{OH})_{4}$ (Chadwick et al., 1987b), valores provavelmente encontrados apenas em soluções básicas (Bohn et al., 1985). A diminuição do $\mathrm{pH}$ para valores inferiores a 9 favorece a precipitação, uma vez que a solubilidade da sílica diminui fortemente.

O diagrama de equilíbrio elaborado pelo Prof. Dr. Vincent Vallés ("Université de Provence”, França), apresentado a seguir na Figura 3.12, mostra que as amostras de água mais próximas da lagoa do Meio estão próximas ou em equilíbrio com a sílica amorfa, sugerindo que está havendo precipitação nos arredores da salina. De fato, as 


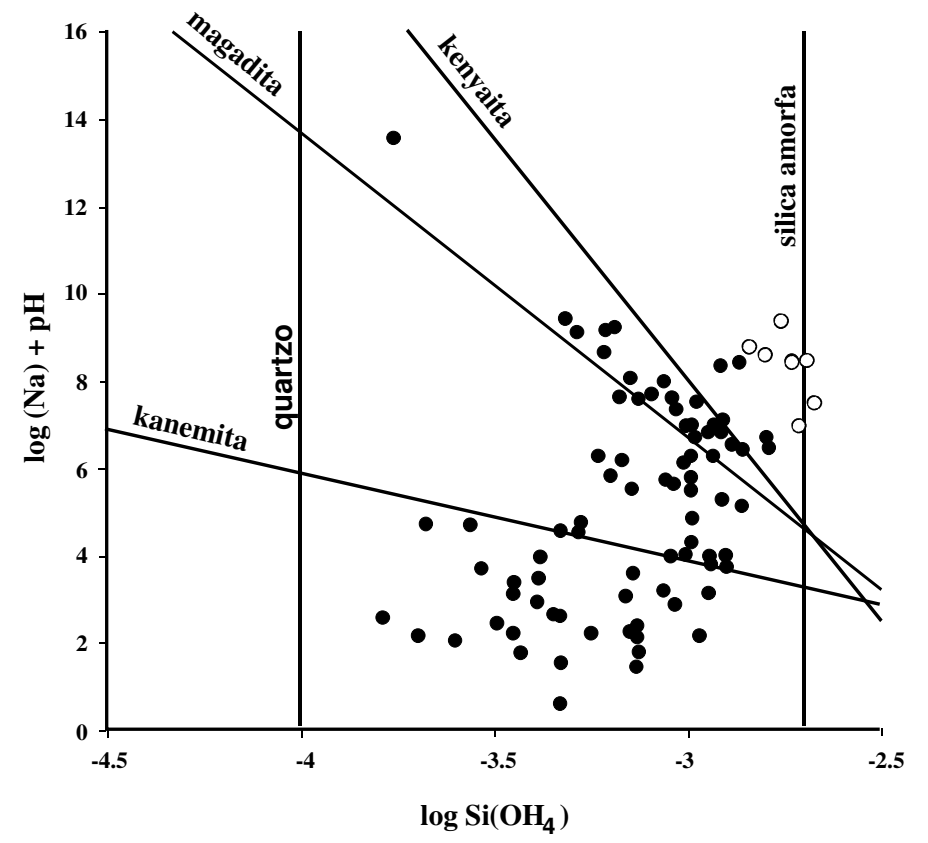

Figura 3.12 - Diagrama de equilíbrio entre as águas analisadas e diferentes minerais (elaborado pelo Prof. Dr. Vincent Valles). Círculos vazados representam amostras dos arredores da lagoa do Meio (Pz2, G0, G1, G2 e lagoa). 
concentrações de sílica nas águas são em maioria comparáveis àquelas consideradas por Chadwick et al. (1987b) como suficientemente altas para permitir a sua precipitação. Deste modo, é bastante provável que o $\mathrm{pH}$ diminua em períodos de grandes cheias, alternados com períodos de mínima seca no local, permitindo a ocorrência de precipitação.

Cabe destacar ainda que, diferentemente dos Pedons 3 a 5, os fragmentos do horizonte 6 em P1 e P2 foram pulverizados em água, $\mathrm{HCl} 1 \mathrm{~N}, \mathrm{NaOH} 1 \mathrm{M}$ e $\mathrm{NaOH} 4 \mathrm{M}$. Estes resultados, aliados ao fato destas amostras apresentarem consistência muito dura e firme, enquadram o horizonte 6 destes pedons como um fragipan. É possível que o grau de cimentação com sílica em P1 e P2 não seja o suficiente para um endurecimento irreversível (Fanning \& Fanning, 1989), mas isto pode ser confirmado apenas com futuras análises de dissolução seletiva.

\section{Gênese de minerais de argila}

Altos valores de $\mathrm{pH}$ conduzem não apenas à solubilização da sílica, mas também do alumínio (Bohn et al., 1985). Desta forma, é esperado que, em determinadas condições ambientais, o $\mathrm{Si}(\mathrm{OH})_{4}$ precipite-se não apenas como sílica amorfa, mas se recombine com $\mathrm{Al}^{3+}$ e cátions básicos e envolva-se na formação de minerais de argila. De fato, a formação autigênica de argilo-minerais tem sido amplamente registrada em solos submetidos a condições fortemente alcalinas (Whittig, 1959; Abtahi, 1977; Mahjoory, 1979). Como já citado nos Materiais e Métodos, indícios de formação autigênica de esmectita e mica, ambos presentes na argila fina, levaram a uma análise mais detalhada destes grupos de minerais nos capítulos 4 e 5, respectivamente.

A caulinita, o outro mineral dominante na argila fina, parece contudo ter uma origem alóctone. Diagramas de estabilidade disponíveis na literatura mostram que este mineral é estável em baixos valores de $\mathrm{pH}-\mathrm{p} K$ e de $\mathrm{pSi}(\mathrm{OH})_{4}$, condições vigentes em solos ácidos e lixiviados (Bohn et al., 1985). Em condições ambientes de temperatura e pressão, a caulinita forma-se como um produto de intemperismo de uma série de minerais primários e secundários, que passam por perdas parciais de cátions básicos e sílica (Murray \& Keller, 1993). Solos bem drenados e submetidos a altas taxas de precipitação favorecem a lixiviação e a conseqüente acidificação dos solos, sendo por isto ideais para sua gênese (Tardy et al., 1973, Velde, 1995). 
O solos presentes no entorno da lagoa do Meio são mal drenados, fortemente alcalinos e apresentam alta saturação por bases trocáveis. Possuem, desta forma, condições opostas às ideais para formação de caulinita, o que sugere que este mineral não se formou nos arredores da lagoa do Meio. Algumas características dão suporte à esta hipótese: 1) seus índices de cristalinidade (IC) não apresentam uma tendência clara de variação em profundidade e ao longo da topossequência; diferentes IC poderiam refletir diferenças nas condições geoquímicas ao longo da topossequência e indicar autigênese deste mineral; 2) argilas neoformadas tendem a se concentrar na fração argila fina, mas há forte presença de caulinita tanto na argila fina quanto na argila grossa; e 3) na fração argila fina, a caulinita ocorre em maioria já nas proximidades da cordilheira, fora do alcance da zona de maior flutuação sazonal da lagoa salina, e em horizontes de pequena profundidade, menos influenciados pelas flutuações do lençol freático.

Assim, é provável que a caulinita da área de estudo tenha sido transportada pelo rio Paraguai e seus afluentes principalmente durante as cheias e depositada junto com os sedimentos arenosos da Formação Pantanal. Como já explicitado no Capítulo 2, as áreas-fonte destes sedimentos localizam-se essencialmente no Planalto de Maracaju, de onde são provenientes grande parte das nascentes dos cursos d'água que banham a região. Os solos aí dominantes são propícios para a formação de caulinita, pois são Areias Quartzosas álicas, ácidas e bem drenadas (atualmente Neossolos Quartzarênicos-Embrapa, 2006), muito semelhantes aos Latossolos de textura média presentes nos arredores (Orioli et al., 1982). Além disto, caulinitas com maiores teores de $\mathrm{Fe}^{3+}$ do que a média esperada, tal como as presentes nos solos da lagoa do Meio, parecem ser relativamente comuns em solos dos meios tropicais (Herbillon, 1976).

Por outro lado, experimentos de dissolução da caulinita em temperatura e pressão ambientes mostram que as concentrações de $\mathrm{Si}(\mathrm{OH})_{4}$ e $\mathrm{Al}^{3+}$ dissolvidos são muito altas em pH fortemente ácidos $(\leq 3)$ e fortemente alcalinos $(\geq 10)$, sendo a taxa de dissolução dependente da atividade de prótons e hidroxilas, respectivamente (Huertas et al., 1999). Como uma grande parte dos valores de $\mathrm{pH}$ das águas e dos solos são fortemente alcalinos, a caulinita presente na área de estudo está provavelmente sofrendo dissolução e liberando localmente $\mathrm{Si}^{4+}, \mathrm{Al}^{3+}$ e $\mathrm{Fe}^{3+}$ para solução. Cristais 
hexagonais de caulinita com vértices arredondados e laterais onduladas ou rugosas e cristais com formas irregulares parecem ser evidências deste processo.

\subsection{4 - $\underline{\text { Classificação dos solos }}$}

Os horizontes 1, 2 e 4 foram classificados, respectivamente, como horizontes A, H e E, mas o horizonte 3 não se enquadrou perfeitamente em nenhuma definição de horizonte pedogenético ou diagnóstico (Oliveira, 2005). O horizonte 5 atende aos requisitos para horizonte diagnóstico glei e destaca-se pelo caráter sódico e carbonático, sendo então denominado de Bkng. O horizonte 6, por sua vez, enquadrase tanto como horizonte glei em toda a topossequência quanto como fragipã em P1 e P2 e duripã em P3, P4 e P5. Estas características aliadas ao seu caráter sódico conferiram-lhe a denominação de Bnxg em P1 e P2 e Bqng em P3, P4 e P5 (Embrapa, 2006).

Apesar dos horizontes Bkng (5) e Bnxg (6) estarem presentes ao longo de toda a topossequência, eles não puderam ser incluídos na classificação de P1 por estarem situados abaixo do limite de profundidade padrão estabelecido pelo Sistema Brasileiro de Classificação de Solos (SiBCS). Desta forma, este pedon foi enquadrado como Neossolo Quartzarênico Órtico, êutrico. A presença do horizonte diagnóstico Bkng dentro de $150 \mathrm{~cm}$ de profundidade e a ocorrência de caráter sálico $(\mathrm{CE}>7 \mathrm{dS} / \mathrm{m})$ e de caráter sódico $(100 \mathrm{Na} / \mathrm{CTC} \geq 15 \%)$ dentro de $100 \mathrm{~cm}$ classificam P2, P3, P4 e P5 como Gleissolo Sálico Sódico, típico (Embrapa, 2006).

\section{5 - Conclusões}

A ocorrência de processos pedogenéticos fundamentais ligados à solonização confirma a presença de solo em todo o entorno da lagoa do Meio, apesar da ausência parcial de vegetação. A alta saturação em sódio e o $\mathrm{pH}$ fortemente alcalino foram responsáveis pelo desenvolvimento de características morfológicas típicas de solos sódicos, tais como feições indicativas de migração de colóides, camadas endurecidas e presença de carbonatos de cálcio, magnésio e sódio neoformados.

Como os solos e as águas relacionadas à lagoa do Meio parecem ser representativos da Baixa Nhecolândia, é possível que a solonização e os processos pedogenéticos fundamentais associados sejam os principais responsáveis pela gênese dos solos do entorno das lagoas salinas. A provável alta saturação em $\mathrm{Na}^{+}$nos solos associados às 
salinas da Baixa Nhecolândia não é retratada, entretanto, no mapa de distribuição dos teores de $\mathrm{Na}^{+}$no complexo sortivo do Pantanal (Figura 2.15, p. 39), organizado por Amaral Filho (1986) e apresentado no Capítulo 2.

Ressalta-se, ainda, que a formação de Podzóis Hidromórficos, tal como sugerido por Sakamoto (1997) e Fernandes (2000), parece não ser possível nas proximidades destas lagoas. Apesar do processo de podzolização ter características morfológicas em comum com o de solonização, tal como a acumulação e migração de matéria orgânica, o primeiro desenvolve-se essencialmente em condições ácidas e o segundo em condições fortemente alcalinas.

\section{6 - Referências Bibliográficas}

Abtahi, A. (1977) Effect of a saline and alkaline ground water on soil gênesis in semiarid Southern Iran. Soil Science Society of America Journal, 41, 583-588.

Alfonsi, R.R. \& Camargo, M.B.P. (1986) Condições Climáticas para a Região do Pantanal Matogrossense. Pp. 29-42 in: Anais do $1^{\circ}$ Simpósio sobre Recursos Naturais e Sócio-Econômicos do Pantanal, 27 de novembro a 4 de dezembro de 1984, Corumbá (MS).

Amaral Filho, Z.P. (1986) Solos do Pantanal Matogrossense. Pp. 91-103 in: Anais do $1^{\circ}$ Simpósio sobre Recursos Naturais e Sócio-Econômicos do Pantanal, 27 de novembro a 4 de dezembro de 1984, Corumbá (MS),.

Anderson, J.U., (1963). An improved pretreatement for mineralogical analysis of samples containing organic matter. Clays and Clay Minerals, 10, 380-388.

Araújo Filho, J.C. (2004) Horizontes cimentados em Argissolos e Espodossolos dos tabuleiros costeiros e em Neossolos Regolíticos e Planossolos da depressão sertaneja no Nordeste do Brasil. Tese de Doutorado, Instituto de Geociências, Universidade de São Paulo.

Barbiéro, L.; Queiroz Neto, J.P.; Sakamoto, A.Y. (2000) Características Geoquímicas dos Solos Relacionadas à Organização Pedológica e à Circulação da Água (Fazenda Nhumirim: EMBRAPA CPAP, Nhecolândia, MS). Pp. 90-100 in: Anais do $3^{\circ}$ Simpósio sobre Recursos Naturais e SócioEconômicos do Pantanal, Corumbá (MS).

Barbiéro, L. Queiroz Neto, J.P. Ciornei, G. Sakamoto, A.Y. Capellari, B. Fernandes, E. Valles, V., (2002). Geochemistry of water and ground water in the Nhecolândia, Pantanal of Mato Grosso, Brazil: variability and associated processes. Wetlands, 22, 528-540.

Barbiéro L.; Furquim, S.A.C.; Vallès, V.; Furian, S.; Sakamoto, A. (2006) Natural Arsenic in Groundwater and Alkaline Lakes at the Upper Paraguay Basin, Pantanal, Brazil. In: Arsenic in Soil and Groundwater Environments: Biogeochemical Interactions (P. Bhattacharya, A.B. Mukherjee, R.H. Loeppert, R.H., editors), Elsevier Book Series.

Biscaye, P. (1965) Mineralogy and sedimentation of recent deep-sea clay in the Atlantic Ocean and adjacent seas and oceans. Geological Society of America Bulletin, 76, 803-832.

Boettinger, J.L. \& Richardson, J.L. (2001) Saline and wet soils of wetlands in dry climates. Pp: 383390 in: Wetland soils. Genesis, hydrology, landscapes, and classification (J.L. Richardson and M.J. Vepraskas, eds). Lewis Publishers, New York.

Bohn, H.L.; McNeal, B.L.; O’Connor, G.A. (1985) Soil Chemistry. A Wiley-Interscience Publication , John Wiley and Sons, New York, 341 p.

Boulet, R. (1992) Uma evolução recente da pedologia e suas implicações no conhecimento da gênese do relevo. Pp.43-51 in: Anais do III Congresso ABEQUA. Belo Horizonte. 
Brum, P.A.R \& Sousa, J.C. (1985) Níveis de Nutrientes minerais para gado, em lagoas ("baías" e "salinas") no Pantanal sul-matogrossense. Pesquisa Agropecuária Brasileira, 20, 1451-1454.

Cantarella, H.; Raij, B.V.; Coscione, A.R.; Andrade, J.C. (2001) Determinação de alumínio, cálcio e magnésio trocáveis em extrato de cloreto de potássio. Pp.189-199 in: Análises químicas para avaliação da fertilidade de solos tropicais (B.V. Raij; J.C. Andrade; H. Cantarella; J.A. Quaggio, eds.). IAC. Campinas.

Capellari, B. (2001) Sensoriamento Remoto Aplicado ao Estudo da Dinâmica Hidrológica da região da Nhecolândia, Pantanal Matogrossense, MS. Dissertação de Mestrado, FFLCH, USP.100 p.

Chadwick, O.A.; Hendricks, D.M.; Nettleton, W.D. (1987a) Silica in Duric Soils: I - A depositional model, 51, 975-982.

Chadwick, O.A.; Hendricks, D.M.; Nettleton, W.D. (1987b) Silica in Duric Soils: II - Mineralogy, 51, 982-985.

Cunha, J. (1942) Cobre do Jauru e lagoas alcalinas do Pantanal (Mato Grosso). Boletim do Laboratório de Produção Mineral, 6, 1-43.

Cunha, N.G. (1980) Considerações sobre os solos da sub-região da Nhecolândia, Pantanal MatoGrossense. Circular Técnica Embrapa, 1, 1-45.

Darragi, F.\& Tardy, Y. (1987) Authigenic trioctahedral smectites controlling pH, alkalinity, sílica, and, magnesium concentrations in alkaline lakes. Chemical Geology, 63, 59-72.

Drees, L.R.; Wilding, L.P.; Smeck, N.E.; Senkayi, A.L. (1989) Silica in soils: quartz and disordered silica polymorphs. Pp: 913-974. In Minerals in Soil Environments (J.B. Dixon. \& S.B Weed, eds.) SSSA Book Series n. 1. Soil Science Society of America.

Empresa Brasileira de Pesquisas Agropecuárias - Embrapa (1997) Plano de utilização da Fazenda Nhumirim, Documento 21, Embrapa Pantanal, Corumbá, 71p.

Empresa Brasileira de Pesquisas Agropecuárias - Embrapa (2006) Sistema Brasileiro de Classificação de Solos. $2^{\mathrm{a}}$ edição, Embrapa Solos, Rio de Janeiro, 306 p.

Eugster, H.P. \& Hardie, L.A. (1978) Saline Lakes. Pp. 237-294 in: Lakes: chemistry, geology and physics (A. Lerman, ed.). Springer-Verlag. Berlin.

Fanning, D.S. \& Fanning, M.C.B. (1989) Soil, morphology, genesis, and classification. John Wiley \& Sons, New York, 395 p.

Fanning, D.S.; Vissarion, Z.K. \& El-Desoky, M.A. (1989) Micas. Pp. 551-634 in: Minerals in Soil Environments (J.B. Dixon \& S.B. Weed, eds). SSSA Book Series, n.1. Soil Science Society of América.

Fehrenbacher, J.B; Wilding, L.P; Odell, R.T; Melsted, S.W. (1963) Characteristics of solonetzic soils in Illinois. Soil Science Society of America Proceedings, 27, 421-431.

Fernandes, E. (2000) Caracterização dos Elementos do Meio Físico e da Dinâmica da Nhecolândia (Pantanal Sulmatogrossense). Dissertação de Mestrado. Departamento de Geografia, Faculdade de Filosofia, Letras e Ciências Humanas, Universidade de São Paulo, 130 p.

Flach, K.W.; Nettleton, L.H.; Gile, L.H.; Cady, J.G. (1969) Pedocementation: induration by silica, carbonates, and sesquioxides in the Quaternary. Soil Science, 107, 442-453.

Gran, G. (1952) Determination of the equivalence point in potentiometric titrations. Acta Chemica Scandinavica, 4, 559-577.

Hamrouni, B. \& Dhahbi, M. (2001) Analytical aspects of silica in saline waters: application to desalination of brackish waters. Desalination, 136, 225-232.

Heck, R.J. \& Mermut, A.R. (1992) Genesis of Natriborolls (Solonetzic) in a closed lake basin in Saskatchewan, Canada. Soil Science Society of America Journal, 56, 842-848.

Herbillon, A.J. (1976) Iron in kaolinite with special reference to kaolinite from tropical soils. Clay Minerals, 11, 201-220.

Huertas, F.J.; Chou, L.; Wollast, R. (1999) Mechanism of kaolinite dissolution at room temperature and pressure. Part II - Kinetic study. Geochimica et Cosmochimica Acta, 63, 3261-3275. 
Jones, B.F. \& Weir, A.H. (1983) Clay minerals of Lake Abert, an alkaline, saline lake. Clays and Clay Minerals, 31, 161-172.

Kodama, H \& Ross, G.J. (1991) Tiron dissolution method used to remove and characterize inorganic components in soils. Soil Science Society of America Journal, 55, 1180-1187.

Kohut, C.K. \& Dudas, M.J. (1994) Characteristics of clay minerals in saline alkaline soils in Alberta, Canada. Soil Science Society of America Journal, 58, 1260-1269.

Kohut, C.K. \& Dudas, M.J. (1995) Evaporite mineralogy and trace-element content of salt-affected soil in Alberta. Canadian Journal of Soil Science, 73, 399-409.

Konen, M.E., Burras, C.L.; Sandor, J.A. (2003) Organic carbon, texture, and quantitative color measurement relationships for cultivated soils in North Central Iowa. Soil Science Society of America Journal, 67, 1823-1830.

Krauskopf, K.B. (1956) Dissolution and precipitation of sílica at low temperatures. Geochimica et Cosmochimica Acta, 10, 1-26.

Lemos, R. C. \& Santos, R. D. (1996) Manual de Descrição e Coleta de Solo no Campo. $3^{\mathrm{a}}$ edição. Sociedade Brasileira de Ciência do Solo. Campinas, 83 p.

Mahjoory, R.A (1979) The nature and genesis of some salt-affected soils in Iran. Soil Science Society of America Journal, 43, 1019-1024.

Moore, D. \& Reynolds, R.C. (1997) X-ray Diffraction and the Identification and Analysis of Clay Minerals, Oxford University Press, 2nd edition, 378 p.

Murray, H.H. \& Keller, W.D. (1993) Kaolins, kaolins, and kaolins. Pp. 1-24 in: Kaolin genesis and utilization (H.H. Murray, W.M. Bundy; C.C. Harvey, eds). Special Publication 1. Clay Minerals Society, Boulder, CO.

Nelson, D.W. \& Sommers, L.E. (2001) Total carbon, organic carbon, and organic matter. Pp. 961-1010 in: Methods of Soil Analysis- Chemical Analysis (D.L. Sparks, ed). $3^{\text {th }}$ edition. Soil Science Society of América, Madison.

Nelson, R.E. (1982) Carbonate and Gypsum. In Page, A.L. (ed) Methods of Soil Analysis - Chemical and Microbiological Properties, part 2, $2^{\text {nd }}$ edition, SSSA Inc., p. 181-198.

Oliveira, J.B. (2005) Pedologia Aplicada. $2^{\text {a }}$ edição, Fealq, Piracicaba, 574 p.

Orioli, A.L.; Amaral Filho, Z.P.; Oliveira, A.B. (1982) Pedologia: levantamento exploratório de solos da Folha SE.21 Corumbá e Parte da Folha SE.20: As regiões fitoecológicas, sua natureza e seus recursos econômicos. Pp. 225-328 in: RADAMBRASIL-Levantamento dos Recursos Naturais. Rio de Janeiro.

Raij, B.V. \& Quaggio, J.A. (2001) Determinação de fósforo, cálcio, magnésio e potássio extraídos com resina trocadora de íons. Pp: 189-199 in: Análises químicas para avaliação da fertilidade de solos tropicais (B.V. Raij; J.C. Andrade; H. Cantarella; J.A. Quaggio, eds.). IAC. Campinas.

Reid-Soukup, D.A. \& Ulery, A. (2002) Smectites. Pp.467-499 in: Soil Mineralogy with Environmental Application (J.B. Dixon \& D.G. Schulze, eds.). SSSA Book Series n. 7. Soil Science Society of America.

Rengasamy, P.; Krishna Murti, S.R.; Sarma, V.A.K. (1975) Isomorphous substitution of iron for aluminum for some soil kaolinites. Clays and Clay Minerals, 23, 211-214.

Ruellan, A. \& Dosso, M. (1993) Regards sur le sol. Universités Francophones. Les Éditions Foucher, Paris.

Sakamoto, A.Y.; Queiroz Neto, J.P.; Fernandes, E. e Lucati, H.M. (1996) Topografia de Lagoas Salinas e seus Entornos no Pantanal da Nhecolândia, MS. P. 40 in: Resumos do II Simpósio sobre Recursos Naturais e Sócio-Econômicos do Pantanal-Manejo e Conservação. 18 a 22 de novembro de 1996, Corumbá, MS. Embrapa Pantanal e UFMS.

Sakamoto, A. Y. (1997) Dinâmica hídrica em uma lagoa salina e seu entorno no Pantanal da Nhecolândia: contribuição ao estudo das relações entre o meio físico e a ocupação, Fazenda São Miguel Firme, MS. Tese de Doutorado defendida no Departamento de Geografia da Faculdade de Filosofia, Letras e Ciências Humanas da Universidade de São Paulo. 183 p. 
Schulze, D.G.; Nagel, J.L.; Van Scoyoc, G.E.; Henderson, T.L.; Baumgardner, M. (1993) Significance of organic matter in determining soil color. Pp. 71-90 in: Soil Color (J.M. Bigham \& E.J. Ciolkosz, eds) Soil Science Society of America Special Publication, 31.

Silva, F.C. (1999) Manual de análises químicas de solos, plantas e fertilizantes. Embrapa. Brasília, DF.

Silva, M.H.S. \& Sakamoto, A. (2003) Perfis pedomorfológicos do Pantanal da Nhecolândia-MS: Um estudo comparativo. Pp.544-552 in: XII Encontro Sul-Matogrossense de Geografia, Três Lagoas, MS. Trabalho completo.

Silva, M.H.S.; Bacani, V.M.; Sakamoto, A. (2004) Caracterização do solo de uma lagoa salina na área da fazenda Santo Inácio, Pantanal da Nhecolândia, MS. In: XIII Encontro Estadual de Geografia. Aquidauana, MS. Trabalho completo.

Simonson, R.W. (1959) Outline of a generalized theory of soil formation. Soil Science Society of America Proceedings, 23, 152-159.

Soil Survey Staff (2006) Keys to soil taxonomy, 10 ${ }^{\text {th }}$ edition, U.S. Department of Agriculture, 341 p.

Soriano, B.M.A. (1996) Caracterização climática da sub-região da Nhecolândia, Pantanal-MS. Pp. 52 in: Resumos do II Simpósio sobre Recursos Naturais e Sócio-Econômicos do Pantanal-Manejo e Conservação. 18 a 22 de novembro Corumbá (MS).

Tardy, Y; Bocquier, G; Paquet, H.; Millot, G. (1973) Formation of clay from granite and its distribution in relation to climate and topography. Geoderma, 10, 271-284.

Theisen, A.A. \& Harward, M.E. (1962) A paste method for preparation of slides for clay mineral identification by X-ray diffraction. Soil Science Society of America Proceedings, 26, 90-91.

United Stated Department of Agriculture-USDA (1996) Soil Survey Laboratory Methods Manual. Soil Survey Investigations Report, 42p.

United States Salinity Laboratory Staff (1954) Diagnosis and improvement of saline and alkali soils. USDA Agriculture Handbook, n. 60., U.S. Government Printing Office, Washington, DC.

Velde, B. (1995) Origin and mineralogy of clays. Clays and the environment. Springer, New York, 333 p.

Westin, F.C. (1953) Solonetz soils on eastern South Dakota: their properties end genesis. Soil Science Society of America Proceedings, 17, 287-293.

Whittig, L.D. (1959) Characteristics and genesis of a solodized-solonetz of California. Soil Science Society of America Proceedings, 23, 469-473. 
Capítulo 4

\section{MINERALOGIA E GÊNESE DE ESMECTITAS PRESENTES NOS SOLOS DO ENTORNO DA SALINA DO MEIO}




\section{4 - MINERALOGIA E GÊNESE DE ESMECTITAS PRESENTES NOS SOLOS DO ENTORNO DA SALINA DO MEIO}

\section{Resumo}

As lagoas salinas da Baixa Nhecolândia oferecem uma boa oportunidade para estudar a neoformação de argilo-minerais em lagos salino-alcalinos, uma vez que a maioria dos solos presentes nesta sub-região é extremamente arenosa. O objetivo deste capítulo é investigar a mineralogia do grupo das esmectitas nos arredores da lagoa do Meio e identificar os mecanismos responsáveis pela formação destes minerais.

Os solos foram coletados ao longo da Topossequência 1 (T1) e analisados por DRX, METEDS e ICP-MS. Amostras de água foram coletadas em um transecto que envolve T1 e submetidas à cromatografia de íons, EAA e ICP-MS.

Minerais do grupo das esmectitas estão concentrados em duas diferentes zonas da topossequência: Zona Alta, composta por todos os horizontes dos Pedons 1 e 2, situados na área que é raramente atingida pelas variações sazonais do nível d'água da salina; e Zona Baixa, composta pelos horizontes superficiais dos Pedons 3 a 5, localizados na área de maior variação sazonal do nível d'água da salina. Na Zona Alta, a esmectita é dioctaédrica e rica em $\mathrm{Al}_{2} \mathrm{O}_{3}$ e $\mathrm{Fe}_{2} \mathrm{O}_{3}$, sendo classificada como do tipo ferribeidelita. Esta fase mineral parece possuir um grau de interestratificação com mica e vermiculita e apresenta teores de $\mathrm{Fe}^{3+}$ similares aos minerais do grupo das micas identificados nos mesmos solos. Estas características sugerem que o mineral do tipo ferribeidelita é originado pela transformação de micas enriquecidas em $\mathrm{Fe}^{3+}$, sendo a vermiculita provavelmente uma fase intermediária nesta transformação. $\mathrm{Na}$ Zona Baixa, as esmectitas são essencialmente trioctaédricas e ricas em $\mathrm{MgO}$, sendo classificadas como do tipo saponita e estevensita. Amostras enriquecidas nestes minerais apresentam teores muito menores de elementos terras raras (ETR). Além disto, análises químicas das águas revelam um controle do $\mathrm{Mg}^{2+}$ e a saturação em relação a Mg-esmectita nas águas mais salinas. As evidências fornecidas pelos teores de ETR e pela química das águas, aliadas à presença de Mg-esmectitas nos locais onde são esperadas máximas taxas de evaporação, provam que os minerais do tipo saponita e estevensita estão se originando por precipitação química diretamente da coluna d'água da lagoa salina.

Palavras-chave: lagoa salina, interestratificação mica-esmectita, ferribeidelita, transformação, Mg-esmectita, saponita, estevensita, neoformação, precipitação química. 
Abstract

Mineralogy and genesis of smectites in the soils around salina do Meio

Saline lakes of Nhecolândia offer a good opportunity to study neoformation of clays in salinealkaline environments since most of their associated soils are very sandy. The objective of this work is to investigate the mineralogy of smectite group in the surrounding of lagoa do Meio and then identify the mechanisms responsible for minerals formation.

Soils were sampling along Toposequence 1 and analyzed by XRD, TEM-EDS, and ICP-MS. Water was collected along a transect involving the lake and submitted to ion chromatography, AAS, and ICP-MS analyses.

Smectite are concentrated at two places of the toposequence: Zone 1, composed by all the horizons of Pedons 1 and 2, located in the area hardly reached by the lake level variation; and Zone 2: composed by the superficial horizon of Pedons 3 to 5 , situated in the area of seasonal lake level variation. At Zone 1, smectite is dioctahedral and rich in $\mathrm{Al}_{2} \mathrm{O}_{3}$ and $\mathrm{Fe}_{2} \mathrm{O}_{3}$, being classified as ferribeidellite-type. This phase seems to present an interstratification with mica and vermiculite and has similar amounts of $\mathrm{Fe}^{3+}$ than the $\mathrm{Fe}$-mica present in the soil. These characteristics suggest that the ferribeidellite-type mineral originates from transformation of Fe-mica and that vermiculite may be an intermediate phase in this transformation. At Zone 2, smectites are mainly trioctahedral and rich in $\mathrm{MgO}$, being classified as saponite- and stevensite-type minerals. In addition, samples enriched in these minerals present much lower REE amounts than other soil samples. Water chemistry analyses show that there is a geochemical control of $\mathrm{Mg}^{2+}$ and saturation with respect to $\mathrm{Mg}$-smectite in the more saline waters. REE amounts and water chemistry evidences, and the presence of $\mathrm{Mg}$-smectite where the maximum of evaporation is expected, prove that saponite- and stevensite-like minerals originate by chemical precipitation from the water column of the saline lake.

Key words: saline lake, mica-smectite interstratification, ferribeidellite, $\mathrm{Mg}$ smectite, saponite, stevensite, transformation, neoformation, chemical precipitation. 


\section{1 - Introdução}

Minerais do grupo das esmectitas são comumente encontrados em lagos salinoalcalinos submetidos à concentração por evaporação. A formação de diferentes tipos de esmectitas neste ambiente parece ocorrer em função do fator de concentração das águas e da quantidade de materiais detríticos disponível. De acordo com Darragi \& Tardy (1987), das soluções menos às mais concentradas e da maior à menor disponibilidade de materiais detríticos, a seqüência de formação de esmectitas seria beidelita, saponita e estevensita ${ }^{1}$. Baseando-se nesta premissa, a beidelita, mineral dioctaédrico rico em $\mathrm{Al}^{3+}$, seria preferencialmente formada por transformação de materiais detríticos, enquanto a estevensita, mineral trioctaédrico rico em $\mathrm{Mg}^{2+}$, seria originada por precipitação das águas em concentração, já que haveria escassez de materiais que serviriam como base para reação.

Apesar de ser amplamente aceito na literatura que esmectitas dioctaédricas autigênicas, tais como montmorilonita e beidelita, são formadas principalmente por transformação de um argilo-mineral precursor em ambiente salino-alcalino (Gac et al., 1977; Torrez Ruiz et al., 1994; Mayayo et al., 2000; Cuevas et al., 2003), a gênese da saponita e da estevensita tem sido atribuída a diferentes mecanismos, tais como a precipitação diretamente da coluna d'água (Tettenhorst \& Moore, 1978; Darragi \& Tardy, 1987; Torrez Ruiz et al., 1994; Mayayo et al., 2000; Akbulut \& Kadir, 2003), a transformação de estruturas internas de argilas pré-existentes (Pozo \& Casas, 1999; Mayayo et al., 2000) ou a transformação por crescimento no topo de estruturas de outros argilo-minerais (Banfield et al., 1991; Hover et al., 1999; Cuevas et al., 2003). Os dois últimos processos parecem contrariar a idéia de formação de estevensita proposta por Darragi \& Tardy (1987), mas estão de acordo com a observação de Jones (1986) de que a gênese de argilo-minerais em ambiente lacustre ocorre muito mais freqüentemente por transformação do que por precipitação.

A discriminação entre argilo-minerais neoformados e detríticos e a identificação exata da estequiometria do mineral neoformado têm sido uma tarefa difícil em ambientes alcalinos sujeitos à evaporação. Isto pode ser explicado pelo fato destes ambientes

\footnotetext{
${ }^{1}$ Fórmulas fornecidas por Darragi \& Tardy (1987) - Beidelita: $\mathrm{Ca}_{0,3}\left(\mathrm{Al}_{1,2} \mathrm{Fe}^{3+}{ }_{0,4} \mathrm{Mg}_{0,6}\right)\left(\mathrm{Si}_{3,6} \mathrm{Al}_{0,4}\right)$ $\mathrm{O}_{10}(\mathrm{OH})_{2}$; Saponita: $\mathrm{Na}_{0,4}\left(\mathrm{Al}_{0,6} \mathrm{Fe}_{0,2} \mathrm{Mg}_{1,8}\right)\left(\mathrm{Si}_{3,8} \mathrm{Al}_{0,2}\right) \mathrm{O}_{10}(\mathrm{OH})_{2}$; e Estevensita:

$\mathrm{Na}_{0,2}\left(\mathrm{Al}_{0,3} \mathrm{Fe}_{0,1} \mathrm{Mg}_{2,3}\right)\left(\mathrm{Si}_{4}\right) \mathrm{O}_{10}(\mathrm{OH})_{2}$.
} 
normalmente serem enriquecidos em argila, já que ocupam áreas rebaixadas na paisagem. Além disto, mesmo que o controle do $\mathrm{Mg}^{2+}$ nas águas seja significativo, a quantidade de argila magnesiana envolvida na precipitação é geralmente baixa se comparada à quantidade de argila já presente nos solos.

Como já citado no Capítulo 1, as lagoas da Baixa Nhecolândia oferecem uma grande oportunidade para o estudo de filosilicatos em ambientes salino-alcalinos modernos, uma vez que a maioria dos solos e sedimentos aí presentes é extremamente arenosa, o que facilita a identificação da estequiometria das argilas e a discriminação de argilas neoformadas.

O objetivo deste capítulo é estudar a mineralogia de minerais do grupo das esmectitas presentes nos solos do entorno da lagoa do Meio e então identificar os processos responsáveis pela sua formação.

\section{2 - Materiais e Métodos}

\subsection{1 - Análises de solo}

Neste item será dado um panorama geral dos materiais e métodos adotados no presente capítulo, mas maiores detalhes podem ser obtidos no Anexo 1. As amostras de solo aqui selecionadas, coletadas nos Pedons 1 a 5 da Topossequência 1 (T1), já foram utilizadas em métodos do Capítulo 3. A Tabela 4.1 mostra quais das amostras coletadas em campo foram usadas em cada uma das análises laboratoriais descritas a seguir.

Grandes quantidades de silte fino $(0,02$ a $0,002 \mathrm{~mm})$, argila grossa $(0,002$ a 0,0002 $\mathrm{mm})$ e argila fina $(<0,0002 \mathrm{~mm})$ de 20 amostras foram separadas através de centrifugação e sedimentação, após destruição da matéria orgânica com hipoclorito de sódio ( $\mathrm{NaOCl}), \mathrm{pH} 9,5$ (Anderson, 1963). A fração argila fina foi então utilizada em todas as análises mineralógicas e químicas descritas daqui a diante.

As 20 amostras fracionadas foram submetidas à Difração de Raios X (DRX), tendo sido utilizado um Difratômetro Siemens D-500 (radiação $\mathrm{K}_{\alpha}$ e alvo de cobre), a uma taxa de $0,02^{\circ} 2 \theta$ por etapa, a cada 1 segundo. Espécimes orientados foram obtidos pelo espalhamento, em uma só direção, de soluções aquosas de argila fina em lâminas de vidro, a fim de facilitar a detecção do espaço $d_{00 l}$ (Theisen $\&$ Harward, 1962). Cin- 
Tabela 4.1 - Amostras selecionadas para diferentes análises de solos incluídas no Capítulo 4.

\begin{tabular}{|c|c|c|c|c|c|}
\hline $\begin{array}{l}\text { Profundidade } \\
\qquad(\mathrm{cm})\end{array}$ & Horizonte & $\begin{array}{c}\text { DRX e } \\
\text { derivados }\end{array}$ & ICP-MS $^{2}$ & $\begin{array}{c}\text { Análise } \\
\text { Estatística }^{3}\end{array}$ & MET-EDS \\
\hline \multicolumn{6}{|c|}{ PEDON 1} \\
\hline $0-40$ & 1 & $X$ & $\mathrm{X}$ & $X$ & --------- \\
\hline 230 & 3 & $X$ & $X$ & $\mathrm{X}$ & ----------- \\
\hline $250-270$ & 5 & $X$ & $X$ & $X$ & ----------- \\
\hline 350 & 6 & $X$ & $\mathrm{X}$ & $\mathrm{X}$ & $\mathrm{X}$ \\
\hline \multicolumn{6}{|c|}{ PEDON 2} \\
\hline $0-40$ & 1 & $X$ & ----------- & ----------- & ----------- \\
\hline 80 & 4 & $X$ & $\mathrm{X}$ & $X$ & ---------- \\
\hline $110-145$ & 5 & $X$ & $\mathrm{X}$ & $\mathrm{X}$ & --------- \\
\hline $168-175$ & 6 & $X$ & $X$ & $\mathrm{X}$ & --------- \\
\hline \multicolumn{6}{|c|}{ PEDON 3} \\
\hline $0-6$ & 1 & $X$ & ----------- & ------------ & ------------ \\
\hline $12-65$ & 4 & $X$ & $X$ & $\mathrm{X}$ & ----------- \\
\hline $68-73$ & 5 & $X$ & $X$ & $X$ & ---------- \\
\hline $78-85$ & 6 & $X$ & $\mathrm{X}$ & $\mathrm{X}$ & ----------- \\
\hline \multicolumn{6}{|c|}{ PEDON 4} \\
\hline $0-5$ & 2 & $\mathrm{X}$ & $\mathrm{X}$ & $X$ & $\mathrm{X}$ \\
\hline $30-40$ & 4 & $\mathrm{X}$ & $X$ & $\mathrm{X}$ & \\
\hline $70-80$ & 5 & $X$ & $X$ & $X$ & ----------- \\
\hline 100 & 6 & $X$ & $X$ & $\mathrm{X}$ & ----------- \\
\hline \multicolumn{6}{|c|}{ PEDON 5} \\
\hline $0-5$ & 2 & $X$ & $X$ & $X$ & $X$ \\
\hline $20-40$ & 4 & $X$ & $\mathrm{X}$ & $\mathrm{X}$ & ----------- \\
\hline 70 & 5 & $X$ & $X$ & $\mathrm{X}$ & ------------ \\
\hline 90 & 6 & $X$ & $\mathrm{X}$ & $X$ & 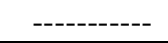 \\
\hline
\end{tabular}

1 - Inclui a análise de Difração de Raios-X, a estimativa semiquantitativa da \% de esmectita em cada assembléia e os cálculos de tamanho dos cristalitos dos cristais de esmectita; 2 - Inclui elementos maiores e ETR; 3 - Análise de Função Discriminante; 4 - Microscópio Eletrônico de Transmissão, acoplado ao Espectrômetro tipo Dispersão em Energia, utilizado para cálculo das fórmulas químicas de cristais individuais.

X - Amostras analisadas; ------- - Amostras não selecionadas para esta análise. 
co diferentes tratamentos foram adotados para auxiliar a identificação dos minerais: saturação com $\mathrm{Mg}^{2+}$, solvatação com etileno glicol (EG) das lâminas saturadas com $\mathrm{Mg}^{2+}$, saturação com $\mathrm{K}^{+}$e aquecimento das lâminas saturadas com $\mathrm{K}^{+}$a $350^{\circ}$ e $550^{\circ} \mathrm{C}$ (Jackson, 1979). As soluções aquosas de argila fina foram ainda liofilizadas e dispostas aleatoriamente em um suporte metálico, com a finalidade de detectar o espaço $d_{060}$ e determinar o caráter dioctaédrico ou trioctaédrico dos minerais.

As intensidades dos picos primários em padrões de EG foram utilizados para a estimativa semi-quantitativa das porcentagens dos argilo-minerais presentes em cada amostra (Biscaye, 1965). Além disto, os picos $d_{001}$ da esmectita em padrões de EG foram usados para estimar o tamanho médio das subunidades, ou cristalitos, que compõem seus cristais, através da aplicação da equação de Scherrer (Moore \& Reynolds, 1997; Thompson \& Ukrainczyk, 2002):

$$
\mathrm{L}=\frac{\lambda \mathrm{K}}{\beta \cos \theta}
$$

onde L é a dimensão média (em $\mathrm{nm}$ ) dos cristalitos; $\lambda$ é o comprimento de onda dos raios-x, com valor de 0,154 nnm; K é uma constante com valor de 1,91 para filosilicatos; $\beta$ é a largura do pico na metade de sua altura (em radianos de $2 \theta$ ); $\theta$ é o ângulo que corresponde ao pico utilizado (em radianos).

Das 20 amostras fracionadas, 18 foram submetidas à análises quantitativas de elementos maiores $\left(\mathrm{SiO}_{2}, \mathrm{Al}_{2} \mathrm{O}_{3}, \mathrm{Fe}_{2} \mathrm{O}_{3}, \mathrm{MnO}, \mathrm{MgO}, \mathrm{CaO}, \mathrm{Na}_{2} \mathrm{O}, \mathrm{K}_{2} \mathrm{O}, \mathrm{TiO}_{2}\right.$ e $\left.\mathrm{P}_{2} \mathrm{O}_{3}\right)$ e de elementos terras-raras (ETR) (La, Ce, Pr, Nd, Sm, Eu, Gd, Tb, Dy, Ho, Er, Tm, Yb, Lu e Y) por Espectrometria de Plasma Acoplada a Detector de Massas (ICP-MS). Os teores da maioria dos ETR foram normalizados de acordo com resultados-padrão obtidos pelo "North America Shale Composition (NASC)" (Gromet et al., 1984). As anomalias de $\mathrm{Ce}$ e $\mathrm{Eu}$ foram calculadas através das seguintes fórmulas: log [5Ce/(4La+Sm)] (Wilde, 1996) e $\log [2 \mathrm{Eu} /(\mathrm{Sm}+\mathrm{Gd})]$ (adaptadas de Ito et al., 2004).

A estimativa semi-quantitativa das porcentagens de esmectita por DRX e a quantificação dos elementos maiores por ICP-MS foram submetidas conjuntamente à Análise Estatística de Função Discriminante a fim de determinar quais elementos químicos estão associados estatisticamente às esmectitas identificadas ao longo da topossequência. A aplicação desta análise no presente capítulo envolveu a definição 
de 4 grupos de amostras com diferentes quantidades de esmectitas: 1) amostras com ausência de esmectitas; 2) amostras com menores porcentagens de esmectitas dioctaédricas $(<30 \%)$; 3) amostras com maiores porcentagens de esmectitas dioctaédricas (30 a 60\%); e 4) amostras com esmectitas trioctaédricas (>60\%).

Por fim, 3 amostras foram selecionadas para análise de esmectitas no Microscópio Eletrônico de Transmissão (MET), tipo FEI-Phillips CM300, acoplado ao Espectrômetro tipo Dispersão em Energia (EDS), modelo Phoenix. Uma gota da suspensão diluída contendo argila fina foi distribuída sobre um filme de carbono fixado a uma pequena tela metálica e as composições químicas de 12 cristais individuais de esmectita foram determinadas. Os dados coletados foram utilizados para o cálculo de fórmulas químicas de cada cristal, conforme procedimento de Moore \& Reynolds (1997). Análises de Espectrometria Mossbauer revelaram que os conteúdos de $\mathrm{Fe}^{2+}$ são iguais ou inferiores a $8 \%$ nas amostras (informação verbal do Dr. Richard Morris, NASA) e, por isto, apenas o $\mathrm{Fe}^{3+}$ foi incluído nas fórmulas.

\subsection{2 - Análises de água}

As amostras de água são as mesmas já utilizadas no Capítulo 3, presentes em um transecto que envolve a Topossequência 1 (T1), a cordilheira do entorno e uma baía adjacente. Ressalta-se que apenas o piezômetro 2 (Pz2), os coletores G0 e G1 e as águas superficiais da própria lagoa do Meio estão localizados em T1.

$\mathrm{O} \mathrm{pH}$ foi analisado no campo (instrumento Sentix 41), os cátions foram analisados por Espectrometria de Plasma Acoplada a Detector de Massas (ICP-MS) (Perkin-Elmer, modelo Elan 6000) e os ânions por Cromatografia de Íons (Dionex, ED50-GP50). Os resultados foram comparados a materiais de referência padrão (Bmoos-01, SLRS4 e SRM1640). A acurácia das análises dos elementos maiores foi inferior a $2 \%$ para as amostras não diluídas e dentro de $10 \%$ para as amostras com a máxima diluição (500 vezes).

$\mathrm{O}$ diagrama de concentração do $\mathrm{Mg}^{2+}$ foi construído considerando-se o $\mathrm{Na}^{+}$como fator de concentração, uma vez que se acredita que este elemento é conservativo. 


\section{3 - Resultados}

\subsection{1 - Caracterização das esmectitas por Difração de Raios X (DRX)}

Os picos de DRX mostram que apenas a fração argila fina possui quantidades significativas de esmectitas. A semi-quantificação dos minerais presentes nesta fração, estimada pela intensidade dos picos em padrões de EG, mostram que há porcentagens expressivas de esmectita em duas diferentes zonas da topossequência (Figura 4.1): Zona Alta - composta por todos os horizontes dos Pedons 1 e 2, situados na área que é raramente atingida pelas variações sazonais do nível superficial da salina; e Zona Baixa - composta pelos horizontes superficiais 1 e 2 dos Pedons 3 a 5, localizados na área de maior variação sazonal do nível superficial da salina. A Zona Baixa possui as maiores porcentagens de esmectitas da topossequência (69 a 73\%), sendo este mineral fortemente dominante nestas assembléias.

Apenas os picos $d_{001}$ das esmectitas estão presentes nos difratogramas $d_{00 l}$, sendo estes largos e assimétricos, com flanco menor voltado para os ângulos mais baixos (Figura 4.2, Anexo 3). Na Zona Alta, alguns destes picos apresentam comportamentos não esperados para membros-finais de esmectitas (Figura 4.3, Anexo 3): a) a maioria das

amostras saturadas com $\mathrm{Mg}^{2+}(\mathrm{P} 1$ : horizontes 1, 3, 5 e 6; P2: horizontes 5 e 6) apresenta uma coalescência entre picos de esmectita e mica; b) em algumas destas amostras (P1 e P2: horizontes 1 e 6), há um colapso total ou parcial dos picos de esmectita para 1,0 $\mathrm{nm}$ em padrões de $\mathrm{K}^{+}$. A aplicação da equação (1) revelou a presença de cristalitos pequenos nos cristais de esmectita em todas as amostras, com tamanhos entre 10,3 a $22,0 \mathrm{~nm}$.

Padrões de DRX não orientados mostram que há diferentes valores $d_{060}$ nas duas zonas de concentração de esmectita. A presença de picos entre 0,149 e 0,150 nm indicam um domínio dioctaédrico na Zona Alta, enquanto que o pico 0,152 nm revela um caráter trioctaédrico na Zona Baixa (Figura 4.4).

\subsection{2 - Caracterização química das esmectitas}

A Análise de Função Discriminante separou claramente os 4 grupos de argila fina com diferentes quantidades de esmectitas (Figura 4.5) e mostrou que apenas 2 funções ("roots") explicam 99\% da variância total dos dados (Tabela 4.2). Os Coeficientes Pa- 


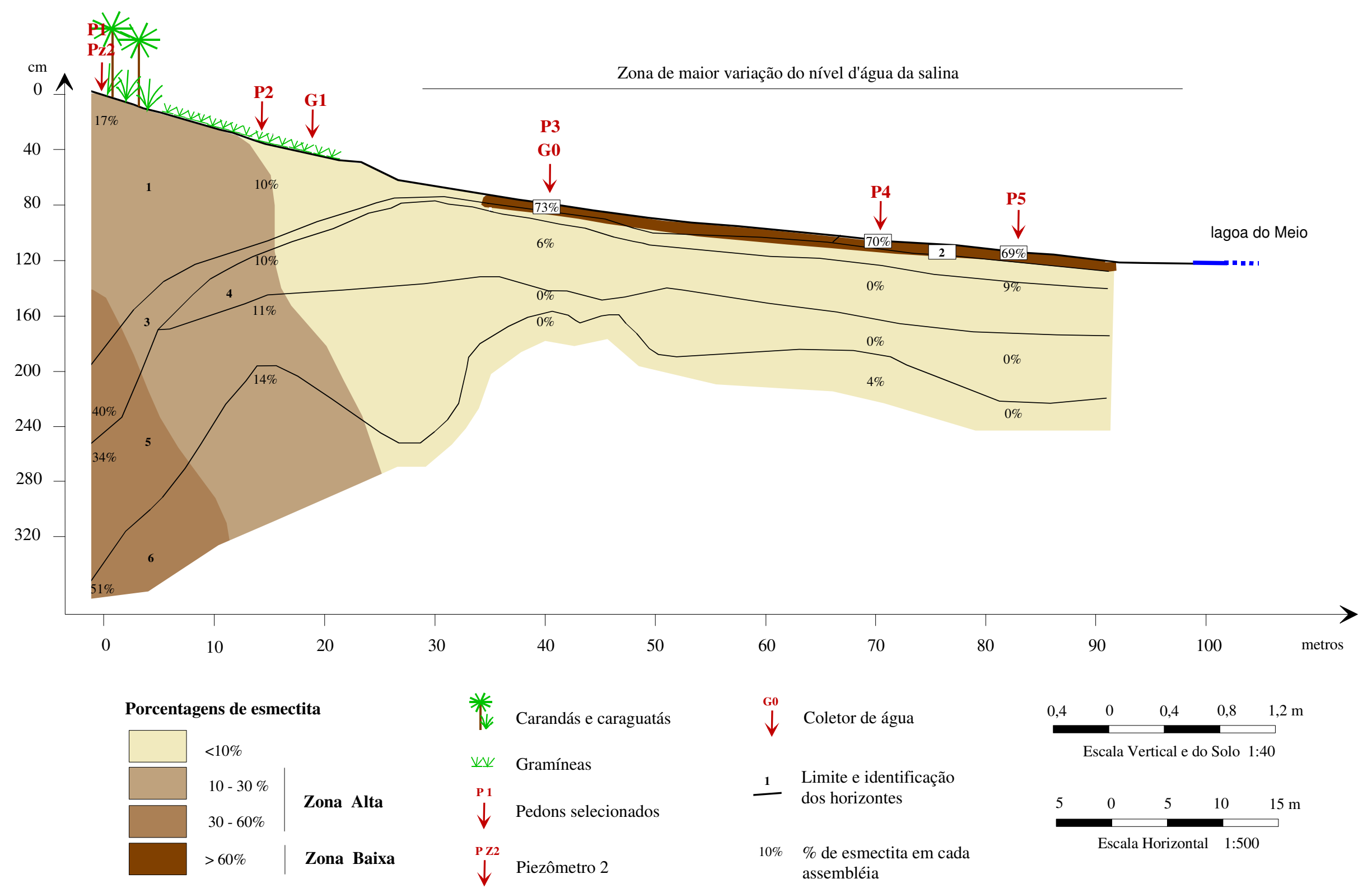

Figura 4.1 - Distribuição das porcentagens de esmectitas ao longo da topossequência 

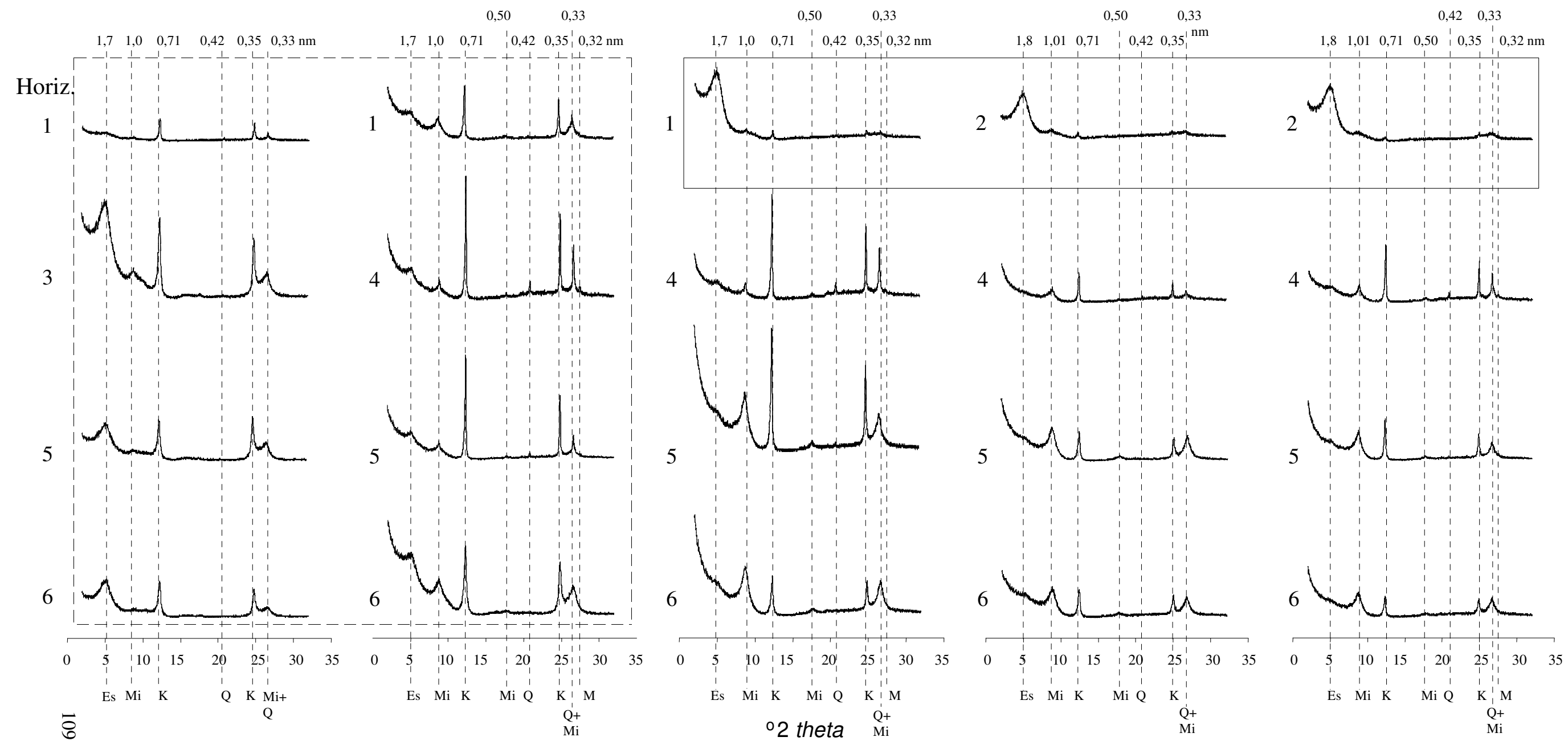

Figura 4.2 - Picos de raios X relativos à argila fina ao longo da Topossequência 1 (tratados com Etileno Glicol). Nota-se que todos os picos da esmectita (Es) são largos e assimétricos. Polígono com linha tracejada: Zona Alta; polígono com linha cheia: Zona Baixa. 
Argila fina - Zona Alta

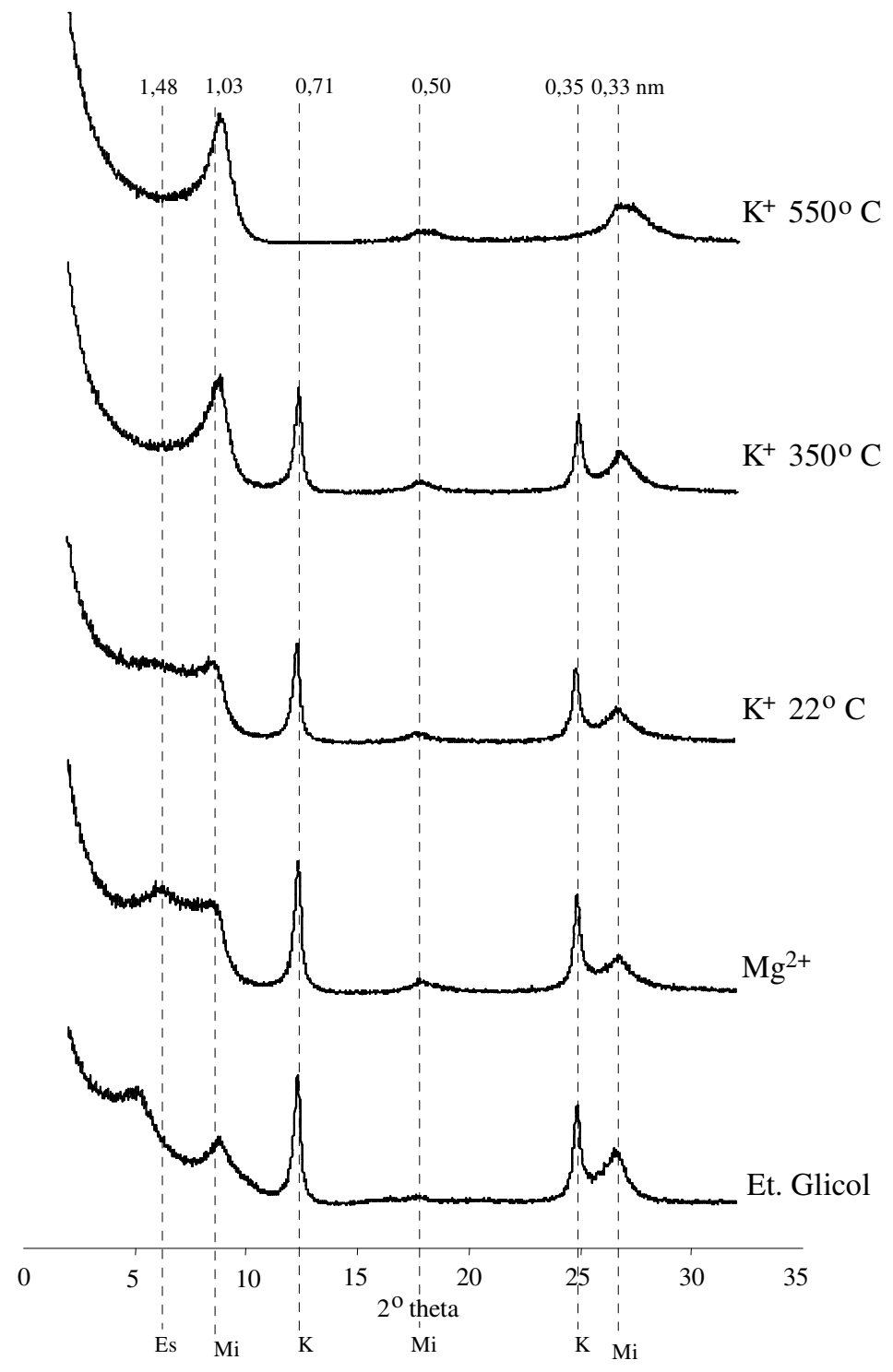

Figura 4.3 - Exemplo do comportamento dos picos de esmectita (Es) (P2, horizonte 6): nota-se a coalescência do picos da esmectita (Es) e mica (Mi) no padrão de $\mathrm{Mg}$ e o parcial colapso do pico da esmectita no padrão de K. As sequências de picos de todas as amostras podem ser vistas no Anexo 3. 


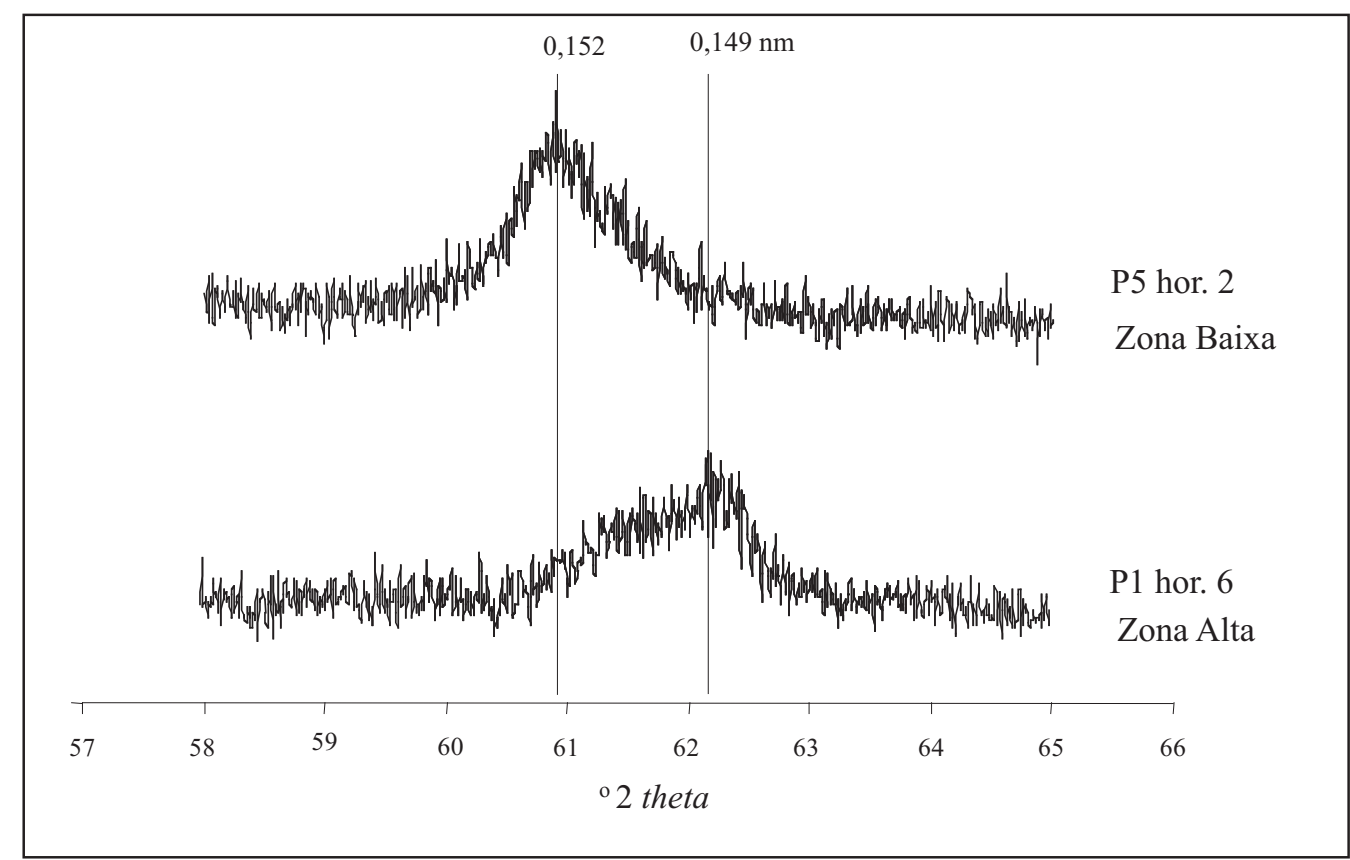

Figura 4.4 - Exemplos de picos $d_{060}$ mostrando o caráter dioctaédrico e trioctaédrico das esmectitas 


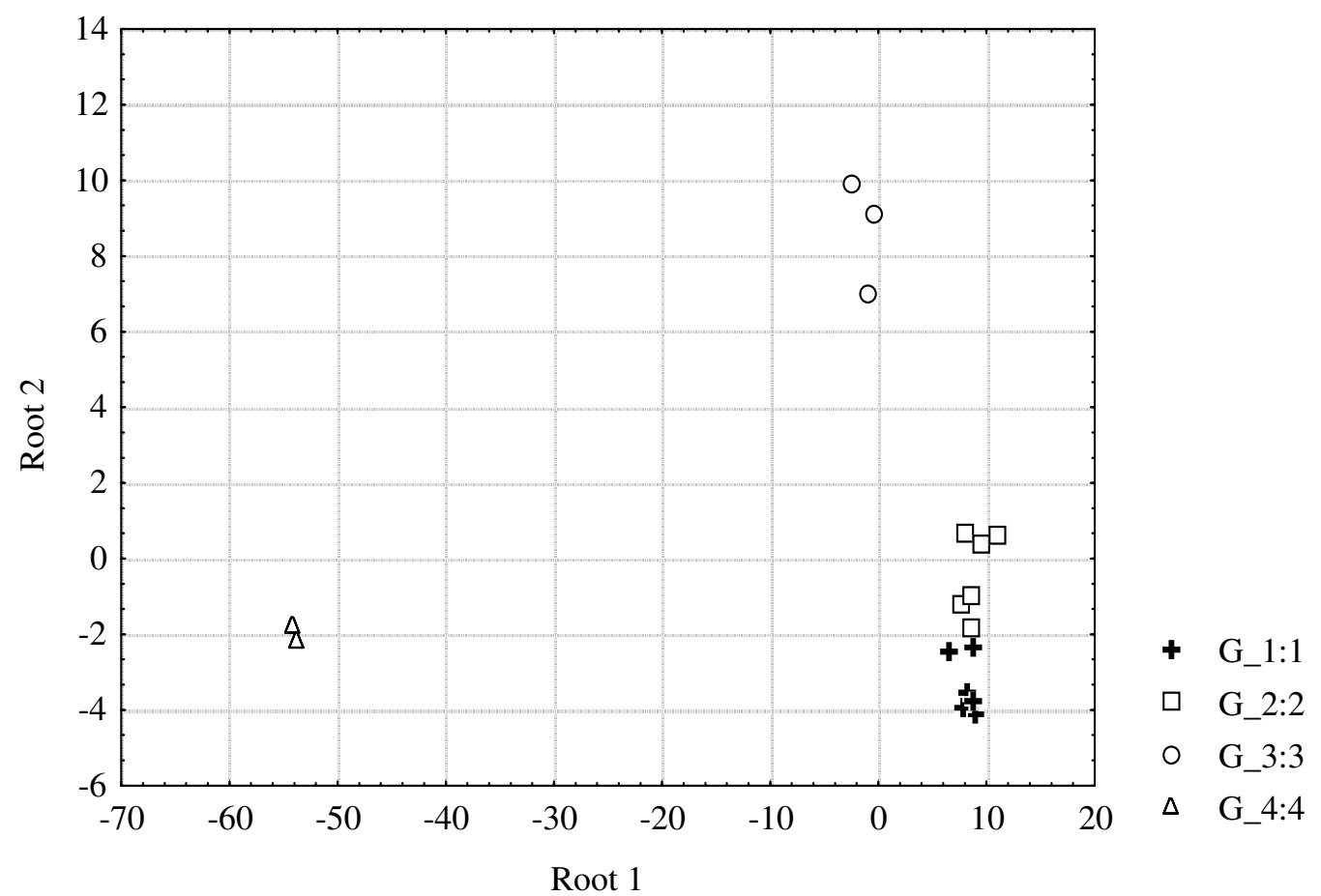

Figure 4.5 - Gráfico relativo à Análise de Fator Discriminante mostrando a sepação nítida de 4 grupos: G1 - amostras com ausência de esmectita; G2 - amostras com menores \% de esmectita dioctaédrica; G3 - amostras com maiores \% de esmectita dioctaédrica; e G4 - amostras com esmectita trioctaédrica. 
Tabela 4.2 - Coeficientes de Função Discriminante

\begin{tabular}{|c|c|c|}
\hline \multicolumn{3}{|c|}{ A - Coeficientes Padrões de Função Discriminante } \\
\hline & Fator 1 & Fator 2 \\
\hline $\mathrm{SiO}_{2}$ & -0.9092 & -0.35636 \\
\hline $\mathrm{Al}_{2} \mathrm{O}_{3}$ & -2.8198 & 1.32658 \\
\hline $\mathrm{Fe}_{2} \mathrm{O}_{3}$ & -7.4907 & 2.25071 \\
\hline $\mathrm{MgO}$ & -4.0868 & 0.78890 \\
\hline $\mathrm{CaO}$ & -3.1194 & 0.46003 \\
\hline $\mathrm{MnO}$ & -1.8136 & 0.05309 \\
\hline $\mathrm{K}_{2} \mathrm{O}$ & 1.8457 & -1.18239 \\
\hline $\mathrm{Na}_{2} \mathrm{O}$ & -0.3264 & -0.70611 \\
\hline $\mathrm{P}_{2} \mathrm{O}_{5}$ & -0.3830 & -0.70893 \\
\hline $\mathrm{TiO}_{2}$ & -5.3147 & 2.33755 \\
\hline Eingenvalues & 485.0747 & 21.55603 \\
\hline Prop. Acum.\% & $95 \%$ & $4 \%$ \\
\hline \multicolumn{3}{|c|}{ B - Coeficientes de Fator Estrutural } \\
\hline & Fator 1 & Fator 2 \\
\hline $\mathrm{SiO}_{2}$ & 0.046194 & -0.077110 \\
\hline $\mathrm{Al}_{2} \mathrm{O}_{3}$ & 0.108277 & 0.446662 \\
\hline $\mathrm{Fe}_{2} \mathrm{O}_{3}$ & 0.042535 & 0.053687 \\
\hline $\mathrm{MgO}$ & -0.287069 & -0.380076 \\
\hline $\mathrm{CaO}$ & -0.133748 & -0.143910 \\
\hline $\mathrm{MnO}$ & -0.018194 & -0.093166 \\
\hline $\mathrm{K}_{2} \mathrm{O}$ & 0.088488 & -0.401072 \\
\hline $\mathrm{Na}_{2} \mathrm{O}$ & 0.023802 & -0.017746 \\
\hline $\mathrm{P}_{2} \mathrm{O}_{5}$ & -0.157039 & -0.241058 \\
\hline $\mathrm{TiO}_{2}$ & 0.032580 & -0.011764 \\
\hline
\end{tabular}


drões de Função Discriminante revelam que $\mathrm{Fe}_{2} \mathrm{O}_{3}, \mathrm{MgO}, \mathrm{Ti}_{2} \mathrm{O}$ e $\mathrm{K}_{2} \mathrm{O}$ são os principais responsáveis pela discriminação dos grupos (Tabela 4.2). Os Coeficientes de Fator Estrutural, por sua vez, destacam $\mathrm{MgO}, \mathrm{MnO}, \mathrm{CaO}$ e $\mathrm{P}_{2} \mathrm{O}_{5}$ no Fator 1 e $\mathrm{Al}_{2} \mathrm{O}_{3}$ e $\mathrm{Fe}_{2} \mathrm{O}_{3}$ no Fator 2 (Tabela 4.2), indicando possivelmente uma associação dos primeiros 4 óxidos à esmectitas trioctaédricas da Zona Baixa e dos 2 últimos óxidos à esmectitas dioctaédricas da Zona Alta.

As fórmulas químicas de 12 cristais individuais (cristais 1 a 12) de esmectitas estão expostas na Tabela 4.3. Na Zona Alta (cristal 1), a substituição de $\mathrm{Si}^{4+}$ por $\mathrm{Al}^{3+}$ no tetraedro é alta, com valor de 0,82 átomos por unidade de fórmula, baseada em 22 ânions (apuf/22). $\mathrm{Al}^{3+}$ e $\mathrm{Fe}^{3+}$ são os principais cátions do octaedro, com valores respectivos de 1,69 e 0,46 apuf/22, confirmando o caráter dioctaédrico sugerido pelos difratogramas $d_{060}$ e $\mathrm{o}$ destaque de $\mathrm{Al}_{2} \mathrm{O}_{3}$ e $\mathrm{Fe}_{2} \mathrm{O}_{3}$ no Fator 2 da Análise Discriminante. A soma de cátions no octaedro é ligeiramente maior que os supostos 2,00 apuf/22 esperados para esmectitas dioctaédricas. A carga total deste espécime é de -0,31 e é proveniente do tetraedro, já que a carga do octaedro é positiva. Magnésio é o cátion dominante na entrecamada, com teor de 0,08 apuf/22.

Na Zona Baixa (cristais 2 a 12), a substituição de $\mathrm{Si}^{4+}$ por $\mathrm{Al}^{3+}$ no tetraedro é baixa, entre 0,00 e 0,20 apuf/22, sendo que valores $\leq 0,10$ apuf/22 são encontrados nos espécimes 3 a 6 e 10 a $12 . \mathrm{Mg}^{2+}$ é o principal cátion no octaedro, com teores entre 1,47 e 2,32 apuf/22, o que confirma o caráter trioctaédrico dominante sugerida pelos difratogramas $d_{060}$ e a forte presença de $\mathrm{MgO}$ apontada no Fator 1 da Análise Discriminante. A soma de cátions no octaedro é bastante inferior ao valor de 3,00 apuf/22 esperado para esmectitas trioctaédricas. A carga total varia de $-0,18$ a $-0,45$, sendo produzida principalmente no octaedro. Entretanto, nos espécimes 3 a 6 e 10 a 12, a carga no octaedro é nitidamente maior do que a do tetraedro, mas nos outros espécimes a carga produzida no tetraedro é geralmente bastante próxima a do octaedro. Potássio, $\mathrm{Ca}^{2+} \mathrm{e} \mathrm{Mg}^{2+}$ são os cátions presentes na entrecamada, sendo $\mathrm{K}^{+}$ou $\mathrm{Ca}^{2+}$ os dominantes, com valores respectivos de 0,00 a 0,16 apuf/22 e 0,05 a 0,21 apuf/22. Cabe destacar ainda que o $\mathrm{Cl}^{-}$substitui o $\mathrm{OH}^{-}$em um intervalo de 0,14 a 0,69 apuf/22, sendo maior no pedon mais próximo a lagoa salina (P5). 
Tabela 4.3 - Óxidos e fórmulas químicas de cristais individuais de esmectitas

\begin{tabular}{|c|c|c|c|c|c|c|c|c|c|c|c|c|}
\hline & \multirow{2}{*}{$\frac{\text { P1 - hor, } 6}{1}$} & \multicolumn{5}{|c|}{ Pedon 4 - horizonte 2} & \multicolumn{6}{|c|}{ Pedon 5 - horizonte 2} \\
\hline & & 2 & 3 & 4 & 5 & 6 & 7 & 8 & 9 & 10 & 11 & 12 \\
\hline$\% \mathrm{SiO}_{2}$ & 52,3 & 60,8 & 64,5 & 62,8 & 62,0 & 63,3 & 57,7 & 55,4 & 60,7 & 60,5 & 59,2 & 65,2 \\
\hline$\% \mathrm{Al}_{2} \mathrm{O}_{3}$ & 35,0 & 9,9 & 3,6 & 6,9 & 7,0 & 4,5 & 9,8 & 2,5 & 10,7 & 0,9 & 1,5 & 2,8 \\
\hline$\% \mathrm{Fe}_{2} \mathrm{O}_{3}$ & 10,0 & 6,2 & 3,7 & 5,4 & 6,3 & 4,8 & 3,7 & 4,9 & 4,2 & 2,9 & 3,7 & 4,1 \\
\hline$\% \mathrm{MgO}$ & 1,3 & 15,7 & 21,0 & 16,8 & 17,7 & 18,9 & 16,4 & 17,4 & 17,1 & 23,6 & 22,8 & 17,4 \\
\hline$\% \mathrm{CaO}$ & 0,8 & 1,5 & 1,1 & 0,8 & 1,2 & 1,1 & 2,5 & 2,4 & 1,3 & 2,2 & 2,9 & 1,9 \\
\hline$\% \mathrm{MnO}$ & 0,0 & 2,8 & 2,9 & 3,5 & 3,0 & 3,9 & 2,8 & 12,2 & 2,6 & 3,7 & 3,9 & 4,7 \\
\hline$\% \mathrm{~K}_{2} \mathrm{O}$ & 0,6 & 1,7 & 0,4 & 2,0 & 1,6 & 1,5 & 0,7 & 1,1 & 0,9 & 0,0 & 0,2 & 0,9 \\
\hline$\% \mathrm{Cl}$ & 0,0 & 1,4 & 2,9 & 1,8 & 1,3 & 2,0 & 6,2 & 4,1 & 2,4 & 6,1 & 5,7 & 3,0 \\
\hline $\mathrm{Si}^{4+}$ & 3,18 & 3,83 & 4,06 & 3,97 & 3,90 & 4,01 & 3,80 & 3,80 & 3,82 & 4,00 & 3,93 & 4,16 \\
\hline $\mathrm{Al}^{3+}$ & 0,82 & 0,17 & 0,00 & 0,03 & 0,10 & 0,00 & 0,20 & 0,20 & 0,18 & 0,00 & 0,07 & 0,00 \\
\hline$\sum$ Tetraedro & 4,00 & 4,00 & 4,06 & 4,00 & 4,00 & 4,01 & 4,00 & 4,00 & 4,00 & 4,00 & 4,00 & 4,16 \\
\hline $\mathrm{Al}^{3+}$ & 1,69 & 0,57 & 0,27 & 0,48 & 0,42 & 0,34 & 0,56 & 0,00 & 0,61 & 0,07 & 0,05 & 0,21 \\
\hline $\mathrm{Fe}^{3+}$ & 0,46 & 0,29 & 0,18 & 0,26 & 0,30 & 0,23 & 0,18 & 0,25 & 0,20 & 0,14 & 0,18 & 0,20 \\
\hline $\mathrm{Mg}^{2+}$ & 0,04 & 1,47 & 1,97 & 1,58 & 1,66 & 1,79 & 1,61 & 1,78 & 1,60 & 2,32 & 2,26 & 1,65 \\
\hline $\mathrm{Mn}^{2+}$ & 0,00 & 0,15 & 0,15 & 0,19 & 0,16 & 0,21 & 0,16 & 0,71 & 0,14 & 0,21 & 0,22 & 0,25 \\
\hline$\sum$ Octaedro & 2,19 & 2,48 & 2,57 & 2,51 & 2,54 & 2,57 & 2,51 & 2,74 & 2,55 & 2,74 & 2,71 & 2,31 \\
\hline \multicolumn{13}{|l|}{ Entrecamada } \\
\hline $\mathrm{K}^{+}$ & 0,05 & 0,14 & 0,03 & 0,16 & 0,13 & 0,12 & 0,06 & 0,10 & 0,07 & 0,00 & 0,02 & 0,07 \\
\hline $\mathrm{Ca}^{2+}$ & 0,05 & 0,10 & 0,07 & 0,05 & 0,08 & 0,07 & 0,18 & 0,18 & 0,09 & 0,16 & 0,21 & 0,13 \\
\hline $\mathrm{Mg}^{2+}$ & 0,08 & 0,00 & 0,00 & 0,00 & 0,00 & 0,00 & 0,00 & 0,00 & 0,00 & 0,00 & 0,00 & 0,00 \\
\hline \multicolumn{13}{|l|}{ Ânions - $\mathrm{O}_{10}$} \\
\hline $\mathrm{OH}^{-}$ & 2,00 & 0,85 & 1,69 & 1,81 & 1,86 & 1,79 & 1,31 & 1,52 & 1,74 & 1,32 & 1,36 & 1,68 \\
\hline $\mathrm{Cl}^{-}$ & 0,00 & 0,15 & 0,31 & 0,19 & 0,14 & 0,21 & 0,69 & 0,48 & 0,26 & 0,68 & 0,64 & 0,32 \\
\hline Carga tetraed. & $-0,82$ & $-0,17$ & 0,24 & $-0,03$ & $-0,10$ & 0,05 & $-0,20$ & $-0,20$ & $-0,18$ & 0,00 & $-0,07$ & 0,63 \\
\hline Carga Octaed. & 0,51 & $-0,17$ & $-0,42$ & $-0,24$ & $-0,19$ & $-0,32$ & $-0,22$ & $-0,25$ & $-0,07$ & $-0,31$ & $-0,36$ & $-0,96$ \\
\hline Carga Total & $-0,31$ & $-0,34$ & 0,18 & $-0,27$ & $-0,29$ & $-0,27$ & $-0,42$ & $-0,45$ & $-0,25$ & $-0,31$ & $-0,43$ & $-0,33$ \\
\hline Carga Entrec. & 0,31 & 0,34 & 0,18 & 0,27 & 0,29 & 0,27 & 0,41 & 0,45 & 0,25 & 0,31 & 0,43 & 0,33 \\
\hline
\end{tabular}

P1: Pedon 1; hor.: horizonte; tetraed.: tetraedro; octaed.: octaedro; entrec.: entrecamada. 


\subsection{3 - Elementos terras-raras (ETR) na composição mineral}

A soma dos ETR na Zona Baixa é muito pequena, sendo geralmente próxima da metade das outras amostras (Tabela 4.4). Há um empobrecimento dos ETR com maior número atômico $(1,16<\mathrm{La} / \mathrm{Lu}<2,49)$, comportamento comumente verificado em sedimentos e solos (Fleet, 1984) (Tabela 4.4, Figura 4.6). As anomalias positivas de Ce e Eu, próximas ou superiores a 0,10, são as mais importantes dos dados coletados, sendo visíveis devido a um claro desvio em relação à tendência de diminuição dos teores no sentido dos elementos mais pesados (Figura 4.6). Estas anomalias estão provavelmente associadas à alternância de condições redutoras e oxidantes predominantes na área de estudo (Wilde, 1996).

\subsection{4 - Química da água}

As principais características químicas das águas superficiais da lagoa do Meio e das águas superficiais do entorno (Pz2, G0 e G1) foram apresentadas no Capítulo 3, mas algumas informações mais relevantes para as esmectitas estudadas serão relembradas aqui. $\mathrm{O}$ pH das águas varia de 7,66 em Pz2, situado na borda da cordilheira, a 9,64 na lagoa do Meio, havendo um aumento paulatino no sentido da salina. Os teores de $\mathrm{Si}(\mathrm{OH})_{4}$ são altos, entre 3,2 e 97,6 mg/L, havendo um aumento gradativo no sentido da lagoa salina. As concentrações de $\mathrm{Al}^{3+}$ e Fe são de 0,0007 a 0,0594 mg/L e de 0,01 a $0,44 \mathrm{mg} / \mathrm{L}$, respectivamente. $\mathrm{O} \mathrm{Mg}^{2+}$ varia de 0,03 a $2,23 \mathrm{mg} / \mathrm{L} \mathrm{e} \mathrm{o} \mathrm{Cl}^{-}$de 15,78 a 76,17 , sendo que os valores deste ânion são maiores nas proximidades da salina (Tabela 3.10, p. 82).

Cabe destacar ainda que o diagrama de concentração, elaborado com todas as amostras coletadas e apresentado na Figura 3.11 (p. 85), mostra que o $\mathrm{Mg}^{2+}$ aumenta de acordo com o fator de concentração $\left(\mathrm{Na}^{+}\right)$até aproximadamente $10 \mathrm{mg} / \mathrm{L}$ de $\log \mathrm{Na}^{+}$e sofre controle a partir daí.

\section{4 - Discussão dos Resultados}

\subsection{1 - Identificação das esmectitas}

A maior largura e a assimetria dos picos $d_{001}$ de esmectita podem ser indicativos da presença de cristais formados por cristalitos muito pequenos (Moore \& Reynolds, 
Tabela 4.4 - Teores de ETR e relação La/Lu nas amostras analisadas.

\begin{tabular}{|c|c|c|c|c|c|c|c|c|c|c|c|c|c|c|c|c|c|c|}
\hline Ped. & Hor. & $\mathbf{L a}$ & $\mathrm{Ce}$ & Pr & Nd & Sm & $\mathbf{E u}$ & Gd & $\mathbf{T b}$ & $\begin{array}{c}\text { Dy } \\
\text { ppm }\end{array}$ & Ho & $\mathbf{E r}$ & $\mathbf{T m}$ & $\mathbf{Y b}$ & $\mathbf{L u}$ & $\mathbf{Y}$ & Soma & $\mathbf{L a} / \mathbf{L u}^{*}$ \\
\hline 1 & 1 & 43,06 & 88,68 & 10,05 & 37,29 & 7,01 & 1,72 & 6,14 & 0,93 & 5,31 & 1,01 & 2,70 & 0,39 & 2,56 & 0,38 & 30,43 & 237,69 & 1,65 \\
\hline 1 & 3 & 63,04 & 178,60 & 19,16 & 77,35 & 16,39 & 4,24 & 15,28 & 2,26 & 12,50 & 2,27 & 6,11 & 0,87 & 5,48 & 0,83 & 67,56 & 471,96 & 1,11 \\
\hline 1 & 6 & 68,06 & 189,20 & 21,69 & 90,81 & 19,28 & 5,03 & 18,30 & 2,74 & 15,56 & 2,90 & 7,75 & 1,05 & 6,35 & 0,92 & 89,27 & 538,93 & 1,08 \\
\hline 1 & 7 & 27,37 & 47,69 & 5,93 & 22,64 & 4,79 & 1,22 & 4,20 & 0,68 & 4,100 & 0,83 & 2,53 & 0,37 & 2,71 & 0,41 & 22,98 & 148,50 & 0,96 \\
\hline 2 & 5 & 51,39 & 143,40 & 14,51 & 55,96 & 10,38 & 2,36 & 7,71 & 1,11 & 5,95 & 1,05 & 2,79 & 0,41 & 2,73 & 0,41 & 30,42 & 330,61 & 1,82 \\
\hline 2 & 6 & 51,82 & 178,40 & 14,91 & 61,78 & 12,18 & 2,97 & 10,22 & 1,43 & 7,70 & 1,38 & 3,60 & 0,49 & 3,16 & 0,46 & 40,38 & 390,92 & 1,62 \\
\hline 2 & 7 & 51,39 & 115,20 & 13,64 & 53,98 & 11,30 & 2,90 & 10,27 & 1,59 & 8,97 & 1,67 & 4,43 & 0,60 & 3,84 & 0,56 & 49,93 & 330,30 & 1,33 \\
\hline 3 & 5 & 53,38 & 119,30 & 11,61 & 42,28 & 7,74 & 1,78 & 6,47 & 0,97 & 5,70 & 1,07 & 3,04 & 0,45 & 3,07 & 0,46 & 31,18 & 288,55 & 1,68 \\
\hline 3 & 6 & 53,65 & 180,90 & 13,64 & 51,87 & 10,32 & 2,52 & 8,82 & 1,34 & 7,46 & 1,39 & 3,74 & 0,54 & 3,49 & 0,52 & 37,02 & 377,26 & 1,49 \\
\hline 3 & 7 & 25,08 & 65,43 & 5,75 & 21,40 & 4,40 & 1,13 & 4,13 & 0,69 & 4,18 & 0,82 & 2,33 & 0,34 & 2,25 & 0,35 & 23,75 & 162,07 & 1,05 \\
\hline 4 & 2 & 12,97 & 37,11 & 3,27 & 12,70 & 2,55 & 0,62 & 2,26 & 0,34 & 1,89 & 0,35 & 0,92 & 0,13 & 0,90 & 0,13 & 9,84 & 86,02 & 1,41 \\
\hline 4 & 5 & 64,16 & 179,20 & 17,41 & 66,99 & 13,55 & 3,25 & 10,73 & 1,55 & 8,04 & 1,32 & 3,21 & 0,43 & 2,69 & 0,37 & 33,58 & 406,51 & 2,49 \\
\hline 4 & 6 & 49,94 & 154,70 & 14,26 & 55,95 & 11,97 & 3,00 & 10,85 & 1,61 & 8,95 & 1,66 & 4,53 & 0,63 & 4,15 & 0,63 & 48,10 & 370,96 & 1,16 \\
\hline 4 & 7 & 58,32 & 183,90 & 15,29 & 59,41 & 12,05 & 2,96 & 10,60 & 1,55 & 8,59 & 1,58 & 4,28 & 0,59 & 3,81 & 0,58 & 45,51 & 409,06 & 1,47 \\
\hline 5 & 2 & 11,17 & 30,82 & 2,84 & 10,78 & 2,20 & 0,52 & 1,95 & 0,29 & 1,64 & 0,29 & 0,78 & 0,11 & 0,76 & 0,12 & 8,45 & 72,75 & 1,36 \\
\hline 5 & 5 & 54,79 & 138,50 & 12,32 & 45,18 & 8,14 & 1,83 & 6,44 & 0,97 & 5,19 & 0,95 & 2,61 & 0,38 & 2,58 & 0,39 & 27,02 & 307,32 & 2,04 \\
\hline 5 & 6 & 58,33 & 180,10 & 16,48 & 65,37 & 13,36 & 3,25 & 11,42 & 1,71 & 9,43 & 1,74 & 4,75 & 0,68 & 4,61 & 0,69 & 49,29 & 421,26 & 1,23 \\
\hline 5 & 7 & 46,00 & 127,80 & 11,46 & 45,08 & 8,95 & 2,19 & 8,04 & 1,19 & 6,70 & 1,27 & 3,59 & 0,50 & 3,27 & 0,49 & 38,31 & 304,88 & 1,36 \\
\hline
\end{tabular}

Ped.: Pedons; Hor.: Horizontes; * valores normalizados com NASC. 


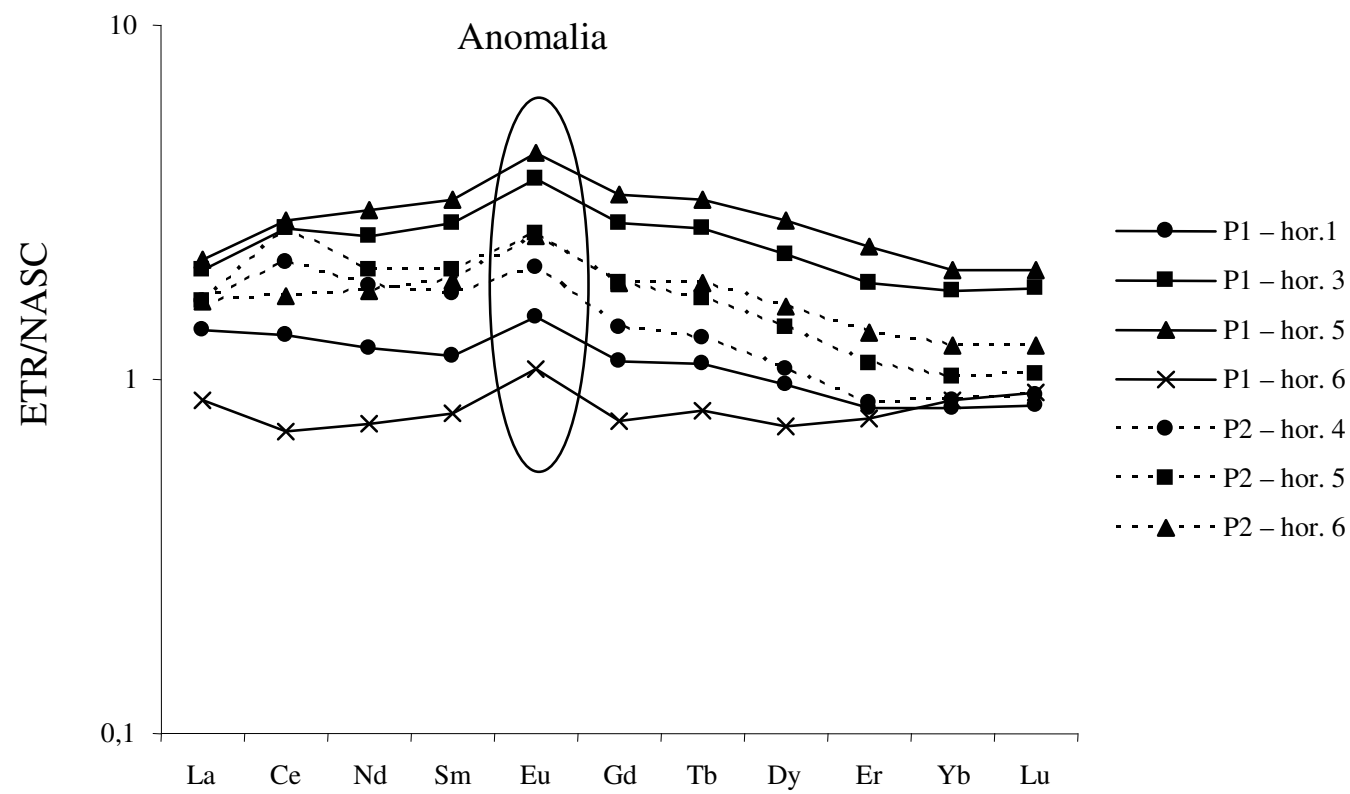

B

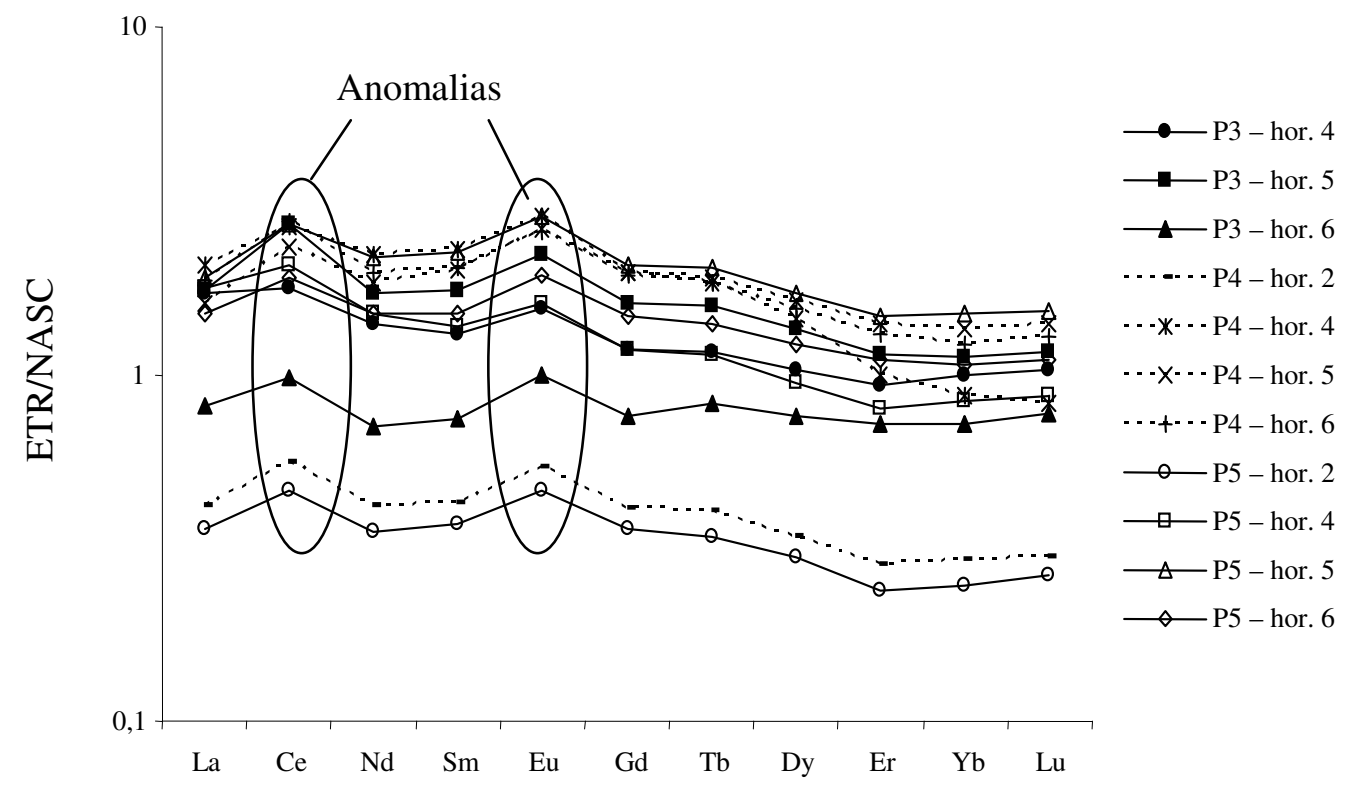

Figura 4.6 - Padrões de ETR normalizados com NASC: A) amostras de P1 e P2; B) amostras de P3, P4 e P5. 
1997; Cuevas et al., 2003), e/ou de interestratificação entre esmectita e algum outro argilo-mineral (Tettenhorst \& Moore, 1978; Moore \& Reynolds, 1997). A aplicação da equação de Scherrer mostra que os cristalitos são efetivamente pequenos em todas as amostras. Por outro lado, a ausência de picos a aproximadamente $4^{\circ} 2 \theta$ em todos os difratogramas saturados com $\mathrm{Mg}^{2+}$ e $\mathrm{K}^{+}$sugere a falta de interestratificação regular (Brindley, 1955), mas as seguintes evidências mostram que provavelmente ocorre interestratificação irregular na Zona Alta: a) a coalescência entre os picos de esmectita e mica na maioria das amostras sugere interestratificação entre estes dois minerais; e b) o colapso para 1,0 nm dos picos saturados com $\mathrm{K}^{+}$em algumas das amostras, associado à expansão destes picos em padrões de EG, são indicativos de camadas mistas de vermiculita e esmectita (Moore \& Reynolds, 1997).

Na Zona Alta, raramente atingida pelo nível superficial da salina, os espaços $d_{060}$ evidenciam o predomínio de minerais dioctaédricos. A fórmula química apresentada na Tabela 4.3 (cristal 1) indica excesso de carga negativa no tetraedro e carga positiva no octaedro, características típicas das esmectitas dioctaédricas beidelita e nontronita. A principal diferença entre estes dois minerais é o tipo de cátion predominante no octaedro: $\mathrm{Al}^{3+}$ na beidelita e $\mathrm{Fe}^{3+}$ na nontronita (Borchardt, 1989). A substituição de $\mathrm{Fe}^{3+}$ por $\mathrm{Al}^{3+}$ nas beidelitas é geralmente muito baixa, comumente inferior a 0,1 apuf/22 (Guven, 1988). Na área de estudo, a predominância de $\mathrm{Al}^{3+}$ e o teor de cerca de 0,5 apuf/22 de $\mathrm{Fe}^{3+}$ na folha octaédrica qualificam o cristal 1 como beidelita enriquecida em ferro, ou ferribeidelita, um mineral intermediário comumente descrito na literatura (ex: Aoki \& Kohyama, 1991; Mayayo et al., 2000). Como há uma grande chance deste mineral não ser um membro final puro, uma vez que está possivelmente intercalado a mica ou vermiculita, é preferível tratá-lo como mineral do tipo ferribeidelita.

Como descrito, a soma de cátions no octaedro do cristal 1 é superior a 2,00 apuf/22. De acordo com Weaver \& Pollard (1973), esta característica normalmente ocorre em beidelitas e nontronitas cujos teores de $\mathrm{Al}^{3+}$ no tetraedro são superiores a 0,5 apuf/22, o que é exatamente o caso da área de estudo. Para estes autores, isto se deve à possível presença de algum hidróxido de alumínio ou ferro na entrecamada. Eles refutam a hipótese da presença de camadas trioctaédricas mistas devido aos baixos teores de 
$\mathrm{Mg}^{2+}$ no octaedro das fórmulas analisadas, os quais são compatíveis com os encontrados no cristal 1.

Na Zona Baixa, sazonalmente atingida pelas flutuações do nível superficial da lagoa salina, os espaços $d_{060}$ mostram o predomínio de minerais trioctaédricos, sendo os valores identificados típicos de estevensita (Decarreaux, 1980), saponita e/ou nontronita (Moore \& Reynolds, 1997). As fórmulas químicas (cristais 2 a 12) indicam a presença de 2 diferentes tipos de esmectitas trioctaédricas. Em um grupo (cristais 3 a 6 e 10 a 12), há pouco ou nenhum $\mathrm{Al}^{3+}$ no tetraedro, o que explica as baixas cargas provenientes desta folha e o excesso de carga proveniente do octaedro. No outro grupo (cristais 2 e 7 a 9), os conteúdos de $\mathrm{Al}^{3+}$ no tetraedro são suficientemente altos para aumentar a contribuição da carga vinda desta folha, que é muito próxima à do octaedro.

Saponita e estevensita são as esmectitas ricas em $\mathrm{Mg}^{2+}$, possuindo caráter trioctaédrico. As diferenças de composição química entre estes dois membros-finais estão justamente nos teores de $\mathrm{Al}^{3+}$ no tetraedro e na conseqüente origem da carga. A estevensita contém pouca ou nenhuma substituição de $\mathrm{Al}^{3+}$ na folha tetraédrica e a maioria da sua carga é originada no octaedro. A saponita apresenta teores ligeiramente maiores de substituição isomórfica de $\mathrm{Al}^{3+}$ no tetraedro e, por isto, há maior contribuição de carga proveniente desta folha (Faust \& Murata, 1953; Weaver \& Pollard, 1973). Baseando-se nestes critérios, as esmectitas do primeiro grupo possuem composição semelhante a da estevensita enquanto as do segundo grupo apresentam composição próxima a da saponita.

Entretanto, duas características presentes nas fórmulas dos cristais 2 a 12 não estão de acordo com a composição clássica de membros-finais de estevensita e saponita. A primeira delas é a substituição de $\mathrm{Cl}^{-}$por $\mathrm{OH}^{-}$, especificidade não encontrada em espécimes de saponita/estevensita descritos na literatura. O segundo é uma soma de cátions do octaedro bem inferior a 3,00 apuf/22. Faust \& Murata (1953) e Faust et al. (1959) afirmam que as posições no octaedro não são totalmente preenchidas em estevensitas, sendo este o principal mecanismo de produção de carga deste mineral. Entretanto, a soma dos cátions do octaedro apresentada por estes autores (2,92 apfu/22) é significativamente maior do que a soma encontrada no presente trabalho (2,31 a 2,74 apfu/22). Tettenhorst \& Moore (1978), Kodama et al. (1988) e Pozo \& 
Casas (1999) reportam uma deficiência octaédrica em saponitas e estevensitas similar à dos cristais aqui estudados e atribuem esta característica a duas possíveis causas: a presença de uma subordinação dioctaédrica ou uma possível dissolução seletiva de alguns dos átomos no octaedro no decorrer das análises. Na área de estudo todas os espécimes ricos em $\mathrm{Mg}^{2+}$, com exceção do 10 e 11, apresentam uma composição intermediária entre as folhas dioctaédrica e trioctaédrica, conforme mostrado na Figura 4.7. Desta forma, os minerais do tipo estevensita e saponita presentes na área de estudo parecem possuir um caráter dominantemente trioctaédrico, mas apresentam uma subordinação dioctaédrica.

Cabe destacar, ainda, que as esmectitas aqui estudadas não apresentam $\mathrm{Na}^{+}$na entrecamada, como era de se esperar em minerais de solos sódicos. Isto se deve provavelmente a uma limitação imposta pelo método de observação de amostras no MET, uma vez que as telas de cobre utilizadas como base das amostras causam interferência na determinação deste elemento (Hover et al., 1999).

\subsection{2 - Gênese dos minerais do tipo ferribeidelita}

Dados de DRX da maioria das amostras que contém esmectita dioctaédrica (Zona Alta) sugerem um grau de interestratificação com mica. Esmectitas transformadas a partir de micas geralmente possuem grande substituição no tetraedro, justamente como o mineral do tipo ferribeidelita descrito neste trabalho. Além disto, as micas que ocorrem nos solos do entorno da lagoa do Meio também são enriquecidas em $\mathrm{Fe}^{3+}$, como será apresentado no próximo capítulo desta tese. Desta forma, minerais do tipo ferribeidelita estão possivelmente sendo originados a partir da transformação de mica na Zona Alta, especialmente no horizonte 6, onde há maior disponibilidade de argila para reação.

A transformação de micas em esmectitas é provavelmente facilitada pelos ciclos de umedecimento/ressecamento provocados pelas flutuações do lençol freático. Apesar dos ciclos de umedecimento e ressecamento serem bastante citados como responsáveis pela fixação do $\mathrm{K}^{+}$, um experimento conduzido por Scott \& Smith (1968) mostra que períodos de ressecamento podem ser tanto responsáveis por sua fixação quanto pela sua liberação. Se a mica está sujeita à abertura de apenas das bordas, o que pode ocorrer durante períodos de umedecimento, a tendência é haver o 


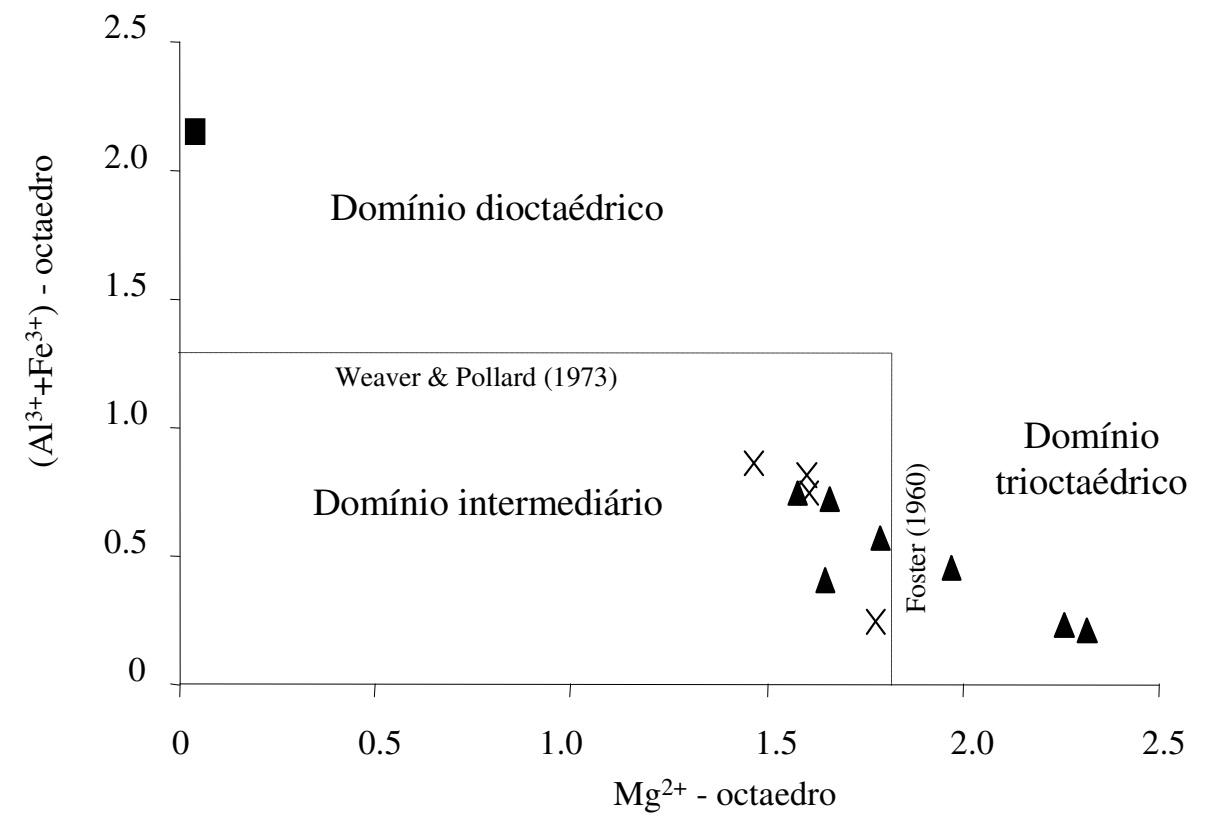

Figura 4.7 - Diagrama mostrando o caráter dioctaédrico, trioctaédrico e intermediário das fórmulas de esmectitas. Símbolos: Triângulos: P5, horizonte 2; X - P4, horizonte 2; Quadrado: P1, horizonte 6. 
colapso de parte da entrecamada durante o ressecamento e a conseqüente fixação de $\mathrm{K}^{+}$. Entretanto, o ressecamento também pode provocar concomitantemente a abertura total de algumas entrecamadas, antes abertas só nas bordas, liberando o $\mathrm{K}^{+}$ anteriormente preso em suas partes internas. A abertura apenas das bordas parece ser mais comum em micas com tamanhos de silte ou maiores, enquanto a abertura de camadas inteiras atinge principalmente micas pequenas, do tamanho de argila (Fanning et al., 1989). Na área de estudo, as micas estão na fração argila fina, sugerindo que o $\mathrm{K}^{+}$esteja sendo liberado de suas entrecamadas. Os Pedons 1 e 2, onde estão as esmectitas dioctaédricas, estão situados nos pontos mais altos da topossequência, sendo provavelmente submetidos a períodos mais longos de ressecamento e, portanto, à maior liberação de $\mathrm{K}^{+}$das micas aí presentes.

A presença de vermiculita também foi detectada nos difratogramas do horizonte 6 da Zona Alta. Este mineral pode ser uma fase intermediária na transformação micaesmectita, mas é considerado instável, tendo rápida duração no processo (Borchardt, 1989). Assim, é possível que haja formação de vermiculita antes da transformação total de mica em esmectita na área de estudo.

\subsection{3 - Gênese dos minerais do tipo saponita e estevensita}

As concentrações de ETR nos solos podem fornecer importantes informações a respeito da gênese destas esmectitas trioctaédricas. Os teores de ETR da maioria das águas naturais são muito inferiores aos presentes nas rochas terrestres (McLennan, 1989). Assim, minerais detríticos ou transformados tendem a apresentar teores de ETR muito superiores aos dos minerais formados por precipitação direta das águas. Este fato tem sido utilizado como ferramenta em ambientes lacustres para distinguir minerais formados por precipitação química (sepiolita, estevensita) daqueles que são herdados (Al-esmectita) ou transformados (paligorsquita) (Torrez Ruiz et al., 1994; López-Galindo et al., 1996; Jamoussi et al., 2003). No presente estudo, os teores de ETR são nitidamente menores nas amostras enriquecidas em minerais do tipo saponita e estevensita (Zona Baixa). Esta evidência sugere que as Mg-esmectitas presentes nos solos do entorno da lagoa do Meio são formadas por precipitação química.

Outras evidências dão forte suporte à ocorrência deste processo de gênese. O diagrama de concentração do $\mathrm{Mg}^{2+}$ mostra que este íon está sendo controlado em 
águas mais salinas, o que sugere um envolvimento na formação de fases minerais. De fato, o diagrama de equilíbrio entre as águas e as fases sólidas, cedido pelo Prof. Dr. Vincent Vallés ("Université de Provence”, França) e apresentado a seguir na Figura 4.8, mostra que as águas mais salinas dos arredores da salina do Meio estão em equilíbrio ou levemente supersaturadas em relação a $\mathrm{Mg}$-filosilicatos (estevensita e sepiolita). Além disto, as Mg-esmectitas da área de estudo ocorrem no horizonte superficial (2) da área sazonalmente atingida pela variação superficial do nível d'água da salina, local onde as máximas taxas de evaporação são esperadas. A precipitação de Mg-esmectitas com composição mista de folhas dioctaédricas e trioctaédricas já foram reportadas por Tettenhorst \& Moore (1978) e Pozo \& Casas (1999) em sedimentos lacustres terciários.

Destaca-se ainda que as características químicas das águas nos arredores da salina do Meio favorecem a neoformação de minerais do tipo saponita e estevensita. Experimentos de síntese efetuados por Siffert (1962) mostraram que a precipitação de esmectitas trioctaédricas a $25^{\circ} \mathrm{C}$ é facilitada pela ocorrência de $\mathrm{pH}$ fortemente alcalino e que, nestas condições, não são necessários altos valores de $\mathrm{Mg}^{2+}$ em solução. Valores de $\mathrm{pH}$ superiores a 8,6 e concentrações de $\mathrm{Mg}^{2+}$ entre 0,03 e 2,23 mg/L nas proximidades da lagoa do Meio (G1, G0 e lagoa) seriam, portanto, propícios ao desencadeamento do processo de neoformação.

A síntese de esmectitas em condições ambientes de temperatura e pressão tem apontado ainda a ocorrência de dois mecanismos envolvidos na precipitação destes minerais: 1) a precipitação inicial de brucita e a fixação posterior de outros íons proveniente da solução (Caillére \& Henin, 1962; Millot, 1970; Harder, 1971); e 2) precipitação de pequenos cristalitos já com composição de esmectita e a posterior coalescência em partículas maiores (Decarreaux, 1980). A não identificação de brucita na área de estudo e a subsaturação das amostras de água estudadas em relação a este mineral, conforme pode ser visto no diagrama de equilíbrio exposto na Figura 4.8, aliadas à ocorrência de cristalitos muito pequenos nos cristais de esmectita, podem indicar uma precipitação inicial de cristalitos com posterior agregação em cristais maiores na área de estudo, conforme sugerido por Decarreaux (1980). 


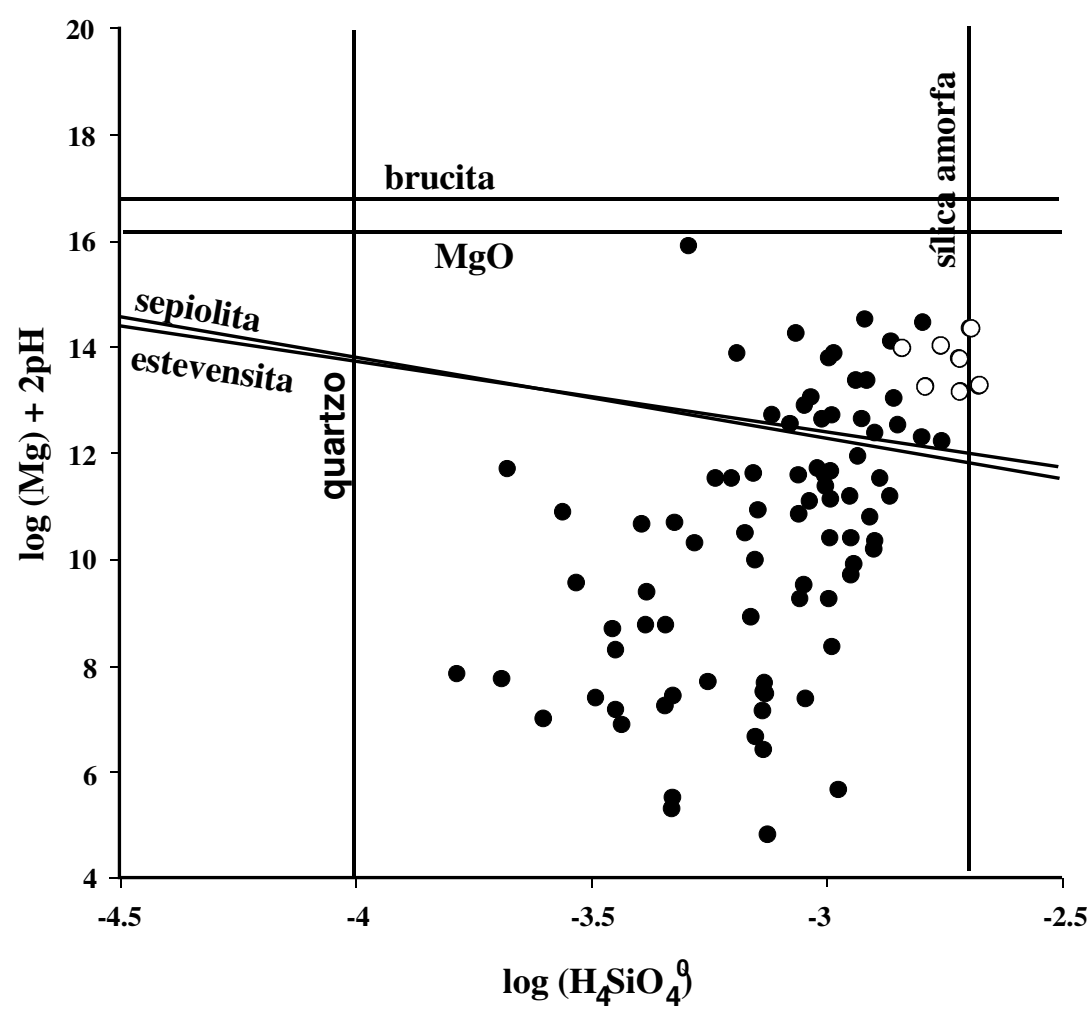

Figura 4.8 - Diagrama de equilíbrio entre as águas analisadas e diferentes minerais (elaborado pelo Prof. Dr. Vincent Valles). Círculos vazados representam amostras dos arredores da lagoa do Meio (Pz2, G0, G1, G2 e lagoa). 


\section{5 - Conclusões}

Este capítulo mostra que as esmectitas dioctaédricas e trioctaédricas presentes nos arredores da lagoa são formadas por diferentes processos. O mineral do tipo ferribeidelita é provavelmente originado pela transformação de um mineral precursor (mica enriquecida em $\mathrm{Fe}^{3+}$ ), um processo de gênese comumente descrito para esmectitas dioctaédricas em ambientes salino-alcalinos. Por outro lado, várias evidências provam que os minerais magnesianos do tipo saponita e estevensita estão sendo formados por precipitação química da coluna d'água da lagoa do Meio, o que descarta as outras possibilidades de gênese descritas na literatura.

A maior solubilidade do $\mathrm{Mg}^{2+}$, se comparada a de íons como $\mathrm{Al}^{3+}$ e $\mathrm{Fe}^{3+}$, explica a formação das esmectitas trioctaédricas no centro da depressão que contém a salina, onde as águas estão mais concentradas.

\section{6 - Referências Bibliográficas}

Akbulut, A. \& Kadir, S. (2003) The Geology and origin of sepiolite, palygorskite and saponite in Neogene lacustrine sediments of the Serinhisar-Acipayam Basin, Denizli, Sw Turkey. Clays and Clay Minerals, 51, 279-292.

Anderson, J.U., (1963). An improved pretreatement for mineralogical analysis of samples containing organic matter. Clays and Clay Minerals, 10, 380-388.

Aoki, S \& Kohyama, N. (1991) The vertical change in clay mineral composition and chemical characteristics of smectite in sediment cores from the southern part of the Central Pacific Basin. Marine Geology, 90, 41-49.

Banfield, J. F.; Jones, B.F.; and Veblen, D.R. (1991) An AEM-TEM study of weathering and diagenesis, Abert Lake, Oregon: II. Diagenetic modification of the sedimentary assemblage. Geochimica et Cosmochimica Acta, 55, 2795-2810.

Biscaye, P. (1965) Mineralogy and sedimentation of recent deep-seaclay in the Atlantic Ocean and adjacent seas and oceans. Geological Society of America Bulletin, 76, 803-832.

Borchardt, G. (1989) Smectites. Pp. 675-728 in: Minerals in Soil Environments (J.B. Dixon and S.B Weed, eds). Soil Science Society of America Book Series n. 1, Soil Science Society of America, Inc., Madison.

Brindley, G.W. (1955) Stevensite, a montmorillonite-type mineral showing mixed-layer characteristics. American Mineralogist, 40, 239-247.

Caillère, S. \& Hénin, S. (1962) Vues d'ensemble sur le problème de la synthèse des mineraux phylliteux à basse température. Pp. 221-230 in: Colloque du CNRS: Genèse et synthèse des argiles, v. 105

Cuevas, J; De La Villa, V.; Ramirez, S.; Petit, S; Meunier, A.; Leguey, S. (2003) Chemistry of Mg smectites in lacustrine sediments from the Vicalvaro sepiolite deposit, Madrid Neogene Basin (Spain). Clays and Clay Minerals, 51, 457:472.

Darragi, F. \& Tardy, Y. (1987) Authigenic trioctahedral smectites controlling pH, alkalinity, silica and magnesium concentrations in alkaline lakes. Chemical Geology, 63, 59-72. 
Decarreaux, A. (1980) Cristallogène expérimentale des smectites magnésiennes: hectorite, stévensite. Bulletin Minéral., 103, 579-590.

Fanning, D.S.; Vissarion, Z.K. \& El-Desoky, M.A. (1989) Micas. Pp. 551-634 in: Minerals in Soil Environments (J.B. Dixon \& S.B. Weed, eds). SSSA Book Series, n.1. Soil Science Society of America.

Faust, G.T \& Murata, K.J. (1953) Stevensite, redefined as a member of the montmorillonite group. The American Mineralogist, 38, 973-987.

Faust, G.T; Hathaway, J.C.; and Millot, G. (1959) A restudy of stevensite and allied minerals. The American Mineralogist, 44, 342-370.

Fleet, A.J. (1984) Aqueous and sedimentary geochemistry of the rare earth elements. Pp. 343-373 in: Rare Earth Element Geochemistry (P. Henderson, editor). Developments in Geochemistry.

Foster, M.D. (1960) Interpretation of the composition of trioctahedral micas. U.S. Geological Survey Professional Paper, 354 B, 11-43.

Gac, J.Y., Droubi, A., Fritz, B., Tardy,Y. (1977). Geochemical behavior of silica and magnesium during the evaporation of waters in Chad. Chemical Geology, 19, 215-228.

Gromet L.P.; Dymek, R.F.; Haskin, L.A.; Korotev, R.L. (1984) The "North American shale composite": its compilation, major and trace element characteristics. Geochimica et Cosmochimica Acta, 48, 2469-2482.

Guven, N. (1988) Smectites. Pp. 497-559 in: Reviews in Mineralogy (S.W. Bailey, ed.),v. 19.

Harder, H. (1971) The role of magnesium in the formation of smectite minerals. Chemical Geology, 10, 31-39.

Hover, V.C.; Walter, L.M.; Peacor, D.R.; Martini, A. (1999) Mg-smectite authigenesis in a marine evaporative environment, salina Ometepec, Baja California. Clays and Clay Minerals, 47, 252-268.

Ito, T.; Komuro, K.; Hatsuya, K.; Nishi, H. (2004) Chemical composition of ferromanganese micronodules in sediments at site 1216, ODP Leg 199, Paleogene equatorial transect. Pp 1-20 in: Proceedings of the Ocean Drilling Program. Scientific Results, 199 (on line publication at wwwodp.tamu.edu/publications/SR.HTML).

Jackson, M.L. (1979) Soil Chemical Analysis-Advanced Course. By author, Madison, 895 pp.

Jamoussi, F; Ben Aboud, A.; López Galindo, A. (2003) Palygorskite genesis through silicate transformation in Tunisian continental Eocene deposits. Clay Minerals, 38, 187-199.

Jones, B.F. (1986) Clay mineral diagenesis in lacustrine sediments. Pp. 291-300 in: Studies in Diagenesis (F.A. Mumpton, editor). US Geological Survey Bulletin, 1578.

Kodama, H.; De Kimpe, C.R.; Dejou, J. (1988) Ferrian saponite in a gabbro saprolite at Mont Mégantic, Quebec. Clays and Clay Minerals, 36, 102-110.

López-Galindo, A.; Ben Aboud, A.; Fenoll Hach-Ali, P.; Casas Ruiz, J. (1996) Mineralogical and geochemical characterization of palygorskite from Gabasa (Ne Spain). Evidence of a detrital precursor. Clay Minerals, 31, 33-44.

Mayayo, M.J.; Bauluz, B.; Gonzalez Lopez, J.M. (2000) Variations in the chemistry of smectites from the Calatayud Basin (NE Spain). Clay Minerals, 35, 365-374.

McLennan, S.M. (1989) Rare earth elements in sedimentary rocks: influence of provenance and sedimentary processes. Pp. 169-200 in: Geochemistry and Mineralogy of Rare Earth Elements (B.R. Lipin and G.A. McKay, editors). Reviews in Mineralogy 21, Mineralogical Society of America, Washington, D.C.

Millot, G. (1970) Geology of clays. Chapman \& Hall, London, 429 pp.

Moore, D. \& Reynolds, R.C. (1997) X-ray Diffraction and the Identification and Analysis of Clay Minerals. Oxford University Press, city, 378 pp.

Pozo, M. \& Casas, J. (1999) Origin of kerolite and associated Mg clays in palustrine-lacustrine environments. The Esquivias deposit (Neogene Madrid Basin, Spain). Clay Minerals, 34, 395-418. 
Scott, A.D. \& Smith, S.J. (1968) Mechanism for soil potassium release by drying. Soil Science Society of America Proceedings, 32, 443-444.

Siffert, B. (1962) Quelques réactions de la silice en solution: la formation des argiles. Mémoires $d u$ Service de la Carte Géologique d'Alsace et de Lorraine, 21, 1-86 p.

Tettenhorst, R. \& Moore Jr., G.E. (1978) Stevensite oolites from the Green River formation of Central Utah. Journal of Sedimentary Petrology, 48, 587-594.

Theisen, A.A. \& Harward, M.E. (1962) A paste method for preparation of slides for clay mineral identification by x-ray diffraction. Soil Science Society of America Proceedings , 26, 90-91.

Thompson, M.L. \& Ukrainczyk, L. (2002) Micas. Pp. 431-466 in: Soil Mineralogy with Environmental Application (J.B. Dixon, \& D. G. Schulze, editors). Soil Science of America Book Series, 7, Soil Science Society of America, Inc., Madison.

Torrez-Ruiz, J.; López-Galindo, A.; Gonzalez-López, J.M.; Delgado, A. (1994) Geochemistry of Spanish sepiolite-palygorskite deposits: genetic considerations based on trace elements and isotopes. Chemical Geology, 112, 221-245.

Weaver, C.E. \& Pollard, L.D. (1973) The Chemistry of Clay Minerals. Elsevier, Amsterdam. 213 pp.

Wilde, P. (1996) The whole-rock Ce anomaly: a potential indicator of eustatic sea-level changes in shales of the anoxic facies. Sedimentary Geology, 101, 43-53. 
Capítulo 5

\author{
MINERALOGIA E GÊNESE DE \\ MICAS NOS SOLOS DO \\ ENTORNO DA SALINA DO MEIO
}




\section{5 - MINERALOGIA E GÊNESE DE MICAS NOS SOLOS DOS ARREDORES DA LAGOA DO MEIO}

\section{Resumo}

A origem autigênica de ilita, glauconita e mica glauconítica já foi relatada em lagos salinoalcalinos, mas apenas a mica glauconítica é comumente formada neste tipo de ambiente. A formação conjunta destes três minerais em um mesmo lago salino-alcalino parece não ter sido observada anteriormente. O objetivo deste capítulo é descrever a mineralogia e identificar os processos responsáveis pela formação de minerais do tipo ilita, glauconita e mica glauconítica no entorno e abaixo da lagoa do Meio.

As amostras de solo foram coletadas ao longo de uma topossequência situada entre o nível d'água superficial da lagoa do Meio no período de seca e a borda da cordilheira e encaminhados para análises de DRX, MET-EDS e ICP-MS. Amostras de água foram coletadas em um transecto que abarca a lagoa do Meio, a cordilheira e a baía adjacente e então submetidas à Cromatografia de Íons, EAA e ICP-MS.

As micas têm caráter dioctaédrico, são fortemente associadas a $\mathrm{Fe}_{2} \mathrm{O}_{3}$ e $\mathrm{Al}_{2} \mathrm{O}_{3}$ e possuem interestratificação com até $20 \%$ de camadas de esmectitas. A classificação de cristais individuais revela que as micas dominantes são do tipo glauconita e mica glauconítica, sendo ainda encontrados alguns cristais de ilita interestratificada. Materiais amorfos associados a cristalitos muito pequenos também foram observados no horizonte enriquecido em mica. As amostras de água superficial da lagoa e de água subterrânea de seus arredores apresentam pH alto, Eh negativo, temperaturas máximas de $40^{\circ} \mathrm{C}$, alta concentração de $\mathrm{K}^{+}$e baixa concentração de $\mathrm{Si}(\mathrm{OH})_{4}$. Experimentos de síntese disponíveis na literatura mostram que águas semelhantes a estas são ideais para a cristalização de micas dioctaédricas a partir da precipitação inicial de hidróxidos amorfos. Desta forma, a composição das águas aliada à presença de materiais amorfos no horizonte com maior presença de mica sugerem que as micas da área de estudo são neoformadas. A formação alternada de glauconita, mica glauconítica e ilita deve ocorrer devido a variações sazonais de $\mathrm{pH}$, temperatura e composição química das águas em microambientes, já que nesta escala as mudanças são provavelmente mais rápidas e extremas.

Palavras-chave: lago salino, micas dioctaédricas, interestratificado mica-esmectita, ilita férrica, precipitação química, neoformação. 


\section{Abstract}

\section{Mineralogy and genesis of micas in the soils around lagoa do Meio.}

Genesis of illite, glauconite, and glauconitic mica through neoformation or transformation of smectite has been reported in sediments associated to alkaline-saline lakes, although only the last mineral is commonly formed in these environments. The occurrence of these three authigenic minerals in the same saline-alkaline lake seems to have not been described before. The objective of this study is to investigate the mineralogy and mechanisms of genesis of illite, glauconite, and glauconitic mica type minerals in the soils surrounding a modern alkaline-saline lake of Nhecolândia.

Soils were sampling along a toposequence and analyzed by XRD, TEM-EDS, and ICP-MS. Water was collect along a transect involving the toposequence and submitted to ion chromatography, AAS, and ICP-MS analyses.

Micas are dioctahedral, strongly associated to $\mathrm{Fe}_{2} \mathrm{O}_{3}$ and $\mathrm{Al}_{2} \mathrm{O}_{3}$, and interstratified with $20 \%$ or less smectite layers. Classification of individual crystals shows that Fe-enriched interstratified glauconite and glauconitic mica are the dominant micas, but a few crystals of mixed-layered illite were recognized. Amorphous materials associated to small crystallites are also present in the horizon enriched in mica. Water samples from the lake and the surrounding water table present high $\mathrm{pH}$, negative Eh, temperatures up to $40^{\circ} \mathrm{C}$, high concentration of $\mathrm{K}^{+}$, and low concentration of $\mathrm{Si}(\mathrm{OH})_{4}$. Synthesis of micas available in the literature shows that similar water conditions allow for dioctahedral mica crystallization from initial precipitation of amorphous hydroxides. Therefore, water characteristics combined to the presence of amorphous materials in the mica-richest horizon suggest that micas of the study area are neoformed. The alternated origin of glauconite, glauconitic mica, and illite mixed-layer minerals probably occurs due to seasonal variations of $\mathrm{pH}$, temperature, and chemical composition of waters in microenvironments, since in this scale the changes are possibly faster and more extreme.

Key words: saline lake, dioctahedral micas, mica-smectite interstratification, ferric illite, chemical precipitation, neoformation. 


\section{1 - Introdução}

Ilita, glauconita e mica glauconítica são as micas dioctaédricas descritas na literatura como possivelmente formadas em ambientes salino-alcalinos. Ilita e glauconita são caracterizadas, respectivamente, por altos teores de $\mathrm{Al}^{3+}$ e altos teores de $\mathrm{Fe}^{3+}$ na estrutura cristalina (Odom, 1984; Srodón \& Eberl, 1984). A mica glauconítica, por sua vez, é um mineral com teores de $\mathrm{Al}^{3+} \mathrm{e} \mathrm{Fe}^{3+}$ intermediários entre ilita e glauconita, sendo também identificada por outros nomes, entre eles ilita glauconítica (Porrenga, 1968) e ilita férrica (Jung, 1954; Baker, 1997, Hugget et al., 2001).

A gênese de ilita e glauconita em ambientes salino-alcalinos é rara (Singer \& Stoffers, 1980; El Albani et al., 2005), sendo a primeira mais freqüentemente formada em ambientes profundos submetidos a diagênese ou metamorfismo (Odom, 1984), e a segunda quase que exclusivamente formada em ambientes marinhos sujeitos a baixas temperaturas (Mcrae, 1972; Odin \& Matter, 1981). A mica glauconítica, por outro lado, é comumente originada em ambientes continentais lacustres salinos, sendo geralmente descrita em sedimentos não atuais (Porrenga, 1968; Rouchy et al., 1993; Jeans et al., 1994; Baker, 1997).

Os mecanismos responsáveis pela gênese destes minerais no entorno de lagos salinos são a neoformação e a transformação a partir de esmectitas. A neoformação é o processo mais comum para a ilita (Jones \& Weir, 1983; Turner \& Fishman, 1991) e para glauconita (El Albani et al., 2005). Quanto à mica glauconítica, a transformação a partir da esmectita é o mecanismo mais aceito (e.g. Keller, 1958; Parry \& Reeves, 1966; Porrenga, 1968), mas a neoformação também já foi registrada (e.g. Jeans et al., 1994).

O objetivo deste capítulo é descrever a mineralogia dos minerais do grupo das micas encontrados nos solos do entorno da lagoa do Meio e identificar os processos responsáveis pela sua formação. Registros na literatura de gênese de ilita, glauconita e mica glauconítica em ambiente salino-alcalino, mesmo que raro para as 2 primeiras, mostra que o ambiente aqui estudado pode ser capaz de oferecer as condições geoquímicas necessárias para uma origem autigênica destes minerais, seja ela por neoformação ou transformação de esmectita. 


\section{2 - Materiais e Métodos}

\subsection{1 - $\underline{\text { Análises de solo }}$}

Este item visa fornecer um panorama geral dos materiais e métodos utilizados no presente capítulo, mas maiores detalhes podem ser encontrados no Anexo 1. As amostras de solo aqui selecionadas, coletadas nos Pedons 1 a 5 (P1 a P5) da Topossequência 1 (T1), já foram utilizadas em métodos expostos nos capítulos anteriores. A Tabela 5.1 mostra quais das amostras coletadas em campo foram usadas em cada uma das análises laboratoriais descritas a seguir.

Análise granulométrica dos solos foi realizada em 20 amostras, a partir do método da pipeta (USDA, 1996). Foram utilizados os seguintes intervalos de tamanho das partículas: 5 frações de areia - areia muito grossa $(1$ a $2 \mathrm{~mm})$, areia grossa $(0,5$ a 1 $\mathrm{mm})$, areia média $(0,25$ a 0,5$)$, areia fina $(0,125$ a $0,25 \mathrm{~mm})$ e areia muito fina $(0,125 \mathrm{a}$ $0,05 \mathrm{~mm}) ; 2$ frações de silte - silte grosso $(0,02$ a $0,05 \mathrm{~mm})$ e silte fino $(0,02$ a 0,002 $\mathrm{mm})$; e 2 frações de argila - argila grossa $(0,002$ a $0,0002 \mathrm{~mm})$ e argila fina $(<0,0002$ $\mathrm{mm})$.

Grandes quantidades de argila fina $(<0,0002 \mathrm{~mm})$, argila grossa $(0,002$ a $0,0002 \mathrm{~mm})$ e silte fino $(0,02$ a $0,002 \mathrm{~mm})$ das 20 amostras foram separadas através de centrifugação e sedimentação, após destruição da matéria orgânica com $\mathrm{NaOCl}, \mathrm{pH}$ 9,5 (Anderson, 1963). A fração argila fina foi então encaminhada para as análises expostas a seguir.

A identificação das micas foi realizada através de Difração de Raios X (DRX). As amostras foram submetidas a 5 diferentes tratamentos: saturação com $\mathrm{Mg}^{2+}$, solvatação das lâminas saturadas em $\mathrm{Mg}^{2+}$ com etileno glicol (EG), saturação com $\mathrm{K}^{+}$ e posterior aquecimento das lâminas saturadas em $\mathrm{K}^{+}$a temperaturas de $350^{\circ} \mathrm{C}$ e $550^{\circ} \mathrm{C}$. Amostras orientadas foram produzidas através do espalhamento, em uma só direção, de pastas de argilas tratadas em lâminas de vidro (Theisen \& Harward, 1962). As lâminas foram analisadas em um Difratômetro Siemens D-500, utilizando-se radiação $\mathrm{K}_{\alpha}$ e alvo de cobre $(\mathrm{Cu})$, e rodadas a uma taxa de $0,02^{\circ} 2 \theta$ por etapa, a cada 1 segundo. Estimativas semi-quantitativas (em \%) da concentração de micas em cada amostra foram determinadas de acordo com a proporção de área dos picos de DRX em padrões de EG, segundo procedimentos de Biscaye (1965). Quantidades em g/kg 
Tabela 5.1 - Amostras selecionadas para diferentes análises de solos incluídas no Capítulo 5.

\begin{tabular}{|c|c|c|c|c|c|c|}
\hline $\begin{array}{l}\text { Profundidade } \\
(\mathbf{c m})\end{array}$ & Horizonte & $\begin{array}{c}\text { Análise } \\
\text { Granulom. }\end{array}$ & $\begin{array}{c}\text { DRX e } \\
\text { derivados }\end{array}$ & $\mathrm{ICP} \mathrm{MS}^{2}$ & $\begin{array}{c}\text { Análise } \\
\text { Estatística }^{3}\end{array}$ & MET-EDS \\
\hline \multicolumn{7}{|c|}{ PEDON 1} \\
\hline $0-40$ & 1 & $\mathrm{X}$ & $\mathrm{X}$ & $\mathrm{X}$ & $\mathrm{X}$ & ------------ \\
\hline 230 & 3 & $X$ & $X$ & $\mathrm{X}$ & $\mathrm{X}$ & ---------- \\
\hline $250-270$ & 5 & $\mathrm{X}$ & $X$ & $\mathrm{X}$ & $\mathrm{X}$ & ------------ \\
\hline 350 & 6 & $\mathrm{X}$ & $X$ & $\mathrm{X}$ & $\mathrm{X}$ & $X$ \\
\hline \multicolumn{7}{|c|}{ PEDON 2} \\
\hline $0-40$ & 1 & $\mathrm{X}$ & $\mathrm{X}$ & -------- & ------- & ----------- \\
\hline 80 & 4 & $\mathrm{X}$ & $\mathrm{X}$ & $X$ & $\mathrm{X}$ & ------------ \\
\hline $110-145$ & 5 & $\mathrm{X}$ & $X$ & $\mathrm{X}$ & $\mathrm{X}$ & ---------- \\
\hline $168-175$ & 6 & $\mathrm{X}$ & $\mathrm{X}$ & $\mathrm{X}$ & $\mathrm{X}$ & ------------ \\
\hline \multicolumn{7}{|c|}{ PEDON 3} \\
\hline $0-6$ & 1 & $\mathrm{X}$ & $\mathrm{X}$ & ----------- & ----------- & ---------- \\
\hline $12-65$ & 4 & $\mathrm{X}$ & $\mathrm{X}$ & $\mathrm{X}$ & $\mathrm{X}$ & ---------- \\
\hline $68-73$ & 5 & $\mathrm{X}$ & $\mathrm{X}$ & $\mathrm{X}$ & $\mathrm{X}$ & ----------- \\
\hline $78-85$ & 6 & $\mathrm{X}$ & $X$ & $\mathrm{X}$ & $\mathrm{X}$ & $\mathrm{X}$ \\
\hline \multicolumn{7}{|c|}{ PEDON 4} \\
\hline $0-5$ & 2 & $\mathrm{X}$ & $\mathrm{X}$ & $\mathrm{X}$ & $\mathrm{X}$ & ------------ \\
\hline $30-40$ & 4 & $\mathrm{X}$ & $X$ & $X$ & $\mathrm{X}$ & ----------- \\
\hline $70-80$ & 5 & $X$ & $X$ & $X$ & $X$ & ------------ \\
\hline 100 & 6 & $X$ & $X$ & $X$ & $\mathrm{X}$ & ----------- \\
\hline \multicolumn{7}{|c|}{ PEDON 5} \\
\hline $0-5$ & 2 & $\mathrm{X}$ & $\mathrm{X}$ & $\mathrm{X}$ & $\mathrm{X}$ & ---------- \\
\hline $20-40$ & 4 & $\mathrm{X}$ & $\mathrm{X}$ & $\mathrm{X}$ & $\mathrm{X}$ & ---------- \\
\hline 70 & 5 & $\mathrm{X}$ & $\mathrm{X}$ & $\mathrm{X}$ & $\mathrm{X}$ & ----------- \\
\hline 90 & 6 & $\mathrm{X}$ & $\mathrm{X}$ & $\mathrm{X}$ & $\mathrm{X}$ & $X$ \\
\hline
\end{tabular}

1 - Inclui a análise de Difração de Raios-X, a estimativa semiquantitativa da \% de mica na assembléia, total em g/kg, índices 1 e 2; \% de camadas de mica nos cristais; 2 - Inclui cátions; 3 - Análise de Função Discriminante; 4 Microscópio Eletrônico de Transmissão, acoplado ao Espectrômetro tipo Dispersão em Energia, utilizado estudo da morfologia e para o cálculo das fórmulas químicas de cristais individuais.

X - Amostras analisadas; ------- - Amostras não selecionadas para esta análise. 
de micas e esmectitas na argila fina de cada horizonte foram obtidas pela seguinte fórmula:

$$
\underline{Q}=\% \text { min } 1 \text { Taf }
$$

$100 \%$

sendo que Q é a quantidade do mineral em g/kg, \% $\%_{\min }$ é a estimativa semi-quantitativa do mineral em cada amostra, calculada pela proporção dos picos de DRX, e Taf é o total de argila fina em $\mathrm{g} / \mathrm{kg}$ em cada amostra, obtido através da análise granulométrica.

A intensidade dos picos das micas foi ainda utilizada para o cálculo de dois índices:

- Índice 1: fornece uma indicação geral sobre o conteúdo de Fe total em micas e é dado pela seguinte fórmula:

$$
\mathrm{I}(001) / \mathrm{I}(002)
$$

sendo que $\mathrm{I}(001)$ e $\mathrm{I}(002)$, representam, respectivamente, a intensidade do pico primário e secundário da mica em padrões tratados com $\mathrm{Mg}^{2+}$. Micas enriquecidas em ferro apresentam picos secundários com intensidades mais fracas, por isto, quanto mais altos os resultados do índice, maiores os teores de ferro presentes no mineral (Brown \& Brindley, 1980; Hugget et al., 2001). De acordo com Deconinck et al. (1988), resultados maiores que 2 já representam um maior conteúdo relativo de ferro na estrutura cristalina.

- Índice 2: verifica a existência de material expansivo nas micas, sendo dado pela seguinte fórmula:

$$
\frac{\mathrm{I}(001) / \mathrm{I}(003)\left(\mathrm{Mg}^{2+}\right)}{\mathrm{I}(001) / \mathrm{I}(003)(\mathrm{EG})}
$$

sendo que $\mathrm{I}(001)$ e $\mathrm{I}(003)$ representam, respectivamente, a intensidade do pico primário e terciário da mica em padrões tratados com $\mathrm{Mg}^{2+}$ e etileno glicol (EG). Valores superiores a 1 já indicam a presença de intercalação entre mica e um material expansivo (Srodón \& Eberl, 1984).

As porcentagens de camadas de micas nos minerais interestratificados foram estimadas de acordo com o valor dos picos de DRX $d_{001}$ e $d_{002}$ tratados com EG. De acordo com Reynolds (1980), pico primário $\geq 0,983 \mathrm{~nm}$ acompanhado de pico 
secundário $\leq 0,516 \mathrm{~nm}$ representam $80 \%$ ou mais de camadas de ilitas em interestratificados com esmectitas. Apesar de no presente trabalho terem sido identificados outros minerais do grupo das micas além de ilita, os resultados devem ser próximos, pois os picos padrões destes outros minerais sofrem poucas variações em relação aos da ilita.

A quantificação dos elementos maiores $\left(\mathrm{SiO}_{2}, \mathrm{Al}_{2} \mathrm{O}_{3}, \mathrm{Fe}_{2} \mathrm{O}_{3}, \mathrm{MnO}, \mathrm{MgO}, \mathrm{CaO}, \mathrm{Na}_{2} \mathrm{O}\right.$, $\mathrm{K}_{2} \mathrm{O}, \mathrm{TiO}_{2}$ e $\mathrm{P}_{2} \mathrm{O}_{5}$ ) em 18 amostras foram realizadas por Espectrometria de Plasma Acoplada a Detector de Massas (ICP-MS) (Perkin-Elmer, Elan 6000).

A estimativa semi-quantitativa das micas por DRX e a quantificação dos elementos maiores por ICP-MS foram submetidas conjuntamente à Análise Estatística de Função Discriminante a fim de determinar quais elementos químicos estão associados estatisticamente às micas identificadas ao longo da topossequência. A aplicação desta análise no presente capítulo envolveu a separação de 3 grupos de amostras com diferentes quantidades de micas: Grupo 1 - amostras com baixas porcentagens de mica $(\leq 30 \%)$; Grupo 2 - amostras com porcentagens significativas de mica (31 a $64 \%)$; Grupo 3 - amostras com altos teores de mica $(\geq 65 \%)$.

A morfologia e a composição química de 10 cristais individuais de micas em 3 amostras selecionadas foram obtidas pelo Microscópio Eletrônico de Transmissão (MET), tipo FEI-Philips CM300, acoplado ao Espectrômetro tipo Dispersão em Energia (EDS), modelo Phoenix. Uma gota de solução aquosa de argila fina bem diluída foi distribuída sobre um filme de carbono fixado a uma pequena tela de cobre, sendo então ampliada e analisada. A composição química de cada cristal, obtida com uma acurácia de 1-3\%, foi utilizada para o cálculo das fórmulas químicas das micas, que foi feito de acordo com Moore \& Reynolds (1997). Dados de espectrometria Mossbauer revelaram que os conteúdos de $\mathrm{Fe}^{2+}$ são iguais ou inferiores a $8 \%$ nas amostras (informações verbais do Dr. Richard Morris, Nasa-Houston) e, por isto, apenas o $\mathrm{Fe}^{3+}$ foi incluído nas fórmulas.

\subsection{2 - Análises de água}

As amostras de água são as mesmas já utilizadas nos capítulos anteriores, presentes em um transecto que envolve a Topossequência 1 (T1), a cordilheira do entorno e uma baía adjacente. Lembra-se que apenas o piezômetro 2 (Pz2), os coletores G0 e G1 e as águas superficiais da própria lagoa do Meio estão localizados em T1. 
As amostras foram submetidas a leituras de campo de Eh (sensor de platina), temperatura, condutividade elétrica (CE) e pH (instrumentos WTW Tetracon 325 e Sentix 41). A quantificação dos ânions $\left(\mathrm{F}^{-}, \mathrm{Cl}^{-}, \mathrm{Br}^{-}, \mathrm{NO}^{3-}, \mathrm{SO}_{4}{ }^{2-}\right.$ e $\left.\mathrm{PO}_{4}{ }^{3-}\right)$ foi realizada por Cromatografia de Íons (Dionex, ED50-GP50) enquanto a quantificação dos

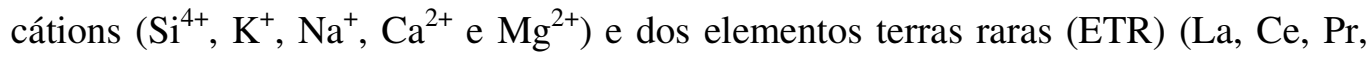
$\mathrm{Nd}, \mathrm{Sm}, \mathrm{Eu}, \mathrm{Gd}, \mathrm{Tb}, \mathrm{Dy}, \mathrm{Ho}, \mathrm{Er}, \mathrm{Tm}, \mathrm{Yb}$ e Y) foi realizada por Espectrometria de Plasma Acoplada a Detector de Massas (ICP-MS) (Perkin-Elmer, Elan 6000). As análises foram comparadas a materiais de referência padrão (Bmoos-01, SLRS4 e SRM1640). A acurácia para a maioria das análises dos elementos maiores foi menor que $2 \%$ para amostras sem diluição e dentro de $10 \%$ para amostras que passaram pela diluição máxima (500 vezes).

\section{3 - Resultados}

\subsection{1 - Caracterização das micas por Difração de Raios X}

Minerais do grupo das micas foram identificados na fração argila fina de todos os horizontes analisados, em concentrações que variam entre 1 e $84 \%$ e quantidades entre 0,05 e $36,37 \mathrm{~g} / \mathrm{kg}$ (Tabela 5.2). Entretanto, suas maiores porcentagens (67 a $84 \%$ ) e quantidades (12,72 a 36,37 g/kg) estão nos horizontes mais profundos (5 e 6 ) dos pedons mais próximos à lagoa salina (P3 a P5) (Figura 5.1, Tabela 5.2).

A ocorrência de apenas picos primários de muito pequena intensidade e com valores $d$ ao redor 1,00 nm sugere ainda traços de mica na fração argila grossa de todas as amostras (Anexo 3). Devido ao fato das quantidades expressivas de mica estarem na argila fina, os resultados descritos a partir daqui referem-se exclusivamente a esta fração.

Os difratogramas da argila fina apresentam as seguintes especificidades dos picos de mica, acompanhadas das seguintes alterações relacionadas aos picos da esmectita nos diferentes tratamentos:

1) os picos primários (001) da mica de todas as amostras tratadas com $\mathrm{Mg}^{2+}$ são largos e assimétricos, geralmente com flanco menor voltado para os ângulos mais baixos (Figura 5.2, Anexo 3);

2) em amostras impregnadas com etileno glicol (EG): os picos primários (001) da mica tornam-se menos assimétricos (Figura 5.2, Anexo 3); em todos os horizontes dos 
Tabela 5.2 - Porcentagens e quantidades de minerais nas assembléias de argila fina

\begin{tabular}{|c|c|c|c|c|c|c|c|}
\hline \multirow[t]{2}{*}{ Pedons } & \multirow[t]{2}{*}{ Horizontes } & \multicolumn{4}{|c|}{ Porcentagens em cada assembléia } & \multicolumn{2}{|c|}{ Quantidades (g/Kg) } \\
\hline & & Caulinita & Micas & Esmectitas & Quartzo & Micas & Esmectitas \\
\hline 1 & 1 & 50 & 32 & 17 & 0 & 4,22 & 2,22 \\
\hline 1 & 3 & 34 & 26 & 40 & 0 & 8,08 & 12,44 \\
\hline 1 & 5 & 41 & 24 & 34 & 0 & 6,84 & 9,69 \\
\hline 1 & 6 & 49 & 1 & 50 & 0 & 0,80 & 40,05 \\
\hline 2 & 1 & 36 & 51 & 10 & 3 & 0,05 & 0,01 \\
\hline 2 & 4 & 46 & 26 & 9 & 20 & 3,09 & 1,07 \\
\hline 2 & 5 & 49 & 40 & 11 & 0 & 3,16 & 0,87 \\
\hline 2 & 6 & 35 & 52 & 14 & 0 & 14,90 & 4,03 \\
\hline 3 & 1 & 5 & 22 & 73 & 0 & 5,41 & 17,95 \\
\hline 3 & 4 & 53 & 23 & 6 & 20 & 6,19 & 1,21 \\
\hline 3 & 5 & 29 & 71 & 0 & 0 & 17,61 & 0,00 \\
\hline 3 & 6 & 15 & 84 & 0 & 1 & 36,37 & 0,00 \\
\hline 4 & 2 & 5 & 26 & 70 & 0 & 4,00 & 10,78 \\
\hline 4 & 4 & 29 & 71 & 0 & 0 & 5,75 & 0,00 \\
\hline 4 & 5 & 19 & 81 & 0 & 0 & 12,72 & 0,00 \\
\hline 4 & 6 & 21 & 75 & 4 & 0 & 25,80 & 0,00 \\
\hline 5 & 2 & 4 & 27 & 69 & 0 & 6,08 & 15,52 \\
\hline 5 & 4 & 37 & 47 & 10 & 7 & 7,00 & 1,49 \\
\hline 5 & 5 & 24 & 67 & 0 & 9 & 12,46 & 0,00 \\
\hline 5 & 6 & 16 & 84 & 0 & 0 & 19,24 & 0,00 \\
\hline
\end{tabular}




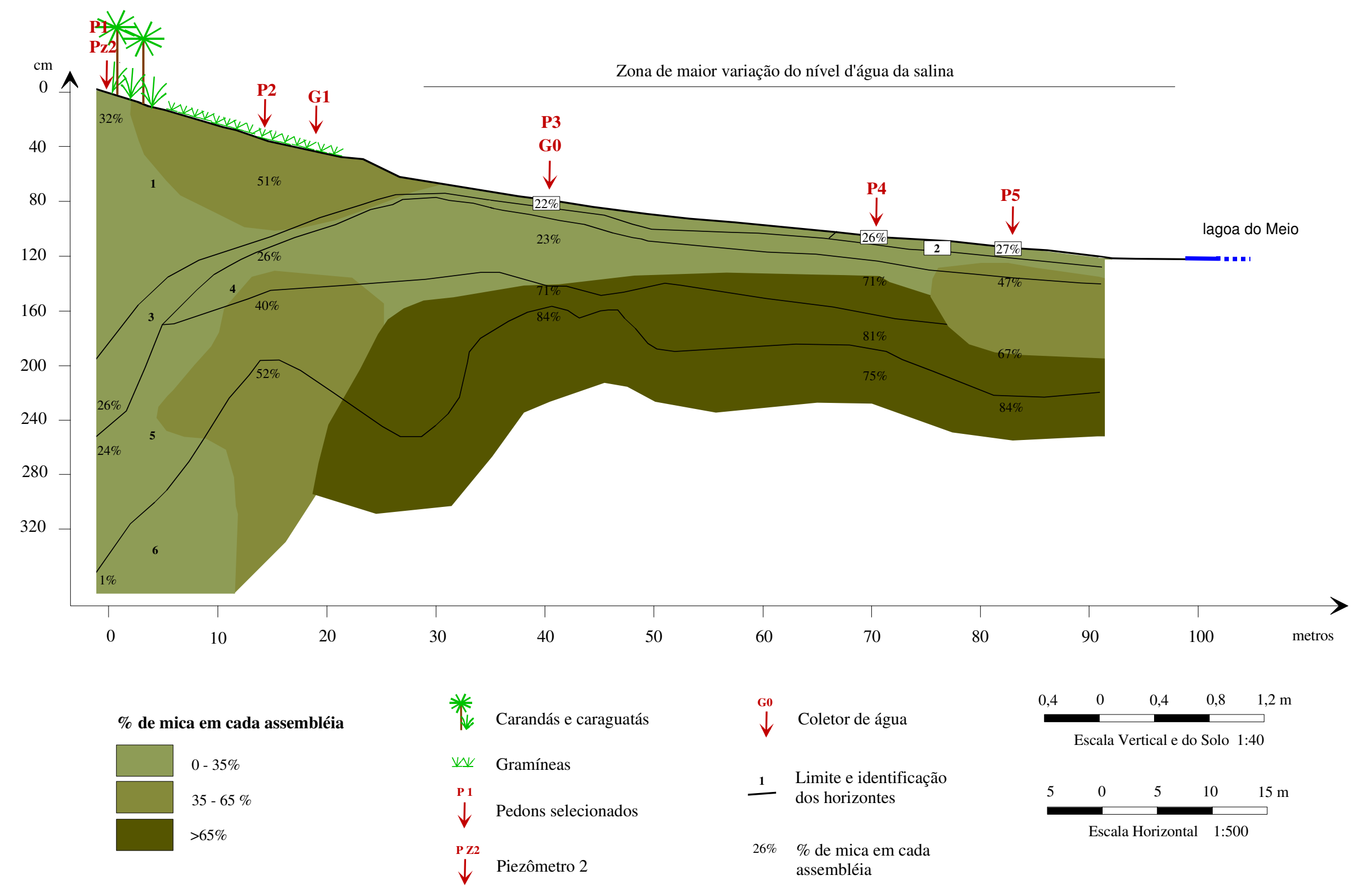

Figura 5.1 - Distribuição das porcentagens de mica ao longo da topossequência 


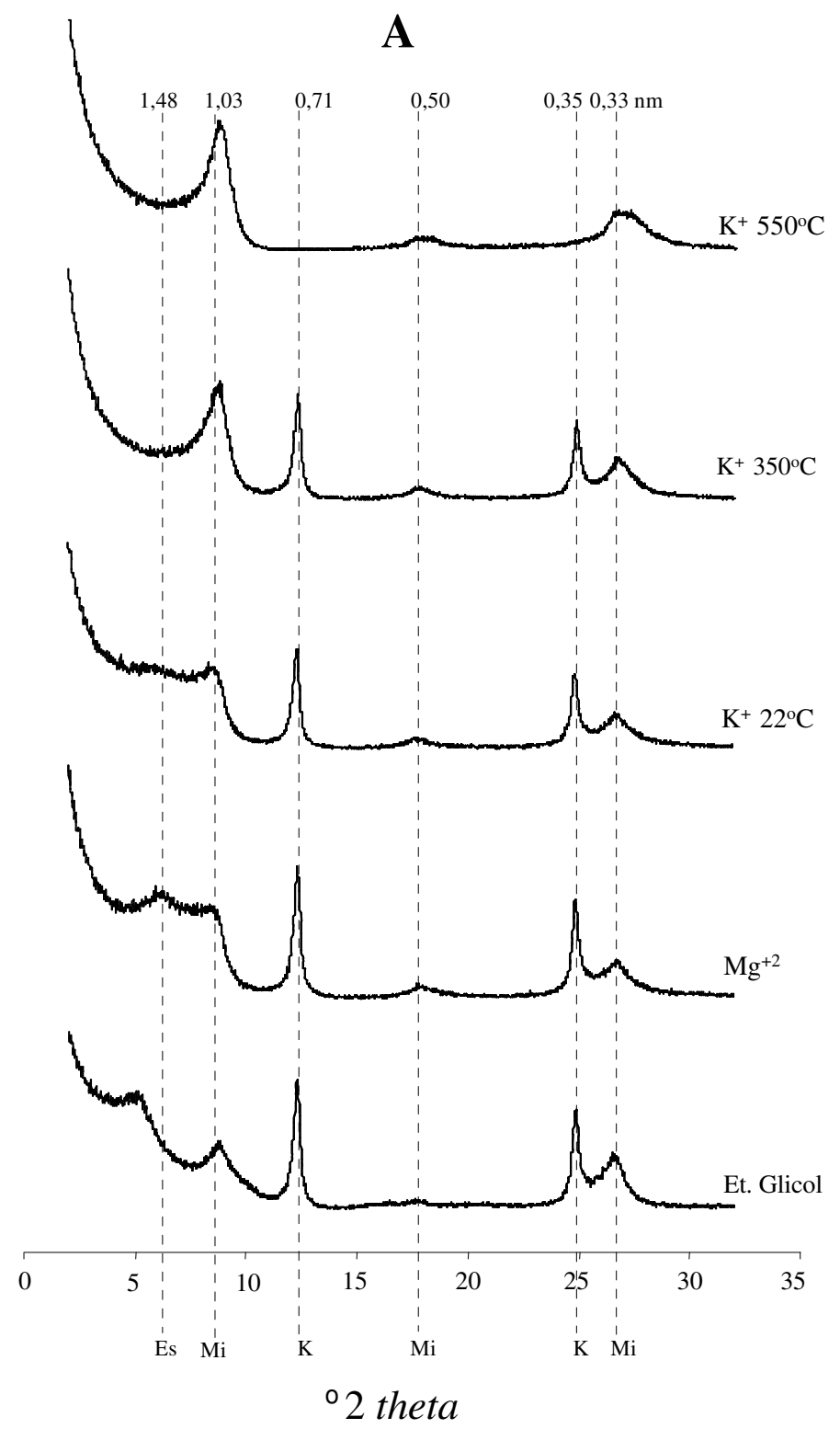

B

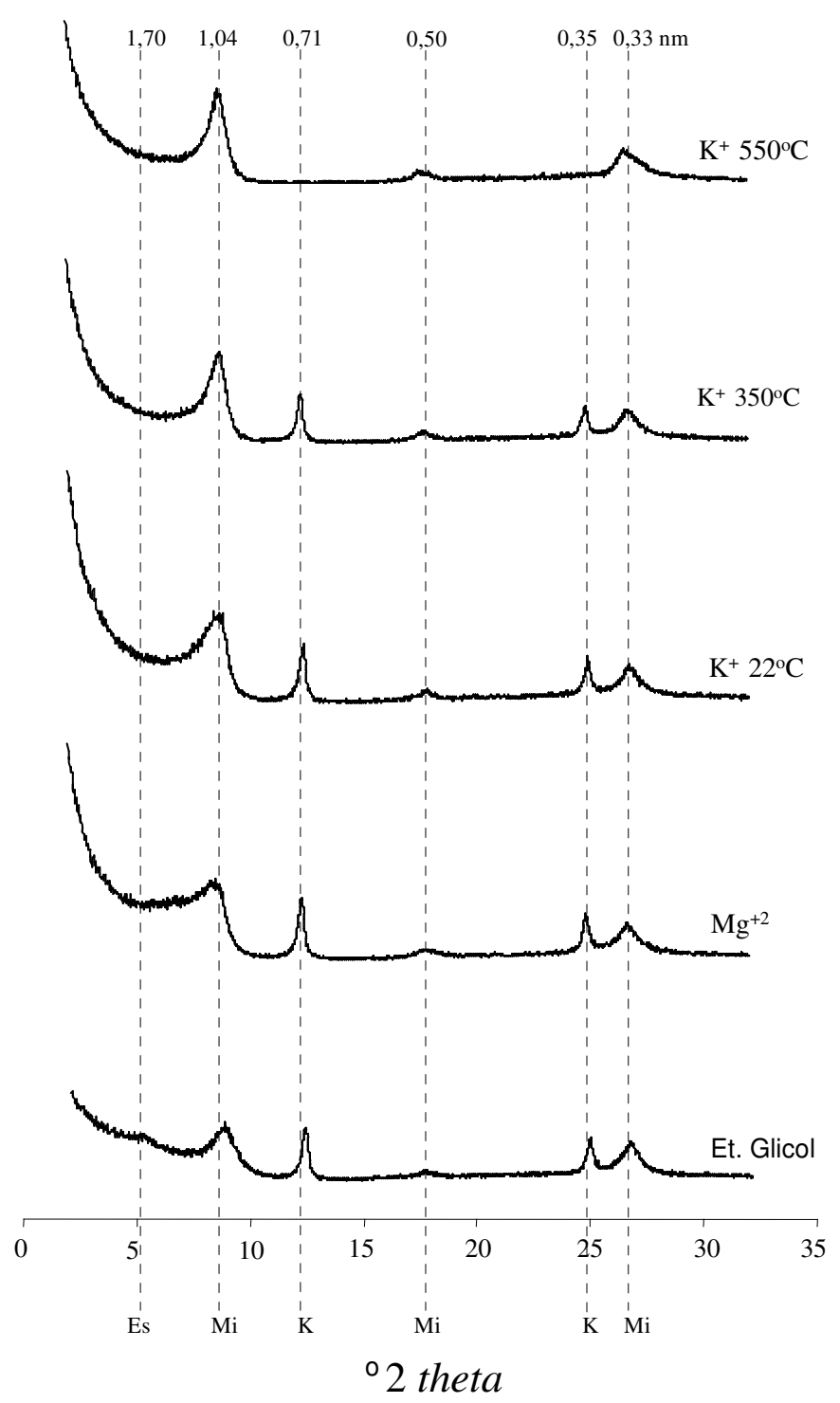

Figura 5.2 - Exemplos de sequência de difratogramas de argila fina submetidos a diferentes tratamentos: A) Pedon 2, horizonte 6 e B) Pedon 4, horizonte 6. Os minerais identificados são Es: esmectita; Mi: mica e K: caulinita. O Anexo 3 apresenta a sequência para todas as amostras. 

Pedons 1 e 2 (P1 e P2) há maior definição do pico da esmectita (1,70 a 1,81 nm) (Figura 5.2A, Anexo 3); nos horizontes 4, 5 e/ou 6 dos Pedons 3, 4 e 5 (P3, P4 e P5) há o aparecimento em menores ângulos de um pico pequeno e geralmente pouco definido com valores $d$ entre 1,7 e 1,8 nm, comparáveis aos de esmectita (Figura 5.2B, Anexo 3).

3) quando aquecidos à temperatura de $350^{\circ} \mathrm{C}$, tanto os picos correspondentes a esmectita em P1 e P2 quanto os pequenos picos correspondentes ao material expansivo em P3 a P5 colapsam e contribuem, juntamente com a mica não expansiva, para a reflexão de aproximadamente 1,0 nm (Figura 5.2, Anexo 3).

O cálculo da razão de intensidade dos picos 001/002 (equação 2), aplicado para estimar os conteúdos de ferro nos cristais, mostra valores entre 2,0 e 50,9 (Tabela 5.3). Assim como as maiores concentrações e quantidades de micas, os maiores valores deste índice também estão presentes nos horizontes mais profundos (5 e 6) dos pedons mais próximos à lagoa salina (P3 a P5). A aplicação da equação 3, útil para verificação de material expansivo nas micas, revela valores $\geq 1,0$, sem uma tendência clara de aumento em profundidade ou ao longo da topossequência (Tabela 5.3).

Por fim, o caráter dioctaédrico das micas interestratificadas é revelado nos difratogramas $d_{060}$ pela presença de picos bem definidos entre 0,149 e $0,151 \mathrm{~nm}$ (Fanning et al., 1989) em todas as amostras (Figura 5.3), com exceção das correspondentes aos horizontes superficiais ( 1 e 2) dos pedons mais próximos à lagoa salina (P3, P4 e P5), onde há forte domínio de esmectitas trioctaédricas. O valor $d_{060}$ de $0,154 \mathrm{~nm}$ presente ao lado dos valores $d_{060} 0,149$ a $0,151 \mathrm{~nm}$ nos horizontes arenosos 1, 3 e/ou 4 de todos os pedons pode corresponder tanto a minerais trioctaédricos quanto à difração máxima do quartzo (Fanning et al., 1989). Já que foram identificados picos de quartzo $(0,42 \mathrm{~nm})$ nos padrões $d_{00 l}$ na grande maioria destas amostras (Anexo 3), o valor 0,154 nm está provavelmente associado a este mineral.

\subsection{2 - Caracterização química das micas}

A Análise de Função Discriminante separou claramente os 3 grupos de argila fina com diferentes quantidades de mica (Figura 5.4) e mostrou que apenas 1 função ("root") explica 98,6\% da variância total dos dados (Tabela 5.4). Os Coeficientes Padrões de Função Discriminante revelam que $\mathrm{Al}_{2} \mathrm{O}_{3}, \mathrm{MgO}$ e $\mathrm{CaO}$ são os principais 
Tabela 5.3 - Índices de caracterização das micas na argila fina

\begin{tabular}{|c|c|c|c|}
\hline Horizontes & $\begin{array}{c}\mathbf{I}(\mathbf{0 0 1}) / \mathbf{I}(\mathbf{0 0 2}) \\
\left(\mathrm{Mg}^{2+}\right)\end{array}$ & $\frac{\mathbf{I}(001) / \mathbf{I}(003)}{\mathbf{I}(001) / \mathbf{I}(003)}$ & $\begin{array}{c}\left(\mathrm{Mg}^{2+}\right) \\
(\mathrm{EG})\end{array}$ \\
\hline & & & \\
\hline 1 & 3,3 & & \\
\hline 3 & 5,1 & 1,7 & \\
\hline 5 & 3,8 & 6,8 & \\
\hline \multirow[t]{2}{*}{6} & 6,3 & & \\
\hline & & & \\
\hline 1 & 2,0 & 1,0 & \\
\hline 4 & 3,3 & & \\
\hline 5 & 12,7 & 3,6 & \\
\hline \multirow[t]{2}{*}{6} & 7,9 & 3,3 & \\
\hline & & & \\
\hline 1 & 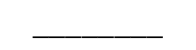 & 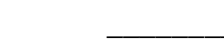 & - \\
\hline 4 & 4,5 & 3,4 & \\
\hline 5 & 26,7 & 4,6 & \\
\hline \multirow[t]{2}{*}{6} & 25,6 & 3,7 & \\
\hline & & & \\
\hline 2 & 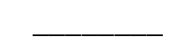 & 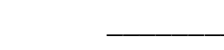 & \\
\hline 4 & $\ldots$ & 1,5 & \\
\hline 5 & 20,6 & 4,4 & \\
\hline \multirow[t]{2}{*}{6} & 15,2 & 2,1 & \\
\hline & & & \\
\hline 2 & ـ & _ & \\
\hline 4 & 5,1 & 2,3 & \\
\hline 5 & 25,7 & 3,9 & \\
\hline 6 & 50,9 & 4,1 & \\
\hline
\end{tabular}

OBS: Valores ausentes representam falta ou pouca definição de pelo menos um dos picos nos difratogramas ou ainda forte presença do quartzo, o qual divide $o$ pico $d_{003}$ com a mica. 


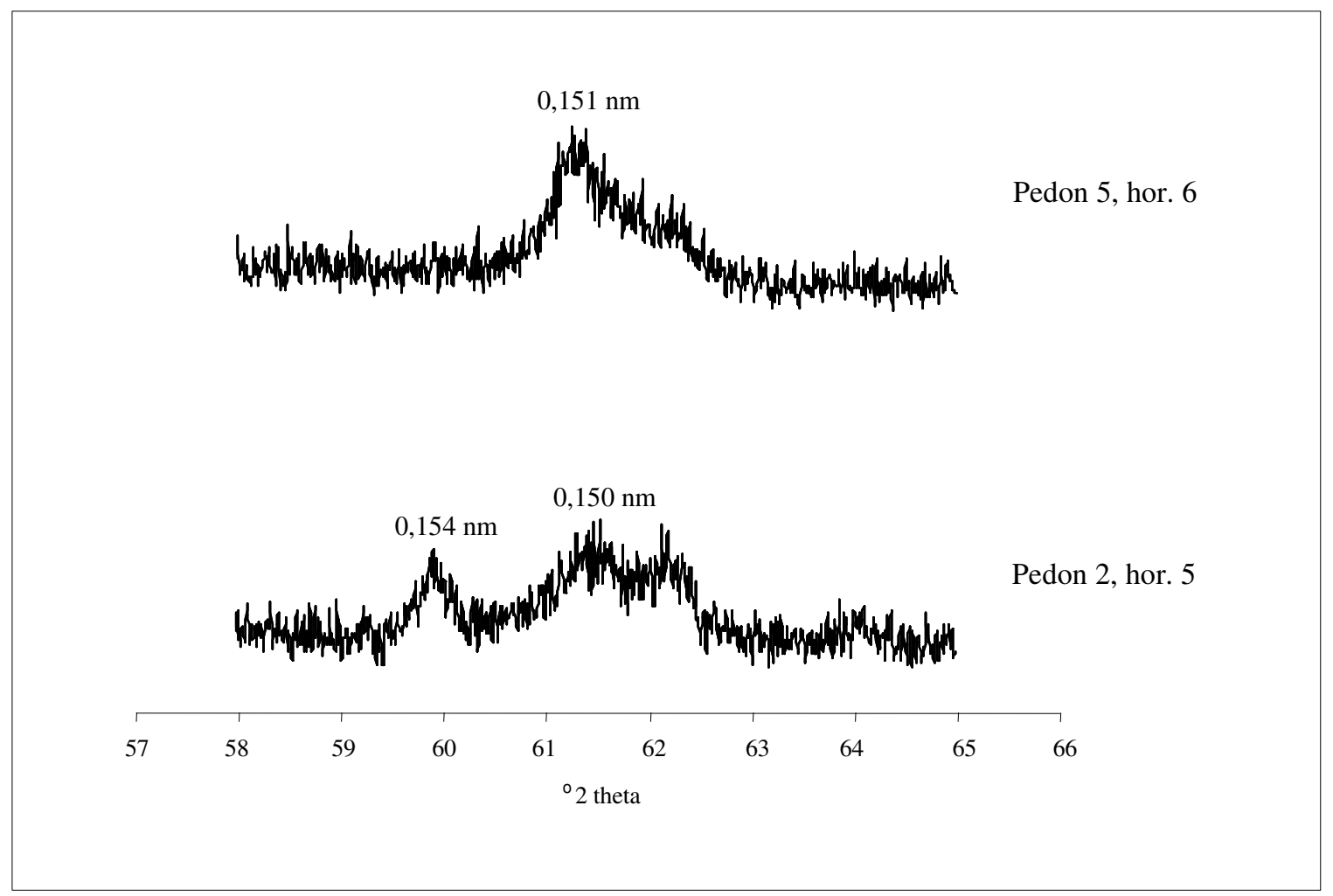

Figura 5.3 - Picos $d_{060}$ mostrando o carater dioctaédrico dos minerais presentes nos Pedons 2 e 5 . O pico $0,154 \mathrm{~nm}$ provavelmente representa o quartzo. 


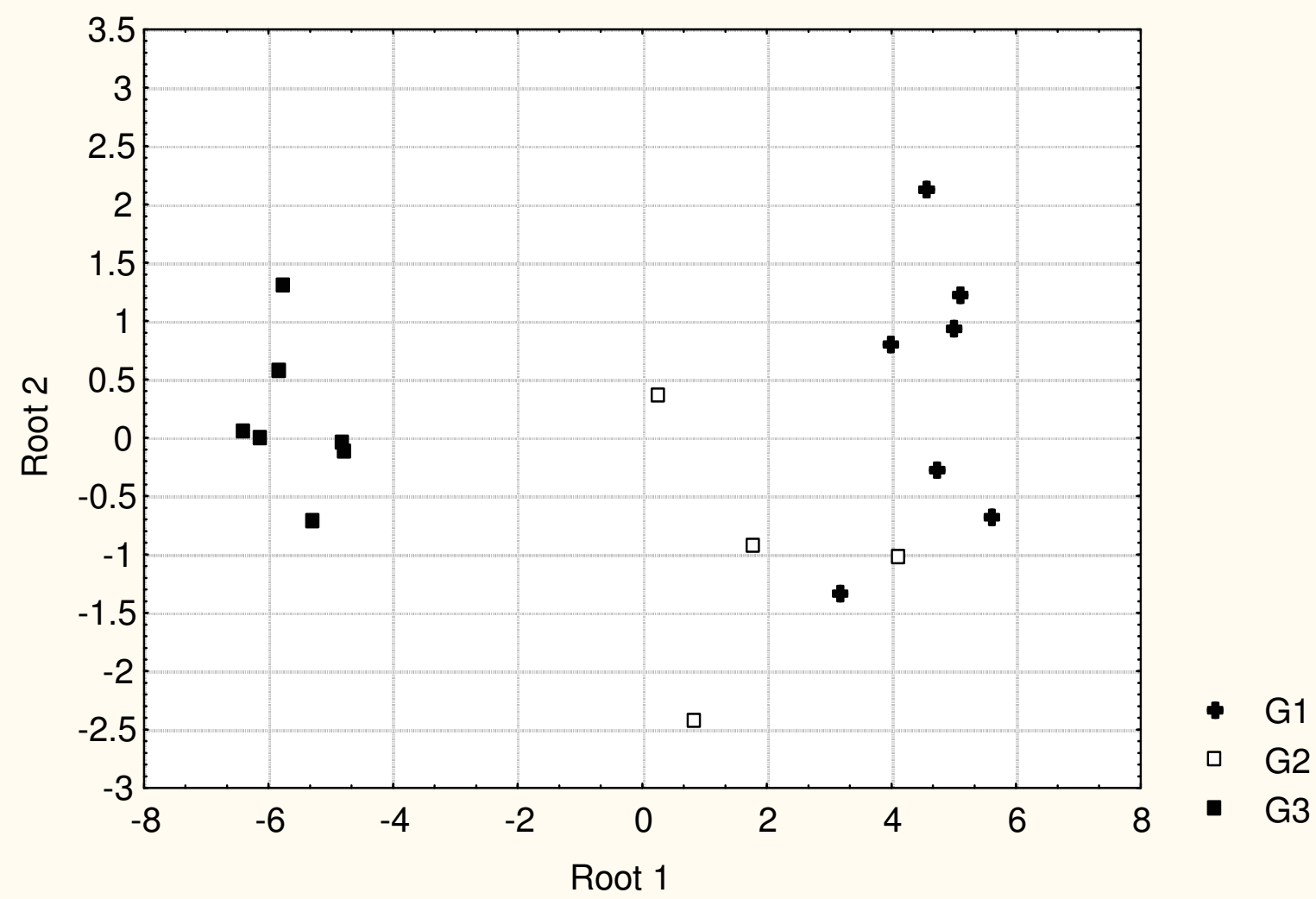

Figura 5.4 - Análises de Função Discriminante mostrando a separação de 3 grupos: G1: amostras com baixos teores de mica ( $\leq 30 \%)$; G2: amostras com teores significativos de micas (31 a $64 \%)$; e G3 - amostras com altos teores de mica $(\geq 65 \%)$. 
Tabela 5.4 - Coeficientes da Análise de Função Discriminante

\begin{tabular}{|c|c|c|}
\hline \multicolumn{3}{|c|}{ A - Coeficientes Padrões de Função Discriminante } \\
\hline & Fator 1 & Fator 2 \\
\hline $\mathrm{SiO}_{2}$ & 2,99042 & 0,683387 \\
\hline $\mathrm{Al}_{2} \mathrm{O}_{3}$ & 6,96745 & $-0,282085$ \\
\hline $\mathrm{Fe}_{2} \mathrm{O}_{3}$ & $-0,52291$ & 1,993252 \\
\hline $\mathrm{MgO}$ & 4,10435 & 0,103924 \\
\hline $\mathrm{CaO}$ & 3,48924 & 1,372249 \\
\hline $\mathrm{MnO}$ & 0,16797 & 0,961042 \\
\hline $\mathrm{K}_{2} \mathrm{O}$ & $-1,21406$ & $-0,596717$ \\
\hline $\mathrm{Na}_{2} \mathrm{O}$ & 1,23461 & 0,927887 \\
\hline Eingenvalues & 25,11317 & 0,356366 \\
\hline Prop. Acum-\% & 98,6 & 1,4 \\
\hline \multicolumn{3}{|c|}{ B - Coeficientes de Fator Estrutural } \\
\hline & Fator 1 & Fator 2 \\
\hline $\mathrm{SiO}_{2}$ & $-0,015395$ & $-0,811642$ \\
\hline $\mathrm{Al}_{2} \mathrm{O}_{3}$ & 0,008221 & $-0,205598$ \\
\hline $\mathrm{Fe}_{2} \mathrm{O}_{3}$ & $-0,136699$ & 0,145227 \\
\hline $\mathrm{MgO}$ & 0,051097 & 0,423018 \\
\hline $\mathrm{CaO}$ & 0,071430 & 0,476670 \\
\hline $\mathrm{MnO}$ & $-0,041145$ & 0,280718 \\
\hline $\mathrm{K}_{2} \mathrm{O}$ & $-0,405815$ & $-0,405957$ \\
\hline $\mathrm{Na}_{2} \mathrm{O}$ & $-0,022234$ & $-0,003126$ \\
\hline
\end{tabular}


responsáveis pela discriminação dos grupos. Os Coeficientes de Fator Estrutural, por sua vez, destacam os óxidos $\mathrm{Fe}_{2} \mathrm{O}_{3}$ e $\mathrm{K}_{2} \mathrm{O}$ como os que apresentam as maiores correlações com a Função 1, o que possivelmente indica uma associação importante destes elementos com a mica.

Os cálculos das fórmulas químicas, baseados nos dados obtidos por MET-EDS para cristais individuais ( 1 a 10 ), estão na Tabela 5.5. A substituição de $\mathrm{Al}^{3+}$ por $\mathrm{Si}^{4+}$ no tetraedro é de 0,24 a 0,93 átomos por unidade de fórmula baseada em 22 ânions (apuf/22), sendo mais baixa nos cristais 7 a 10, localizados no pedon mais próximo à lagoa salina (P5). $\mathrm{Al}^{3+}$ e $\mathrm{Fe}^{3+}$ são os principais cátions do octaedro, confirmando o caráter dioctaédrico sugerido pelos difratogramas $d_{060}$ e a importante presença do $\mathrm{Fe}_{2} \mathrm{O}_{3}$ apontada pela Análise Discriminante. Os teores de $\mathrm{Al}^{3+}$ no octaedro estão entre 0,62 e 1,94 apuf/22 enquanto os de $\mathrm{Fe}^{3+}$ variam de 0,19 a 1,44 apuf/22, sendo que em 4 das 10 espécimes analisadas (cristais $1,2,7$ e 10) o $\mathrm{Fe}^{3+}$ é o cátion dominante. Destaca-se ainda a presença de pequenas quantidades de $\mathrm{Mg}^{2+}$ e $\mathrm{Mn}^{2+}$ no octaedro de alguns dos cristais, sendo que este último ocorre apenas no pedon mais próximo à lagoa salina (P5) (cristais de $\mathrm{n}^{\mathrm{o}} 7$ a 10).

Potássio, $\mathrm{Mg}^{2+}$ e/ou $\mathrm{Ca}^{2+}$ são os cátions presentes na entrecamada dos cristais analisados. Os teores de $\mathrm{K}^{+}$variam de 0,02 a 0,70 apuf/22, sendo maiores nos cristais 7 a 10 (>0,40 apuf/22), situados no pedon mais próximo à lagoa salina (P5). Trata-se do cátion dominante na entrecamada de 7 cristais (1,2, 5 e 7 a 10), o que confirma o destaque dado a este elemento na Análise Discriminante. Em 1 cristal (6), o $\mathrm{K}^{+}$

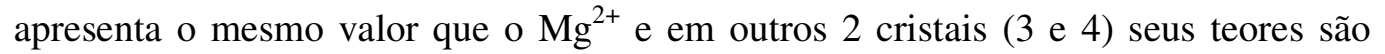
inferiores aos do $\mathrm{Mg}^{2+}$ e/ou do $\mathrm{Ca}^{2+}$.

A carga total varia de $-0,19$ a $-0,85$, sendo que os menores valores $(\leq-0,53)$ estão nos cristais $2,3,4$ (P1) e 6 (P5), enquanto os maiores valores $(\geq-0,68)$ estão nos cristais 7 a 10 (P5). A carga é produzida principalmente no tetraedro em todos os cristais de P1 e P3 (1 a 5) e em 1 cristal do P5 (6), e principalmente no octaedro nos outros 4 espécimes de P5 (7 a 10).

\subsection{3 - Morfologia dos cristais de mica}

As imagens fornecidas pelo Microscópio Eletrônico de Transmissão (MET) mostram que as micas ocorrem em formato de ripas ("laths") (Velde, 1995), ou seja, folhas de aspecto linear com dimensões nitidamente maiores em uma direção (Figura 5.5). Nas 
Tabela 5.5 - Óxidos e fórmulas químicas de cristais individuais de micas e de material amorfo.

\begin{tabular}{|c|c|c|c|c|c|c|c|c|c|c|c|}
\hline \multirow[b]{3}{*}{ Óxidos } & \multicolumn{10}{|c|}{ Cristais Individuais } & \multirow{3}{*}{$\begin{array}{c}\text { Amorfo } \\
\text { P3, hor.6 } \\
\text { A }\end{array}$} \\
\hline & \multicolumn{4}{|c|}{ Pedon 1 , horizonte 6} & \multirow{2}{*}{$\frac{\mathrm{P} 3 \text {, hor.6 }}{5}$} & \multicolumn{5}{|c|}{ Pedon 5 , horizonte 6} & \\
\hline & 1 & 2 & 3 & 4 & & 6 & 7 & 8 & 9 & 10 & \\
\hline$\% \mathrm{SiO}_{2}$ & 56,9 & 55,3 & 49,6 & 53,8 & 55,3 & 53,4 & 58,8 & 58,1 & 57,4 & 57,4 & 73,8 \\
\hline$\% \mathrm{Al}_{2} \mathrm{O}_{3}$ & 14,7 & 13,1 & 33,8 & 34,7 & 27,7 & 39,1 & 13,0 & 16,1 & 17,8 & 12,4 & 10,2 \\
\hline$\% \mathrm{Fe}_{2} \mathrm{O}_{3}$ & 19,5 & 29,4 & 12,8 & 8,2 & 8,2 & 4,3 & 16,4 & 13,5 & 13,3 & 14,6 & 9,1 \\
\hline$\% \mathrm{MgO}$ & 4,3 & 0,0 & 1,8 & 2,1 & 2,9 & 1,5 & 6,0 & 4,4 & 4,0 & 6,5 & 2,8 \\
\hline$\% \mathrm{CaO}$ & 0,0 & 0,0 & 0,8 & 0,8 & 0,0 & 0,0 & 0,0 & 0,0 & 0,0 & 0,0 & 0,0 \\
\hline$\% \mathrm{MnO}$ & 0,0 & 0,0 & 0,0 & 0,0 & 0,0 & 0,0 & 0,7 & 0,7 & 0,6 & 0,7 & 0,9 \\
\hline$\% \mathrm{~K}_{2} \mathrm{O}$ & 4,7 & 2,1 & 1,2 & 0,3 & 4,8 & 1,7 & 5,1 & 7,1 & 6,8 & 8,4 & 4,1 \\
\hline $\mathrm{Si}^{4+}$ & 3,66 & 3,61 & 3,07 & 3,24 & 3,43 & 3,19 & 3,76 & 3,72 & 3,67 & 3,74 & ---------- \\
\hline $\mathrm{Al}^{3+}$ & 0,34 & 0,39 & 0,93 & 0,76 & 0,57 & 0,81 & 0,24 & 0,28 & 0,33 & 0,26 & ---------- \\
\hline$\sum$ Tetraedro & 4,00 & 4,00 & 4,00 & 4,00 & 4,00 & 4,00 & 4,00 & 4,00 & 4,00 & 4,00 & --------- \\
\hline $\mathrm{Al}^{3+}$ & 0,77 & 0,62 & 1,54 & 1,71 & 1,49 & 1,94 & 0,74 & 0,94 & 1,01 & 0,69 & --------- \\
\hline $\mathrm{Fe}^{3+}$ & 0,94 & 1,44 & 0,60 & 0,37 & 0,39 & 0,19 & 0,79 & 0,65 & 0,64 & 0,72 & --------- \\
\hline $\mathrm{Mg}^{2+}$ & 0,29 & 0,00 & 0,00 & 0,00 & 0,12 & 0,00 & 0,43 & 0,37 & 0,32 & 0,55 & --------- \\
\hline $\mathrm{Mn}^{2+}$ & 0,00 & 0,00 & 0,00 & 0,00 & 0,00 & 0,00 & 0,04 & 0,04 & 0,03 & 0,04 & ---------- \\
\hline ¿Octaedro & 2,00 & 2,06 & 2,14 & 2,08 & 2,00 & 2,13 & 2,00 & 2,00 & 2,00 & 2,00 & --------- \\
\hline $\mathrm{K}^{+}$ & 0,39 & 0,18 & 0,09 & 0,02 & 0,39 & 0,13 & 0,42 & 0,58 & 0,55 & 0,70 & ---------- \\
\hline $\mathrm{Ca}^{2+}$ & 0,12 & 0,00 & 0,17 & 0,19 & 0,15 & 0,13 & 0,15 & 0,05 & 0,06 & 0,08 & --------- \\
\hline $\mathrm{Mg}^{2+}$ & 0,00 & 0,00 & 0,05 & 0,05 & 0,00 & 0,00 & 0,00 & 0,00 & 0,00 & 0,00 & --------- \\
\hline Craga Tetraedro & $-0,34$ & $-0,39$ & $-0,93$ & $-0,76$ & $-0,57$ & $-0,81$ & $-0,24$ & $-0,28$ & $-0,33$ & $-0,26$ & --------- \\
\hline Carga Octaedro & $-0,29$ & 0,20 & 0,40 & 0,25 & $-0,12$ & 0,41 & $-0,47$ & $-0,41$ & $-0,35$ & $-0,59$ & --------- \\
\hline Carga Total & $-0,63$ & $-0,19$ & $-0,53$ & $-0,51$ & $-0,69$ & $-0,40$ & $-0,71$ & 0,69 & $-0,68$ & $-0,85$ & --------- \\
\hline Carga Entrecamada & 0,63 & 0,18 & 0,53 & 0,50 & 0,69 & 0,39 & 0,70 & 0,68 & 0,68 & 0,85 & --------- \\
\hline
\end{tabular}

P3: Pedon 3; hor.: horizonte. 

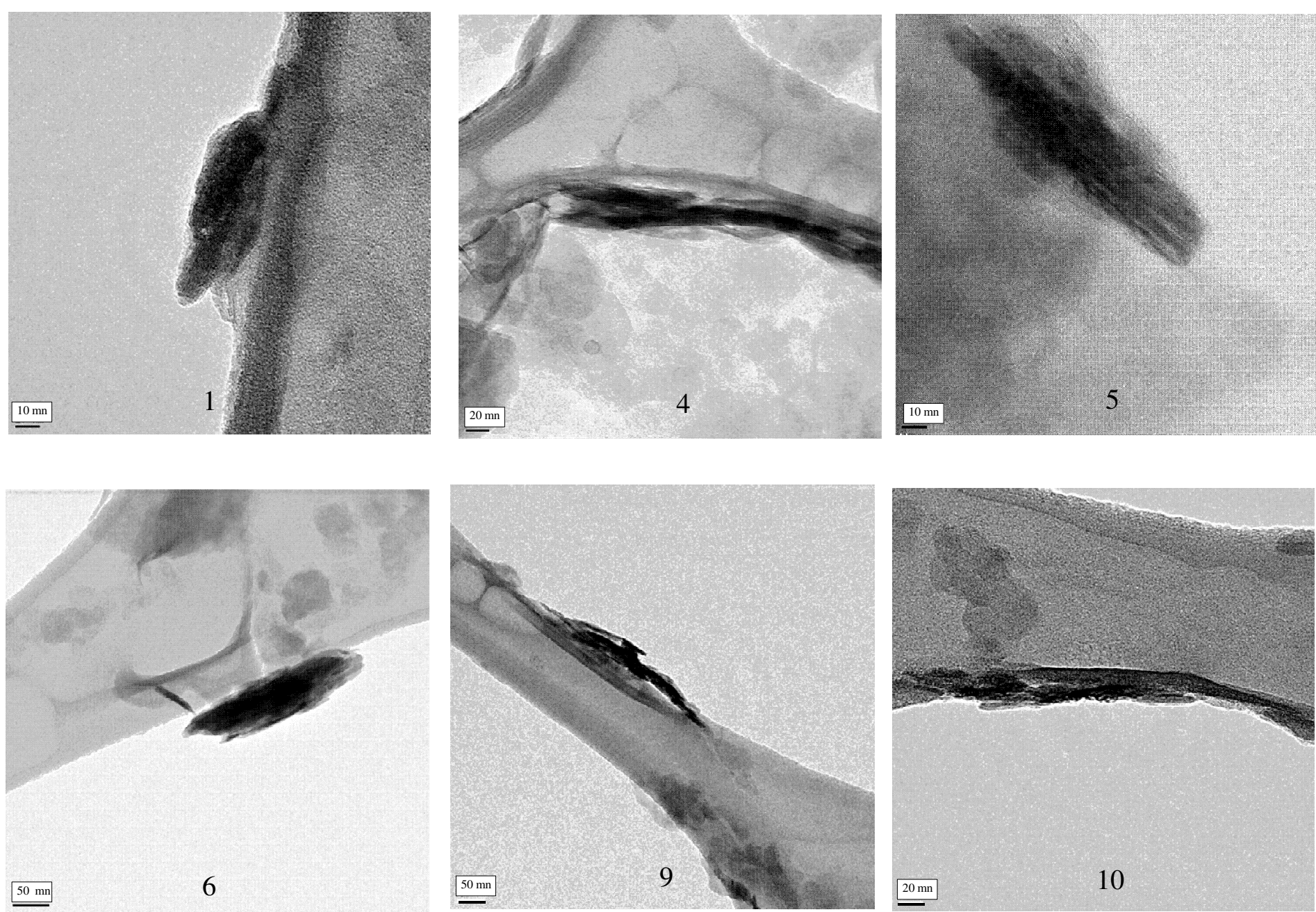

Figura 5.5 - Imagens de cristais de mica obtidas por MET, identificadas de acordo com a numeração apresentada na Tabela 5.5. 
imagens de alta resolução (Figura 5.6) é possível diferenciar camadas e entrecamadas paralelas entre si e visualizar o espaço $d_{001}$ em domínios coerentes dispersos arranjados em diferentes orientações dentro de uma mesma partícula. Foram contadas o máximo de 5 camadas nos domínios reconhecidos nas imagens. Os padrões de Difração de Elétrons em Área Selecionada confirmam que estes minerais exibem uma estrutura ordenada em longo alcance, com valor $d_{001}$ de 1,00 nm (10 ) (Figura 5.7A).

Destaca-se ainda a presença de muitos cristalitos associados a uma material amorfo enriquecido em $\mathrm{SiO}_{2}$ no horizonte 6 do Pedon 3 (Figura 5.7B, Tabela 5.5). A ausência de ordem de longo alcance é revelada pelo não reconhecimento de um espaçamento regular nos padrões de Difração de Elétrons em Área Selecionada.

\subsection{4 - Características da água}

A Tabela 5.6 mostra os resultados das análises de água da lagoa do Meio, do piezômetro (Pz2) e dos coletores (G0 e G1) localizados ao longo da Topossequência 1. Alguns destes resultados já foram apresentados nos capítulos anteriores, mas serão repetidos aqui para facilitar a leitura. Os dados mostram um $\mathrm{pH}$ alcalino, entre 7,66 e 9,64, condutividade elétrica (CE) entre 6,19 e 19,18, potencial Redox (Eh) redutor, de $-25,2$ a $-364,5$ e temperaturas altas, variando entre 31,2 e $40,2^{\circ} \mathrm{C}$. Nota-se um aumento paulatino de $\mathrm{pH}$ e temperatura no sentido da lagoa salina.

Tabela 5.6 - Características selecionadas das águas superficiais da lagoa do Meio e das águas subterrâneas dos arredores (cátions com duas repetições).

\begin{tabular}{|c|c|c|c|c|c|c|c|c|c|}
\hline \multirow[b]{2}{*}{$\mathrm{pH}$} & \multirow[b]{2}{*}{----- } & \multicolumn{2}{|c|}{ Pz2 } & \multicolumn{2}{|c|}{ G1 } & \multicolumn{2}{|c|}{ G0 } & \multicolumn{2}{|c|}{ Lagoa do Meio } \\
\hline & & 7,66 & |------ & 8,66 & ---------- & 9,25 & --------- & 9,64 & |------ \\
\hline $\mathrm{EC}$ & $\mathrm{dS} / \mathrm{m}$ & 6,19 & & 8,76 & & 19,18 & & 12,74 & \\
\hline Eh & ----- & $-25,2$ & ------- & -217 & ---------- & $-364,5$ & --------- & -125 & -------- \\
\hline Temp. & ${ }^{\circ} \mathrm{C}$ & 31,1 & ------- & 31,2 & ---------- & 34,2 & --------- & 40,2 & ------- \\
\hline $\mathrm{Si}(\mathrm{OH})_{4}$ & & 3,2098 & 3,5155 & 36,9463 & 38,6839 & 51,4686 & 52,3721 & 97,6426 & 89,5579 \\
\hline $\mathrm{Al}^{3+}$ & & 0,0007 & 0,0007 & 0,0196 & 0,0594 & 0,0039 & 0,0040 & 0,0514 & 0,0272 \\
\hline $\mathrm{Fe}$ & $\mathrm{mol}$ & 0,0826 & 0,4466 & 0,0319 & 0,0439 & 0,0120 & 0,0342 & 0,0553 & 0,0880 \\
\hline $\mathrm{Mg}^{2+}$ & $\mathrm{mg} / \mathrm{L}$ & 1,0813 & 1,1843 & 0,0356 & 0,0372 & 0,2202 & 0,2241 & 2,2365 & 2,0513 \\
\hline $\mathrm{K}^{+}$ & & 34,6911 & 37,9959 & 230,1342 & 240,9576 & 1094,8175 & 1114,0353 & 945,9906 & 867,66 \\
\hline $\mathrm{Ca}^{2+}$ & & 6,2313 & 6,8249 & 1,4463 & 1,4720 & 4,2313 & 4,3056 & 8,5382 & 7,8313 \\
\hline $\mathrm{Mn}^{2+}$ & & 2,0144 & 2,2063 & ------- & -------- & 0,0558 & 0,0568 & 0,0582 & 0,0534 \\
\hline
\end{tabular}



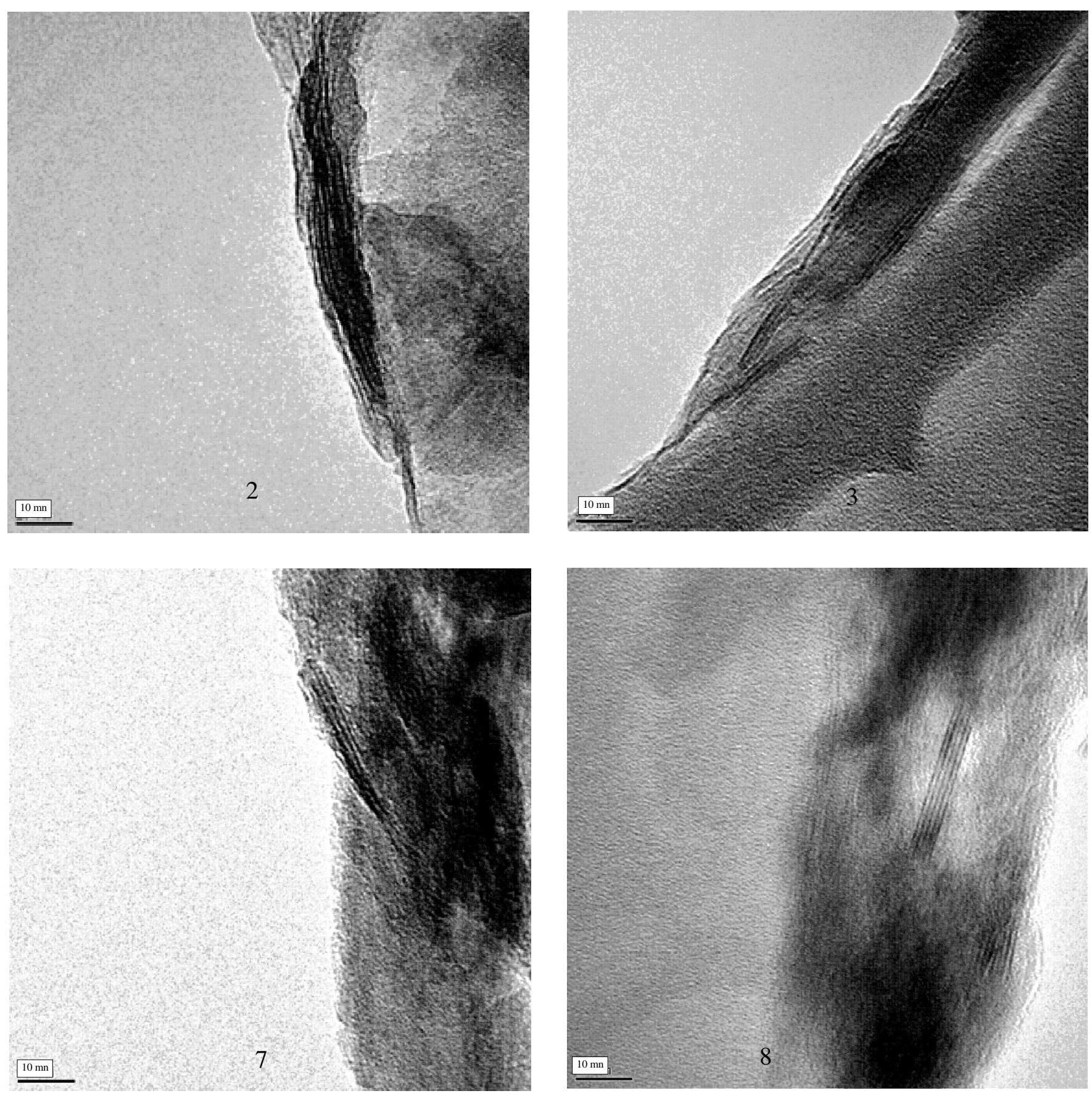

Figura 5.6 - Imagens de cristais de mica obtidas por MET, identificadas de acordo com a numeração apresentada na Tabela 5.5. O maior aumento presente nestas imagens possibilita a visualização de camadas e entrecamadas paralelas entre si. 
A

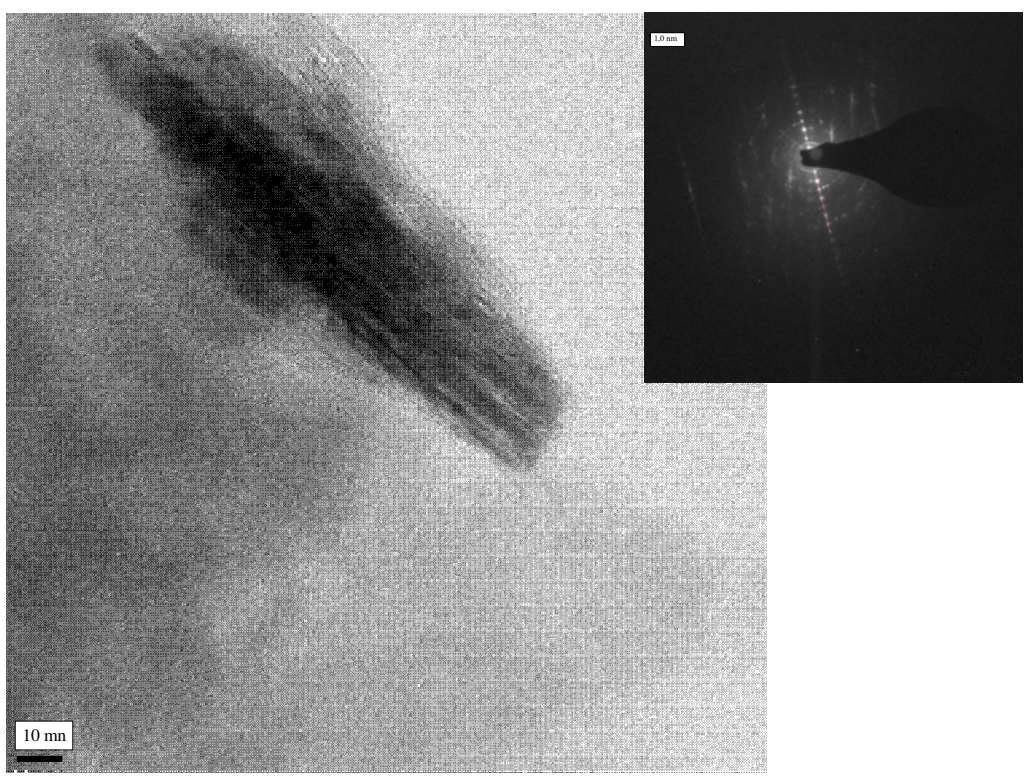

B

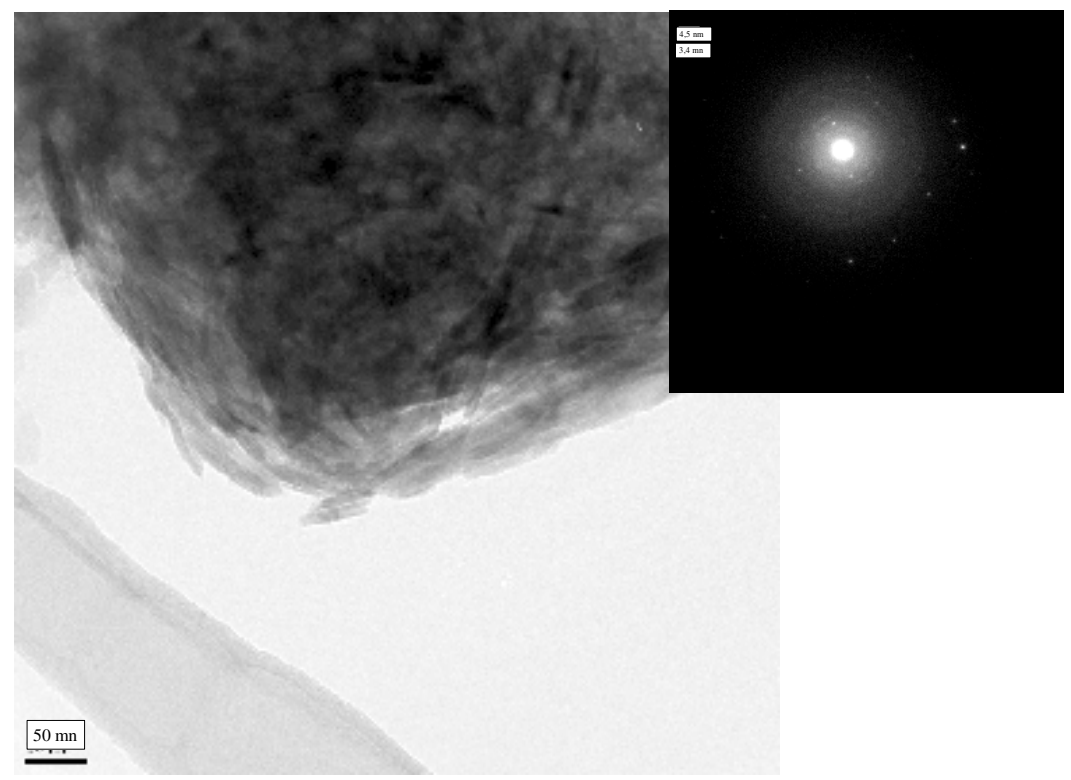

Figura 5.7 - Imagens de TEM e Padrões de Difração de Elétrons em Areas Selecionadas do P3 (hor. 6), mostrando: A) estrutura cristalina com ordem de longo alcance $(1,0 \mathrm{~nm})$ e B) material amorfo associado a cristalitos. 
Dos cátions apresentados na Tabela 5.6, destacam-se os teores muito altos de $\mathrm{K}^{+}$nas águas da lagoa e no ponto coletor mais próximo a ela. As concentrações de $\mathrm{Si}(\mathrm{OH})_{4}$ são inferiores a $100 \mathrm{mg} / \mathrm{L}$, com contínuo aumento no sentido da lagoa salina. Já os teores de $\mathrm{Al}^{3+}, \mathrm{Mg}^{2+}$ e Fe são baixos ao longo de toda a topossequência, variando de 0,00 a $0,05,0,03$ a 2,23 e 0,01 a $0,44 \mathrm{mg} / \mathrm{L}$, respectivamente.

O diagrama de concentração do $\mathrm{K}^{+}$, elaborado com as amostras coletadas ao longo de todo o transecto, mostra um controle deste elemento nas águas mais mineralizadas, nas proximidades de $100000 \operatorname{logNa}{ }^{+}(\mathrm{mg} / \mathrm{L})$ (Figura 5.8).

\section{4 - Discussão dos Resultados}

\subsection{1 - Caracterização por Difração de Raios X (DRX)}

Os valores $\geq 2,0$ obtidos pela aplicação da razão da intensidade dos picos 001/002 (equação 2) sugerem um enriquecimento geral em ferro na estrutura cristalina das micas em todas as amostras (Deconinck et al., 1988). É interessante ressaltar que durante o fracionamento verificou-se que as amostras de argila fina enriquecidas em micas (horizontes 5 e 6) apresentaram coloração verde (Figura 5.9), o que corrobora com o fato destes minerais possuírem maiores teores de ferro (Odom, 1984).

A aplicação da equação 3 sugere ainda que a mica está intercalada a um material expansivo, já que todos os valores obtidos são $\geq 1,0$ (Srodón \& Eberl, 1984). As seguintes especificidades dos difratogramas mostram que este material expansivo é esmectita: a) picos $d_{001}$ de mica amplos e assimétricos em padrões de $\mathrm{Mg}^{2+}$ (Porrenga, 1968; Thompson \& Ukrainczyk, 2002); b) picos $d_{001}$ de mica menos assimétricos e melhor definição ou surgimento de pequenos picos de esmectita em padrões de EG; e c) colapso destes picos de esmectita em amostras aquecidas a 350 e $550^{\circ} \mathrm{C}$ (Borchardt, 1989). A presença de espaços $d_{001}$ e $d_{002}$ de mica entre 0,999 e $1,1013 \mathrm{~nm}$ e 0,498 e $0,504 \mathrm{~nm}$, respectivamente, sugerem que estes minerais interestratificados possuem mais de $80 \%$ de camadas de mica (Reynolds, 1980).

\subsection{2 - Classificação das micas}

Os minerais ilita e glauconita diferenciam-se principalmente pelos teores de $\mathrm{Al}^{3+}$ no tetraedro $\left(\mathrm{Al}^{\mathrm{IV}}\right)$ e $\mathrm{Fe}^{3+}$ no octaedro $\left(\mathrm{Fe}^{\mathrm{VI}}\right)$. Os dados compilados por Weaver \& Pollard (1973) mostram que a substituição média de $\mathrm{Si}^{4+}$ por $\mathrm{Al}^{3+}$ no tetraedro é de 0,60 


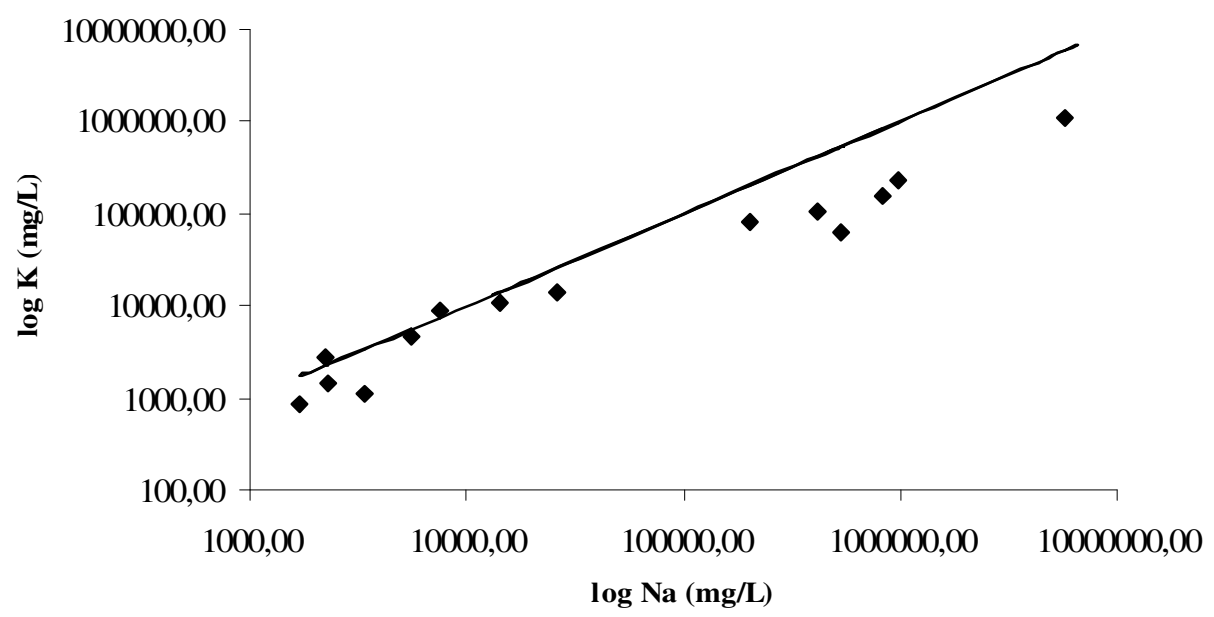

Figura 5.8 - Diagrama de concentração do $\mathrm{K}^{+}$. 


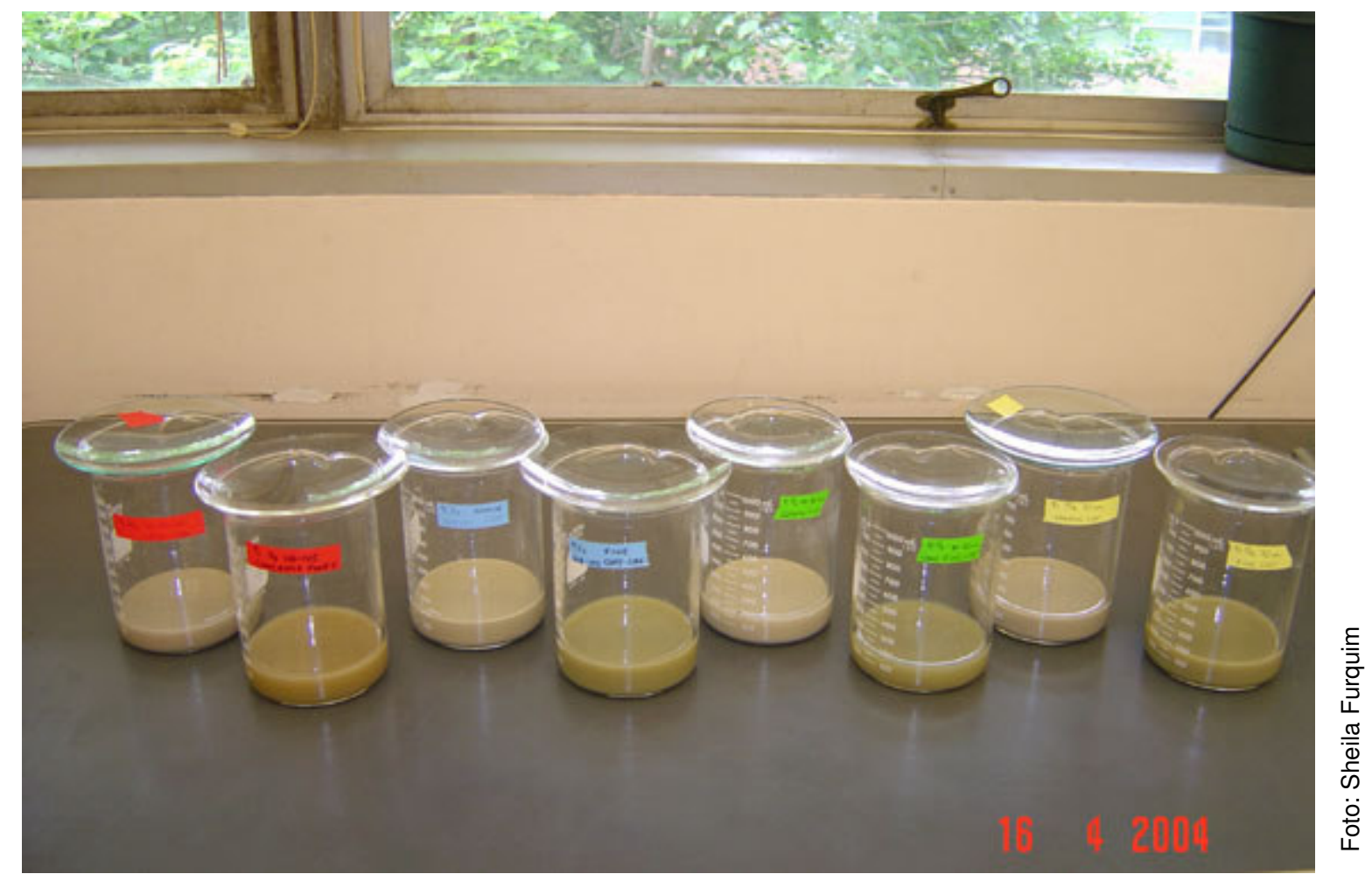

Figura 5.9 - Béqueres de trás com argila bege (grossa) e béqueres da frente com argila esverdeada (fina) em solução aquosa. 
apuf/22 na ilita e de 0,35 apuf/22 na glauconita, enquanto o teor médio de $\mathrm{Fe}^{3+}$ no octaedro é de 0,23 apuf/22 na ilita e de 1,01 apuf/22 na glauconita. A mica glauconítica, por sua vez, apresenta valores de $\mathrm{Al}^{\mathrm{IV}} \mathrm{e} \mathrm{Fe}^{\mathrm{VI}}$ intermediários entre ilita e glauconita.

Kossovskaya \& Drits (1970) sugerem ainda a aplicação do índice $\mathrm{Fe}^{3+} /\left(\mathrm{Fe}^{3+}+\mathrm{Al}^{3+}\right)$ para diferenciar estes minerais, já que seus valores variam de 0,05 a 0,20 para ilita, 0,20 a 0,40 para mica glauconítica e 0,50 a 1,00 para glauconita.

As micas identificadas na Tabela 5.5 como cristais 4 e 6 possuem composição semelhante a da ilita, já que exibem teores de $\mathrm{Al}^{\mathrm{IV}}$ bem maiores que a média deste mineral e baixos teores de $\mathrm{Fe}^{\mathrm{VI}}$. As identificadas pelos números 1, 2, 7 e 10 possuem composição semelhante a da glauconita, pois apresentam teores de $\mathrm{Al}^{\mathrm{IV}}$ próximo ou abaixo da média deste mineral e altos teores de $\mathrm{Fe}^{\mathrm{VI}}$. Já os outros cristais $(3,5,8$ e 9) possuem valores de $\mathrm{Al}^{\mathrm{IV}}$ e $\mathrm{Fe}^{\mathrm{VI}}$ comparáveis à composição da mica glauconítica (Figura 5.10). O cálculo do índice $\mathrm{Fe}^{3+} /\left(\mathrm{Fe}^{3+}+\mathrm{Al}^{3+}\right)$ confirma esta classificação, já que os cristais 4 e 6 apresentam valores entre 0,09 e 0,18, os cristais 1, 2, 7 e 10 apresentam valores entre 0,51 e 0,70 e os cristais 3,5,8 e 9 apresentam valores entre 0,21 e 0,40 .

A interestratificação com camadas expansivas de esmectitas, como indica os padrões de DRX, provavelmente afeta a quantidade de $\mathrm{K}^{+}$e a carga total na entrecamada destes cristais e distancia-os da composição ideal das micas com presença de ferro. De acordo com os dados compilados por Weaver \& Pollard (1973), os teores de $\mathrm{K}^{+}$na entrecamada variam entre 0,43 e 0,98 apuf/22 na ilita e entre 0,40 a 0,77 apuf/22 na glauconita. No presente trabalho, 6 espécimes (cristais 1 a 6 ) possuem teor de $\mathrm{K}^{+}$ inferior a 0,40 apuf/22. Já foi demonstrado que a quantidade de $\mathrm{K}^{+}$na entrecamada é inversamente proporcional à quantidade de camadas expansivas em ilitas (Hower \& Mowatt, 1966) e glauconitas (Hower, 1961; Bentor \& Kastner, 1965). Desta forma, os cristais 1 a 6 provavelmente possuem uma maior quantidade de camadas interestratificadas, enquanto que os cristais 7 a 10, localizados no ponto mais próximo da lagoa salina (P5), devem ser os que apresentam menor quantidade de camadas mistas. Como alguns teores de $\mathrm{K}^{+}$estão muito abaixo dos intervalos apresentados por Weaver \& Pollard (1973), é ainda possível que uma parte do $\mathrm{K}^{+}$tenha sido perdida durante as análises, conforme já observado por Ferrel \& Carpenter (1990). 


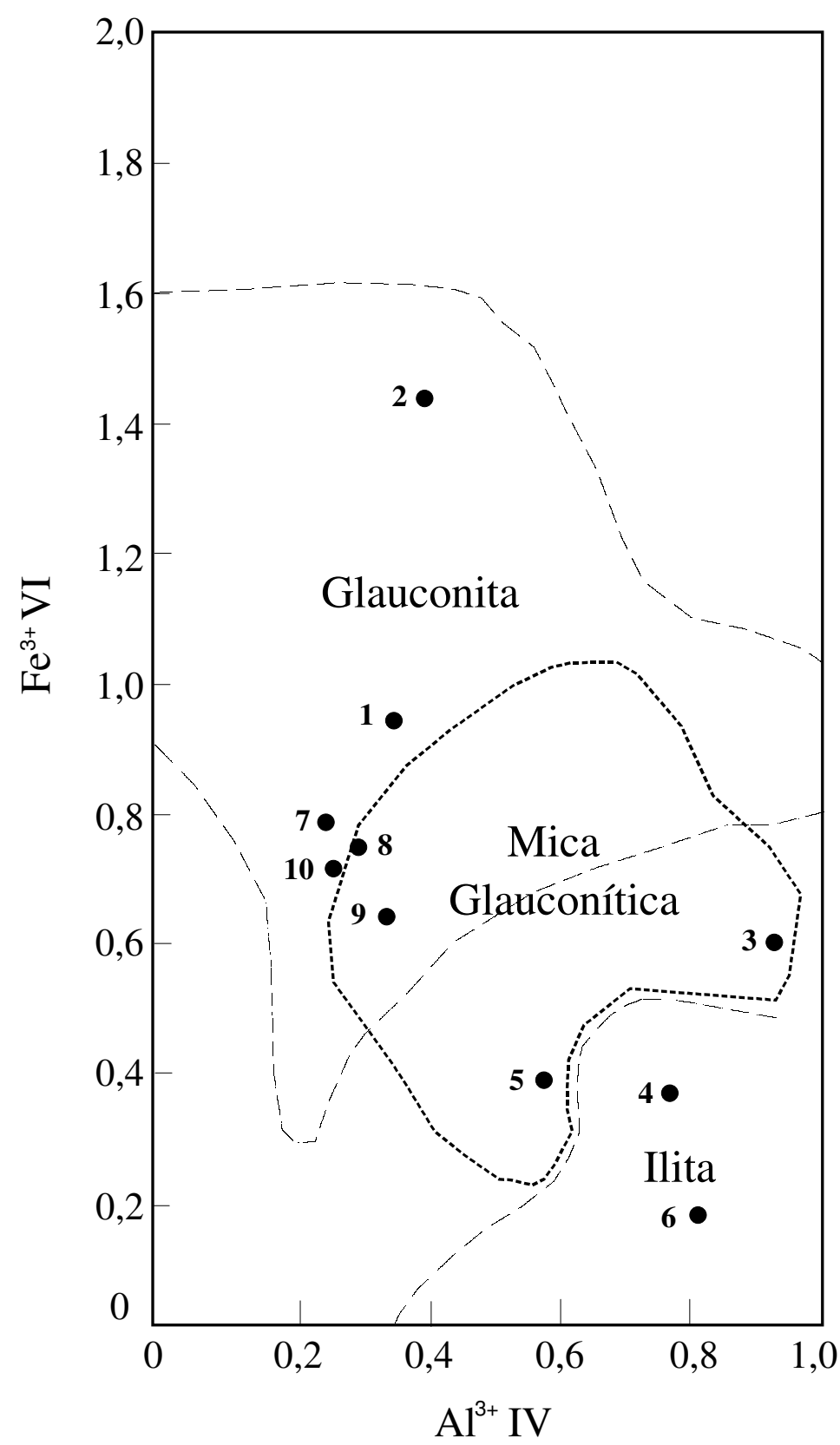

Figura 5.10 - Classificacão das ilitas, glauconitas e micas glauconíticas da área de estudo (adaptação de Porrenga, 1968). Os números dos cristais são os mesmos apresentados na Tabela 5.5. 
As médias de carga total na entrecamada de minerais-padrão de ilita e glauconita são de $-0,72$ e $-0,78$, respectivamente (Weaver \& Pollard, 1973). No presente trabalho, os cristais de número 2, 3, 4 e 6 apresentam carga igual ou inferior a -0,53, estando muito próximos ou abaixo do limite inferior esperado para minerais do grupo das micas (0,5 mol (e-)) (Fanning et al., 1989), mas dentro dos limites de carga dos minerais do grupo das esmectitas (0,2 a 0,6 mol (e')) (Reid-Soukup \& Ulery, 2002). É importante notar que enquanto estes cristais possuem as menores cargas, os cristais 7 a 10 apresentam cargas que estão entre as mais altas. Estes fatos reforçam a idéia de que os minerais com menor quantidade de camadas mistas localizam-se provavelmente no pedon mais próximo à lagoa salina (P5).

Tais características atípicas desencorajam a classificação destes cristais como ilita, glauconita e micas glauconítica strictu sensu, sendo melhor denominá-las como interestratificados ilita-esmectita, glauconita-esmectita e mica glauconítica-esmectita.

Vale ressaltar ainda que, assim como as esmectitas estudadas, as micas também não apresentam $\mathrm{Na}^{+}$na entrecamada, provavelmente devido a interferências causadas pela tela de cobre utilizada como suporte das amostras no MET.

\subsection{3 - Origem dos minerais}

Experimentos (Eberl et al., 1986; Eberl et al., 1993), revisão de literatura (Hower, 1961) e estudos de caso (Porrenga, 1968; Singer \& Stoffers, 1980; Deconinck et al., 1988; Hugget et al., 2001) mostram que a transformação de esmectitas em ilita, glauconita ou mica glauconítica em condições superficiais de pressão e temperatura requer grande suprimento de $\mathrm{K}^{+}$, condições alcalinas, ciclos de umedecimento e ressecamento e, é claro, quantidade suficiente do mineral precursor. As condições alcalinas possibilitam as reações químicas para adequação de carga e a fixação do $\mathrm{K}^{+}$ e os ciclos de ressecamento/umedecimento podem promover ou acelerar o último processo (Eberl et al., 1986; Eberl et al., 1993). No caso da glauconita e mica glauconítica, ainda é necessário haver grande disponibilidade de ferro e condições redutoras, necessárias para a mobilidade deste elemento (Hower, 1961; McConchie et al., 1979).

Apesar da lagoa do Meio aparentemente atender estes requisitos, uma análise mais detalhada sugere que as micas aqui estudadas não estão sendo originadas pela transformação da esmectita: 
1) Experimentos conduzidos por Eberl et al. (1986) e Eberl et al. (1993) mostraram que, no caso de transformação de esmectitas em micas em ambientes submetidos a ciclos de umedecimento/ressecamento, os minerais interestratificados originados por fixação de $\mathrm{K}^{+}$possuem o máximo de $50 \%$ de camadas de mica. Os interestratificados aqui estudados apresentam mais de $80 \%$ de camadas de minerais do grupo das micas, o que sugere que outro processo deve ser o responsável pela gênese destes minerais.

2) As esmectitas trioctaédricas neoformadas presentes principalmente nos horizontes superficiais dos Pedons 3, 4 e 5 apresentam composição química muito diferente das micas interestratificadas em questão (Tabelas 4.3, p. 115, e 5.5). Tais micas possuem teores muito maiores de $\mathrm{Al}^{3+}$ e de $\mathrm{Fe}^{3+}$ (com exceção da ilita, cristal 6, Tabela 5.5) e teores muito menores de $\mathrm{Mg}^{2+}$, além de não apresentarem o ânion $\mathrm{Cl}^{-}$, uma especificidade dos minerais do tipo saponita e estevensita aqui estudados. Além disto, a quantidade absoluta de esmectita trioctaédrica presente atualmente em superfície é de apenas $47 \mathrm{~g} / \mathrm{kg}$, o que sugere uma produção possivelmente insuficiente para formar cerca de $200 \mathrm{~g} / \mathrm{kg}$ de micas distribuídas ao longo de toda a topossequência. Destacase, ainda, que experimentos de transformação de esmectita em ilita mostram que as esmectitas trioctaédricas são muito menos reativas do que as dioctaédricas (Odom, 1984). Assim, os minerais do tipo saponita e estevensita provavelmente não são os minerais precursores das micas.

3) As esmectitas dioctaédricas situadas nos Pedons 1 e 2 possuem um grau de interestratificação com mica e composição próxima à da ferribeidelita. Algumas evidências já expostas no Capítulo 4 sugerem que este mineral é provavelmente originado a partir de transformação das micas aqui estudadas e não o contrário. As principais são: a) presença de vermiculita apenas no horizonte esverdeado dos Pedons 1 e 2, mineral tipicamente intermediário no processo de transformação de mica em esmectita (Robert, 1973); b) esmectitas originadas a partir de micas tendem a ter maior substituição isomórfica no tetraedro (Borchardt, 1989); de fato, tanto a ferribeidelita quanto a maioria das micas aqui descritas, em especial as situadas nos pedons mais distantes da lagoa salina, possuem carga originada principalmente no tetraedro; c) micas do tamanho de argila submetidas ao ressecamento tendem mais a liberar do que fixar $\mathrm{K}^{+}$em suas entrecamadas (Scott \& Smith, 1968); os Pedons 1 e 2 são os que estão sujeitos à períodos mais longos de ressecamento e, portanto, à grandes liberações de $\mathrm{K}^{+}$. A presença de apenas $1 \%$ de micas no horizonte 6 de $\mathrm{P} 1$, 
medidas pelos padrões de EG (Tabela 5.2), sugere que esta transformação em esmectita é efetivamente intensa neste pedon. Além disto, é mais provável que 200 $\mathrm{g} / \mathrm{kg}$ de micas distribuídas ao longo de toda a topossequência seja o mineral precursor de $70 \mathrm{~g} / \mathrm{kg}$ de esmectitas localizadas apenas nos Pedons 1 e 2 do que o inverso. Desta forma, as esmectitas dioctaédricas provavelmente também não são os minerais precursores das micas.

Por outro lado, experimentos de síntese realizados por Harder (1974) e Harder (1980) mostraram que a origem de interestratificado ilita-esmectita e glauconita, respectivamente, pode ocorrer a partir de neoformação em condições superficiais de pressão e temperatura. O mecanismo responsável envolveu a precipitação inicial de hidróxidos amorfos a partir de soluções contendo diferentes concentrações de $\mathrm{Al}^{3+}$, $\mathrm{Si}(\mathrm{OH})_{4}, \mathrm{Fe}, \mathrm{Mg}^{2+}$ e $\mathrm{K}^{+}$, e a posterior cristalização dos minerais após alguns dias de espera. As principais condições de neoformação nos experimentos foram $\mathrm{pH}$ alcalino, concentrações de $\mathrm{Si}(\mathrm{OH})_{4}$ inferiores a $100 \mathrm{mg} / \mathrm{L}$ e altas concentrações de $\mathrm{K}^{+}$na solução $(\geq 300 \mathrm{mg} / \mathrm{L})$. A presença de mais de $1000 \mathrm{mg} / \mathrm{L}$ de $\mathrm{Mg}^{2+}$ parece ser fundamental para a cristalização da ilita-esmectita, enquanto presença de $\mathrm{Fe}(0,6$ a 2 $\mathrm{mg} / \mathrm{L}$ ) e condições levemente redutoras foram necessárias para a formação da glauconita. Concentrações de $\mathrm{Si}(\mathrm{OH})_{4}$ abaixo de $100 \mathrm{mg} / \mathrm{L}$ são necessárias para que haja permanência de monômeros de $\mathrm{Si}(\mathrm{OH})_{4}$ na solução, pois sua polimerização tende a manter o precipitado amorfo. A presença de $\mathrm{Mg}^{2+}$ aparentemente facilita a formação da coordenação octaédrica do $\mathrm{Al}^{3+}$, necessária para a gênese de filosilicatos, enquanto as condições redutoras são necessárias para permitir a mobilidade do Fe.

A neoformação de ilita (Jones \& Weir, 1983; Turner \& Fishman, 1991), glauconita (El Albani et al., 2005) e micas glauconíticas (Keller, 1958; Parry \& Reeves, 1966; Porrenga, 1968) ao redor e abaixo de lagos salino-alcalinos denotam que estes ambientes são capazes de apresentar as condições requeridas nos experimentos de síntese. A área de estudo, em específico, parece atender tais requisitos, como exposto a seguir:

1) As características químicas das águas associadas à lagoa do Meio parecem atender as condições necessárias para a neoformação de micas, conforme exposto por Harder (1974) e Harder (1980). Tais águas apresentam pH alcalino (entre 7,6 e 9,6), concentrações médias de $\mathrm{Si}(\mathrm{OH})_{4}$ inferiores a $100 \mathrm{mg} / \mathrm{L}$, Eh negativo (entre -25 e 
-364) e concentrações de $\mathrm{K}^{+}$superiores a $300 \mathrm{mg} / \mathrm{L}$ nos pontos mais mineralizados (lagoa e G0). As concentrações de Fe (0,01 a 0,08 mg/L) e $\mathrm{Mg}^{2+}(0,03$ a 2,23 mg/L), entretanto, são mais baixas do que as verificadas no experimento. Contudo, Harder (1980) enfatiza que a concentração de Fe no mar, onde se origina a maioria das glauconitas, também é menor do que a observada por ele durante a síntese, sugerindo que este elemento deve ser parcialmente oriundo de dissolução de minerais préexistentes dentro do pacote sedimentar. Quanto ao $\mathrm{Mg}^{2+}$, ressalta-se que as condições experimentais do autor envolveram $\mathrm{pH} 8$ e temperatura de $20^{\circ} \mathrm{C}$, mas Harder (1972) e Harder (1974) afirmam que sob maiores temperaturas e $\mathrm{pH}$ mais alcalino a necessidade de $\mathrm{Mg}^{2+}$ diminui brutalmente.

Adiciona-se o fato de que o diagrama de concentração apresentado na Figura 5.8 mostra um claro controle do $\mathrm{K}^{+}$nas águas mais salinas, sugerindo que este elemento pode estar se envolvendo na formação de alguma fase mineral.

Os resultados mostraram que as micas glauconíticas e glauconitas interestratificadas são as micas dominantes na área de estudo, havendo poucos cristais de ilita interestratificada. A quantidade disponível de Fe na área de estudo deve variar, na maior parte do tempo, para atender ora as necessidades para formar micas glauconíticas, ora as necessidades para formar glauconitas. A maior disponibilidade de $\mathrm{Fe}$ e a conseqüente formação de glauconita interestratificada deve ocorrer em períodos de maiores estiagens, quando as águas atingem concentrações mais altas. Diferentes taxas de dissolução de minerais portadores de $\mathrm{Fe}$, como sugerido por Harder (1980), também podem ser responsáveis pelo fornecimento de maiores ou menores quantidades deste elemento. As caulinitas amplamente distribuídas na área de estudo são portadoras de $\mathrm{Fe}$ e as condições alcalinas vigentes são ideais para sua desestabilização, como já comentado no Capítulo 3.

Já a presença mais escassa de ilita interestratificada nos solos da área de estudo possivelmente deva-se a períodos com baixa concentração de Fe combinada a altas temperaturas, fundamentais para baixar os teores de $\mathrm{Mg}^{2+}$ necessários para a gênese deste mineral. $\mathrm{Na}$ área de estudo, a temperatura das águas atingiu o máximo de $40^{\circ} \mathrm{C}$ nas medições efetuadas em campo. Este valor é o dobro do estipulado no experimento de síntese de ilita-esmectita, mas ainda é possível que temperaturas mais altas sejam eventualmente atingidas. 
Patranabis e Fukuoka (1998) já haviam descrito a formação autigênica conjunta de ilitas, glauconitas e micas glauconíticas, mas em ambiente marinho. Segundo estes autores, a ocorrência destes três minerais em um mesmo ambiente é ditada muito mais por variações químicas em microambientes do que no ambiente como um todo. Assim, é mais provável que as variações ambientais necessárias para a formação de cada um destes minerais na área de estudo ocorram mais efetivamente em microescala.

2) $\mathrm{O}$ material amorfo enriquecido em $\mathrm{SiO}_{2}$ e associado a pequenas cristalizações, observado no horizonte 6 do Pedon 3, pode ser um indício de que o mecanismo de neoformação das micas na área de estudo é semelhante ao verificado nos experimentos de síntese. Os teores de $\mathrm{Fe}, \mathrm{Mg}^{2+}$ e $\mathrm{K}^{+}$do material amorfo $(9,1 \%, 2,8 \%$ e $4,1 \%$ ) são muito próximos aos da mica glauconítica interestratificada identificada no horizonte 6 do Pedon 3 (8,2\%, 2,9\% e 4,8\%), sugerindo que este seja o precipitado inicial a partir do qual esta mica cristalizou-se. Ressalta-se que o horizonte 6 evidencia a ocorrência das maiores quantidades de sílica amorfa da topossequência, como explicitado no Capítulo 3, podendo ser este o motivo da maior concentração de mica estar justamente neste horizonte.

É possível que a identificação pontual destes amorfos por MET-EDS na topossequência deva-se a diferenças de condições experimentais a que as amostras foram submetidas. A amostra do horizonte 6, Pedon 3, foi submetida à condições ácidas durante o período entre o fracionamento e a observação no MET. Todas as outras amostras permaneceram em meio alcalino, além de terem esperado um tempo maior pela disponibilidade do instrumento. Os compostos de sílica tornam-se extremamente solúveis a pH muito alcalinos e a sílica amorfa, em especial, é ainda mais solúvel que as formas cristalinas (Drees et al., 1989). Apesar das águas e solos da área de estudo já serem alcalinos, a solubilidade da sílica cresce exponencialmente após pH superior a 9, o que significa que leves aumentos de $\mathrm{pH}$ nos meios de análise podem ter sido suficientes para promover a dissolução dos materiais amorfos nas 3 amostras submetidas ao MET-EDS.

Os cinco argumentos aqui expostos levam a considerar as micas identificadas na área de estudo como frutos de neoformação. É difícil saber, entretanto, se tais micas já se formam com um grau de interestratificação ou se o processo de incorporação de 
camadas de esmectita inicia-se após sua formação. Independentemente do fato das micas originarem-se ou não interestratificadas, evidências como o aumento de camadas de esmectitas nas micas no sentido lagoa-cordilheira e o surgimento de esmectitas dioctaédricas apenas nos pedons mais próximos da cordilheira, sugerem um aumento da interestratificação após a sua formação, sendo este maior nos pontos mais altos da topossequência. Como já explicitado no Capítulo 4, isto se deve provavelmente à maior duração dos períodos de ressecamento a que estão submetidos o Pedon 2 e, principalmente, o Pedon 1 (Scott \& Smith, 1968).

$\mathrm{O}$ processo de transformação de em esmectita ocorre pela liberação do $\mathrm{K}^{+}$e sua substituição por íons hidratáveis $\left(\mathrm{Ca}^{2+}, \mathrm{Mg}^{2+}\right)$ nas entrecamadas (Fanning et al., 1989). Com a abertura de algumas das entrecamadas, outros íons também podem estar sendo adsorvidos pelo mineral interestratificado. As amostras da área de estudo enriquecidas em micas apresentam teores de elementos terras raras (ETR) superiores do que o supostamente esperado para minerais neoformados (Torrez Ruiz et al., 1994; Lopez-Galindo et al., 1996), como pode ser visto na Tabela 4.4 (p.117). Estes elementos podem estar sendo adsorvidos nas entrecamadas abertas das micas durante sua transformação em esmectita. A dissolução de outros minerais, como a caulinita, por exemplo, pode ser a responsável pela alta disponibilidade de ETR no meio.

\section{5 - Conclusões}

A formação autigênica conjunta de minerais do tipo ilita, glauconita e mica glauconítica nos solos associados à lagoa do Meio parece ser inédita em ambiente salino-alcalino. A neoformação, mecanismo de origem destes minerais na área de estudo, é comumente retratada para ilita e glauconita, mas é rara na gênese de mica glauconítica. A gênese alternada de cada um destes minerais nos arredores da salina

parece depender de condições específicas atingidas por variações de características químicas do meio, provavelmente desencadeadas por concentrações sazonais das águas e por diferentes taxas de dissolução mineral. Tais variações devem ocorrer mais efetivamente em microambientes, já que nesta escala as mudanças são mais rápidas e extremas.

A formação de ilita e glauconita em ambiente salino-alcalino e estudos de mica glauconítica em lagos atuais são pouco comuns, por isto o presente trabalho amplia o 
conhecimento sobre as características do meio e processos envolvidos na gênese destes minerais.

\section{6 - Referências Bibliográficas}

Anderson, J.U., (1963). An improved pretreatement for mineralogical analysis of samples containing organic matter. Clays and Clay Minerals, 10, 380-388.

Baker, J.C. (1997) Green ferric clay in non-marine sandstones of the Rewan Group, southern Bowen Basin, Eastern Australia. Clay Minerals, 32, 499-506.

Bentor, Y.K. and Kastner, M. (1965) Notes on the mineralogy and origin of glauconite. Journal of Sedimentology and Petrology, 35, 155-166.

Biscaye, P. (1965) Mineralogy and sedimentation of recent deep-sea clay in the Atlantic Ocean and adjacent seas and oceans. Geological Society of America Bulletin, 76, 803-832.

Borchardt, G. (1989) Smectites. Pp. 675-727 in: Minerals in Soil Environments (J.B. Dixon \& S.B. Weed, eds). Soil Science of America Book Series, 1, Soil Science Society of America, Inc., Madison.

Brown, G.; Brindley, G.W. (1980) X-ray diffraction procedures for clay mineral identification. Pp: 305-359 in: Crystal Structures of Clay Minerals and their X-ray identification (G.W. Brindley, G. Brown, eds). Mineralogical Society, London.

Deconinck, J.F.; Strasser, A.; Debrabant, P. (1988) Formation of illitic minerals at surface temperatures in the Purbeckian sediments (lower Berrisian, Swiss and French Jura). Clay Minerals, 23, 91-103.

Drees, L.R.; Wilding, L.P.; Smeck, N.E.; Senkayi, A.L. (1989) Silica in soils: quartz and disordered silica polymorphs. Pp. 913-974 in: Minerals in Soil Environments (J.B. Dixon and S.B. Weed, eds). Soil Science of America Book Series, 1, Soil Science Society of America, Inc., Madison.

Eberl, D.D.; Srodón, J.; Northrop, H.R. (1986) Potassium fixation in smectite by wetting and drying, pp.296-326 in: Geochemical processes at mineral surface (J.A. Davis \& K.F. Hayes, editors). American Chemical Society Symposium Series, 323.

Eberl, D.D.; Velde, B.; McCormick, T. (1993) Synthesis of illite-smectite from smectite at earth surface temperatures and high pH. Clay Minerals, 28, 49-60.

El Albani, A; Meunier, A; Fürsich, F. (2005) Unusual ocurrence of glauconite in a shallow lagoonal environment (Lower Cretaceous, northern Aquitaine Basin, SW France). Terra Nova, 17, 537-544.

Fanning, D.S.; Vissarion, Z.K. \& El-Desoky, M.A. (1989) Micas. Pp. 551-634 in: Minerals in Soil Environments (J.B. Dixon and S.B. Weed, eds. Soil Science of America Book Series, 1, Soil Science Society of America, Inc., Madison.

Ferrel, R.E; Carpenter, P.K. (1990) Application of the electron microprobe and image analysis in the study of clays. Pp. 108-132 in: Electron Optical Methods in Clay Science (I.D.R. Mackinnon \& F.A. Mumpton, eds). CMS Workshop Lectures, 2, Clay Minerals Society, Boulder, CO.

Harder, H. (1972) The role of magnesium in the formation of smectite minerals. Chemical Geology, 10, 31-39

Harder, H. (1974) Illite mineral synthesis at surface temperatures. Chemical Geology, 14, 241-253.

Harder, H. (1980) Syntheses of glauconita at surface temperatures. Clays and Clay Minerals, 28, $217-$ 222

Hower, J. (1961) Some factors concerning the nature and origin of glauconite. American Mineralogist, 46, 313-334.

Hower, J. and Mowatt, T.C. (1966) The mineralogy of illites and mixed layer illite / montmorillonites. American Mineralogist, 51, 825-854.

Huggett, J.M.; Gale, A.S.; Clauer, N. (2001) The nature and origin of non-marine 10A clay from the Late Eocene and Early Oligocene of the Isle of Wight (Hampshire Basin), UK. Clay Minerals. 36, 447-464. 
Jeans, C.V.; Mitchell, J.G.; Scherer, M; Fisher, M.J. (1994) Origin of the Permo-Triassic clay mica assemblage. Clay Minerals, 29, 575-589.

Jones, B.F., Weir, A.H. (1983) Clay minerals of Lake Abert, an alkaline, saline lake. Clays and Clay Minerals 3, 161-172.

Jung, J. (1954) Les illites du basin oligocène de Salins (Cantal). Bulletin de la Société Française de Minéralogie et Cristallographie, 77, 1231-1249.

Keller, W.D. (1958) Glauconitic mica in the Morrison Formation in Colorado. Clays and Clay Minerals, 5, 120-128.

Kossovskaya, A.G. and Drits (1970) V.A. The variability of micaceous minerals on sedimentary rocks. Sedimentology, 15, 83-101.

López-Galindo, A.; Ben Aboud, A.; Fenoll Hach-Ali, P.; Casas Ruiz, J. (1996) Mineralogical and geochemical characterization of palygorskite from Gabasa (Ne Spain). Evidence of a detrital precursor. Clay Minerals, 31, 33-44.

McConchie, D.M.; Ward, J.B.; McCann, V.H.; Lewis, D.W. (1979) A Mössbauer investigation of glauconite and its geological significance. Clays and Clay Minerals, 27, 339-348.

Mcrae, S.G. (1972) Glauconite. Earth Science Reviews, 8, 397-440.

Moore, D. \& Reynolds, R.C. (1997) X-ray Diffraction and the Identification and Analysis of Clay Minerals. Oxford University Press, $2^{\text {nd }}$ edition, $378 \mathrm{p}$.

Odin, G.S and Matter, A. (1981) Origin of glauconites. Sedimentology, 28, 611-641.

Odom, E. (1984) Glauconite and Celadonite Minerals. Pp. 545-572 in: Micas (S.W. Bailey, editor). Reviews in Mineralogy, 13. Mineralogical Society of America, Whashington, D.C.

Parry, W.T. and Reeves Jr, C.C. (1966) Lacustrine glauconitic mica from Pluvial Lake Mound, Lynn and Terry Counties, Texas. American Mineralogist, 51, 229-235.

Patranabis, S.; Fukuoka, M. (1998) Fe-illites in a Proterozoic deep marine slope deposit in the Penganga Group of the Pranhita Godavari Valley: their origin and environmental significance. Journal of Geology, 106, 741-749.

Porrenga, D.H. (1968) Non-marine glauconitic illite in the Lower Oligocene of Aardebrug, Belgium. Clay minerals. 7, 421-430.

Reid-Soukup, D.A. \& Ulery, A. (2002) Smectites. Pp. 467-499 in: Soil Mineralogy with Environmental Application (J.B. Dixon, \& D. G. Schulze, eds). Soil Science of America Book Series, 7, Soil Science Society of America, Inc., Madison.

Reynolds, R.C. (1980) Interstratified clay minerals. Pp 249-303 in: Crystal Structures of Clay Minerals and Their X-Ray Identification (G.W. Brindley and G. Brown, editor), 5, Mineralogical Society, London.

Robert, M. (1973) The experimental transformation of mica toward smectite; relative importance of total charge and tetrahedral substitution. Clays and Clay Minerals, 21, 167-174.

Rouchy, J.M.; Camoin, G., Casanova, J. \& Deconinck, J.F. (1993) The central palaeo-Andean basin of Bolivia (Potosi area) during the late Cretaceous and early Tertiary: reconstruction of ancient saline lakes using sedimentological, paleoecological and stable isotope records. Palaeogeography, Palaeoclimatology, Palaeoecology, 105, 179-198.

Scott, A.D. and Smith, S.J. (1968) Mechanism for soil potassium release by drying. Soil Science Society of America Proceedings, 32, 443-444.

Singer, A., Stoffers, P. (1980). Clay mineral diagenesis in two East African lakes. Clay Minerals, 15, 91-307.

Srodón, J. \& Eberl, D.D. (1984) Illite. Pp. 495-544 in: Micas (S.W. Bailey, ed.). Reviews in Mineralogy, 13. Mineralogical Society of America, Washington, D.C.

Theisen, A.A. \& Harward, M.E. (1962) A paste method for preparation of slides for clay mineral identification by x-ray diffraction. Soil Science Society of America Proceedings, 26, 90-91. 
Thompson, M.L. \& Ukrainczyk, L. (2002) Micas. Pp. 431-466 in: Soil Mineralogy with Environmental Application (J.B. Dixon, \& D. G. Schulze, eds). Soil Science of America Book Series, 7, Soil Science Society of America, Inc., Madison.

Torres Ruiz, J., López-Galindo, A., González-López, J.M., Delgado, A. (1994). Geochemistry of Spanish sepiolite-palygorskite deposits: genetic considerations based on trace elements and isotopes. Chemical Geology, 112, 221-245.

Turner, C.E. and Fishman, N.S. (1991) Jurassic Lake Toodichi, a large alkaline, saline lake, Morrison Formation, Eastern Colorado Plateau. Geological Society of America Bulletin, 103, 538-558.

United Stated Department of Agriculture-USDA (1996) Soil Survey Laboratory Methods Manual. Soil Survey Investigations Report, 42.

United States Department of Agriculture - USDA (2002) Field Book for Describing and Sampling Soils, version 2.0.

Velde, B. (1995) Origin and mineralogy of clays. Clays and the environment. Springer-Verlag Berlin Heidelberg, $333 \mathrm{p}$.

Weaver, C.E. and Pollard, L.D. (1973) The Chemistry of Clay Minerals. Elsevier, Amsterdam. 213 p. 


\section{Capítulo 6}

CONCLUSÕES GERAIS 


\section{1 - Conclusões Gerais}

\subsection{1 - Aprofundamento do conhecimento dos solos}

Mostrou-se que os solos do entorno da lagoa do Meio são profundamente influenciados pelas águas superficiais da salina e subsuperficiais de seu entorno. Trata-se de solos com pH fortemente alcalino e alta saturação em $\mathrm{Na}^{+}$, submetidos à solonização. Estas características desencadearam na área de estudo a ocorrência dos seguintes processos pedogenéticos típicos de solos sódicos: a) migração de matéria orgânica perfil abaixo, reconhecida principalmente pela presença de volumes verticais com baixos valores e cromas em horizonte subsuperficial e arenoso (horizonte 4); b) precipitação de minerais carbonáticos reconhecidos por Difração de Raios $\mathrm{X}$, como calcita $\left(\mathrm{CaCO}_{3}\right)$, dolomita $\left(\mathrm{CaMgCO}_{3}\right)$ e nahcolita $\left(\mathrm{NaHCO}_{3}\right)$, em nódulos concentrados principalmente no horizonte subsuperficial bruno-acinzentado (horizonte 5); e c) precipitação de sílica amorfa principalmente no horizonte subsuperficial esverdeado e enriquecido em argila (horizonte 6), processo evidenciado em campo pelo forte endurecimento deste horizonte e, em laboratório, pela preservação de torrões submersos em $\mathrm{HCl} 1 \mathrm{~N}$ e sua pulverização quando submersos em $\mathrm{NaOH} 4 \mathrm{M}$.

Até o momento, os estudos dos solos associados às lagoas salinas da Nhecolândia eram em grande maioria preliminares, baseados quase que exclusivamente em dados de campo. Assim, os resultados aqui obtidos aprofundaram o conhecimento sobre estes solos na medida em que foram ampliados os métodos de pesquisa e foi reconhecida a ocorrência de determinados processos pedogenéticos.

\subsection{2 - Controle de íons, formação de minerais e gênese das águas salinas}

Os resultados do presente trabalho confirmam a hipótese de Barbiéro et al. (2000) e Barbiéro et al. (2002) de que a precipitação de carbonatos e a formação de silicatos magnesianos são os responsáveis pelo controle químico do $\mathrm{Ca}^{2+}, \mathrm{Mg}^{2+} \mathrm{e} \mathrm{Si}(\mathrm{OH})_{4}$ nas águas mais salinas da Nhecolândia. $\mathrm{Na}$ área de estudo, diagramas de concentração envolvendo as águas superficiais da lagoa do Meio e subsuperficiais da cordilheira do entorno e de uma baía adjacente mostram que, assim como no estudo regional das águas efetuado por Barbiéro et al. (2002), ocorre uma diminuição das concentrações do $\mathrm{Ca}^{2+}, \mathrm{Mg}^{2+}$ e $\mathrm{Si}(\mathrm{OH})_{4}$ nas águas mais mineralizadas situadas na lagoa do Meio e no seu entorno imediato. $\mathrm{O}$ envolvimento do $\mathrm{Ca}^{2+}$ e de parte do $\mathrm{Mg}^{2+}$ na precipitação de 
carbonatos nos solos dos arredores desta salina foi confirmado pela ocorrência de nódulos milimétricos a centimétricos, principalmente no horizonte subsuperficial 5 , compostos por até $44 \%$ de carbonato de cálcio equivalente e com presença dos minerais calcita $\left(\mathrm{CaCO}_{3}\right)$ e dolomita $\left(\mathrm{CaMgCO}_{3}\right)$. Entretanto, o controle da maior parte do $\mathrm{Mg}^{2+}$, aliado ao do $\mathrm{Si}(\mathrm{OH})_{4}$, ocorre pela neoformação de esmectitas trioctaédricas do tipo saponita e estevensita no horizonte superficial 2, sendo estes minerais caracterizados pela dominância absoluta de $\mathrm{Mg}^{2+}$ no octaedro. Ressalta-se, contudo, que os silicatos magnesianos não são formados no horizonte subsuperficial esverdeado enriquecido em argila, como haviam previsto Barbiéro et al. (2000), mas sim no horizonte superficial 2, situado na zona de maior variação sazonal da lagoa.

As neoformações de carbonatos e silicatos magnesianos nos solos dos arredores da lagoa do Meio atestam que estes processos são provavelmente os responsáveis pela alta variabilidade entre as águas doces das baías/vazantes e as salgadas das salinas/arredores, conforme proposto por Barbiéro et al. (2002). O aumento atual da concentração das águas devido às altas taxas de evaporação no Pantanal promoveria a concentração de íons e a supersaturação de alguns deles, com a conseqüente participação em fases minerais, fenômenos responsáveis pela mudança de perfil químico das águas mais mineralizadas. Desta forma, o presente trabalho fornece fortes evidências de que a presença de sal nas águas das lagoas salinas da Nhecolândia, historicamente atribuída a heranças do Pleistoceno, é atual ou ao menos tem contribuição de processos atuais.

É possível, ainda, que a origem das próprias depressões que contém as lagoas salinas também ocorra por processos atuais e não por processos associados a climas semiáridos do passado, tais como a formação de "sebhkas" (Tricart, 1982) ou o isolamento de meandros abandonados (Ab'Saber, 1988). Um rebaixamento geoquímico dos arredores da salina poderia estar ocorrendo devido à dissolução do quartzo e a conseqüente solubilização da sílica nos solos dominantemente arenosos aí presentes, sendo este processo desencadeado pelo $\mathrm{pH}$ fortemente alcalino das águas e soluções dos solos associados à lagoa do Meio. Entretanto, estudos mais aprofundados voltados a este objetivo precisam ser feitos para testar esta hipótese. 


\subsection{3 - Mecanismos de gênese dos minerais}

As seguintes evidências apresentadas neste trabalho comprovam que as esmectitas magnesianas do tipo saponita e estevensita estão sendo originadas por precipitação química diretamente das águas superficiais da lagoa do Meio: a) presença de teores muito menores de elementos terras raras (ETR) nas amostras enriquecidas por esmectitas trioctaédricas, comparáveis aos de minerais precipitados apresentados na literatura; b) controle do $\mathrm{Mg}^{2+}$ e de $\mathrm{Si}(\mathrm{OH})_{4}$ nas águas em concentração, sugerindo o envolvimento destes íons na formação de silicatos magnesianos; c) equilíbrio ou supersaturação das águas da salina do Meio e seu entorno em relação aos minerais saponita e estevensita (conforme diagrama de equilíbrio elaborado pelo Prof. Dr. Vincent Vallés); e d) presença destes minerais trioctaédricos apenas no horizonte superficial 2, situado na zona de maior variação sazonal do nível superficial da salina.

Assim, os resultados aqui apresentados mostram que é possível a neoformação de esmectitas magnesianas do tipo saponita e estevensita em ambientes sujeitos a concentração evaporativa. Este resultado contraria as posições de Eugster \& Hardie (1978) e Jones (1986), que acreditam que as únicas fases que se originariam pela nucleação direta a partir das águas seriam a sepiolita, a magadita e o talco. Por outro lado, concorda com os resultados de outros autores, como por exemplo, Tettenhorst \& Moore (1978), Velde (1985) e Torres Ruiz et al. (1994), que também reconheceram a formação de saponita, estevensita e/ou paligorsquita por precipitação química em águas em processo de concentração.

Mostrou-se, ainda, que as micas dioctaédricas do tipo ilita, glauconita e mica glauconítica, dominantes nas assembléias de argila fina do horizonte subsuperficial esverdeado e enriquecido em argila (horizonte 6), estão sendo conjuntamente formadas por precipitação química diretamente das soluções mineralizadas dos solos. As principais evidências deste processo são o reconhecimento na área de estudo das mesmas condições ideais para precipitação de micas obtidas em experimentos de síntese: a) $\mathrm{pH}$ fortemente alcalino, Eh redutor e concentrações específicas de $\mathrm{Si}(\mathrm{OH})_{4}$ e $\mathrm{K}^{+}$nas águas da lagoa salina e dos arredores; e b) presença de material amorfo, precursor para cristalização da mica.

Ressalta-se que o estudo mineralógico destas micas am ambiente salino-alcalino moderno é uma importante contribuição ao conhecimento do ambiente de formação 
destes minerais, uma vez que eles têm sido, em grande maioria, descritos em sedimentos antigos.

Por fim, cabe destacar que a representatividade das águas e dos solos associados à salina do Meio permite admitir que os resultados da presente pesquisa são provavelmente encontrados na maioria das lagoas salinas da Nhecolândia.

\section{2 - Referências Bibliográficas}

Ab'Saber, A.N. (1988) O Pantanal Mato-Grossense e a Teoria dos Refúgios. Revista Brasileira de Geografia, 50, p 9-57.

Barbiéro, L.; Queiroz Neto, J.P.; Sakamoto, A.Y. (2000) Características Geoquímicas dos Solos Relacionadas à Organização Pedológica e à Circulação da Água (Fazenda Nhumirim: Embrapa CPAP, Nhecolândia, MS). Pp. 90-100 in: Anais do $3^{\circ}$ Simpósio sobre Recursos Naturais e SócioEconômicos do Pantanal, Corumbá (MS).

Barbiéro, L. Queiroz Neto, J.P. Ciornei, G. Sakamoto, A.Y. Capellari, B. Fernandes, E. Valles, V., (2002). Geochemistry of water and ground water in the Nhecolândia, Pantanal of Mato Grosso, Brazil: variability and associated processes. Wetlands, 22, 528-540.

Eugster, H.P. \& Hardie, L.A. (1978) Saline Lakes. Pp. 237-294 in: Lakes: chemistry, geology and physics (A. Lerman, ed.). Springer-Verlag.

Jones, B.F. (1986). Clay mineral diagenesis in lacustrine sediments. Pp. 291-300 in: Studies in Diagenesis (F.A. Mumpton, ed.). US Geol. Surv. Bull., 1578.

Tettenhorst, R. \& Moore, G.E. (1978) Stevensite oolites from the green river formation of Central Utah. Journal of Sedimentary Petrology, 48, 587-594.

Torres Ruiz, J., López-Galindo, A., González-López, J.M., Delgado, A. (1994). Geochemistry of Spanish sepiolite-palygorskite deposits: genetic considerations based on trace elements and isotopes. Chemical Geology, 112, 221-245.

Tricart, J. (1982) El Pantanal: Un ejemplo del impacto de la Geomorfología sobre el medio ambiente. Geografia, 7, 37-50.

Velde, B. (1985) Clay Minerals: a physico-chemical explanation of their occurrence. Developments in Sedimentology, 40. Elsevier, 427 p. 
ANEXOS 


\section{ANEXO 1}

Descrição detalhada dos métodos mineralógicos e das análises estatística e manométrica 


\section{Índice do Anexo 1:}

\begin{tabular}{|c|l|}
\hline 1.1 - Pré-tratamento das amostras & 3 \\
\hline 1.2 - Difração de Raios X & 4 \\
\hline 1.2 .1 - O fenômeno da difração e o difratômetro de raios X & 4 \\
\hline 1.2 .2 - Tratamentos e confecção das lâminas & 6 \\
\hline 1.2 .3 - Semi-quantificação das amostras de argila fina & 7 \\
\hline $1.2 .4-$ Análises de amostras não orientadas & 7 \\
\hline 1.3 - Análise Estatística de Função Discriminante & 8 \\
\hline 1.4 - Liofilização & 8 \\
\hline 1.5 - MET - EDS & 9 \\
\hline 1.6 - Análise Manométrica & 11 \\
\hline 1.7 - Referências Bibliográficas & 11 \\
\hline
\end{tabular}




\section{1 - DESCRIÇÃO DETALHADA DOS MÉTODOS MINERALÓGICOS E DAS ANÁLISES ESTATÍSTICA E MANOMÉTRICA}

Vinte amostras distribuídas em 5 pontos ao longo da Topossequência 1 foram escolhidas para análises de argila fina, argila grossa e silte fino em Difração de Raios X (DRX). Destas, apenas algumas amostras representativas de argila fina foram selecionadas para análise no Microscópio Eletrônico de Transmissão (MET), acoplado ao Espectrômetro tipo Dispersão em Energia (EDS). O solo total destas 20 amostras selecionadas inicialmente e alguns nódulos carbonáticos passaram ainda por Análise Manométrica.

As análises de DRX e Manométrica, e todos os procedimentos associados, foram realizadas por mim no "Laboratory of Soil Mineralogy, Department of Environmental Sciences, University of California- Riverside (UCR), sob a supervisão do Dr. Robert Graham. O MET-EDS foi operado pelo Prof. Dr. Krassimir N. Bozhilov, do "Central Facility for Advanced Microscopy and Microanalysis, University of California, Riverside (UCR)", mas todas as sessões foram acompanhadas e direcionadas por mim e, algumas delas, pelo Prof. Dr. Robert Graham.

Detalhes a respeito dos materiais e métodos utilizados nas análises mineralógicas serão expostos a seguir.

\section{1 - Pré-Tratamento das Amostras}

O fracionamento dos solos, procedimento comum que antecede a realização de análises mineralógicas, consiste em separar as partículas de acordo suas propriedades físicas, magnéticas ou elétricas a fim de diminuir a complexidade da amostra e, assim, facilitar a identificação e quantificação das fases minerais presentes. O tipo mais comum de fracionamento, e adotado neste trabalho, é a separação granulométrica já que diferentes tipos de minerais tendem a ocorrer em tamanhos específicos de partículas (Amonette, 2002).

O primeiro passo do fracionamento é eliminar os agentes que causam a floculação, tais como carbonatos e matéria orgânica, para auxiliar na dispersão dos colóides do solo (Jackson, 1979; Amonette, 2002). A remoção destes agentes também diminui certas interferências que podem atrapalhar ou impedir a identificação de outros minerais: a presença de carbonatos dificulta, por exemplo, a orientação paralela das partículas de argila nas lâminas, o que pode gerar fracos padrões de Difração de Raios X (Kunze \& Dixon, 1986); a matéria orgânica também causa problemas na orientação paralela das argilas em lâminas (Douglas \& Fiessinger, 1971).

No presente trabalho, apenas a matéria orgânica foi removida, já que alguns testes mostraram que a quantidade de carbonatos presente no solo total não é suficiente para causar interferências significativas. A eliminação da matéria orgânica foi feita pelo método do hipocloreto de sódio $(\mathrm{NaOCl})$, ajustado para pH 9.5 com ácido clorídrico $(\mathrm{HCl})$. Outro método comum envolve o uso do peróxido de hidrogênio $\left(\mathrm{H}_{2} \mathrm{O}_{2}\right)$, mas esta substância pode causar degradação dos minerais de argila, não sendo, portanto, adequada para análises mineralógicas (Douglas \& Fiessinger, 1971). A 
oxidação da matéria orgânica a partir do uso de $\mathrm{NaOCl}-\mathrm{HCl}$ pode ser descrita de acordo com a seguinte reação: $\mathrm{CH}_{2} \mathrm{O}+2 \mathrm{NaOCl} \rightarrow 2 \mathrm{Na}^{+}+2 \mathrm{Cl}^{-}+\mathrm{H}_{2} \mathrm{O}+\mathrm{CO}_{2}$. De maneira geral, este método consiste inicialmente em adicionar $\mathrm{NaOCl}-\mathrm{HCl}$ à amostra de solo, misturar, aquecer a uma temperatura de $80^{\circ} \mathrm{C}$ por 15 minutos, centrifugar e descartar o sobrenadante. Estes passos são repetidos até que o sobrenadante esteja aparentemente claro, denotando não haver mais matéria orgânica na solução. Em seguida, deve-se adicionar cloreto de sódio $(\mathrm{NaCl})$ para lavar os produtos da decomposição, centrifugar e decantar (Anderson, 1963; Jackson, 1979).

O segundo passo do fracionamento é a efetiva dispersão das partículas individuais com a adição de água destilada, centrifugação e descarte do sobrenadante repetidas vezes, até que a fração argila entre em suspensão (Amonette, 2002). Por fim, o terceiro passo consiste no fracionamento propriamente dito, tendo sido adotado neste trabalho a separação granulométrica das partículas em 5 frações de areia: areia muito grossa $(1 \mathrm{a} 2 \mathrm{~mm})$, areia grossa $(0,5 \mathrm{a} 1 \mathrm{~mm})$, areia média $(0,25$ a 0,5 $\mathrm{mm})$, areia fina $(0,125 \mathrm{a} 0,25 \mathrm{~mm})$ e areia muito fina $(0,125$ a $0,05 \mathrm{~mm}) ; 2$ frações de silte: silte grosso $(0,02$ a $0,05 \mathrm{~mm})$ e silte fino $(0,02$ a $0,002 \mathrm{~mm})$; e 2 frações de argila: argila grossa $(0,002$ a $0,0002 \mathrm{~mm})$ e argila fina $(<0,0002 \mathrm{~mm})$.

A separação destas partículas foi feita pelo método de sedimentação, utilizando a Lei de Stokes para o cálculo da velocidade de sedimentação de cada fração:

$$
\mathrm{V}=\frac{\mathrm{g}\left(\mathrm{s}_{\mathrm{p}}-\mathrm{s}_{1}\right) \mathrm{D}^{2}}{18 n}
$$

sendo V a velocidade de sedimentação em $\mathrm{cm} / \mathrm{s}, \mathrm{g}$ a constante gravitacional $\left(980 \mathrm{~cm} / \mathrm{s}^{2}\right) ; \mathrm{s}_{\mathrm{p}}$ a gravidade específica da partícula; $s_{1}$ a gravidade específica da água; D o diâmetro da partícula em $\mathrm{cm}$; e $n$ viscosidade do meio (tabelada de acordo com a temperatura ambiente) (Jackson, 1979).

As separações da argila total e, posteriormente, do silte fino foram feitas com a adição de carbonato de sódio diluído $\left(\mathrm{NaCO}_{3}\right)$, agitação manual, centrifugação (no caso da argila) e sifonagem do sobrenadante nas profundidades e tempos de sedimentação calculados de acordo com equação (1). A centrifugação para separação da argila total foi feita a $500 \mathrm{rpm}$ por 6 minutos, em uma centrífuga IEC Model 2K, da International Equipment Company. A argila fina foi separada da argila grossa a partir de uma super-centrífuga refrigerada RC 5C plus, da marca Sorvall, utilizando-se $4000 \mathrm{rpm}$ por 16 minutos. O silte grosso e as areias foram secos por 2 horas na estufa e então peneirados (Jackson, 1979).

\section{2 - Difração de Raios X (DRX)}

\subsection{1 - O fenômeno da difração e o difratômetro de raios X}

Esta técnica é amplamente utilizada para identificação das fases minerais presentes nos solos, já que fornece informações relativamente rápidas e precisas (Gomes, 1988). O princípio de identificação dos minerais por difração de raios $\mathrm{X}$ consiste no fato de que cada estrutura cristalina possui um arranjo tridimensional dos átomos, que é sistemático e único. Os raios $\mathrm{X}$ possuem comprimentos de 
onda com a mesma magnitude de grandeza que as distâncias entre os planos estruturais dos cristais e, por isto, sofrem difração entre estes planos, sendo esta típica de cada estrutura cristalina (Jackson, 1979; Moore \& Reynolds, 1997).

$\mathrm{O}$ difratômetro de raios $\mathrm{X}$ é composto basicamente de um tubo onde os raios X são gerados, de um suporte para a amostra e de um receptor que mede a intensidade dos raios $\mathrm{X}$ difratados, sendo os dois últimos ajustáveis a qualquer posição angular em relação ao feixe de elétrons (Cullity, 1978). No tubo gerador, os elétrons são emitidos a partir de um filamento de tungstênio aquecido por correntes de 10 a $100 \mathrm{~mA}$ e acelerados no vácuo por voltagens de 15 a $60 \mathrm{kV}$ na direção de um alvo metálico. Dentro do alvo, os elétrons acelerados chocam-se com os elétrons do metal, sendo os últimos deslocados para órbitas mais afastadas do núcleo e o espaço vazio imediatamente preenchido por elétrons presentes em órbitas com maiores níveis de energia. Cada transferência de elétrons de um nível energético mais alto para um mais baixo resulta na emissão de radiação X (Whittig \& Allardice, 1986; Moore \& Reynolds, 1997). A energia gerada por transferência de elétrons dos níveis 2s e 2p (L) para o nível 1s (K) são as mais freqüentemente utilizadas em difração de raios X, sendo chamada $\mathrm{K}_{\alpha}$ (Whittig \& Allardice, 1986). A saída dos raios X do tubo gerador ocorre através de uma janela de berílio e por pequenas aberturas que limitam e direcionam o feixe diretamente para a amostra (Moore \& Reynolds, 1997).

Quando os raios encontram a amostra ocorre o fenômeno de difração, que envolve a absorção e a reemissão com interferência construtiva de raios $\mathrm{X}$ pelos átomos de um cristal. A interferência construtiva ocorre quando dois ou mais raios estão em fase e, para que um feixe difratado possa ser observado e medido, ele deve ser composto por um grande número de raios interferindo construtivamente (Moore \& Reynolds, 1997). A lei de Bragg relaciona de forma quantitativa esta interferência construtiva com a distância de separação dos planos de átomos em um cristal a partir da seguinte equação:

$$
\mathrm{n} \lambda=2 \mathrm{~d} \sin \theta
$$

onde $n \lambda$ é o número integral de comprimentos de onda (1, 2, 3, etc) em uma determinada distância percorrida pelo raio; d é a distância de separação dos planos de átomos em um cristal; $\theta$ é o ângulo crítico para determinado espaço- $d$ em que os raios entrarão em fase. Já que os minerais possuem diferentes distâncias interatômicas em 3 dimensões, os ângulos em que a difração ocorre serão diferentes para cada mineral. No difratômetro, a amostra e o detector dos raios difratados são rotacionados em uma taxa determinada pelo operador para que o ângulo de incidência do feixe varie. Uma vez que se conhece $n \lambda\left(\mathrm{K}_{\alpha}\right.$ do alvo) e $\theta$ (dado pelo difratômetro), é possível calcular a distância $d$, que é única para cada mineral, possibilitando a sua identificação (Whittig \& Allardice, 1986; Moore \& Reynolds, 1997).

Os raios difratados pela amostra são coletados por um detector responsável por converter os raios X em pulsos elétricos. O número de pulsos da corrente por unidade de tempo, determinado por um contador, é diretamente proporcional à intensidade dos raios que estão sendo detectados (Cullity, 1978). Os sinais então gerados correspondem a picos que são plotados em um gráfico de 
intensidade dos raios difratados vs. ângulo de difração em ${ }^{\circ} 2 \theta$ (Moore \& Reynolds, 1997). O valor de $d$ para cada pico é geralmente calculado pelo programa que comanda o difratômetro e fornecido em ângstrons ou nanômetros. A comparação destes valores com fichas ou tabelas que listam espaços- $d$ característicos dos mais diversos minerais (por exemplo, JCPDS, 1973; JCPDS, 1974) possibilitam a identificação dos minerais presentes na amostra. Neste trabalho, utilizou-se um difratômetro Siemens D-500, com radiação $\mathrm{K}_{\alpha}$ e alvo de cobre $(\mathrm{Cu})$. As lâminas foram rodadas a uma taxa de $0,02^{\circ} 2 \theta$ por etapa ("scanstep"), a cada $1 \mathrm{~s}$.

\subsection{2 - Tratamentos e confecção das lâminas}

As amostras de argila fina, argila grossa e silte passaram por 5 diferentes tratamentos:

- Saturação com $\mathrm{Mg}^{2+}$ e $\mathrm{K}^{+}$

A amostra de cada fração foi dividida em duas, sendo uma parte saturada com $\mathrm{Mg}^{2+}$ e a outra com $\mathrm{K}^{+}$, através de adição de solução de $\mathrm{MgCl}_{2}$ e $\mathrm{KCl}$, respectivamente, e posterior centrifugação. Estes tratamentos são importantes por três motivos: 1) para que os minerais de argila expansíveis mantenham apenas 1 tipo de cátion trocável adsorvido nas entrecamadas, assegurando que a expansão destes minerais por adição de água seja uniforme em todos os cristais da mesma espécie; 2) para minimizar estas adições e flutuações em absorção de água pela entrecamada devido a flutuações de umidade relativa do ar (Whittig \& Allardice, 1986); 3) para auxiliar na identificação dos minerais, uma vez que a reação com os dois cátions pode desencadear mudanças na posição dos picos: a esmectita, por exemplo, sofre expansão com a adição de $\mathrm{Mg}^{2+}$, o que provoca um deslocamento de seu pico para maiores ângulos $2 \theta$, se comparado às esmectitas saturadas com $\mathrm{K}^{+}$ (Reid-Soukup \& Ulery, 2002; Whittig \& Allardice, 1986). Mica e caulinita não são afetadas por estes tratamentos (Whittig \& Allardice, 1986).

Duas lâminas orientadas foram feitas para cada fração analisada, uma com amostra saturada em $\mathrm{Mg}^{2+}$ e outra com amostra saturada em $\mathrm{K}^{+}$e depois analisadas por DRX. Quando os minerais de argila estão orientados, ou seja, seus planos de difração basal $(00 l)$ encontram-se paralelos entre si e à superfície da lâmina, ocorre uma detecção preferencial de filossilicatos em detrimento de outros minerais. Utilizou-se o método de orientação sugerido por Theisen \& Harward (1962), que consiste em espalhar uma pasta de argila na lâmina de vidro com o uso de uma espátula, fazendo movimentos sempre no mesmo sentido.

- Impregnação com Etileno Glicol

Após terem sido lidas no Difratômetro de Raios $\mathrm{X}$, as lâminas saturadas em $\mathrm{Mg}^{2+}$ foram impregnadas com Etileno Glicol. Este tratamento é fundamental para diferenciar esmectita de vermiculita e clorita, já que os 3 minerais apresentam espaço- $d$ semelhantes em amostras saturadas com $\mathrm{Mg}^{2+}$. Como a esmectita é afetada por este tratamento e a vermiculita e a clorita não são, a distinção entre elas é possível de ser feita. Destaca-se ainda que mica e caulinita também não sofrem mudanças (Whittig \& Allardice, 1986).

Etileno Glicol é um líquido composto por grandes moléculas orgânicas que são adsorvidas pela superfície interna das esmectitas, produzindo sua expansão e, portanto, um aumento significativo do 
seu espaço-d (geralmente para 1.7-1.8, Whittig \& Allardice, 1986). O método utilizado para impregnação consiste em colocar a lâmina saturada em $\mathrm{Mg}^{2+}$ em uma plataforma no interior de um dessecador parcialmente cheio de etileno glicol e, em seguida, expor a amostra ao vapor proveniente deste líquido através da inserção do dessecador no forno a $60^{\circ} \mathrm{C}$ (Moore \& Reynolds, 1997), por 2 horas (Reid et al., 1996). As lâminas foram analisadas por DRX pelo menos 12 horas após terem saído do forno.

- Aquecimento a $350^{\circ}$ e $550^{\circ} \mathrm{C}$

As lâminas saturadas com $\mathrm{K}^{+}$foram submetidas a estas temperaturas por 1 hora em um forno Muffle de $1125^{\circ} \mathrm{C}$ (Fisher Scientific), sendo analisadas por DRX após cada um dos tratamentos. O aquecimento a $350^{\circ} \mathrm{C}$ é importante para o reconhecimento da esmectita pura ou intercalada, pois promove o colapso deste mineral e a mudança de seu espaço- $d$ para valores semelhantes ao da ilita $(1,0 \mathrm{~nm}) . \mathrm{O}$ aquecimento a $550^{\circ} \mathrm{C}$, por sua vez, promove a destruição da caulinita e haloisita e, portanto, o desaparecimento dos picos correspondentes. Mica e clorita não são afetadas por estes tratamentos (Jackson, 1979).

\subsection{3 - Semi-quantificação das amostras de argila fina}

Estimativas semi-quantitativas das porcentagens de cada mineral em cada uma das amostras de argila fina foram feitas de acordo com a proporção de área dos picos de DRX em padrões de etileno glicol-EG (Biscaye, 1965). Assumiu-se que caulinita, mica, esmectita e/ou quartzo compõem 100\% de cada amostra. Os picos $d_{001}$ dos 3 minerais foram foto-copiados, recortados e individualmente pesados em uma balança digital com 4 casas de precisão. Os pesos foram então normalizados, considerando-se o peso da esmectita, 4 vezes o peso da mica, 2 vezes o peso da caulinita e 8 vezes o

peso do quartzo. A soma total foi obtida a partir da soma dos pesos normalizados dos minerais de cada amostra. Por fim, as porcentagens de cada mineral foram obtidas multiplicando-se o seu peso normalizado por 100 e dividindo-se pela soma total.

\subsection{4 - Análise de amostras não orientadas}

Amostras de solo sem nenhum tratamento prévio foram dispostas de modo não orientado em um suporte metálico e examinadas por DRX. Este procedimento possibilita a identificação preferencial de minerais que não são filossilicatos e, por isto, foi utilizado para procura de carbonatos.

O suporte metálico utilizado possui uma depressão quadrada central com dimensões de $0,4 \mathrm{~cm}$ de largura, $0,4 \mathrm{~cm}$ de comprimento e $0,1 \mathrm{~cm}$ de profundidade. Uma lâmina de vidro foi usada para tampar esta depressão, deixando-se apenas uma abertura muito pequena, por onde a amostra foi colocada com auxílio de uma espátula. O uso da lâmina é necessário para manter a superfície da amostra lisa. Após toda a depressão ter sido preenchida, a lâmina foi cuidadosamente retirada e a amostra foi encaminhada para análise. 


\section{3 - Análise Estatística de Função Discriminante}

As porcentagens de mica fornecidas pela semi-quantificação dos minerais (argila fina) e os elementos maiores medidos por ICP-MS foram submetidos à Análise de Função Discriminante a fim de determinar quais elementos apresentam maior associação com as amostras enriquecidas em mica. Esta análise estatística correlaciona agrupamentos de dados semelhantes com variáveis independentes e baseia-se na extração sucessiva de funções que irão fornecer a melhor discriminação possível entre grupos. A primeira função extraída irá explicar a maior parte possível da variância dos dados, enquanto a segunda função irá trabalhar com a variância restante e assim sucessivamente (Statistica for Windows, Release 4.3, 1993). No presente trabalho, esta análise foi escolhida por ser uma alternativa para análise de variáveis múltiplas onde parte dos dados não apresenta distribuição normal.

As amostras de argila fina foram divididas em 3 grupos: Grupo 1 - amostras com pequenas quantidades de mica (0 a 29\%), Grupo 2 - amostras com médias quantidades de mica (30 a 65\%), e Grupo 3 - amostras com grandes quantidades de mica (66 a 100\%). Os óxidos $\mathrm{SiO}_{2} \mathrm{Al}_{2} \mathrm{O}_{3}, \mathrm{Fe}_{2} \mathrm{O}_{3}$, $\mathrm{MgO}, \mathrm{CaO}, \mathrm{MnO}, \mathrm{K}_{2} \mathrm{O}, \mathrm{Na}_{2} \mathrm{O}$ foram considerados como variáveis independentes. Dois conjuntos de coeficientes foram então aplicados: Coeficientes Padrões de Função Discriminante, que fornecem a contribuição individual de cada variável para formação de cada função discriminante extraída, e Coeficientes de Fator Estrutural, que apresentam a correlação entre as variáveis independentes e as novas funções formadas. Estudos estatísticos mostram que este último conjunto de coeficientes é mais apropriado para interpretação substantiva das funções (Statistica for Windows, Release 4.3, 1993).

\section{4 - Liofilização ('Freeze-Drying”)}

Em análises mineralógicas, as amostras não utilizadas na confecção de lâminas permanecem em solução aquosa e precisam passar por uma secagem para serem analisadas de forma não orientada por DRX (como exposto no item anterior). Uma das formas de realizar esta secagem é a aplicação do processo de liofilização, que consiste em congelar e secar materiais sob vácuo, o que provoca a sublimação do solvente e a permanência de um resíduo sólido, de natureza macia, suave e pouco volumosa (Malcolm, 1968).

Esta técnica apresenta muitas vantagens se comparada à simples secagem da argila ao ar, pois o produto final é muito melhor para ser esboroado e é menos sujeito as modificações químicas ou estruturais, podendo, portanto, ser estocado por tempos prolongados. Além disto, argilas liofilizadas não sofrem danos durante o processo e podem entrar em suspensão instantaneamente como material coloidal, enquanto as argilas secas ao ar podem ser parcialmente destruídas durante a secagem e demoram muito mais tempo para entrar novamente em suspensão.

As frações de argila fina e grossa das 20 amostras analisadas foram liofilizadas em um "Freeze-Dry System", modelo Lyph Lock 45, Labconco. Cada amostra é colocada em um tubo de ensaio de 100 $\mathrm{ml}$, o qual é propriamente identificado e tampado com uma rolha de borracha. A seguir, os tubos são congelados de quatro em quatro em um pote de isopor com etanol e gelo seco $\left(\mathrm{CO}_{2}\right)$. Para que 
sejam congelados, os tubos são inicialmente deixados dentro do pote de isopor por 1 minuto, retirados, girados na posição horizontal por 20 segundos e então recolocados no pote para que outro tubo seja girado. Este procedimento é importante para agilizar a liofilização, uma vez que promove a adesão da amostra às paredes do tubo e, portanto, maximiza sua superfície específica. Após congeladas, as amostras são colocadas em potes apropriados, os quais são anexados ao sistema de vácuo do aparelho (Malcolm, 1968). No presente trabalho, as amostras foram deixadas 3 dias no vácuo, em média.

\section{5 - Microscopia Eletrônica de Transmissão (MET), acoplado a microssonda equipada com Espectrômetro tipo Dispersão em Energia (EDS)}

O Microscópio Eletrônico de Transmissão (MET) é um instrumento óptico formado por quatro componentes básicos: sistema de iluminação, composto por uma fonte de radiação, geralmente um filamento de tungstênio, e por 2 lentes condensadoras que focam o feixe de elétrons sobre a amostra; sistema de manipulação da amostra, formado por uma câmara fechada que permite a entrada de apenas uma mínima quantidade de ar ao colocar a amostra; sistema de formação da imagem, constituído pela lente objetiva e pelas lentes projetoras, as quais focam o feixe de elétrons que passou pela amostra e produzem a imagem final magnificada; e sistema de registro da imagem, que converte a radiação em uma imagem permanente, sobre uma emulsão fotográfica que pode ser observada e analisada (Pérez, 2003).

Duas das grandes vantagens do microscópio eletrônico de transmissão são a presença de lentes que utilizam comprimentos de onda não captadas diretamente pelo olho humano e a capacidade de atingir uma resolução de até $0.2 \mathrm{~nm}$, o que permite, em mineralogia, a observação de partículas individuais de cristais de argila (Pérez, 2003; Gilkes, 1994).

A microssonda eletrônica baseia-se na combinação de técnicas de microscopia eletrônica e análises de raio-x. O equipamento exige, portanto, elementos comuns a ambos, como uma fonte de elétrons, um sistema óptico eletrônico, um suporte de amostras e um sistema de detecção de raio-x, neste caso o espectrômetro tipo dispersão em energia (EDS). Quando uma microrregião da amostra amplificada pelo MET é bombardeada pelo feixe de elétrons no interior do microscópio, ocorre o mesmo fenômeno já descrito no item 1.2.1: elétrons dos átomos que compõe a amostra passam para uma camada externa de maior energia e, ao retornarem ao estado original, emitem radiação X. A energia então emitida é correlacionada ao comprimento de onda dos raios $\mathrm{X}$, que é único para cada elemento químico. Desta forma, a identificação qualitativa da composição química do alvo é feita pela identificação das radiações emitidas e sua relação com os comprimentos de onda específicos. A quantificação dos elementos químicos, por sua vez, requer comparações das intensidades da radiação com espécimes padrão com composição conhecida (Sawhney, 1986; Farina, 1998).

Pequenas quantidades de argila fina liofilizada em solução aquosa de cada amostra representativa foram separadas após o fracionamento e diluídas ainda mais em água destilada, sendo que apenas 1 gota foi distribuída sobre um filme de carbono fixado a uma pequena tela metálica ampliada e analisada. Com a resolução possibilitada pelo MET, a emissão de raios X pelo EDS possibilitou 
determinar e quantificar os elementos químicos de cristais de argila isolados em óxidos, com uma acurácia de 1-3\% para elementos com Z $>9$. O microscópio eletrônico de transmissão utilizado constitui um FEI-Philips CM300, sendo este acoplado a uma microssonda eletrônica com detector de energia dispersiva-EDAX.

Fórmulas estruturais para cada cristal individual foram calculadas a partir da quantificação dos elementos químicos, de acordo com o método exposto por Moore \& Reynolds (1997). A Tabela 1 organiza os passos seguidos para a transformação das porcentagens de peso de cada óxido obtido por MET-EDS (colunas 1 e 2) em número de cátions por unidade de fórmula (coluna 7). O cálculo foi baseado em 22 ânions $\left(\mathrm{O}_{10} \mathrm{OH}_{2}\right)$, por se tratar de argila 2:1. Com o intuito de demonstrar o método, foi utilizado um exemplo hipotético mantendo-se apenas 3 casas decimais arredondadas no cálculo. Ressalta-se, entretanto, que o arredondamento em poucas casas decimais no decorrer de todo o processo torna o cálculo impreciso e, por isto, só foi realizado no resultado final de cada fórmula do presente trabalho.

Tabela 1 - Exemplo de cálculo de fórmula química, segundo Moore \& Reynolds (1997)

\begin{tabular}{lcccccc}
\hline \multicolumn{1}{c}{1} & 2 & 3 & 4 & 5 & 6 & 7 \\
\hline Óxido & $\%$ de Peso & $\begin{array}{c}\text { Peso } \\
\text { Atômico }\end{array}$ & $\begin{array}{c}\text { Peso } \\
\text { Equivalente }\end{array}$ & $\begin{array}{c}\text { Equiv. } \\
\text { Grama/ Carga }\end{array}$ & $\begin{array}{c}\text { Val.Cátion/ } \\
\text { Un.Form. }\end{array}$ & $\begin{array}{c}\mathbf{N}^{0} \text {. Cátions/ } \\
\text { Un. Form. }\end{array}$ \\
\hline $\mathrm{SiO}_{2}$ & 55,9 & 60,085 & 15,021 & 3,721 & 14,422 & 3,606 \\
$\mathrm{Al}_{2} \mathrm{O}_{3}$ & 14,9 & 101,961 & 16,994 & 0,877 & 3,399 & 1,133 \\
$\mathrm{Fe}_{2} \mathrm{O}_{3}$ & 19,7 & 159,692 & 26,615 & 0,740 & 2,868 & 0,956 \\
$\mathrm{MgO}$ & 4,5 & 40,311 & 20,156 & 0,223 & 0,864 & 0,432 \\
$\mathrm{CaO}$ & 0,2 & 56,079 & 28,040 & 0,007 & 0,027 & 0,013 \\
$\mathrm{~K}_{2} \mathrm{O}$ & 4,8 & 94,203 & 47,102 & 0,102 & 0,395 & 0,395 \\
& & & & $5,67 / 22=0,258$ & & \\
\hline
\end{tabular}

O Peso Equivalente (coluna 4) é o peso atômico por unidade de carga de cátion em cada óxido e é calculado dividindo-se o peso atômico do óxido (coluna 3) pela carga do cátion. A Equivalência em Grama (coluna 5) é a proporção atômica por unidade de carga do cátion e é obtida pela divisão do peso molecular do óxido (coluna 2) pelo peso equivalente (coluna 4). A soma da coluna 5 é então dividida por 22, a valência de $\mathrm{O}_{10} \mathrm{OH}_{2}$, para a obtenção de um fator normalizante ou da porcentagem de peso a ser balanceada por cada carga de valência do oxigênio. A coluna 6 fornece a valência do cátion por unidade de fórmula e representa a divisão da equivalência em grama (coluna 5) por este fator normalizante. Por fim, a coluna 7 é o número de cátions por unidade de fórmula, obtido pela divisão da coluna 6 pela valência de cada cátion. Estes valores são então distribuídos no tetraedro, octaedro e entrecamada de cada fórmula. A totalidade do $\mathrm{Si}^{4+}$ e, se necessário, uma parte do $\mathrm{Al}^{3+}$ ou $\mathrm{Fe}^{3+}$ são atribuídas ao tetraedro até que se complete idealmente 4 cátions. $\mathrm{O}$ restante do $\mathrm{Al}^{3+} \mathrm{e}$ do $\mathrm{Fe}^{3+}$ e cátions como $\mathrm{Fe}^{2+}, \mathrm{Mn}^{2+}$ e $\mathrm{Ti}^{4+}$ vão para o octaedro, que idealmente totaliza 2 cátions. $\mathrm{O} \mathrm{K}^{+}$é inteiramente atribuído à entrecamada $\mathrm{e}{\mathrm{o} \mathrm{Ca}^{2+}}^{2} \mathrm{Mg}^{2+}$ podem estar tanto no octaedro quanto na 
entrecamada. Assim, a fórmula estrutural para o exemplo dado é a seguinte: $\left(\mathrm{K}_{0,395} \mathrm{Mg}_{0,13} \mathrm{Ca}_{0,01}\right)^{\mathrm{I}}\left(\mathrm{Al}_{0.74} \mathrm{Fe}_{0.96} \mathrm{Mg}_{0.3}\right)^{\mathrm{VI}}\left(\mathrm{Si}_{3,61} \mathrm{Al}_{0,39}\right)^{\mathrm{IV}}\left(\mathrm{O}_{10} \mathrm{OH}_{2}\right)$.

\section{6 - Análise Manométrica}

Esta análise permitiu a medição da quantidade de carbonatos de cálcio equivalentes em amostras de solo e nódulos, ambos sem nenhum tratamento prévio.

$\mathrm{O}$ princípio deste método baseia-se na medição do gás $\mathrm{CO}_{2}$ produzido pela dissolução de $\mathrm{CaCO}_{3}$ por $\mathrm{HCl}$, de acordo com a equação abaixo:

$$
\mathrm{CaCO}_{3}+2 \mathrm{HCl} \longrightarrow \mathrm{Ca}+2 \mathrm{Cl}^{-}+\mathrm{H}_{2} \mathrm{O}+\mathrm{CO}_{2}(\mathrm{~g})
$$

Na medida em que o gás $\mathrm{CO}_{2}$ é liberado pela reação em um sistema fechado, com volume e temperaturas constantes, a pressão relacionada a este gás aumenta e pode ser determinada por um manômetro. $\mathrm{O}$ aumento da pressão é linearmente relacionado ao teor de $\mathrm{CO}_{2}$ presente nos carbonatos, possibilitando a sua quantificação (Nelson, 1982).

Para manter o sistema fechado, utilizou-se um recipiente próprio para ser selado com uma borracha envolvida por tampa de alumínio. No interior deste recipiente colocou-se a amostra devidamente pesada e um pequeno tudo de ensaio com $\mathrm{HCl}$ concentrado $(12 \mathrm{~N})$. O recipiente foi então selado com o auxílio de uma ferramenta e então curvado para permitir que o ácido saísse do pequeno tubo e entrasse em contato com a amostra. Após 1 hora uma parte da tampa de alumínio foi retirada, e uma agulha ligada a um manômetro digital foi inserida na parte da borracha então exposta na tampa. As medidas foram realizadas em um manômetro de modelo digital, da marca Dwyer, série 477.

O procedimento completo foi repetido 3 vezes para cada amostra, para garantir maior a precisão. A conversão dos dados de pressão em mmHg em gramas de $\mathrm{CaCO}_{3}$ baseiam-se no cálculo de uma regressão a partir da medição de amostras puras de $\mathrm{CaCO}_{3}$.

\section{7 - Referências Bibliográficas}

Amonette, J.E. (2002) Methods for Determination of Mineralogy and Environmental Availability. Pp. 153197 in: Soil Mineralogy with Environmental Applications (J.B.Dixon \& D.Z. Schulze, eds.). SSSA Book Series n.7, Soil Science Society of America Inc, $1^{\text {st }}$ edition, Madison.

Anderson, J.U., (1963). An improved pretreatement for mineralogical analysis of samples containing organic matter. Clays and Clay Minerals, 10, 380-388.

Biscaye, P. (1965) Mineralogy and sedimentation of recent deep-seaclay in the Atlantic Ocean and adjacent seas and oceans. Geological Society of America Bulletin, 76, 803-832.

Cullity, B.D. (1978) Elements of X-ray Diffraction, Addison-Wesley Publishing Company, $2^{\text {nd }}$ edition, 555 p.

Douglas, L.A. \& Fiessinger, F. (1971) Degradation of clay minerals by $\mathrm{H}_{2} \mathrm{O}_{2}$ treatments to oxidize organic matter. Clay and Clay Minerals, 19, 67-68.

Farina, M (1998) Fundamentos de microscopia analítica para biólogos. Pp. 161-177 in: Técnicas Básicas de Microscopia Eletrônica aplicada às Ciências Biológicas (W. Souza, ed.). UENF-Depto de Editoração Eletrônica, Rio de Janeiro. 
Gilkes, R.J. (1994) Transmission Electron Microscope Analysis of Soil Materials. Pp. 177-204 in: Quantitative Methods in Soil Mineralogy (J.E. Amonette \& L.W. Zelazny, eds.). Soil Science Society of America Inc, SSSA Miscellaneous Publication.

Gomes, C.F. (1988) Argilas, o que são e para que servem. Fundação Calouste Gulbenkian. Lisboa. P.173194.

Jackson, M.L. (1979) Soil Chemical Analysis-Advanced Course. $2^{\text {nd }}$ ed.M.L.Jackson, Madison, WI.

Joint Committee on Power Diffraction Standards - JCPDS (1973) Selected Powder Diffraction Data for Minerals -Data Book. Publication DBM-1-23. JCPDS.

Joint Committee on Power Diffraction Standards - JCPDS (1974) Selected Powder Diffraction Data for Minerals -Search Manual, Fink Method. Publication M-1-23F. JCPDS.

Kunze, G.W. \& Dixon, J.B. (1986) Pretreatment for Mineralogical Analysis. Pp. 91-100 in: Methods of Soil Analysis - Physical and Mineralogical Methods (A. Klute, ed.). Part 1, Agronomy, n.9, ASA-SSSA Publisher, $2^{\text {nd }}$ edition, Madison.

Malcolm, R.L (1968) Freeze-Drying of Organic Matter, Clays, and Other Earth Materials. U.S. Geological Survey Professional Paper, 600-C, C211-C216.

Moore, D. \& Reynolds, R.C. (1997) X-ray Diffraction and the Identification and Analysis of Clay Minerals, Oxford University Press, 2nd edition, $378 \mathrm{p}$.

Nelson, R.E. (1982) Carbonate and Gypsum. Pp. 181-198 in: Methods of Soil Analysis - Chemical and Microbiological Properties (A.L. Page, ed). Part 2, $2^{\text {nd }}$ edition, Soil Science Society of America Inc.

Pérez, G.R. (2003) Microscopía Electrónica de Transmisión (MET). Área Biomédica: teoría y práctica. Editora Guadalupe Ltda. Colombia, 285 p.

Reid, D.A, Graham, R.C.; Douglas, L.A.; Amrhein, C. (1996) Smectite Mineralogy and Charge Characteristics along an Arid Geomorphic Transect. Soil Science Society of America Journal, 60, 16021611.

Reid-Soukup, D.A. \& Ulery, A. (2002) Smectites. Pp: 467-499 in: Soil Mineralogy with Environmental Application (J.B. Dixon \& D.G. Schulze, eds.). SSSA Book Series n. 7. Soil Science Society of America Inc.

Sawhney, B.L. (1986) Electron Microprobe Analysis. Pp.271-290 in: Methods of Soil Analysis - Physical and Mineralogical Methods (A. Klute, ed.), Part 1, Agronomy, n.9, ASA-SSSA Publisher, $2^{\text {nd }}$ edition, Madison.

Theisen, A.A. \& Harward, M.E. (1962) A paste method for preparation of slides for clay mineral identification by x-ray diffraction. Soil Science Society of America Proceedings, 26, 90-91.

Whittig, L.D. \& Allardice, W.R. (1986) X-ray Difraction Techniques. Pp. 331-362 in: Methods of Soil Analysis - Physical and Mineralogical Methods (A. Klute, ed.), Part 1, Agronomy, n.9, ASA-SSSA Publisher, $2^{\text {nd }}$ edition, Madison. 


\section{ANEXO 2 \\ Organização da cobertura pedológica nas Topos- sequências 2 e 3}




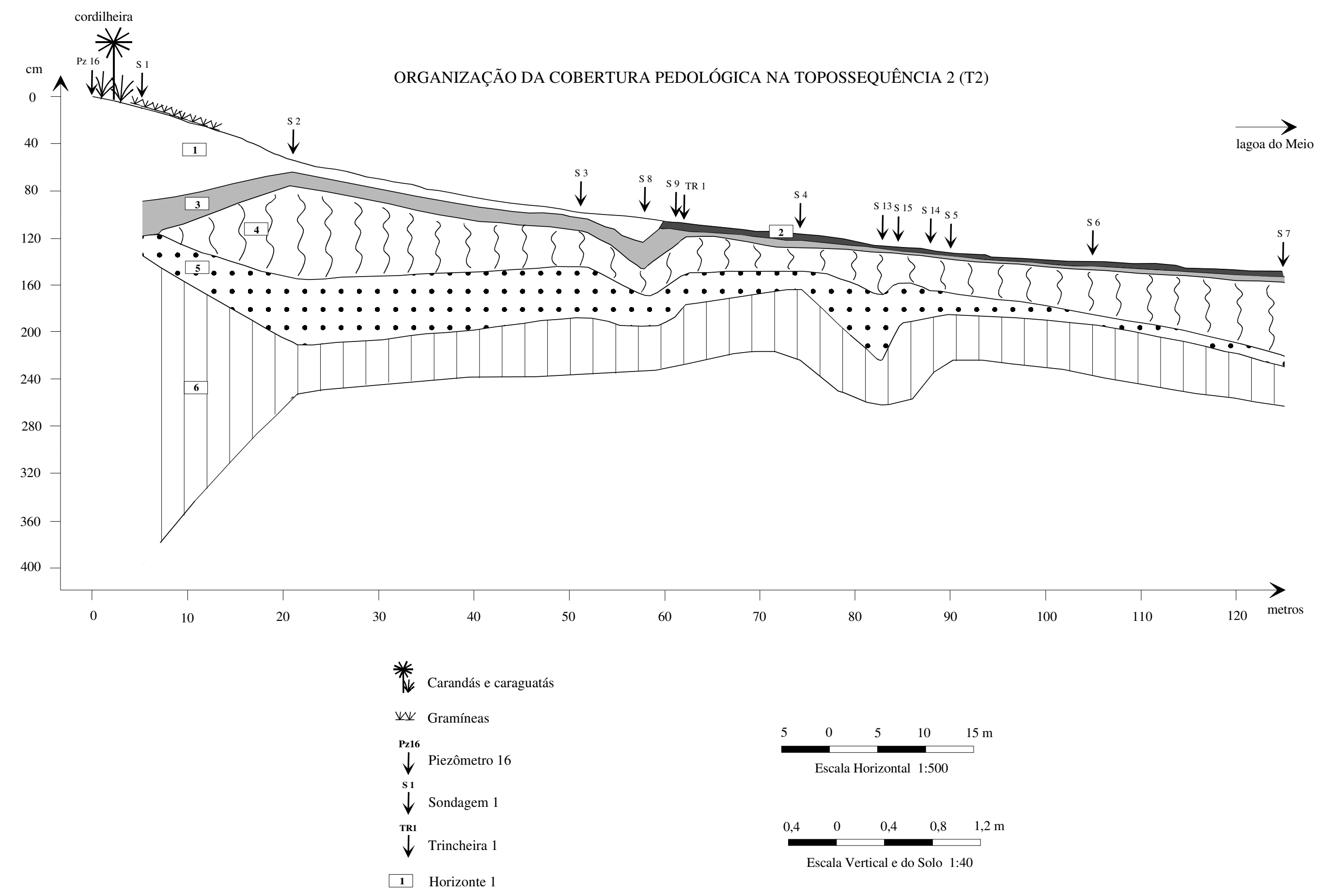


ORGANIZAÇÃO DA COBERTURA PEDOLÓGICA NA TOPOSSEQUÊNCIA 3 (T3)

cordilheira

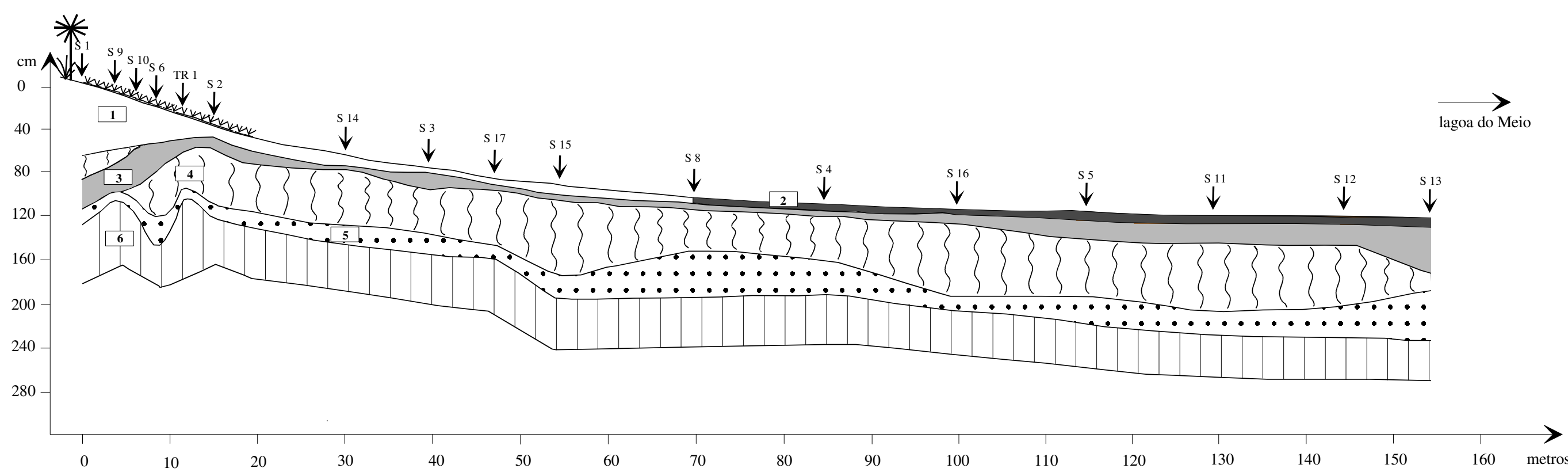

悉 Carandás e caraguatás

wㅡ Gramíneas

Pz16

$\downarrow$ Piezômetro 16

$\downarrow$ si

$\downarrow$ Trincheira 1

1 Horizonte 1 $\underbrace{0,4 \quad 0 \quad 0,4 \quad 0,8 \quad 1,2 \mathrm{~m}}_{\text {Escala Vertical e do Solo } 1: 54}$

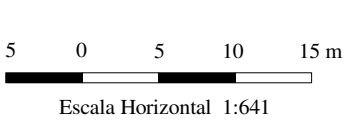

Escal Horizontal 1:641 


\section{ANEXO 3}

Curvas de DRX submetidas a diferentes tratamentos 
Legenda dos minerais identificados nas figuras a seguir:

Es - esmectita

$\mathrm{Mi}$ - mica

$\mathrm{K}$ - caulinita

Q - quartzo

$\mathrm{M}$ - microclina

C - calcita

A - albita 


\section{P1 - horizonte 1}

Argila fina

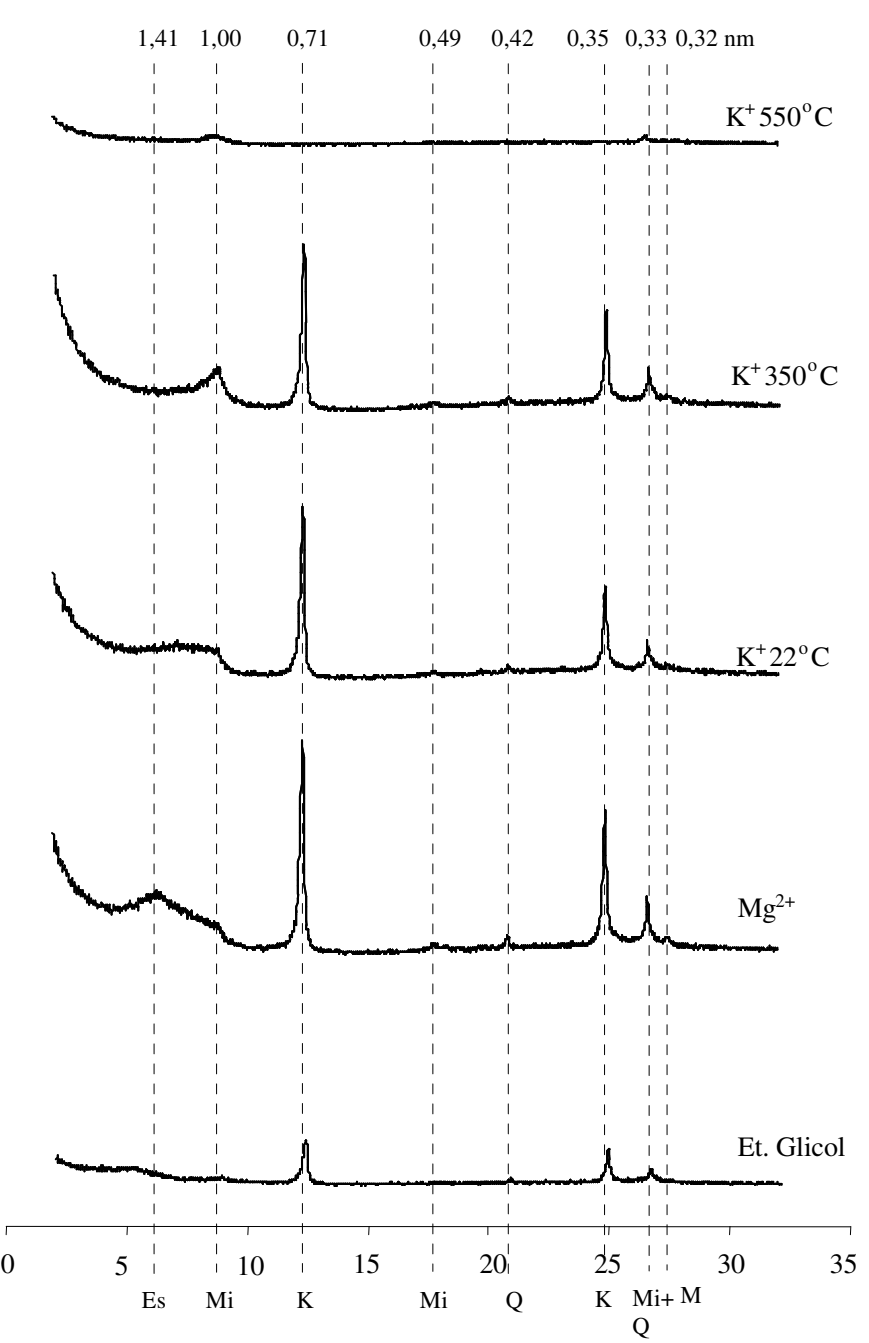

Argila Grossa

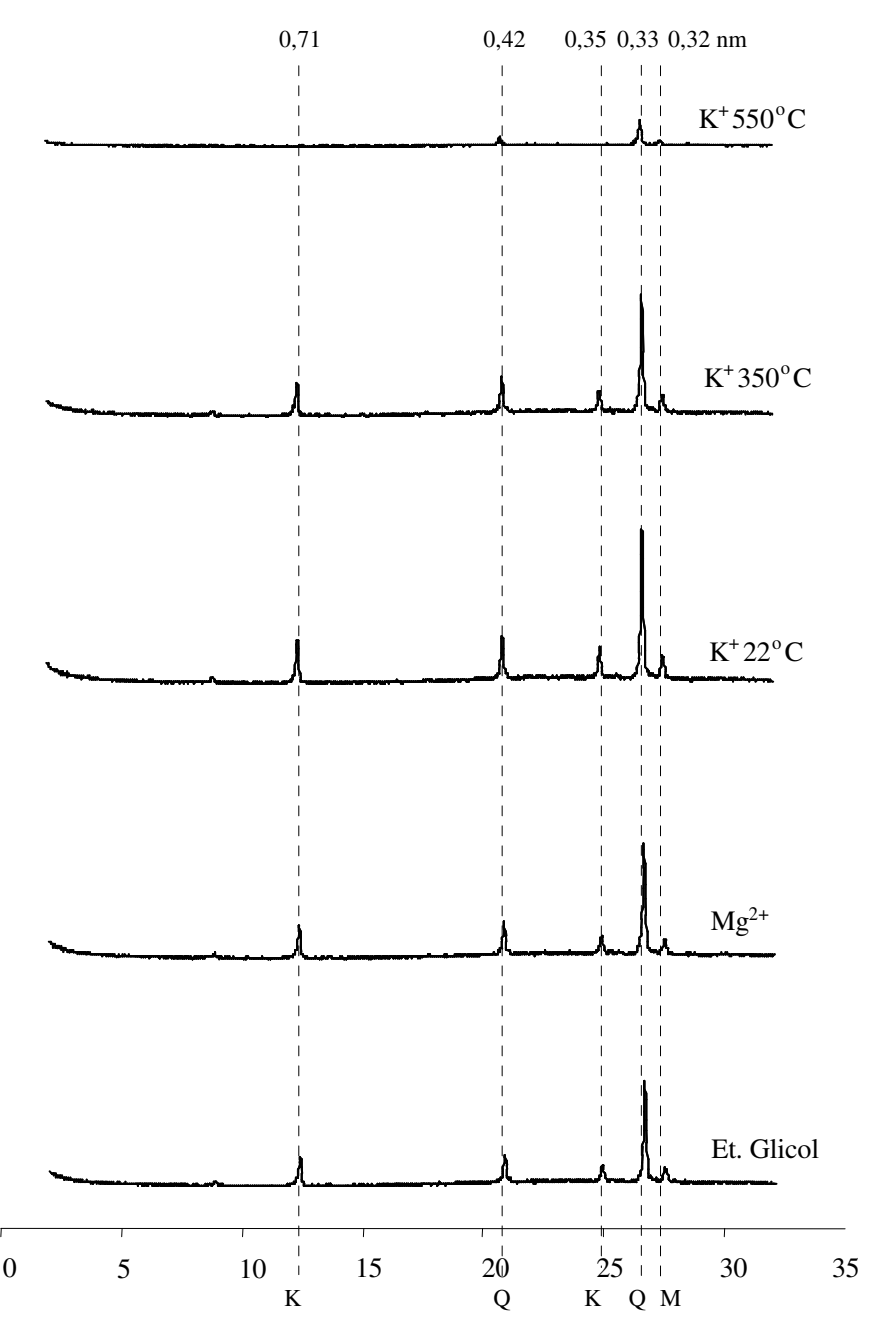

Silte Fino

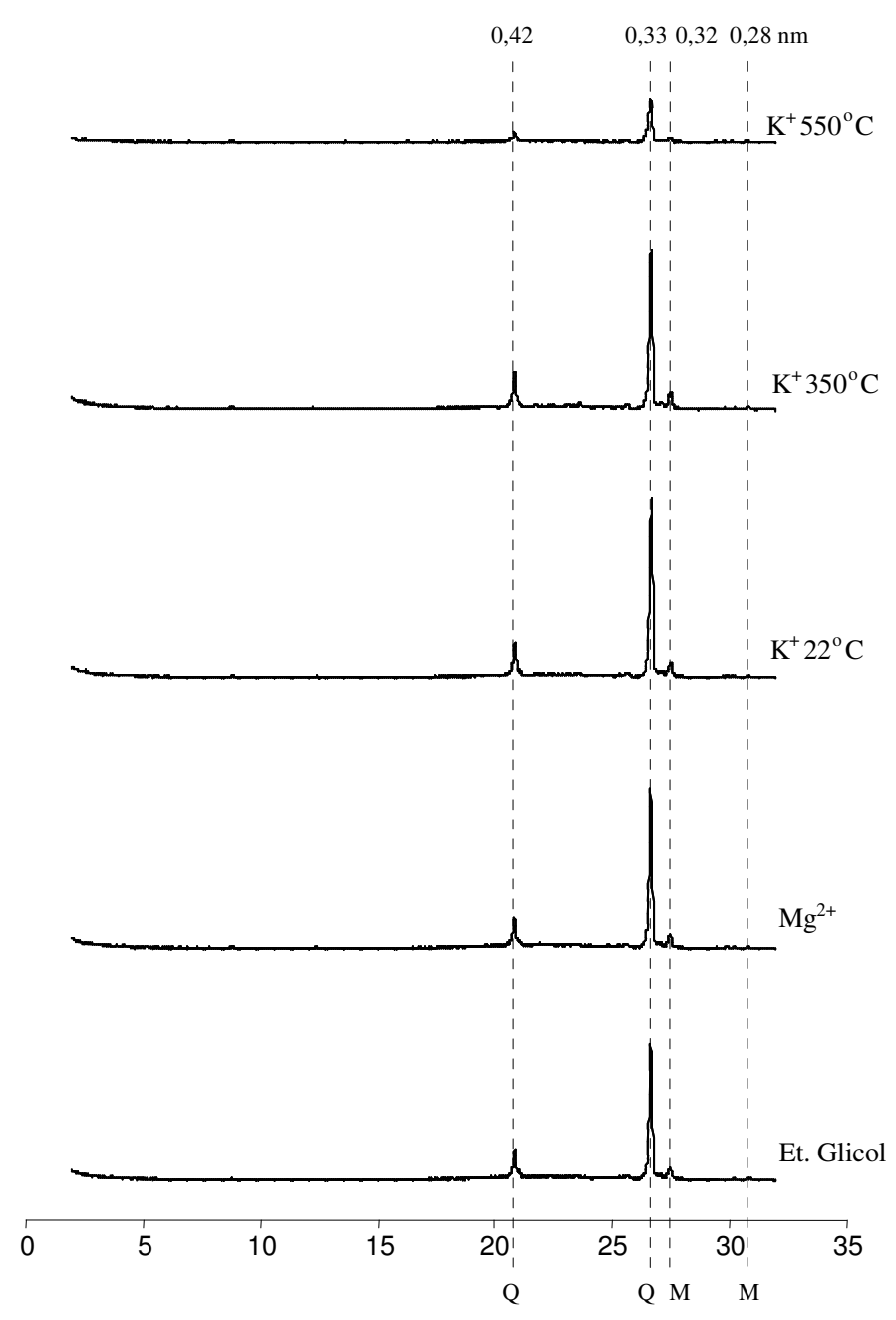

${ }^{\circ} 2$ theta 


\section{P1 - horizonte 3}
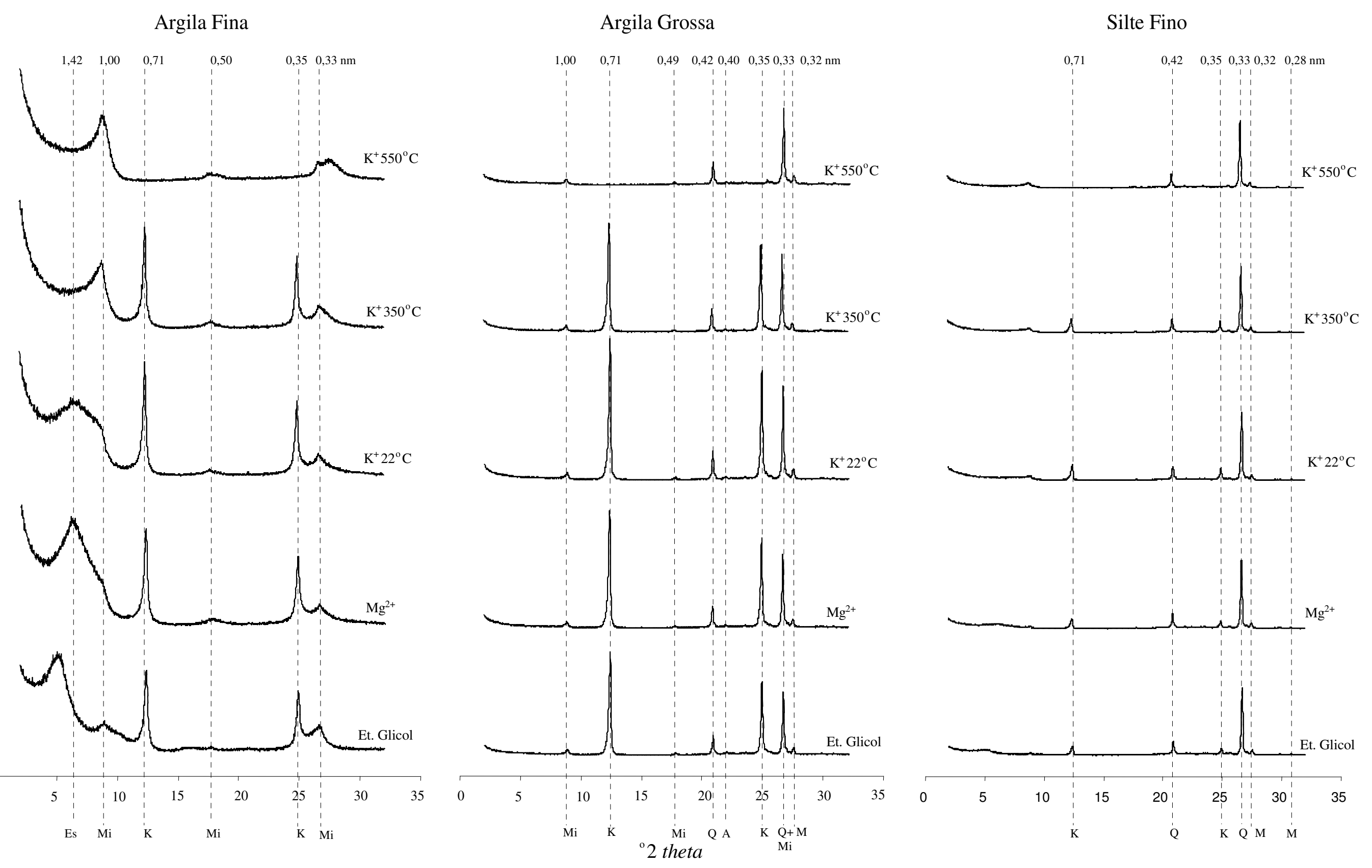
P1 - horizonte 5
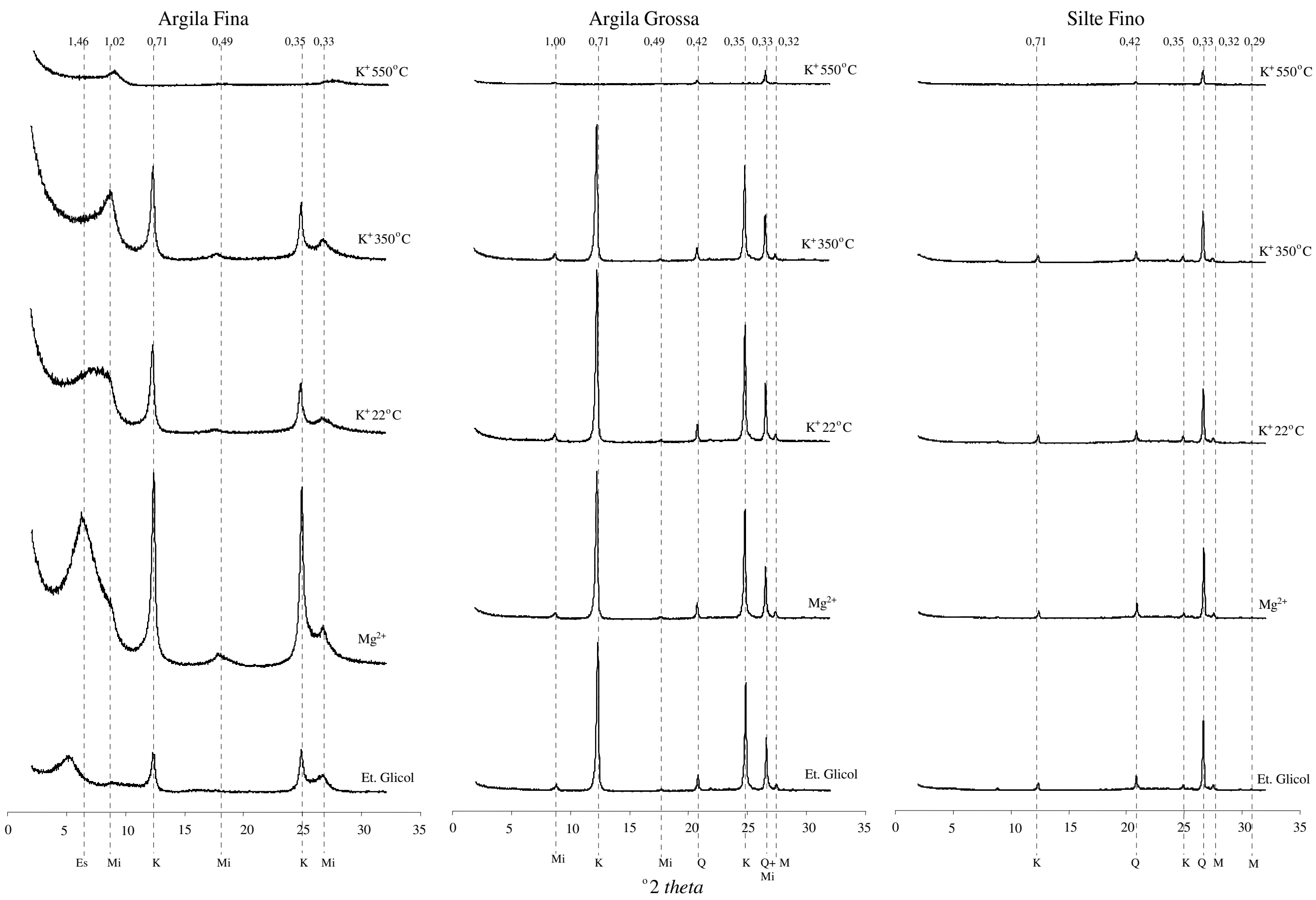


\section{P1 - horizonte 6}

Argila Fina
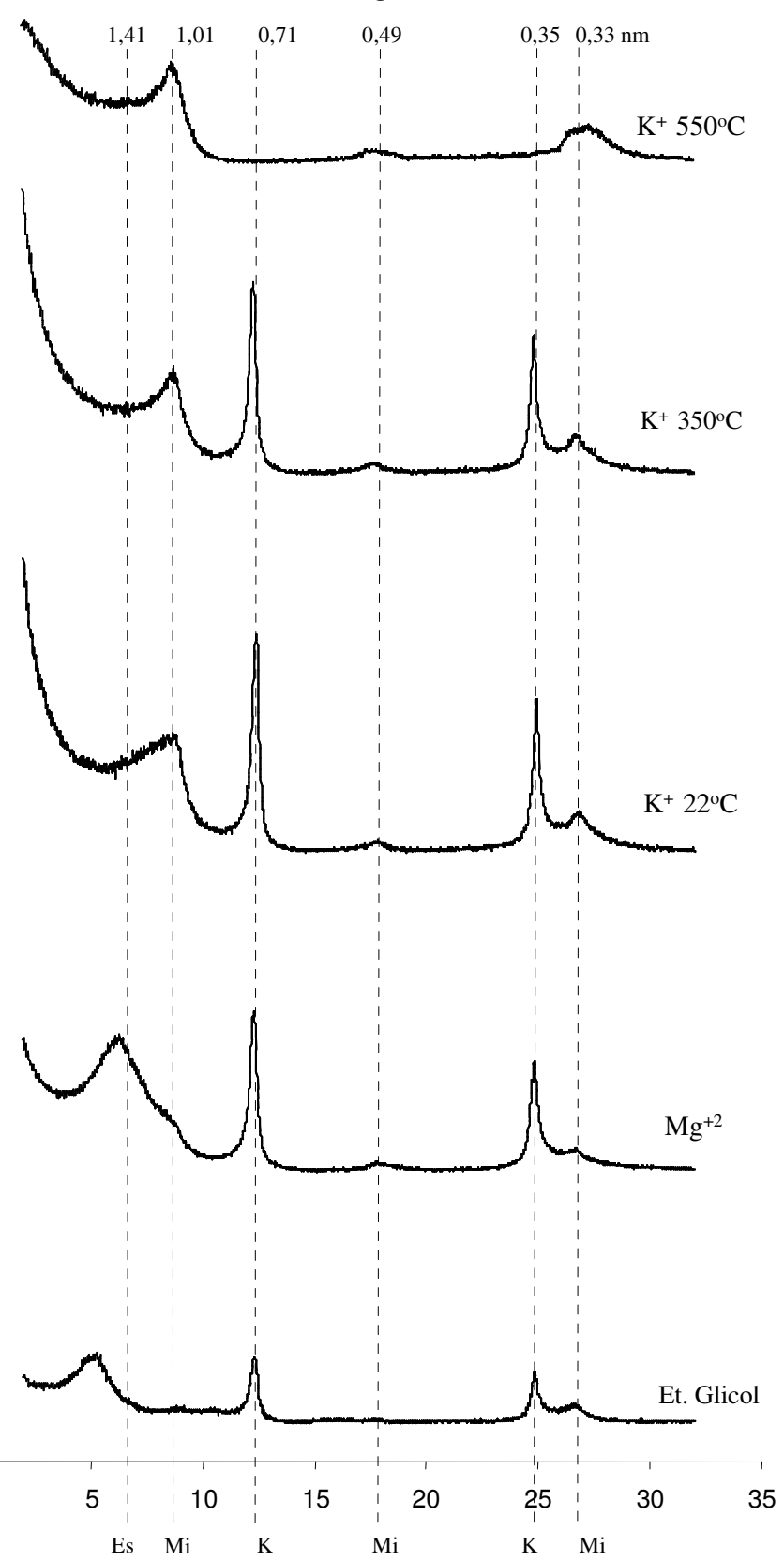

Argila Grossa

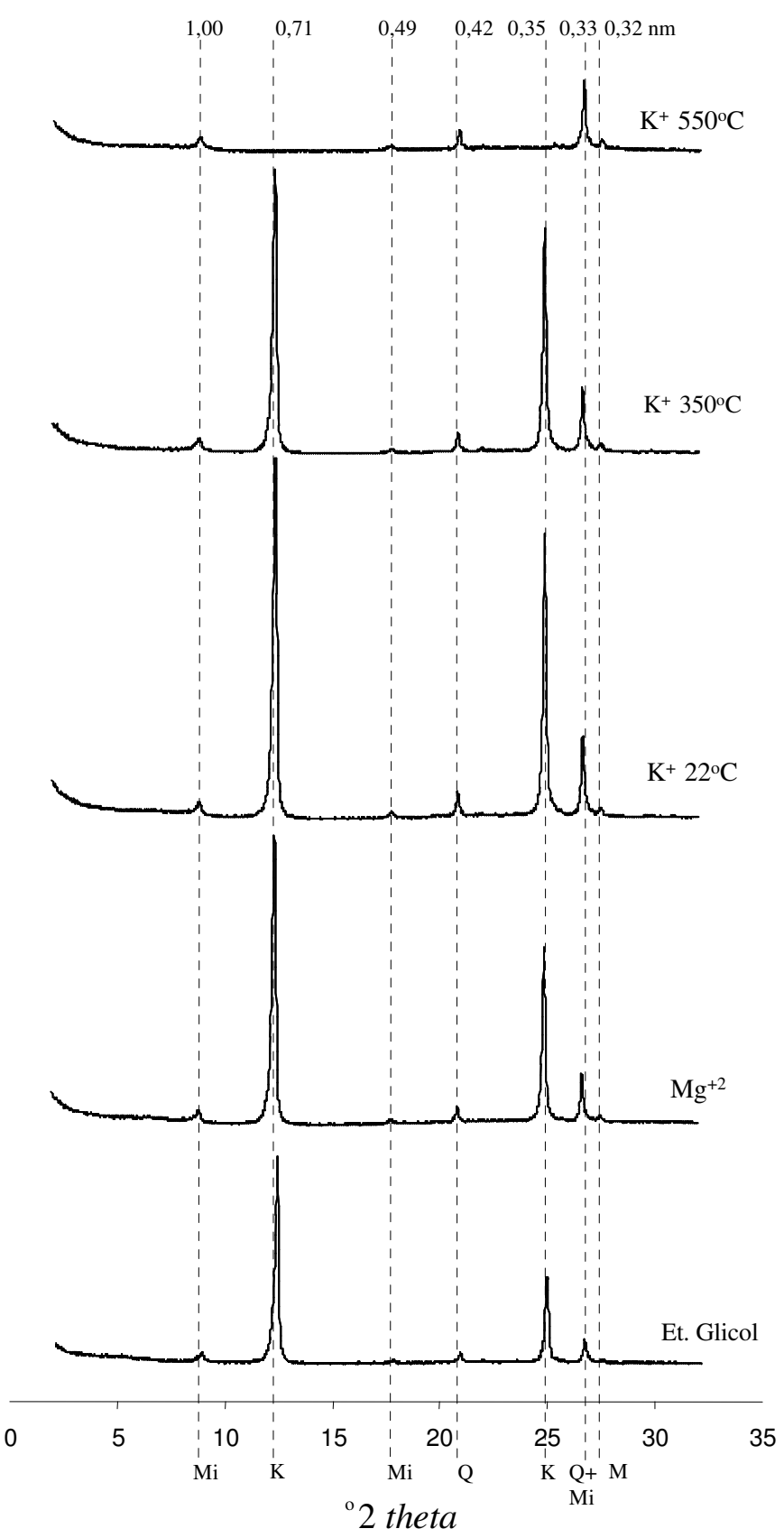

Silte Fino
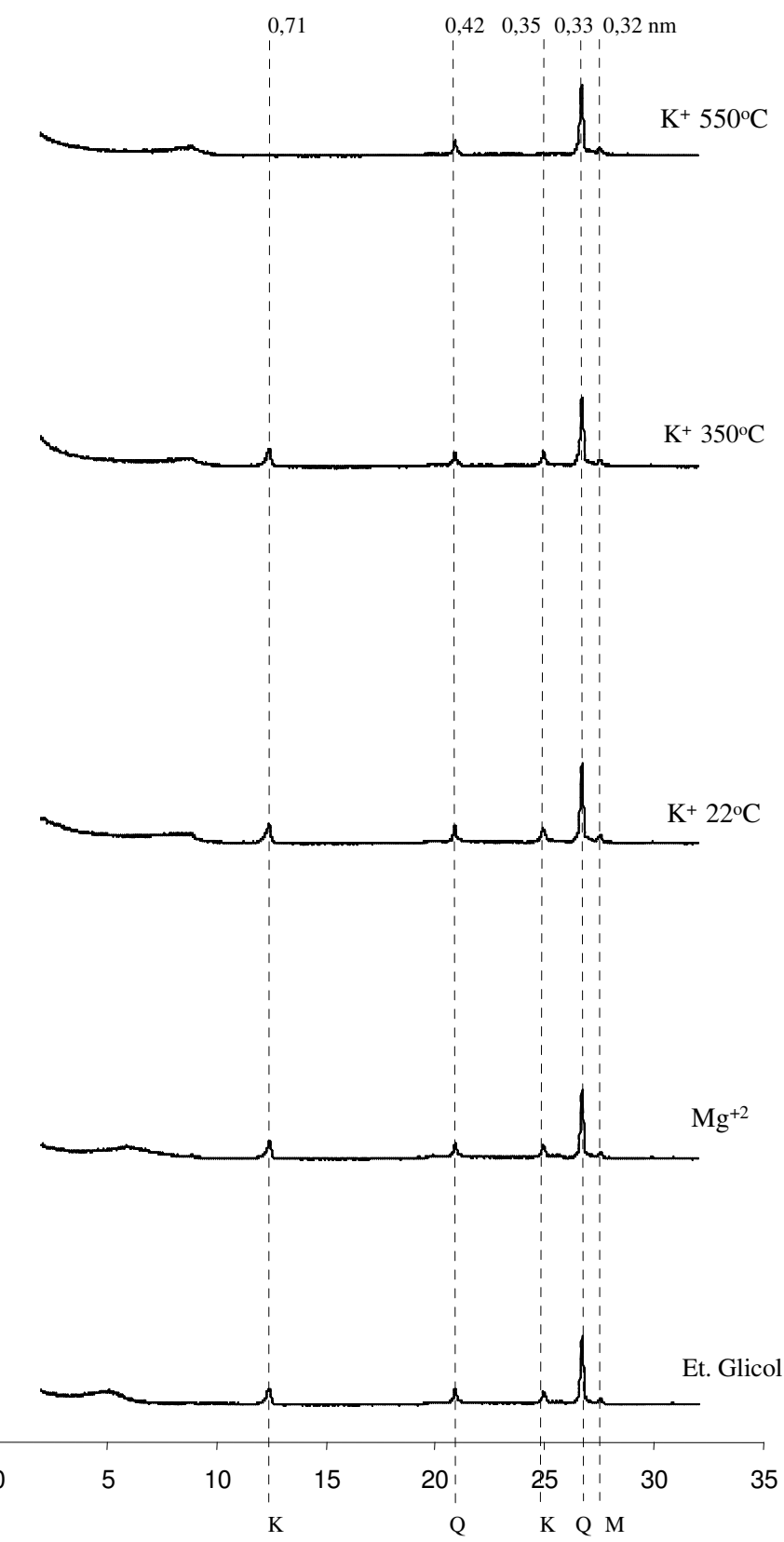


\section{P2 - horizonte 1}

\section{Argila Fina}

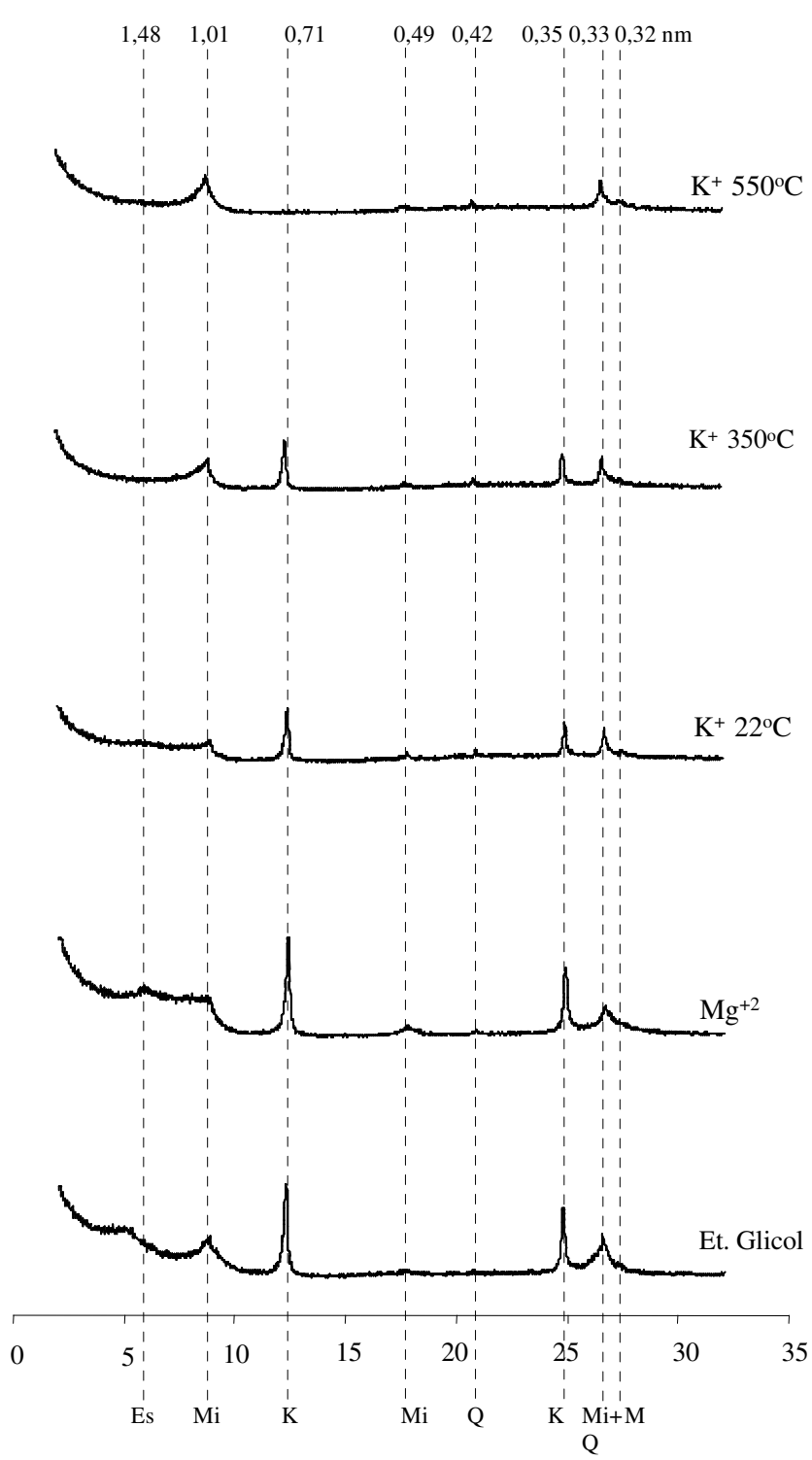

Argila Grossa

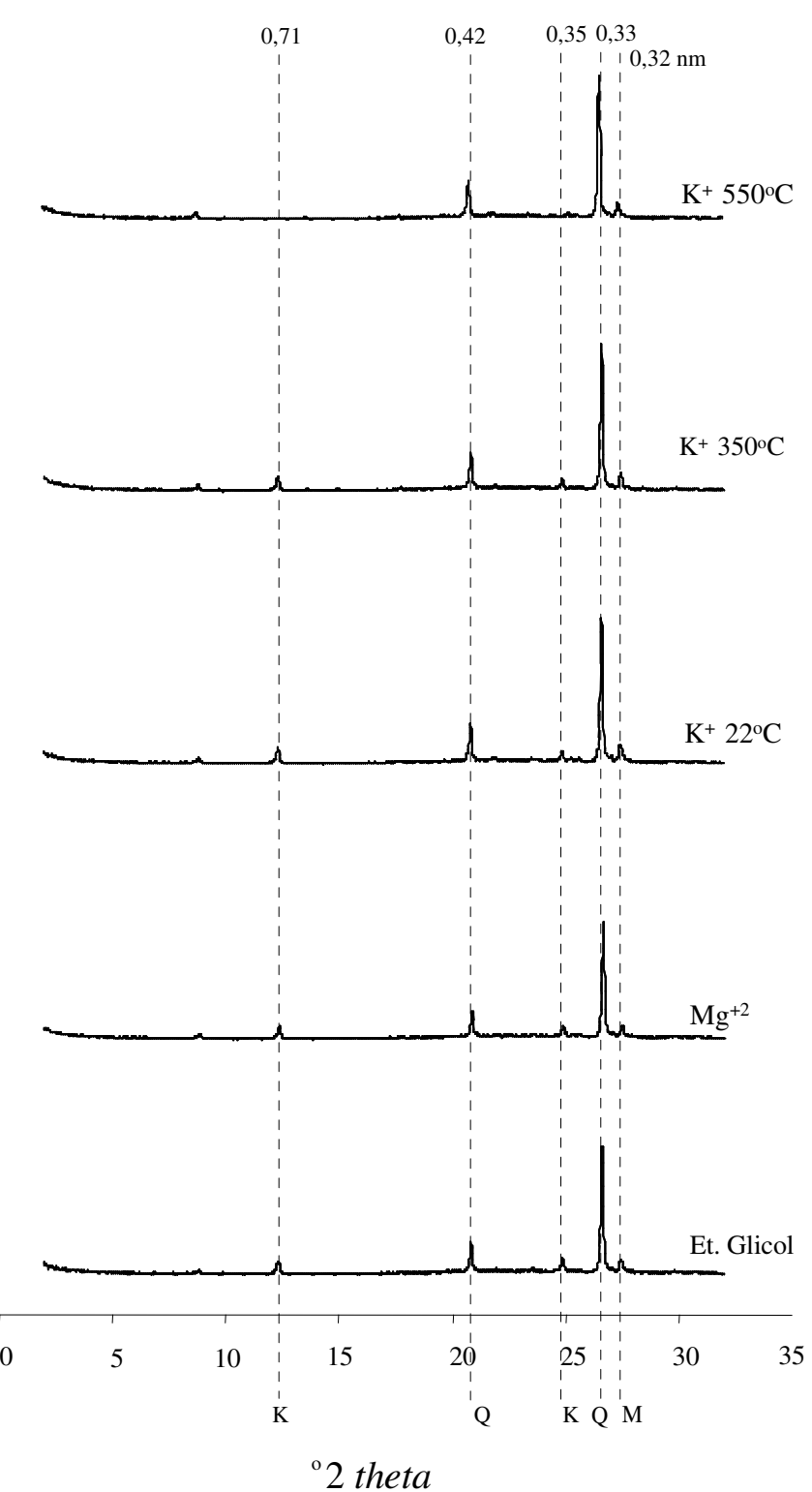

Silte Fino

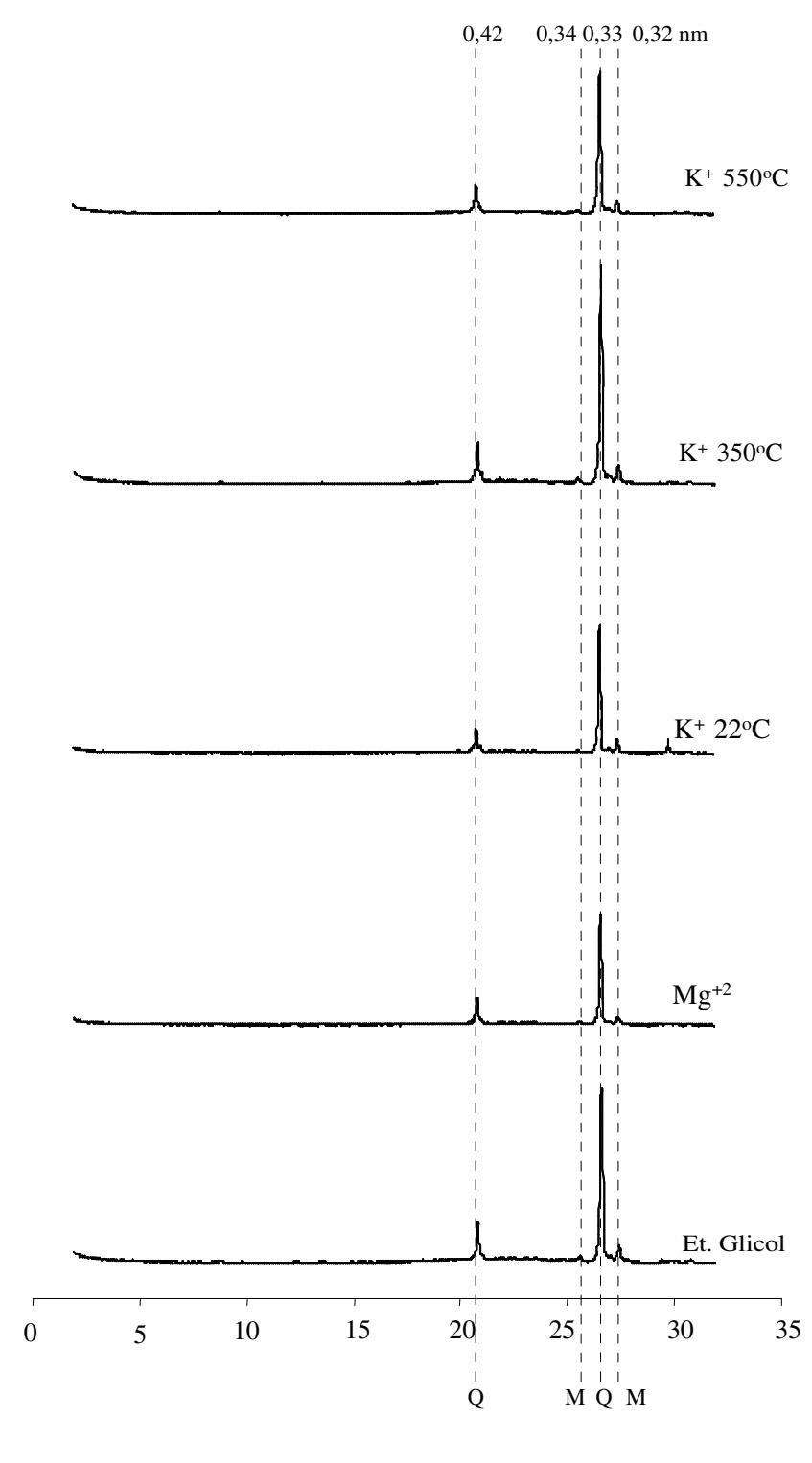




\section{P2 - horizonte 4}

Argila Fina

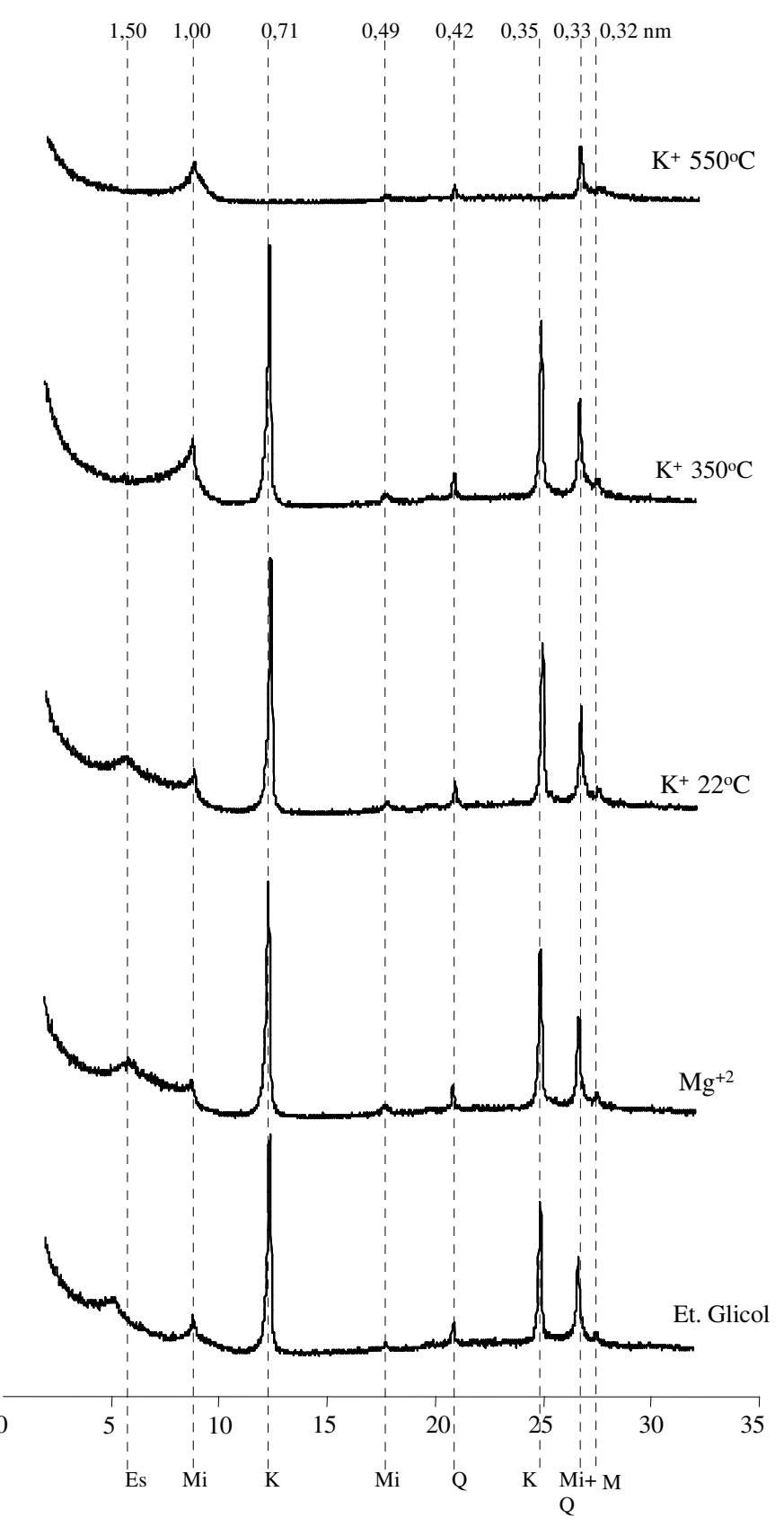

Argila Grossa

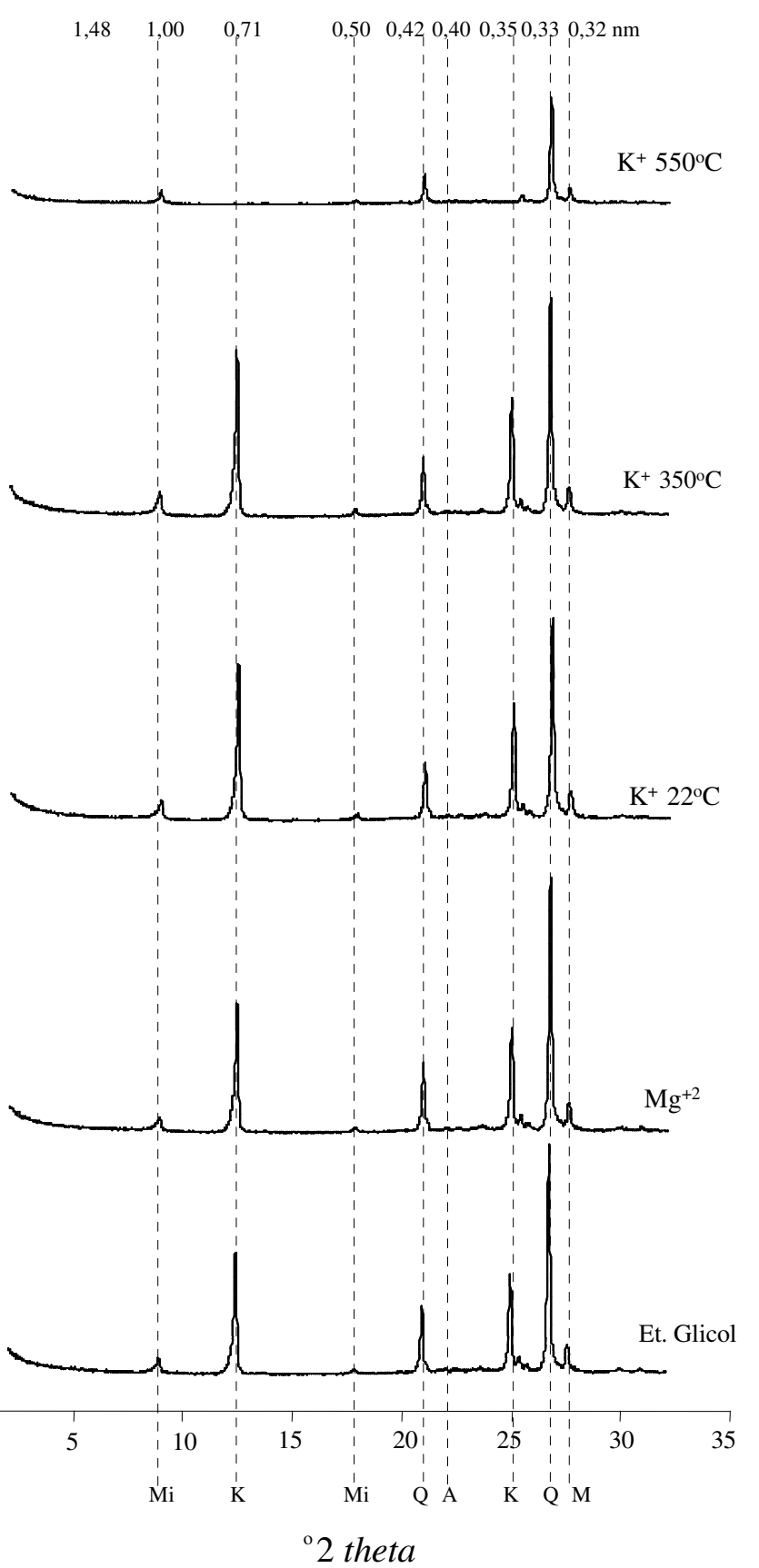

Silte Fino

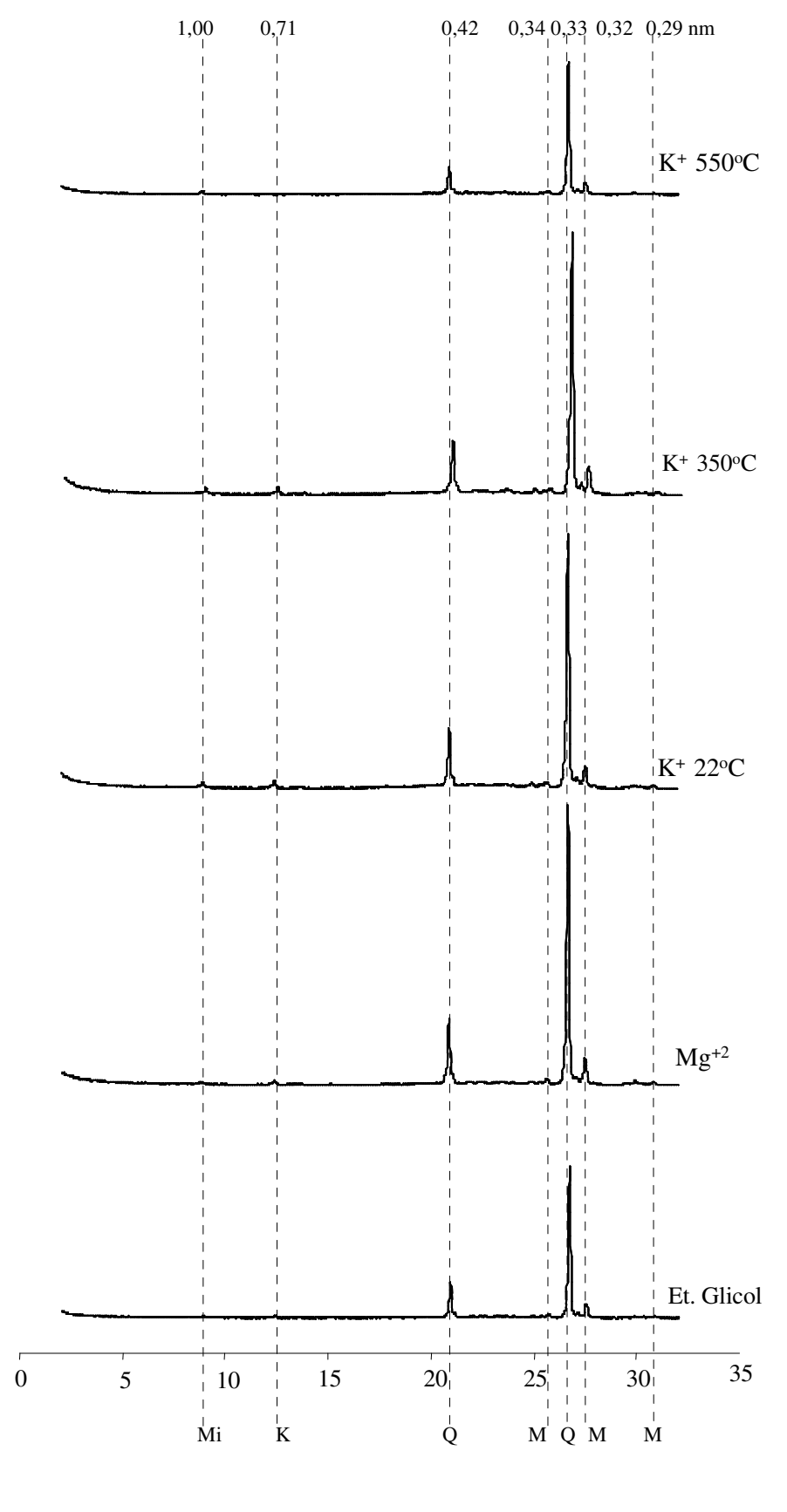




\section{P2 - horizonte 5}

Argila Fina

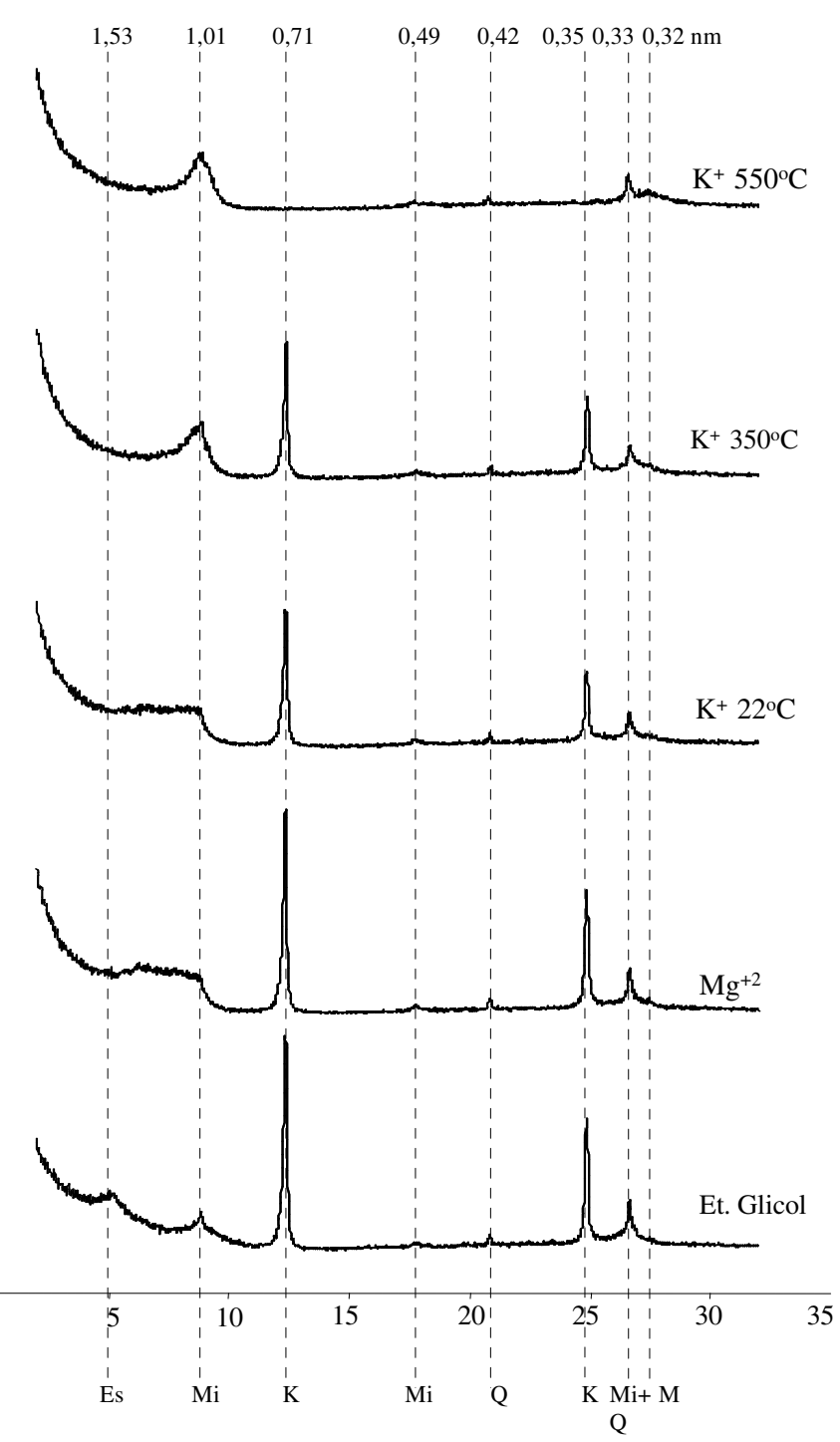

Argila Grossa

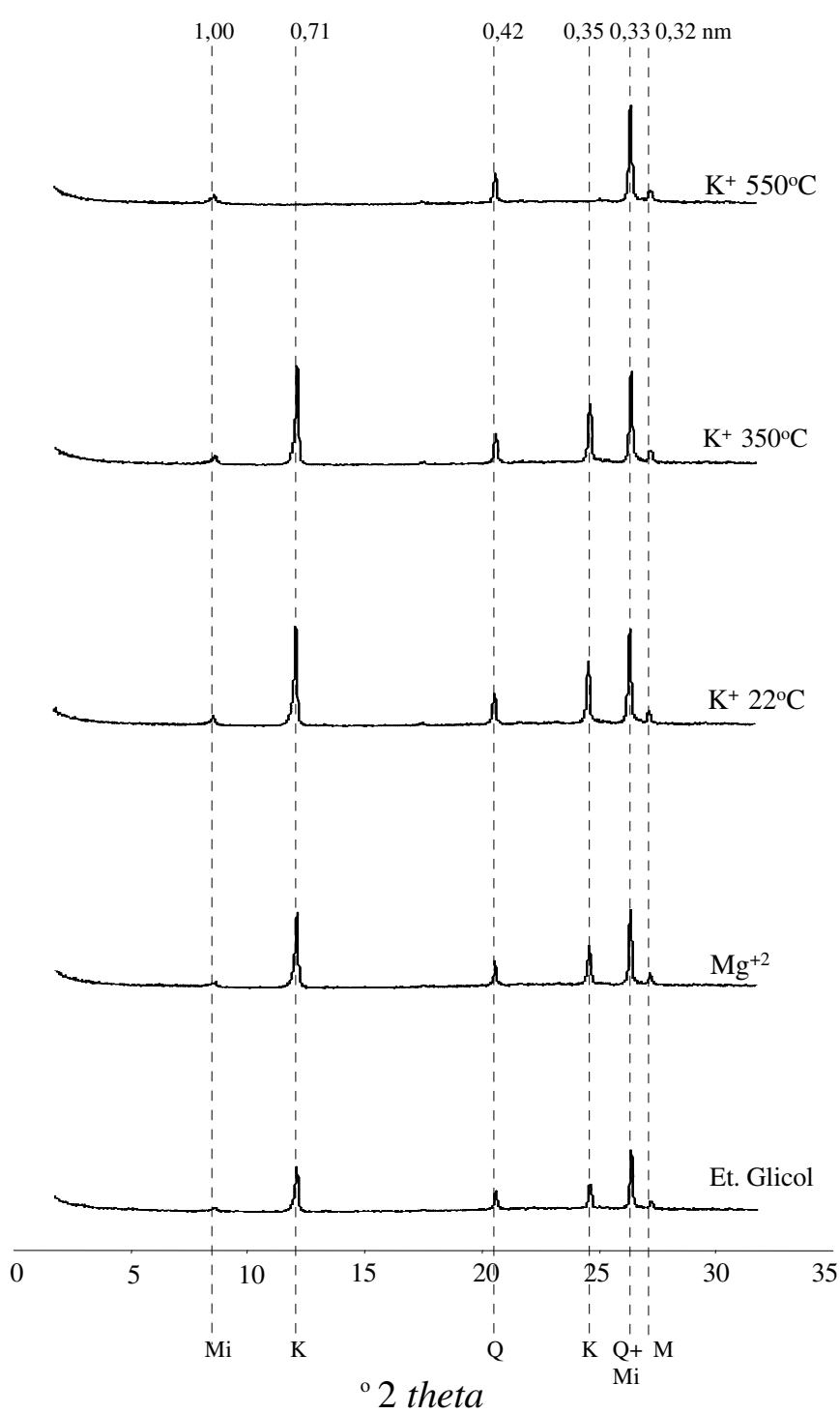

Silte Fino

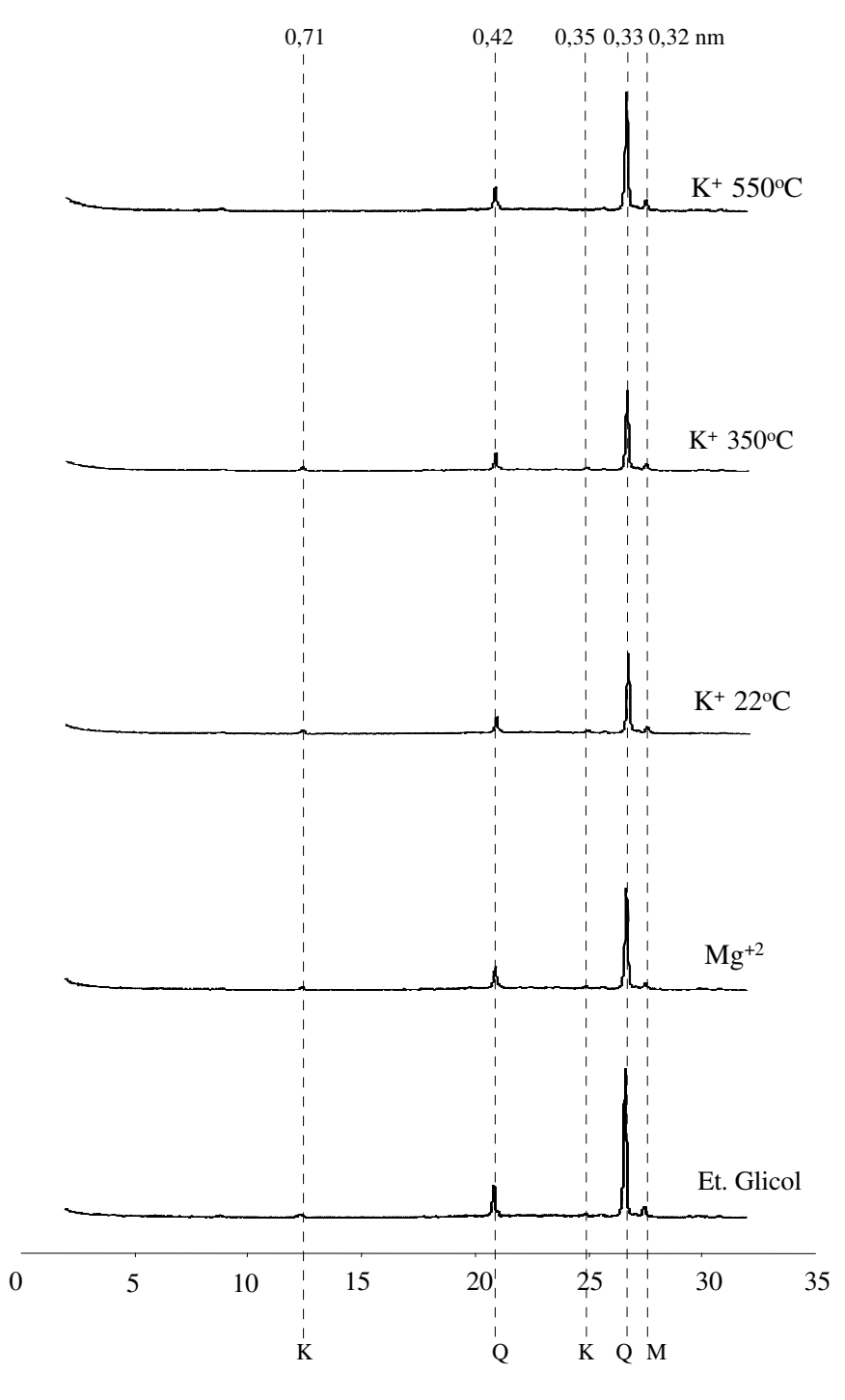




\section{P2 - horizonte 6}
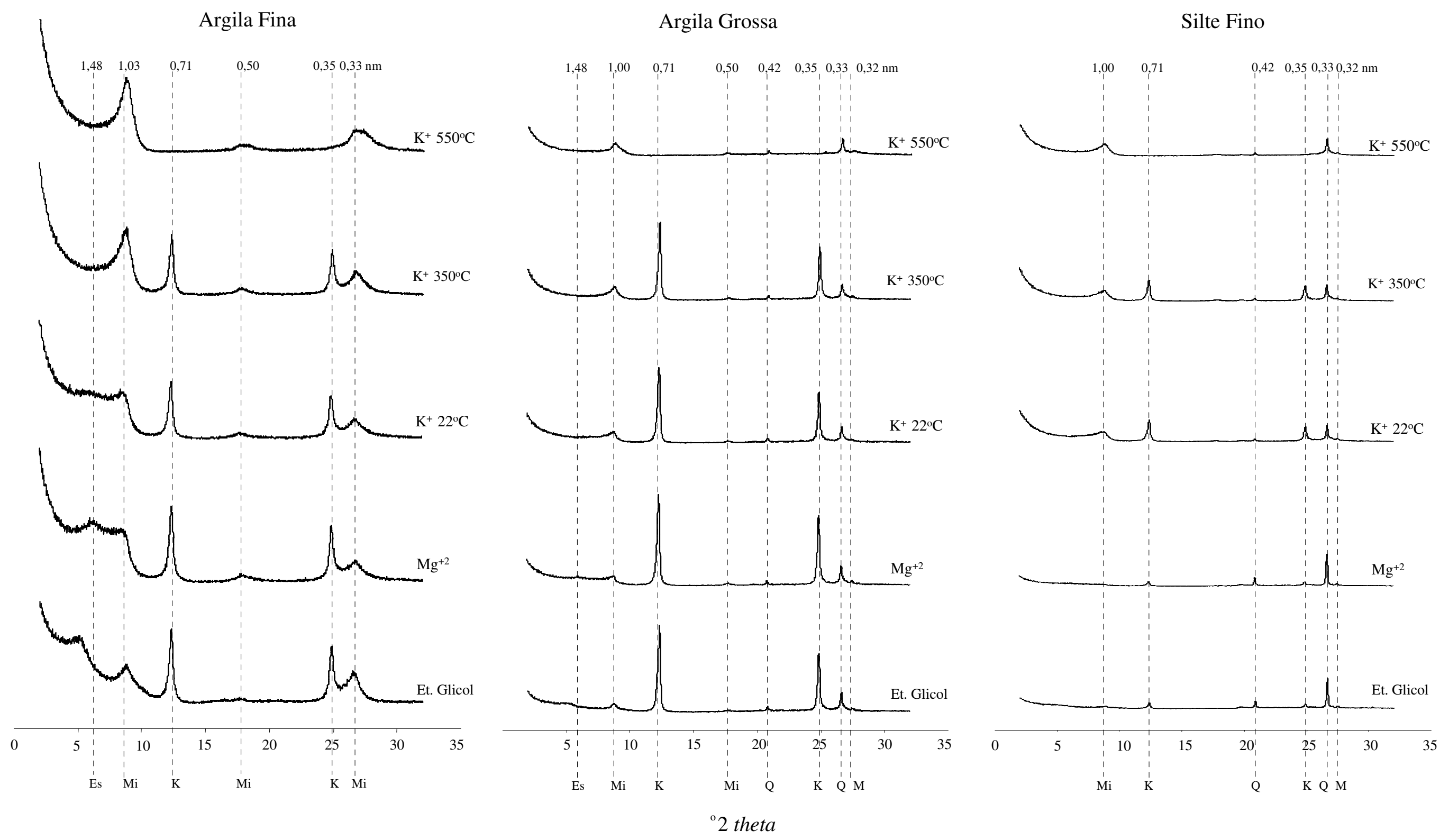


\section{P3 - horizonte 1}

Argila Fina

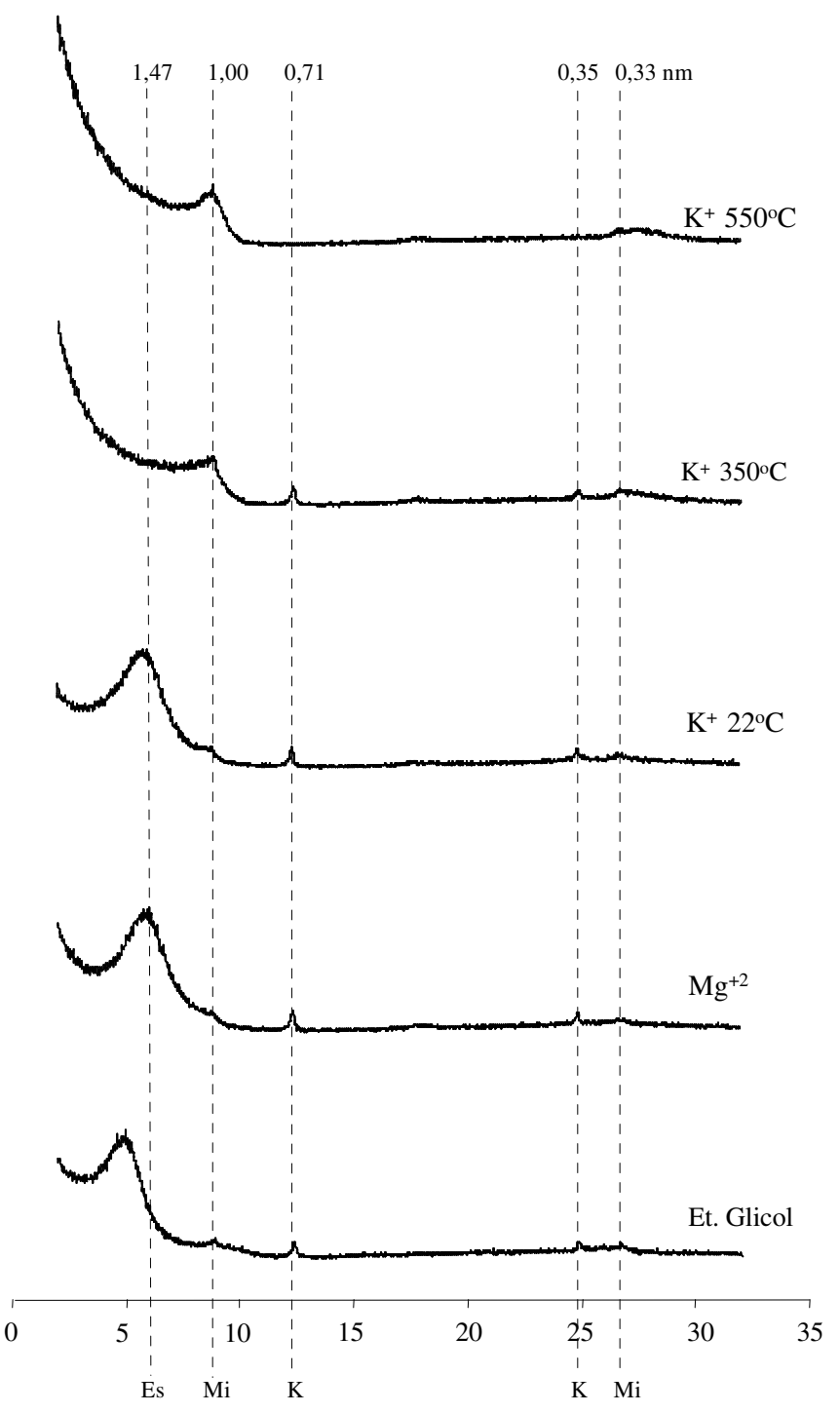

Argila Grossa

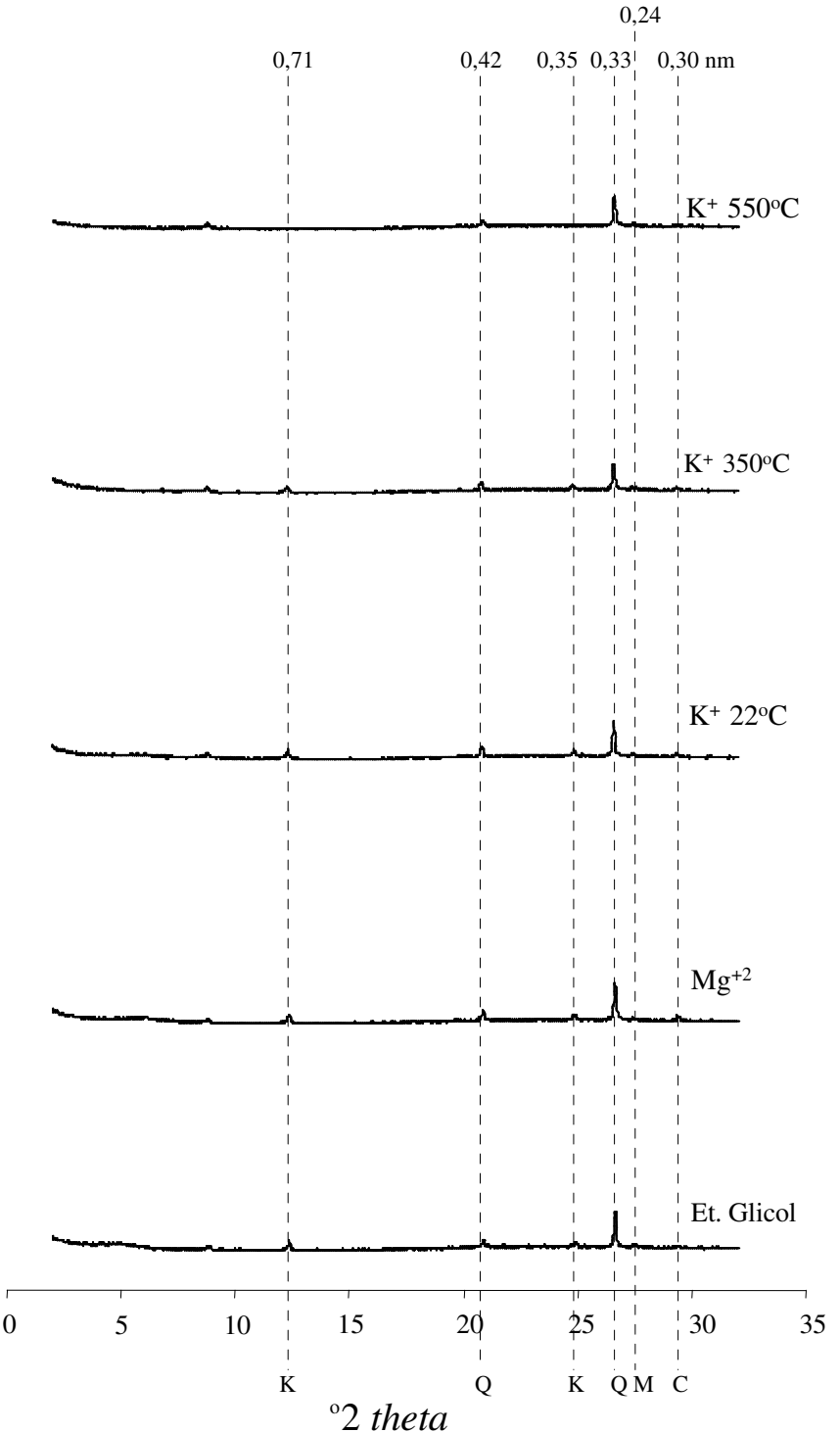

Silte Fino

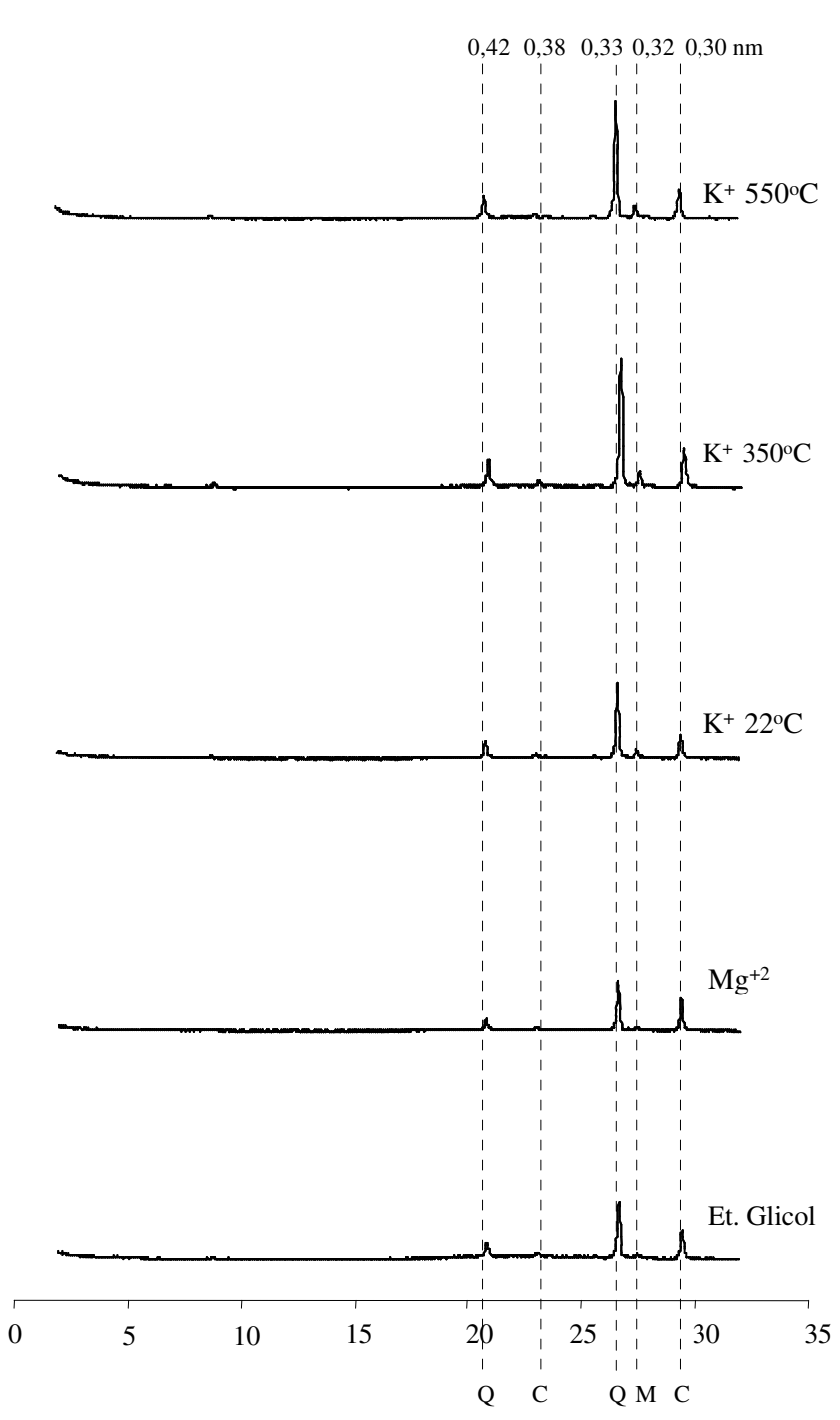




\section{P3 - hor. $4 \quad$ Argila Fina}

$\begin{array}{lllllll}1,48 & 1,00 & 0,71 & 0,50 & 0,42 & 0,35 & 0,330,32 \mathrm{~nm}\end{array}$
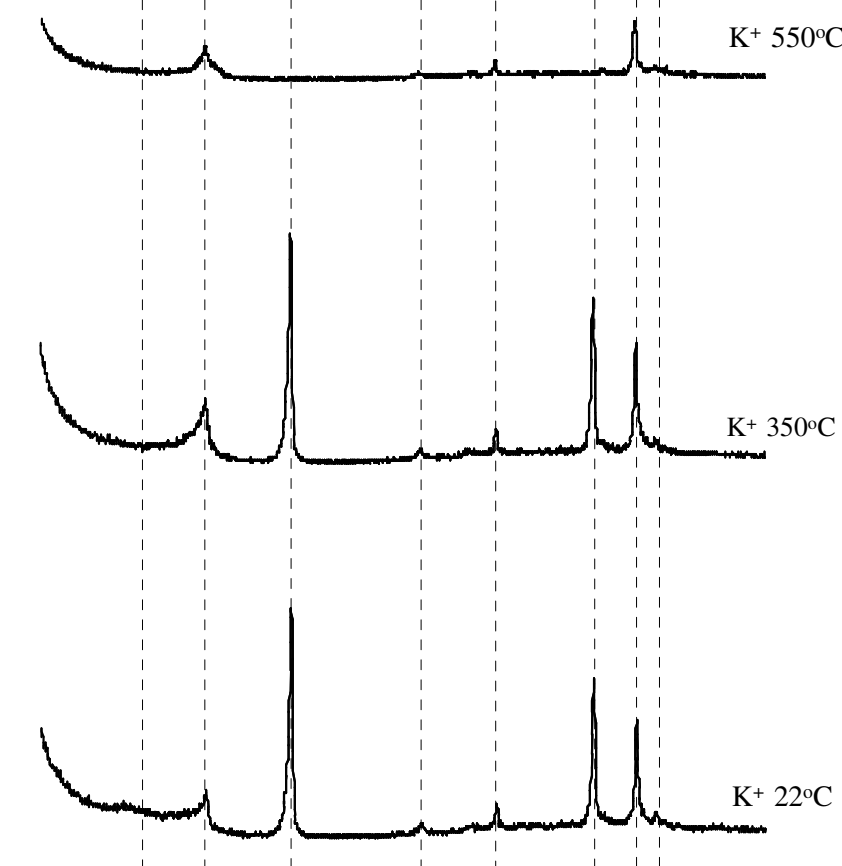

$\mathrm{Mg}^{+2}$

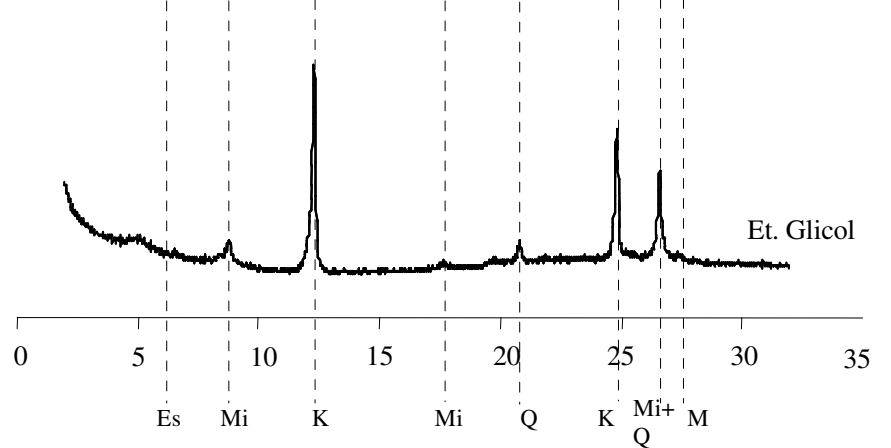

Argila Grossa

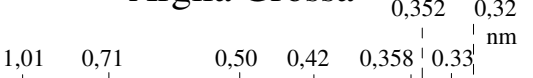

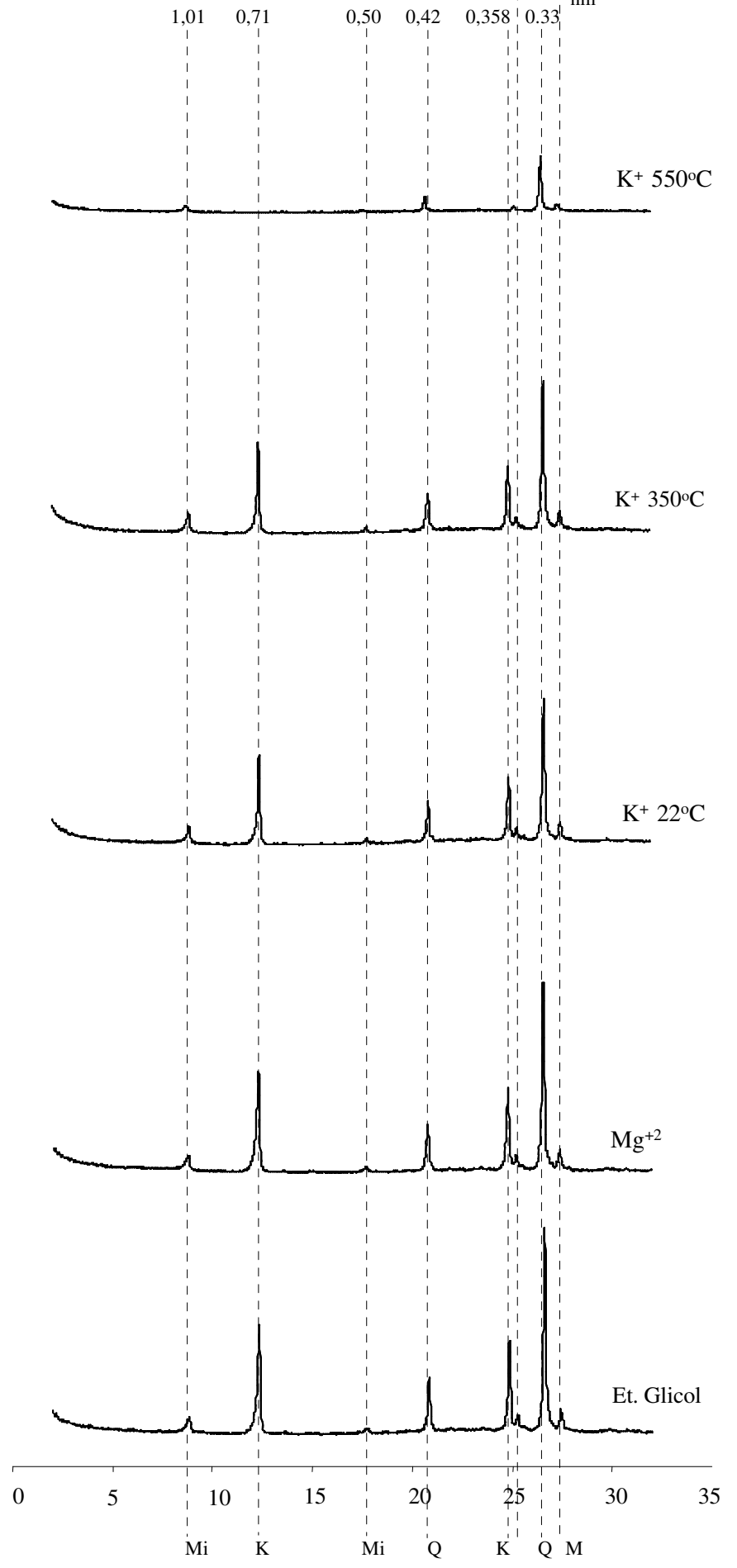

Silte Fino

$\begin{array}{lll}0,40 & 0,35 & 0,33\end{array}$

$\begin{array}{l:llll}0,42 & 0,37 & 0,34 & 0,32 \mathrm{~nm}\end{array}$

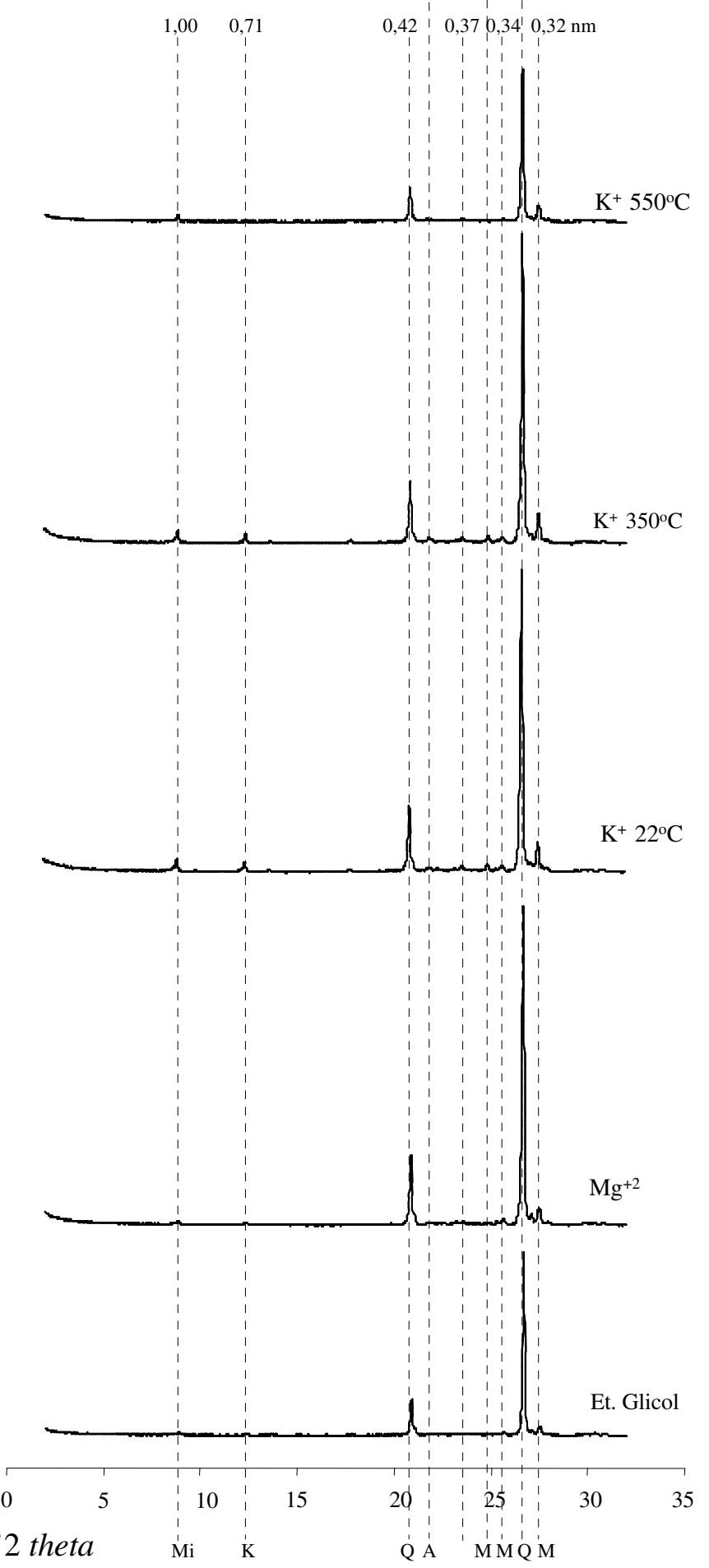




\section{P3 - hor. 5 Argila Fina}

$\begin{array}{llllll}1,02 & 0,71 & 0,49 & 0,35 & 0,33 & \mathrm{~nm}\end{array}$
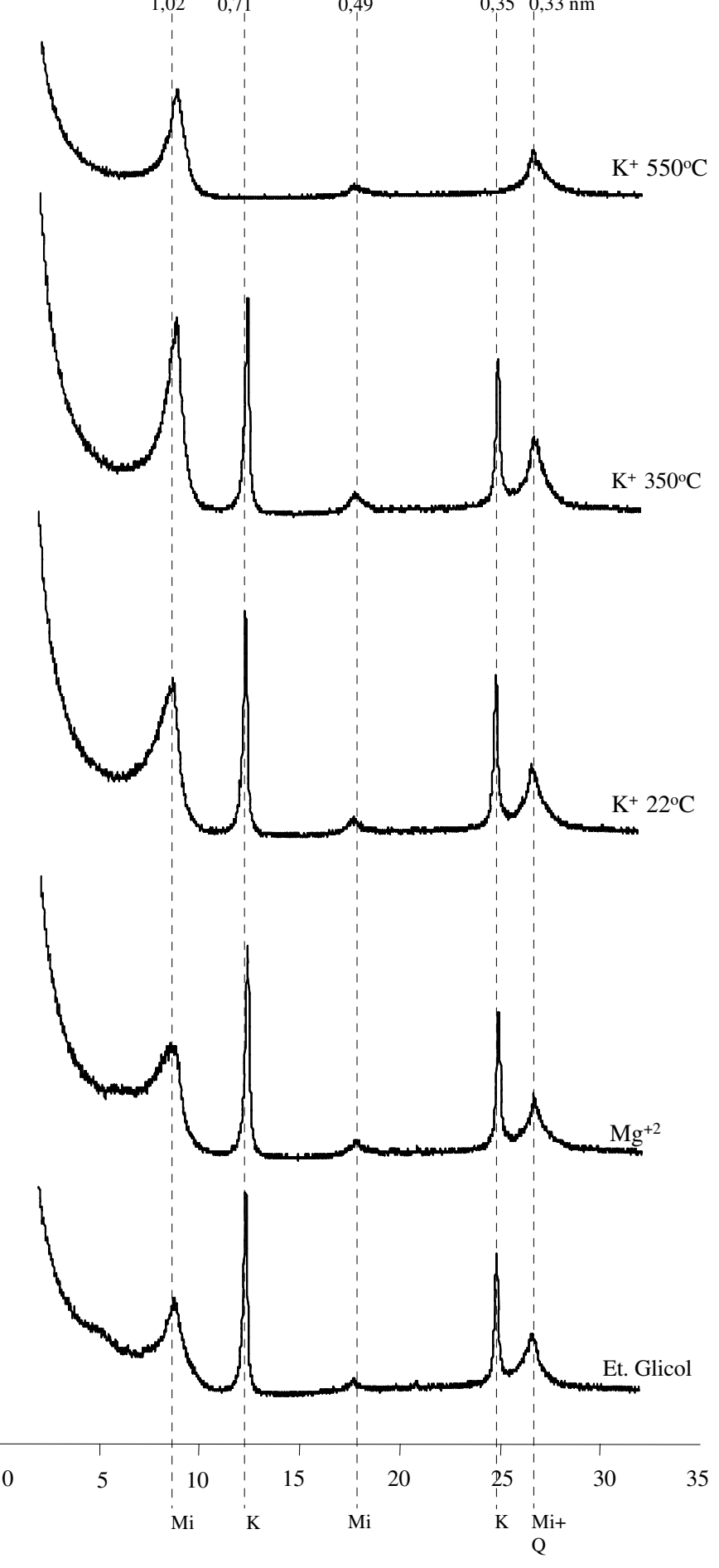

Argila Grossa

$\begin{array}{lllllll}1,00 & 0,71 & 0,50 & 0,42 & 0,400,35 & 0,33 & 0,32 \mathrm{~nm}\end{array}$
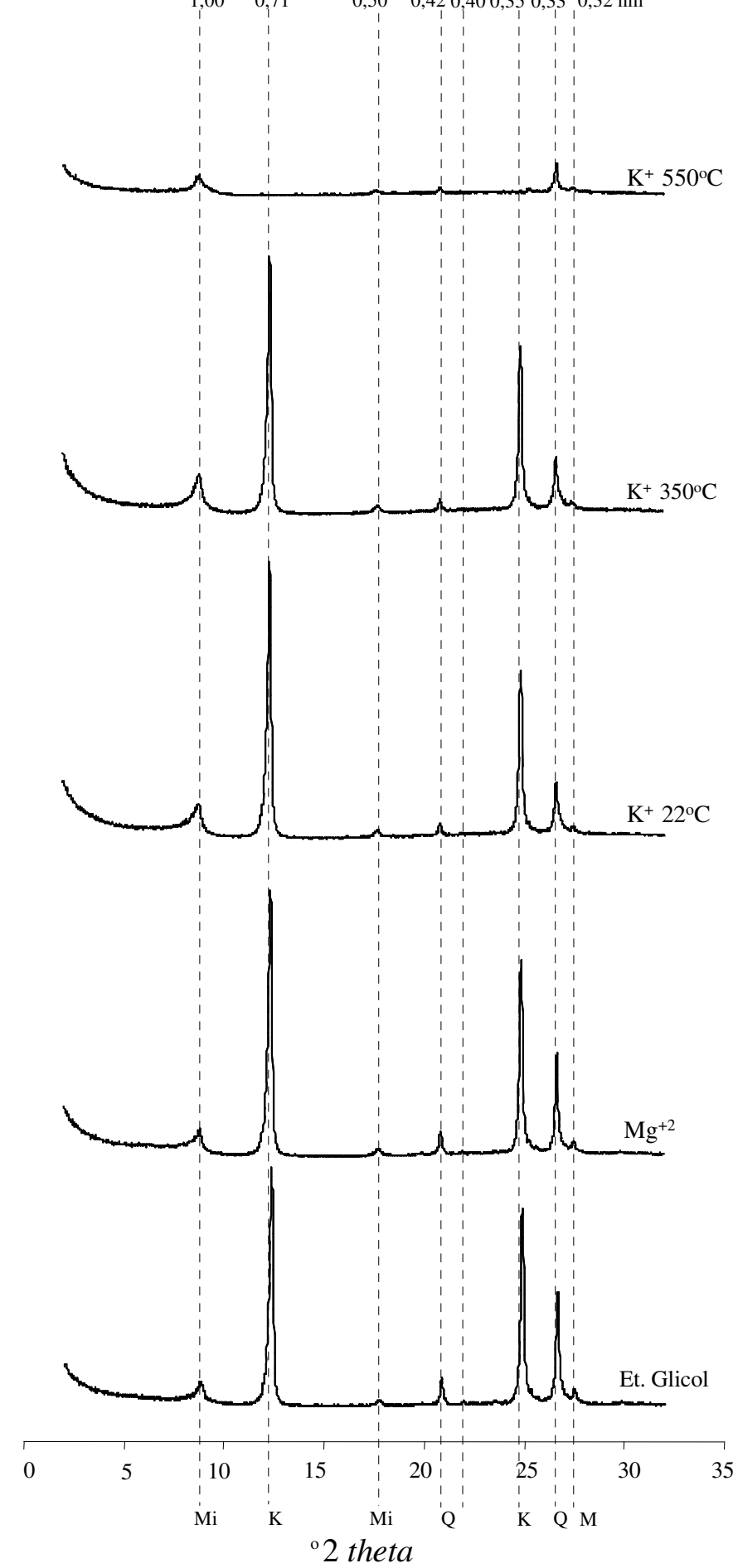

Silte Fino

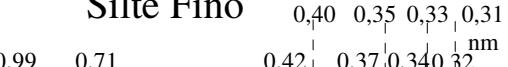

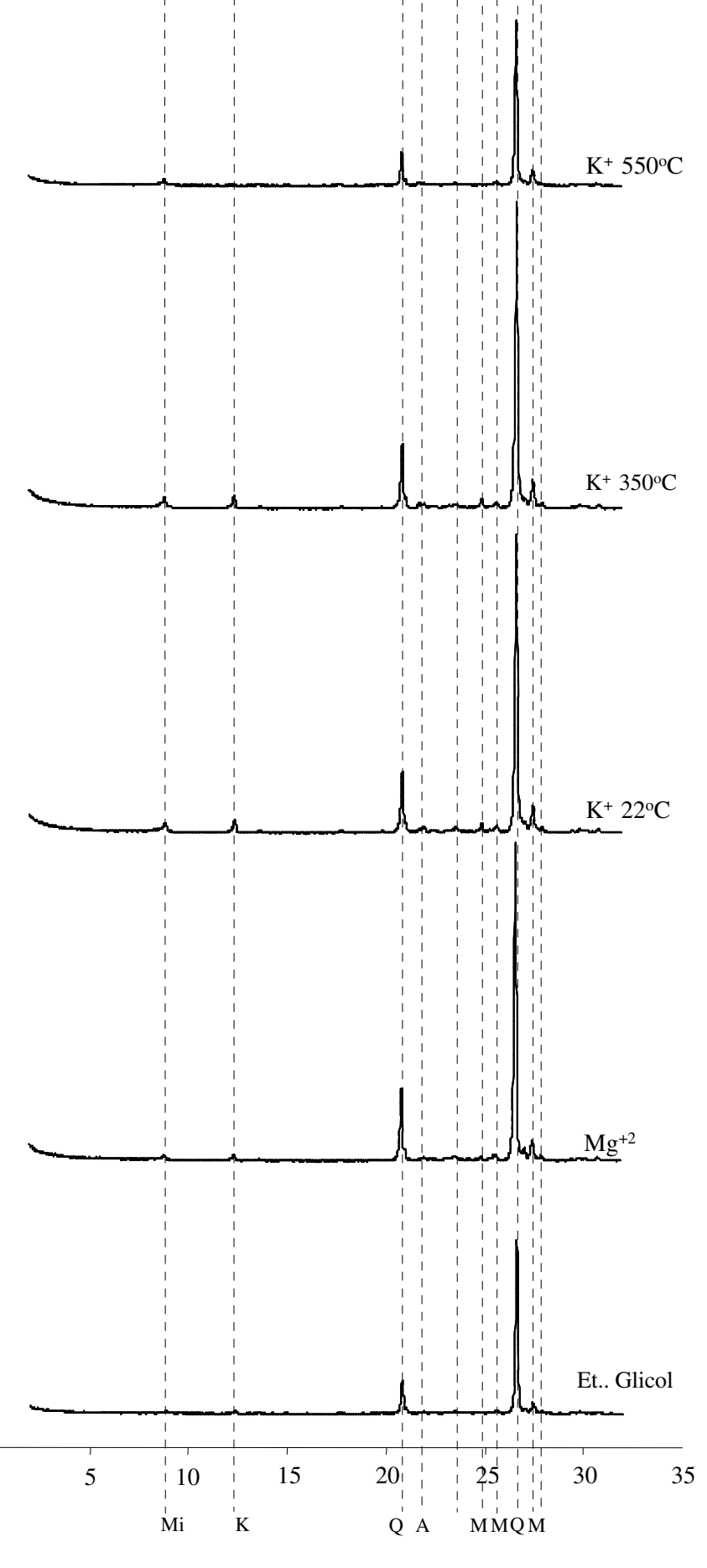




\section{P3 - horizonte 6}

Argila Fina

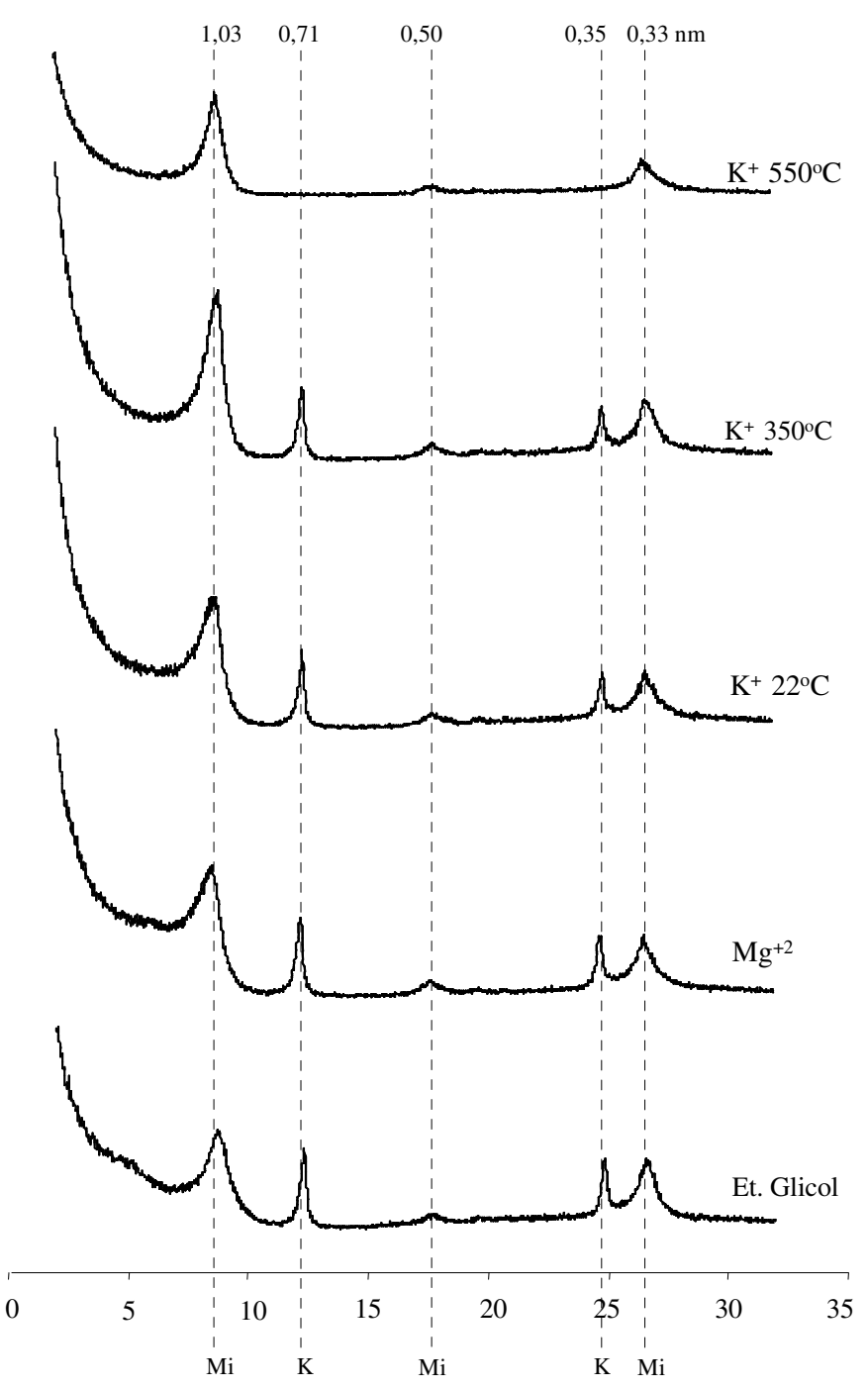

Argila Grossa

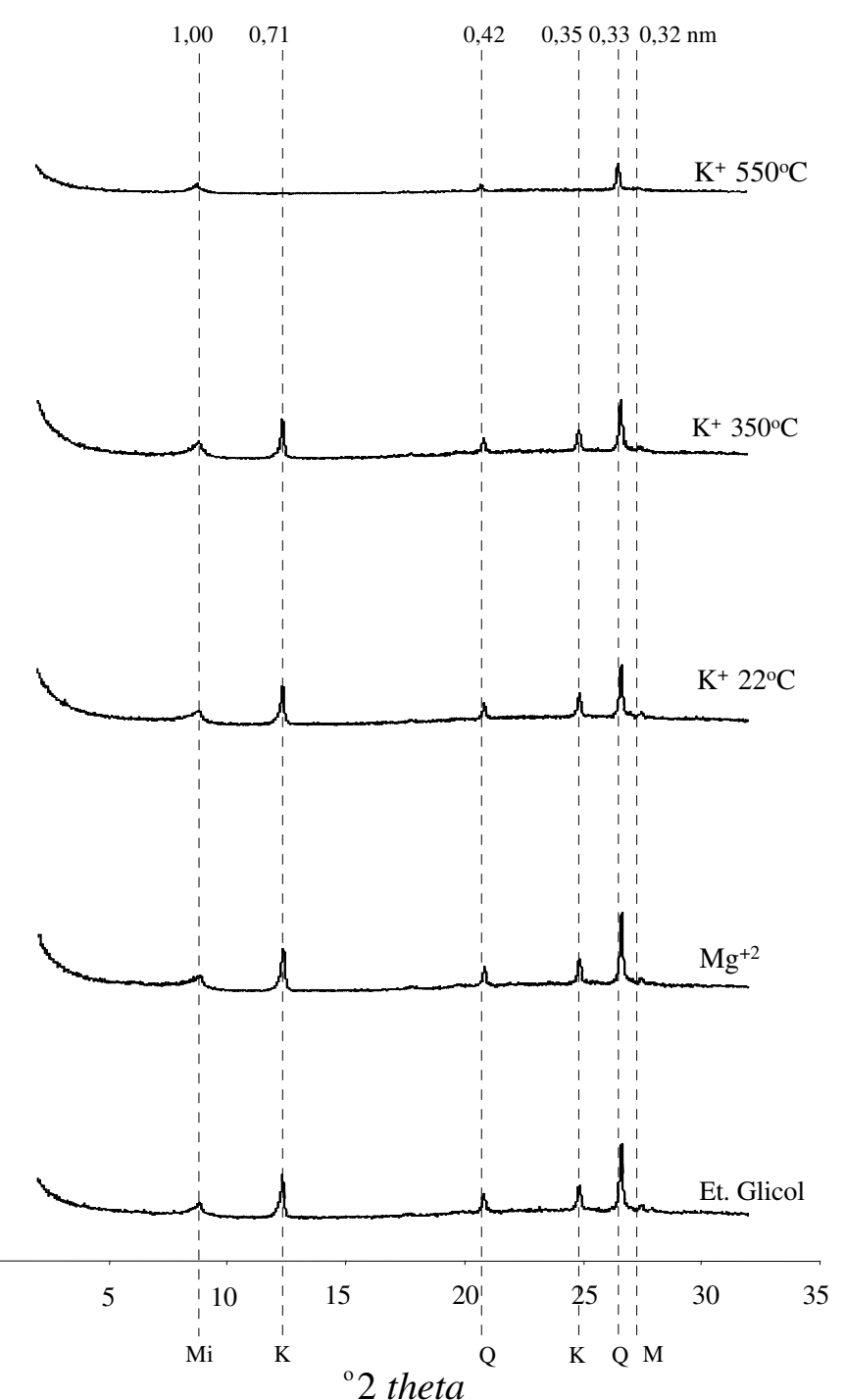

Silte Fino

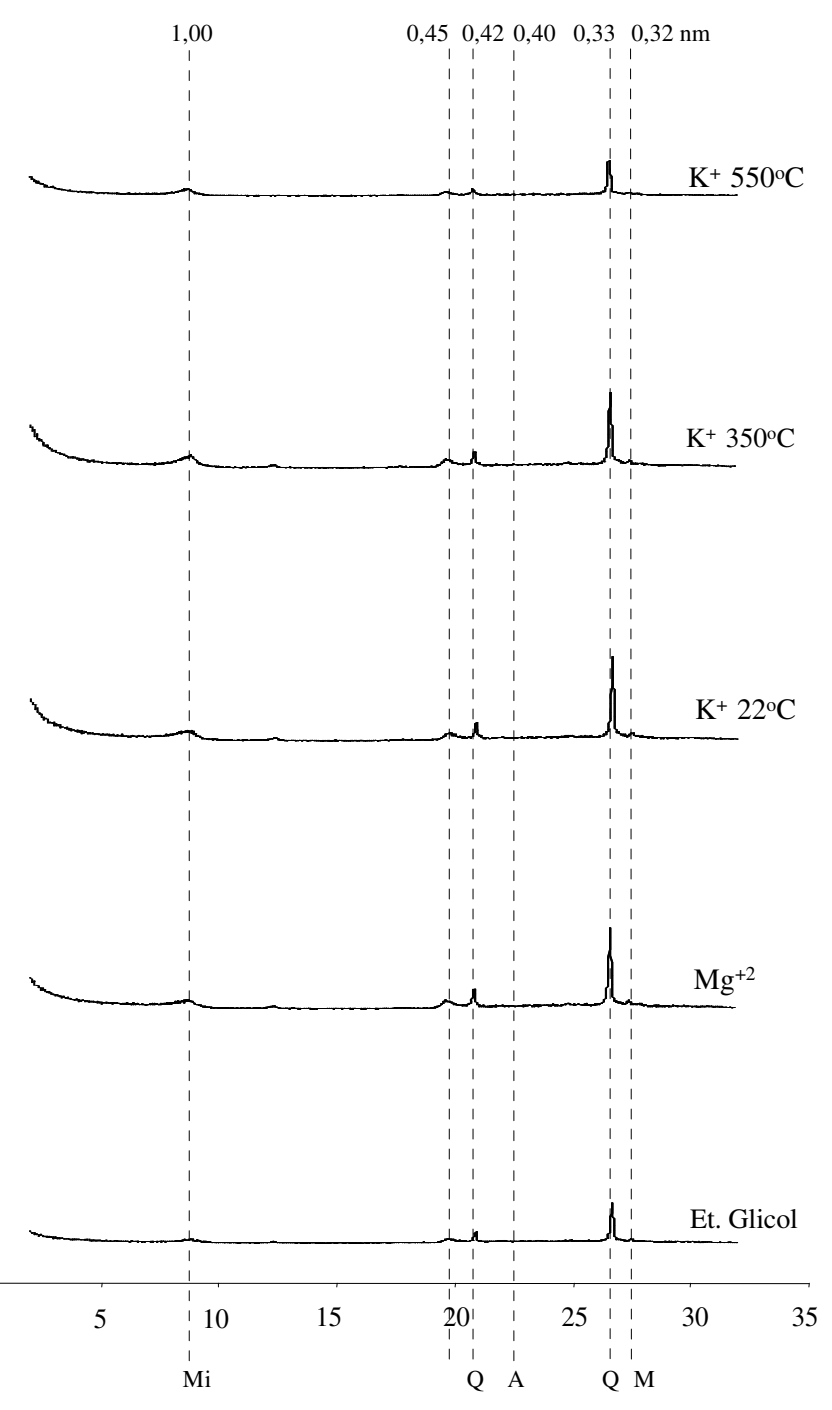




\section{P4 - horizonte 2}

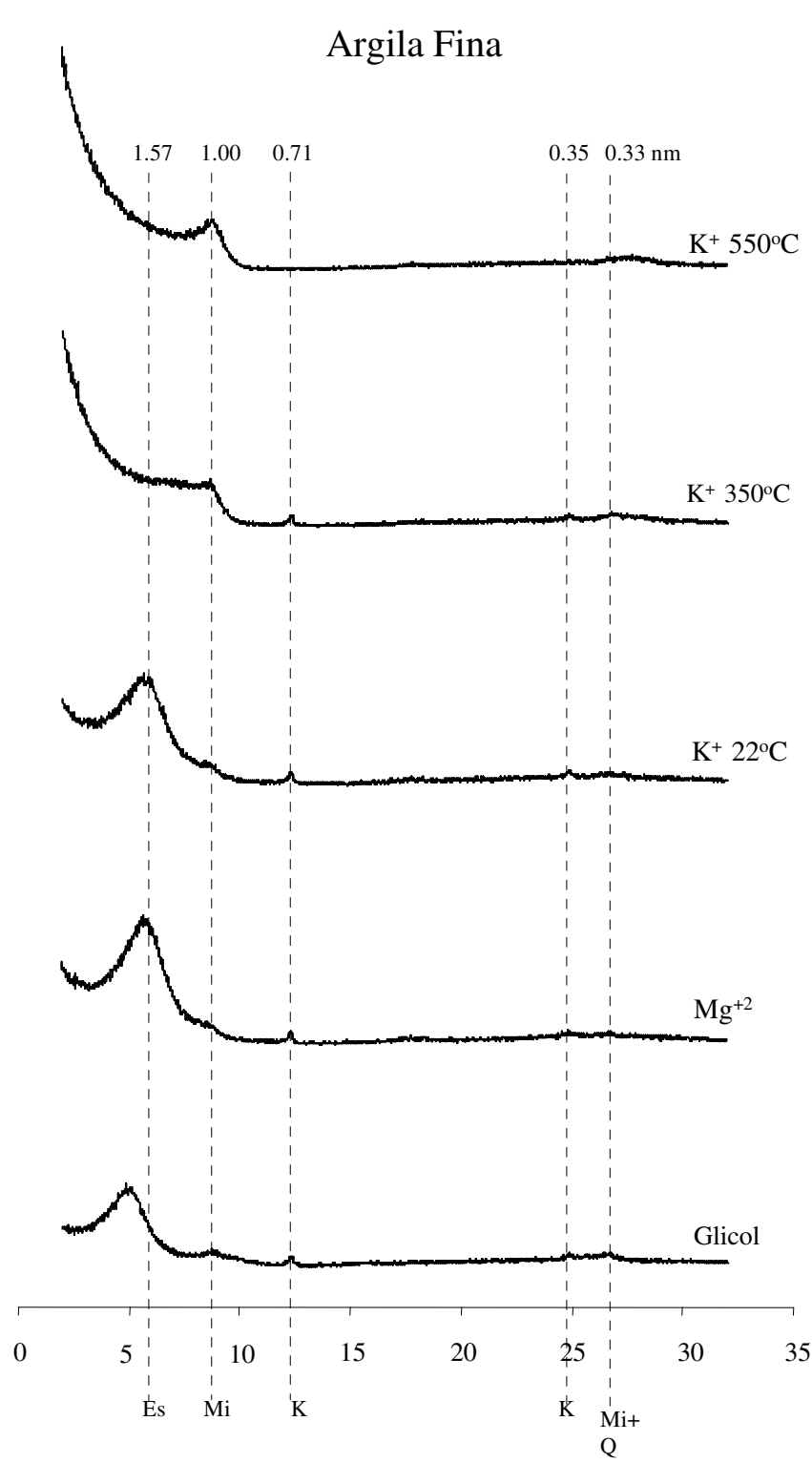

Argila Grossa

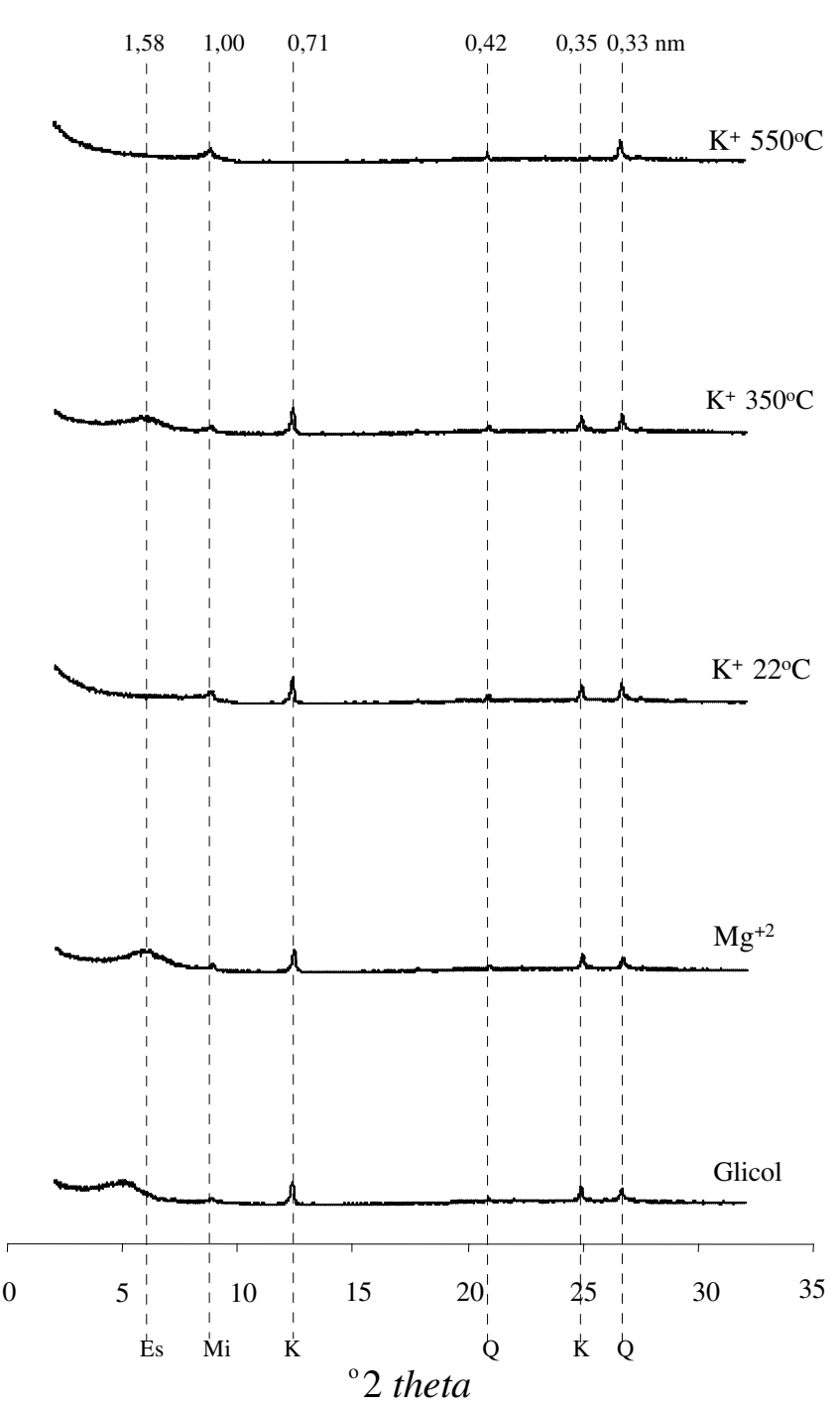

Silte Fino

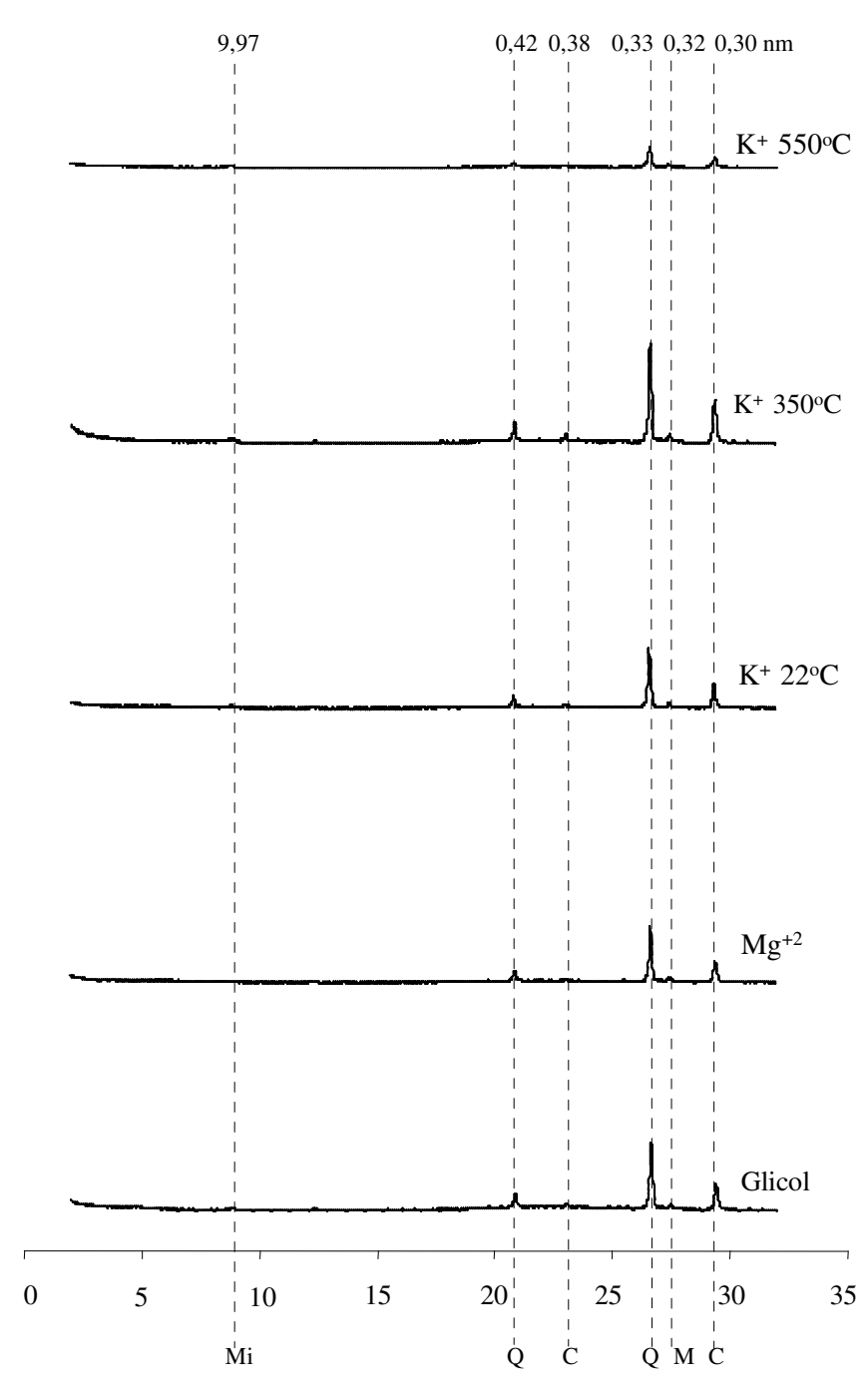



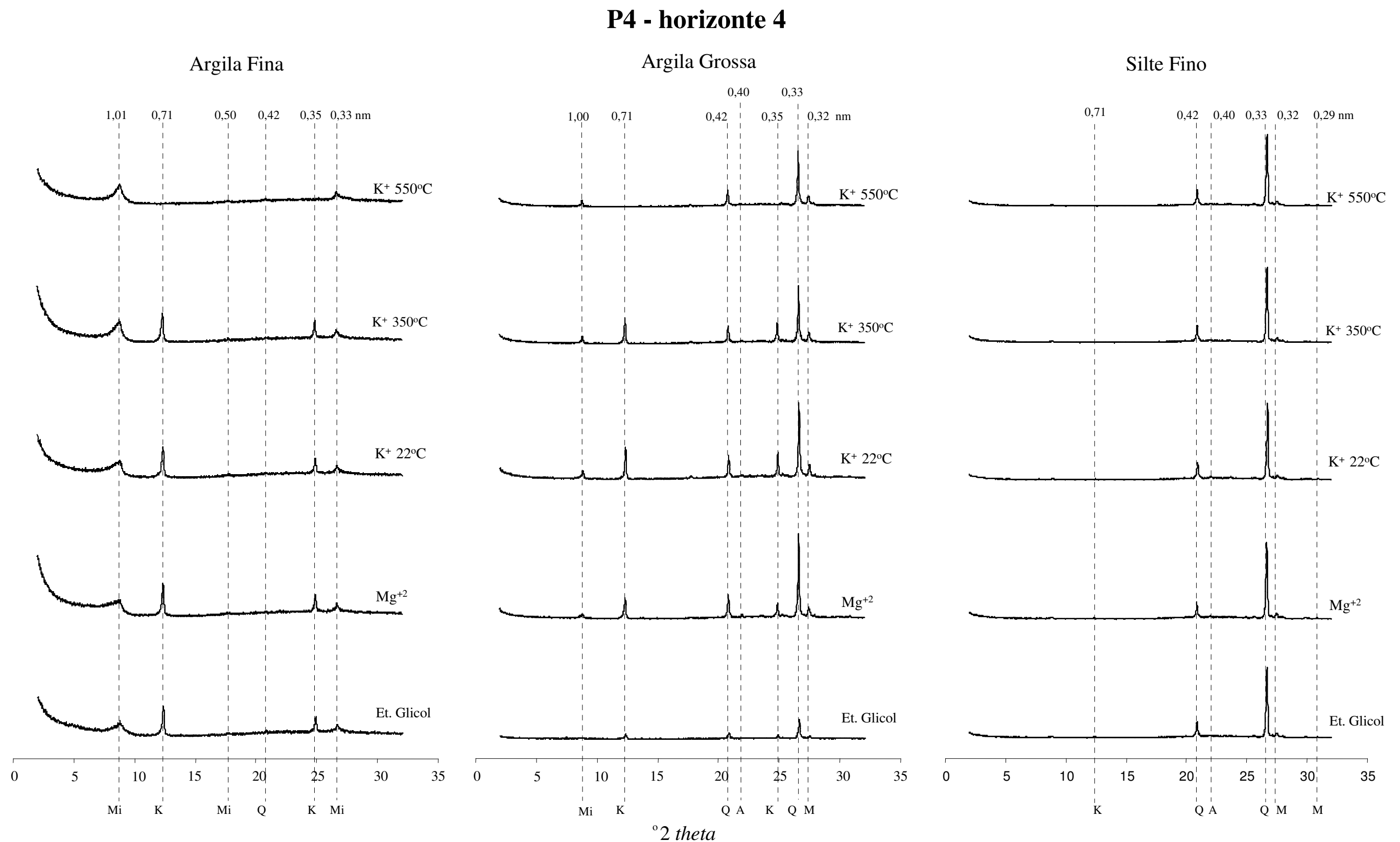


\section{P4 - horizonte 5}

Argila Fina

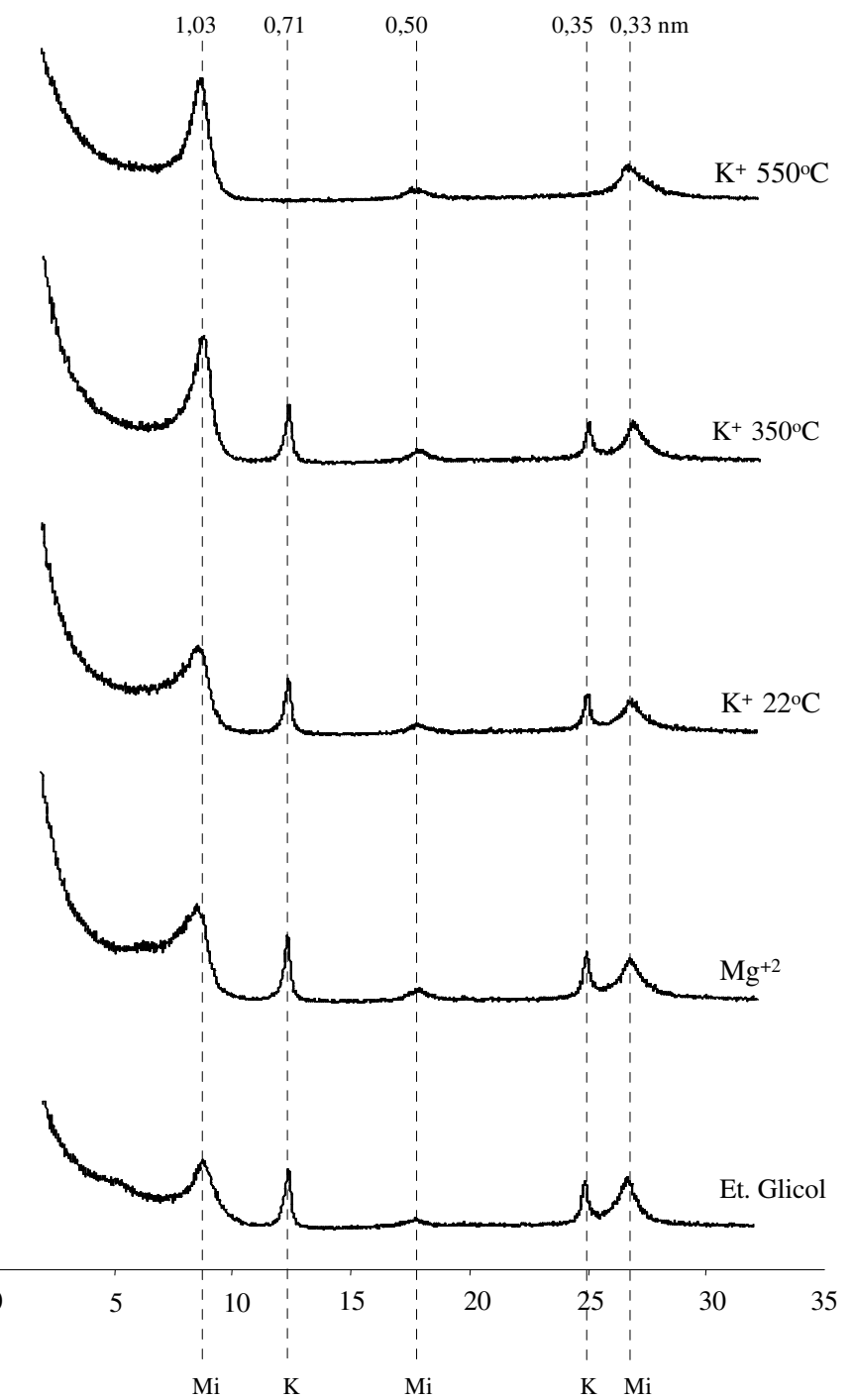

Argila Grossa

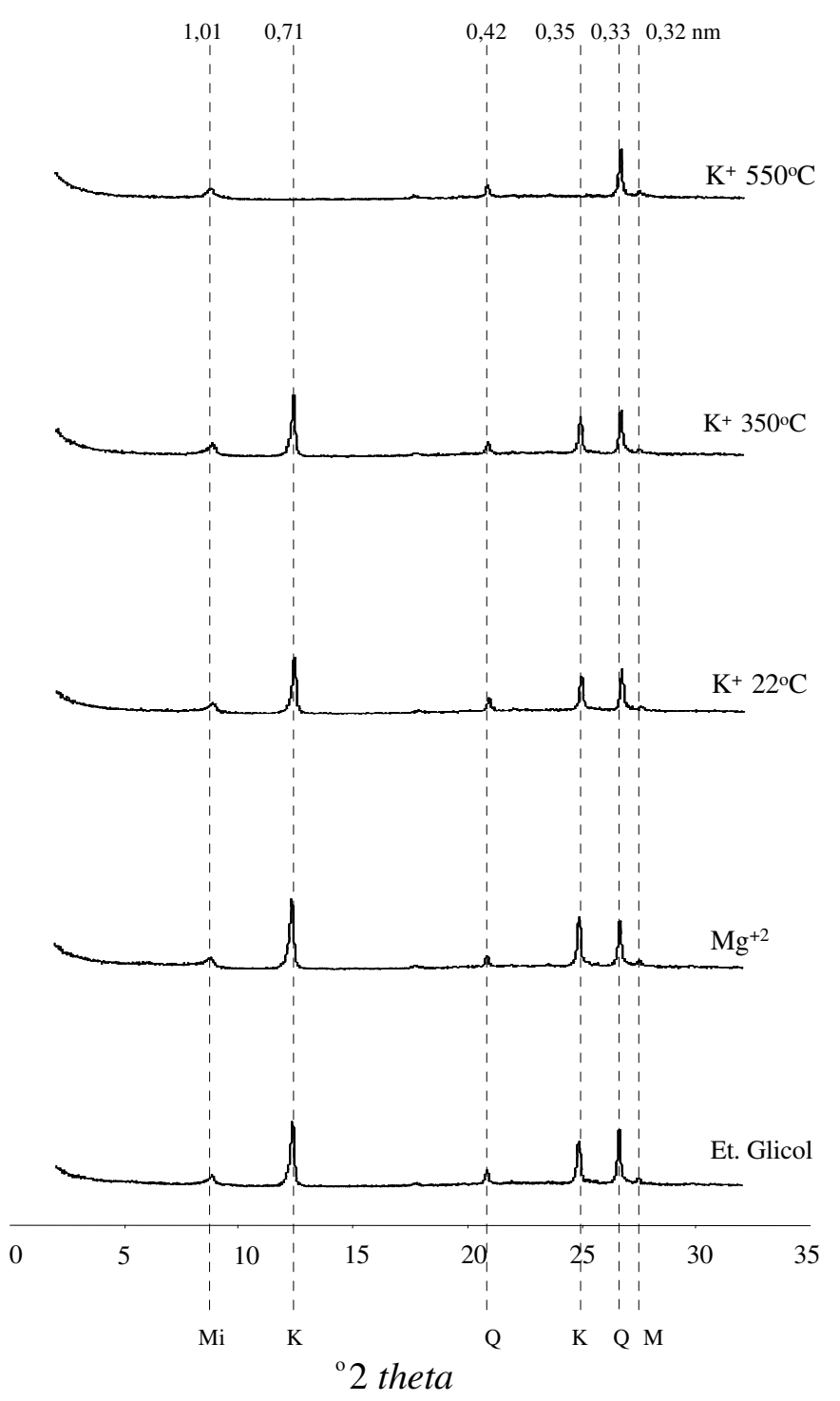

Silte Fino

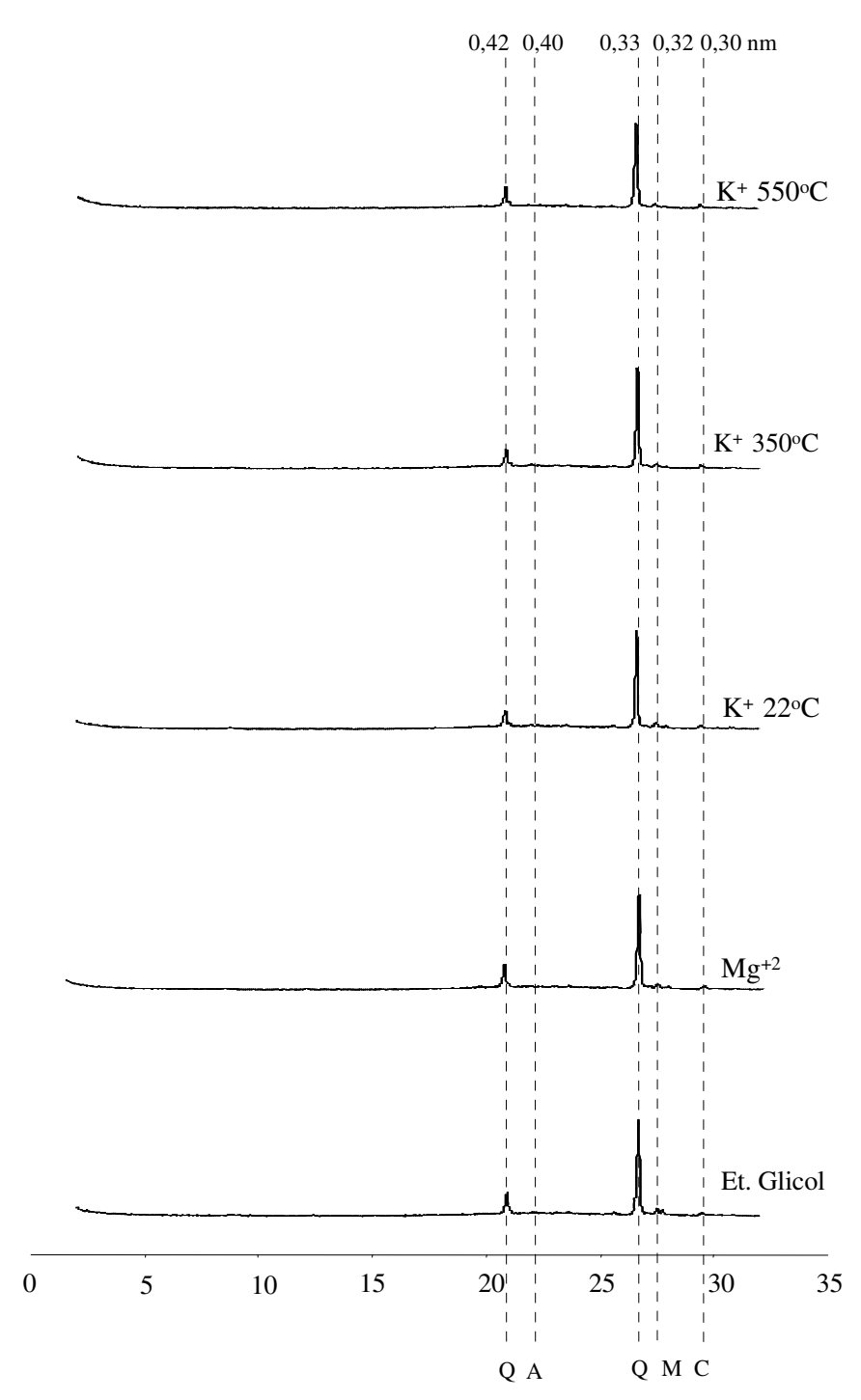




\section{P4 - horizonte 6}

Argila Fina

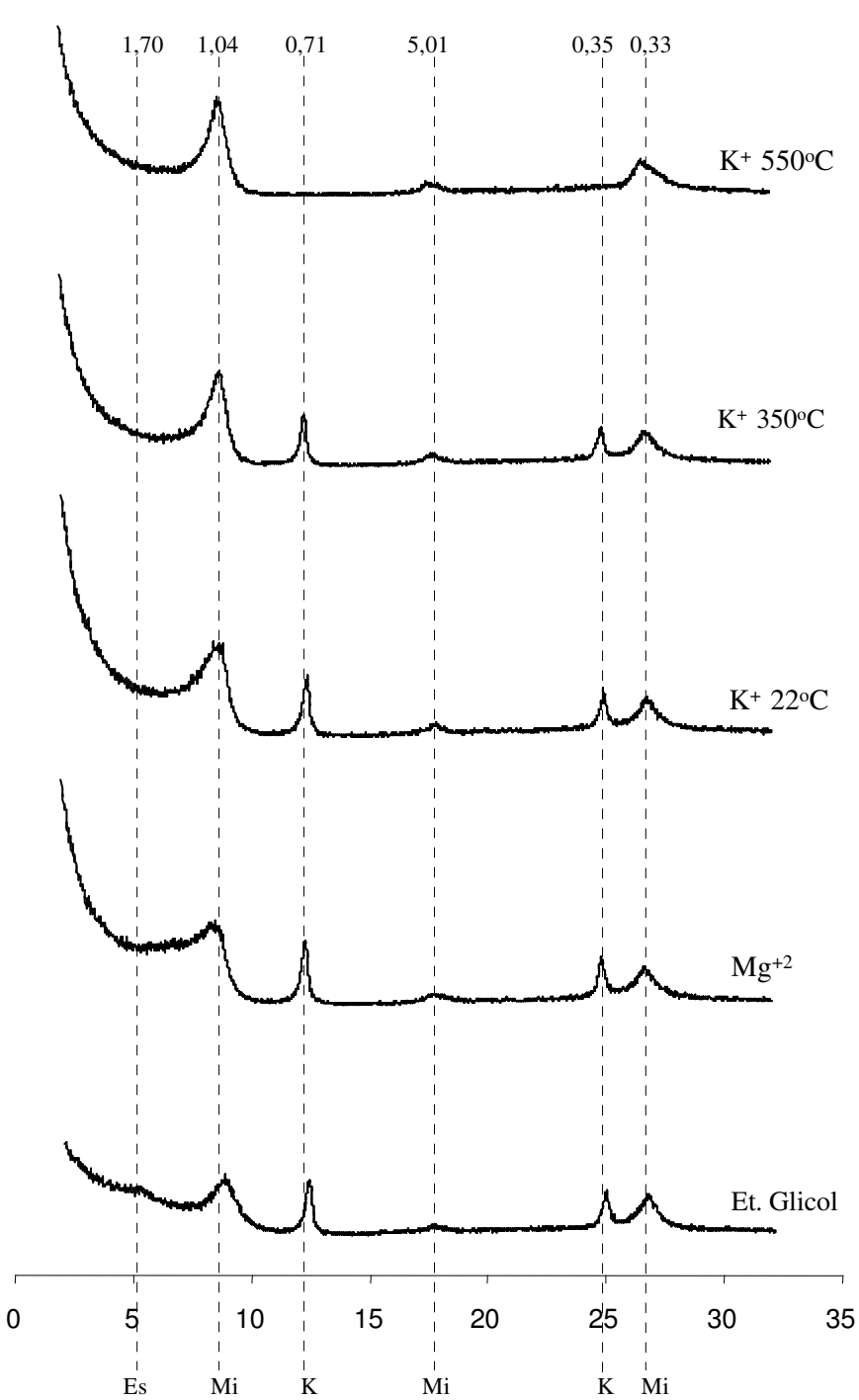

Argila Grossa

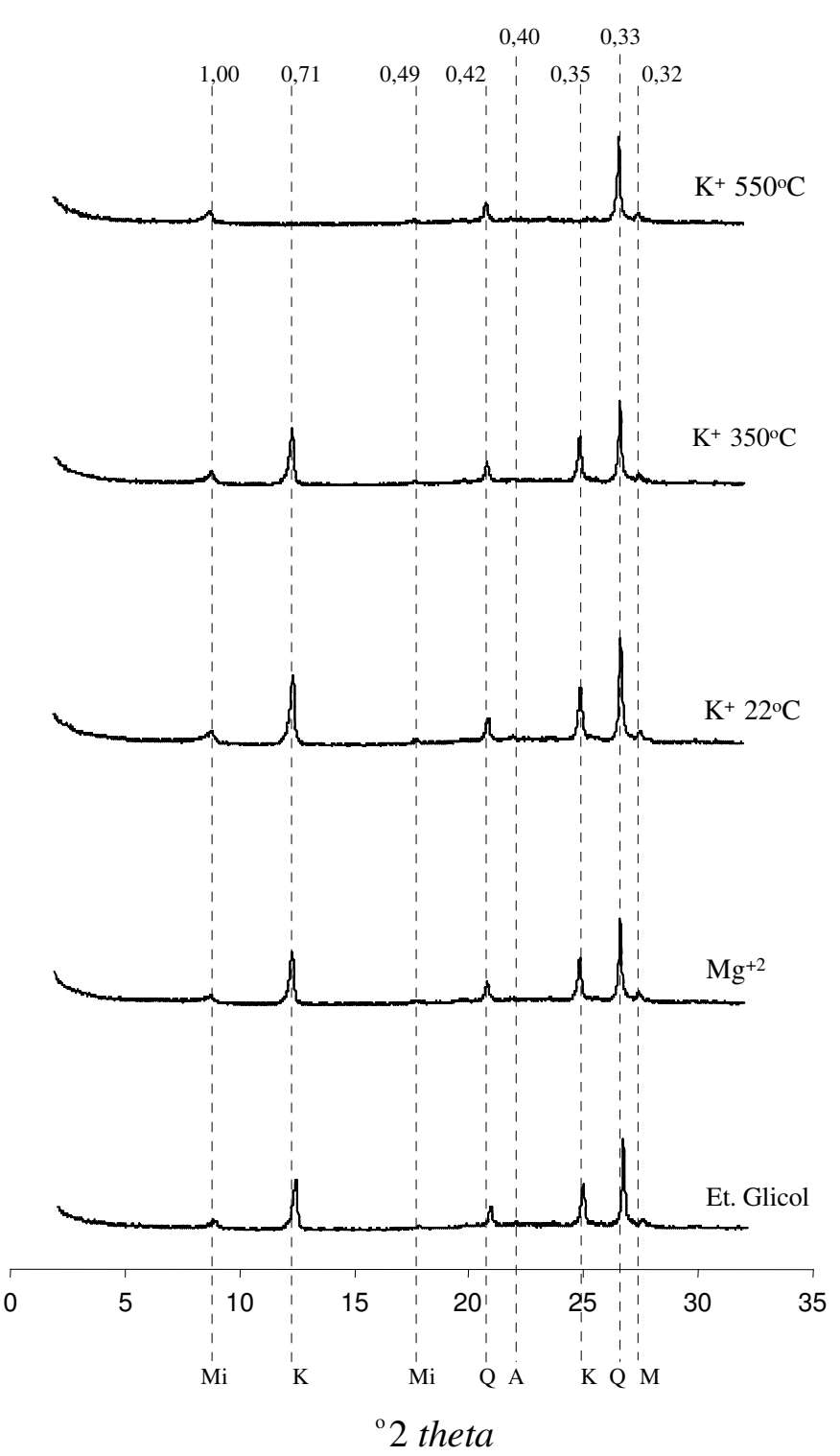

Silte Fino

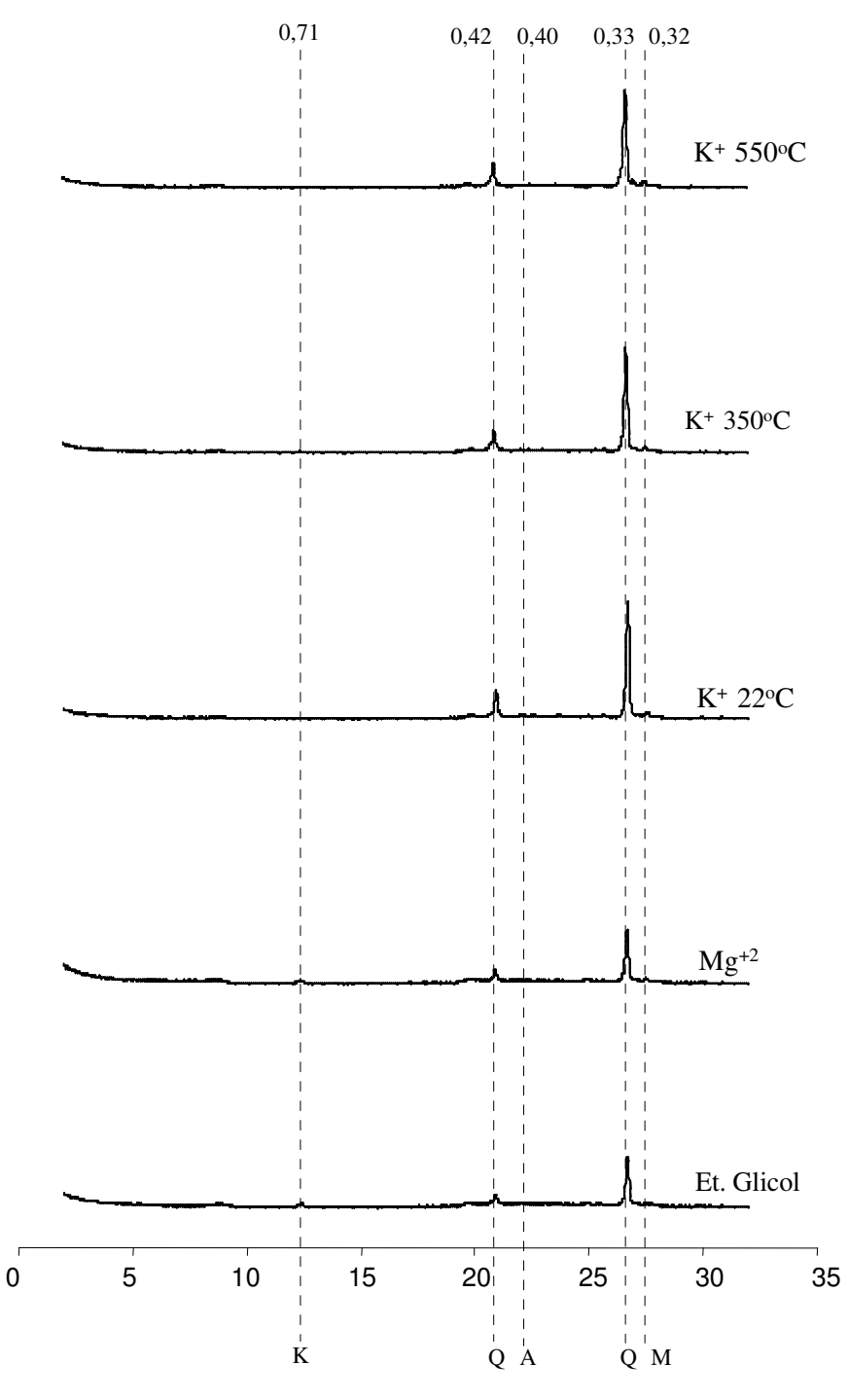


P5 - horizonte 2

Argila Fina

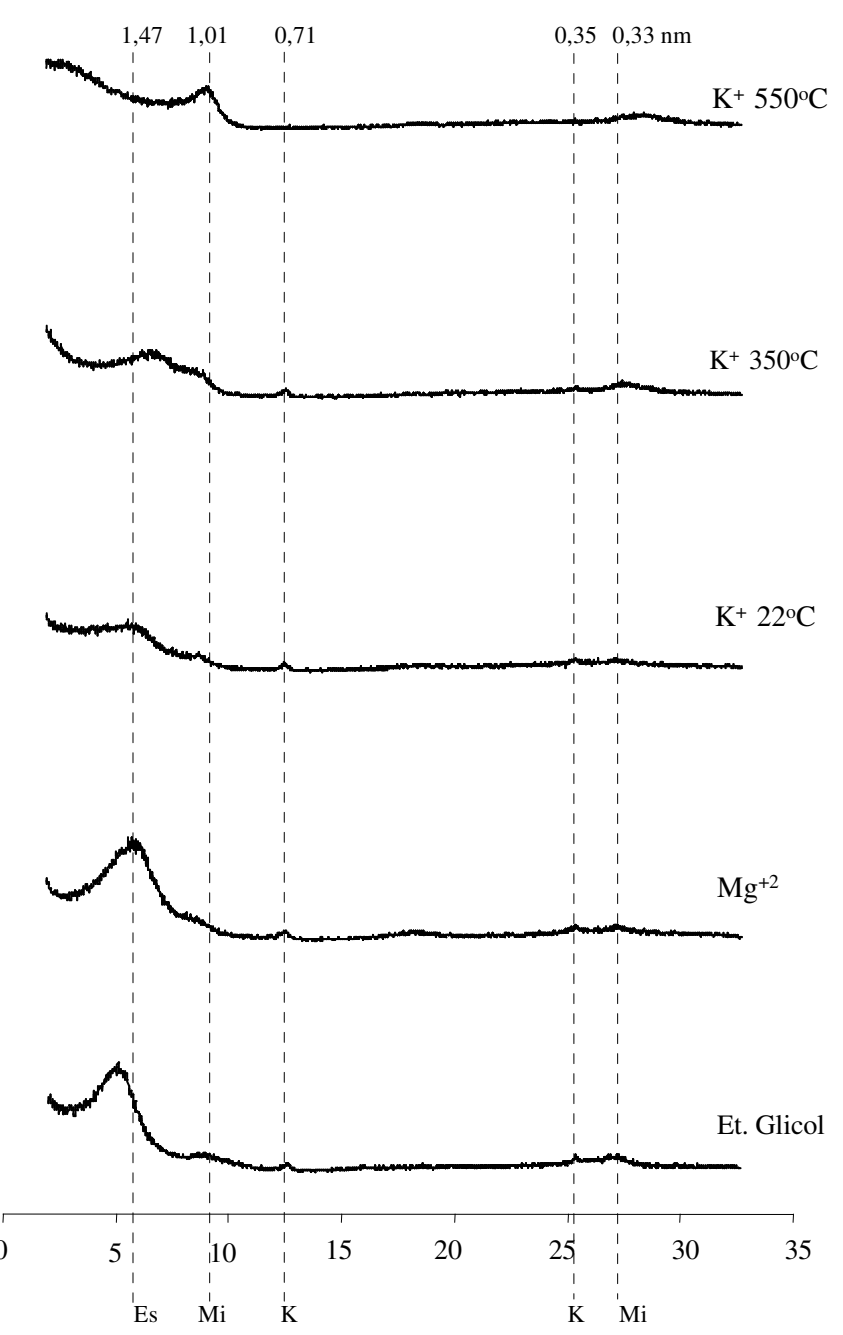

Argila Grossa

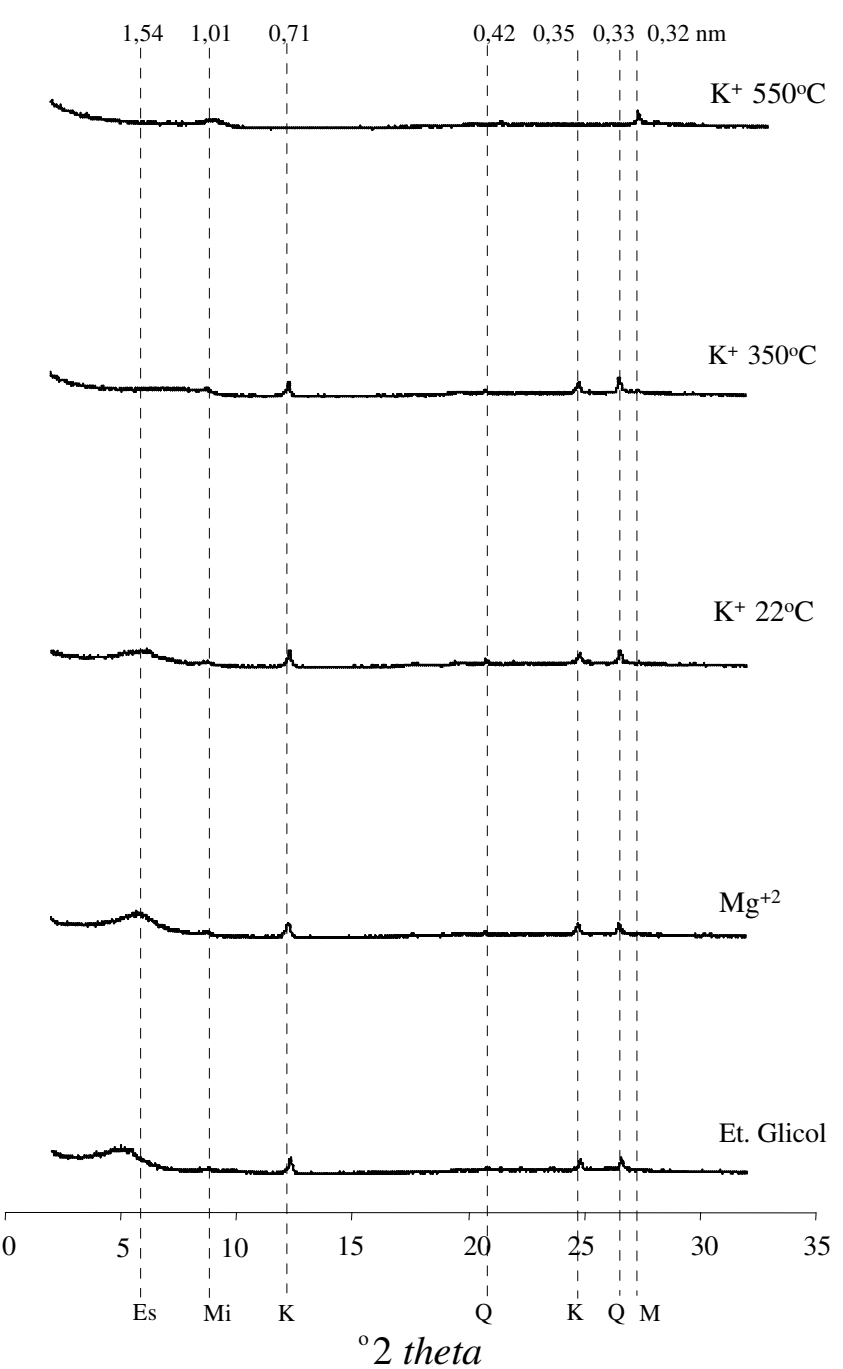

Silte Fino

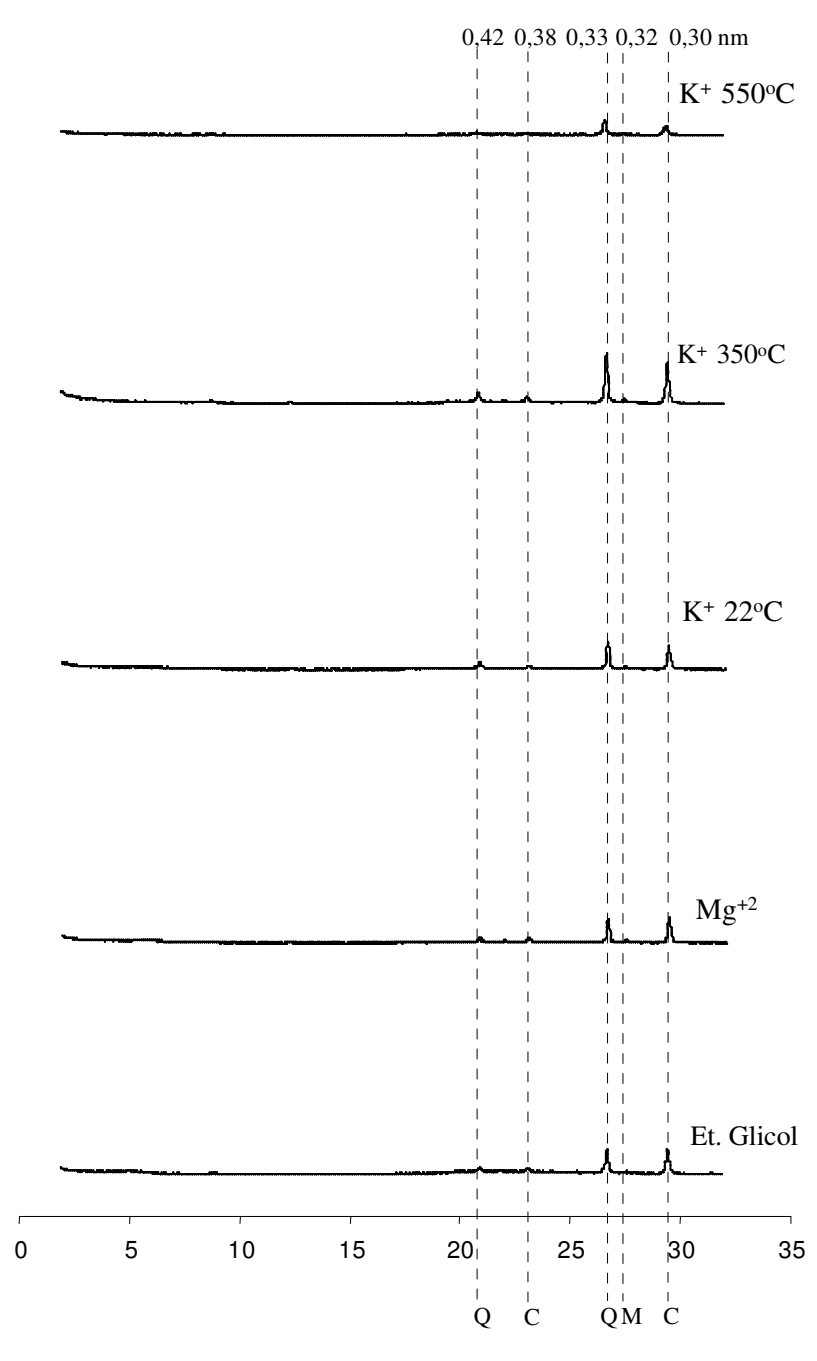




\section{P5 - horizonte 4}

Argila Fina

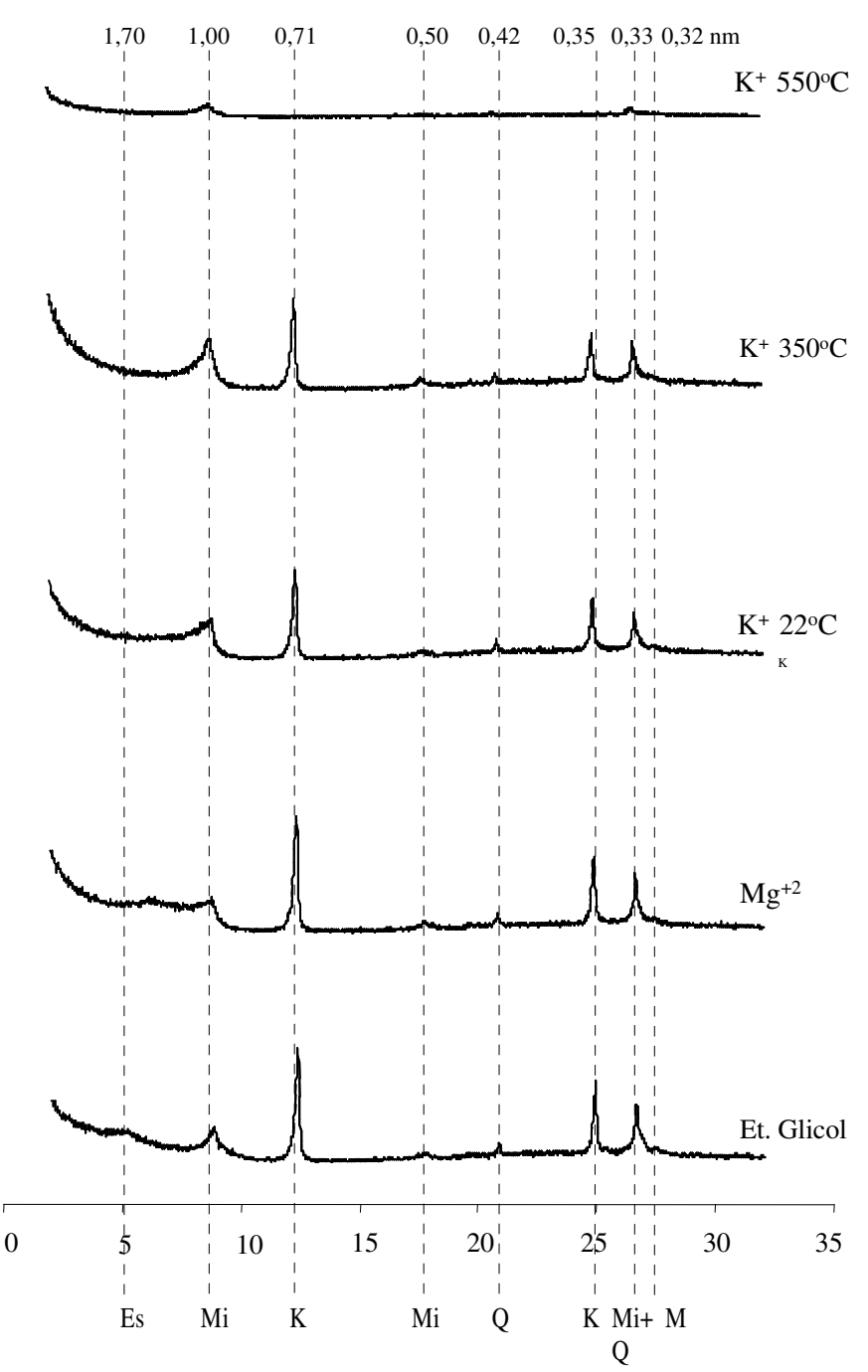

Argila Grossa

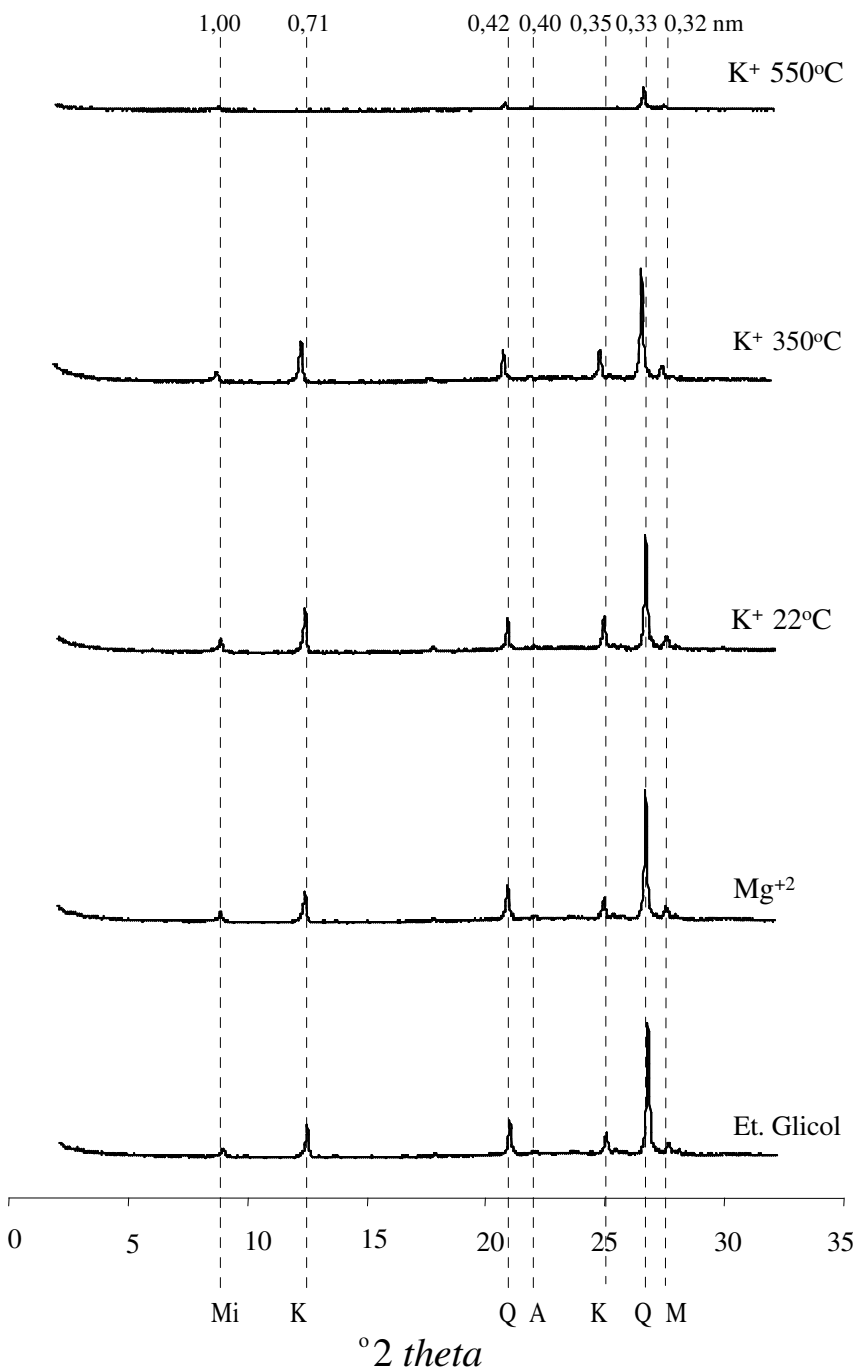

Silte Fino

$\begin{array}{llllll}0,42 & 0,40 & 0,33 & 0,32 & 0,28 & \mathrm{~nm}\end{array}$

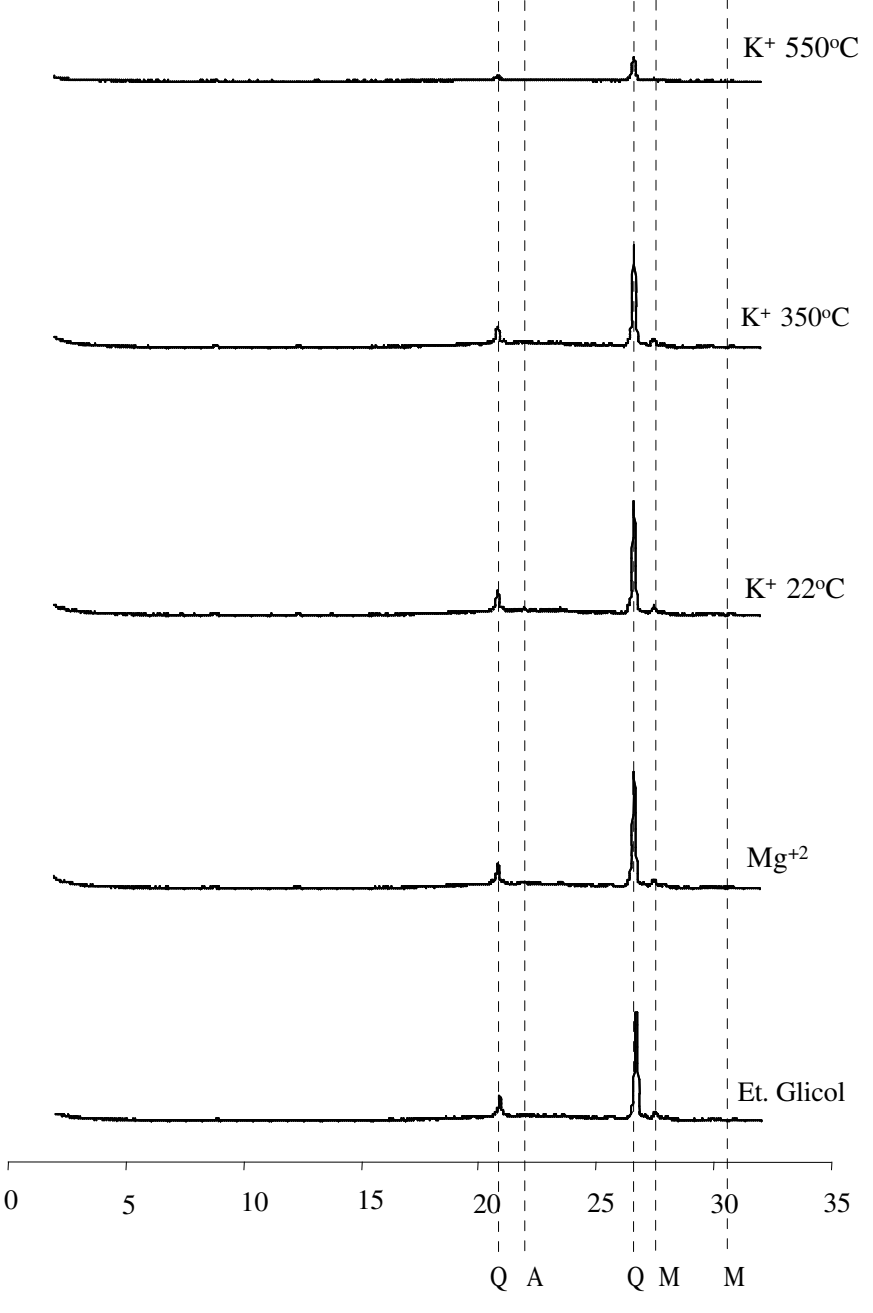




\section{P5 - Horizonte 5}

\section{Argila Fina}

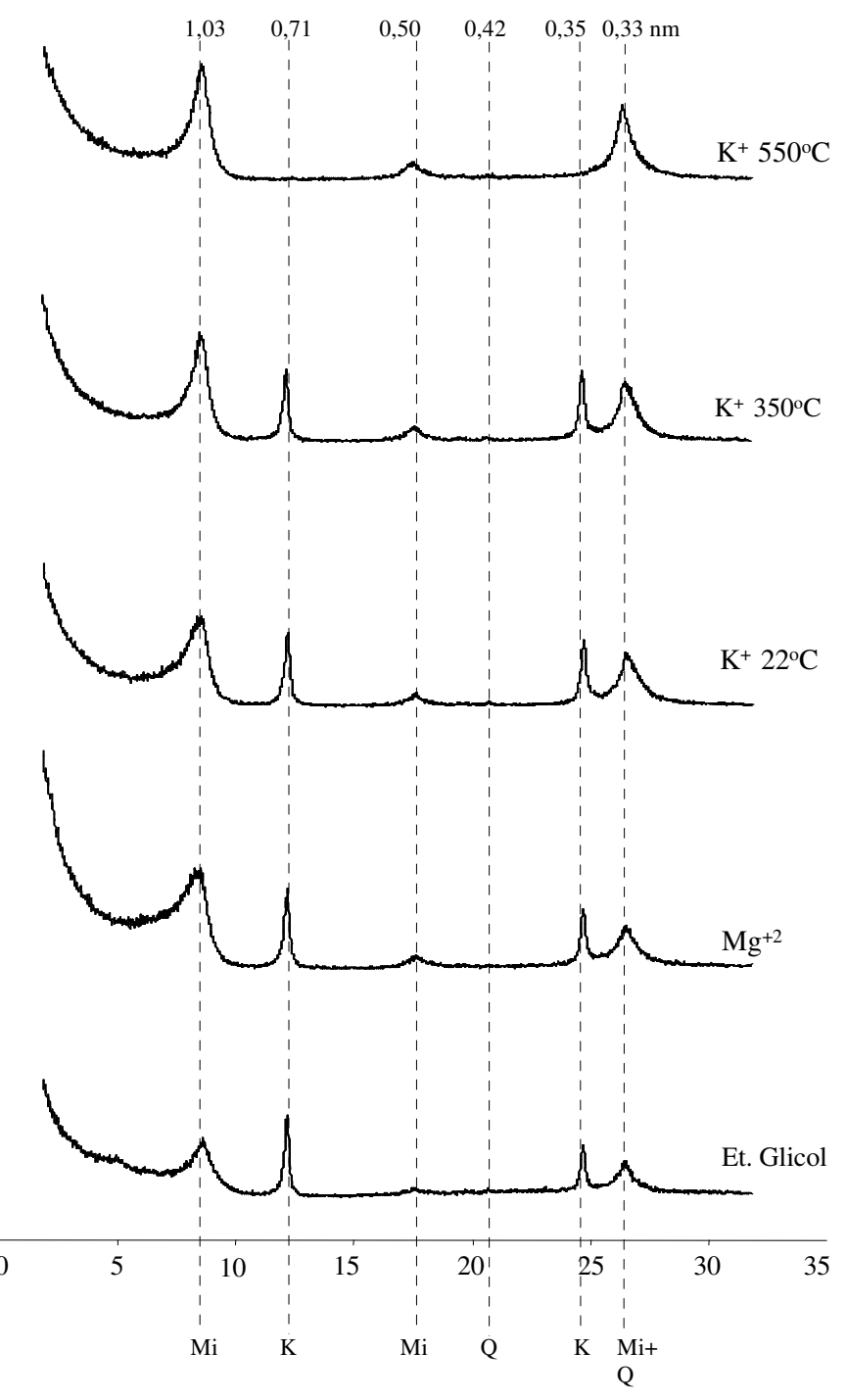

Argila Grossa

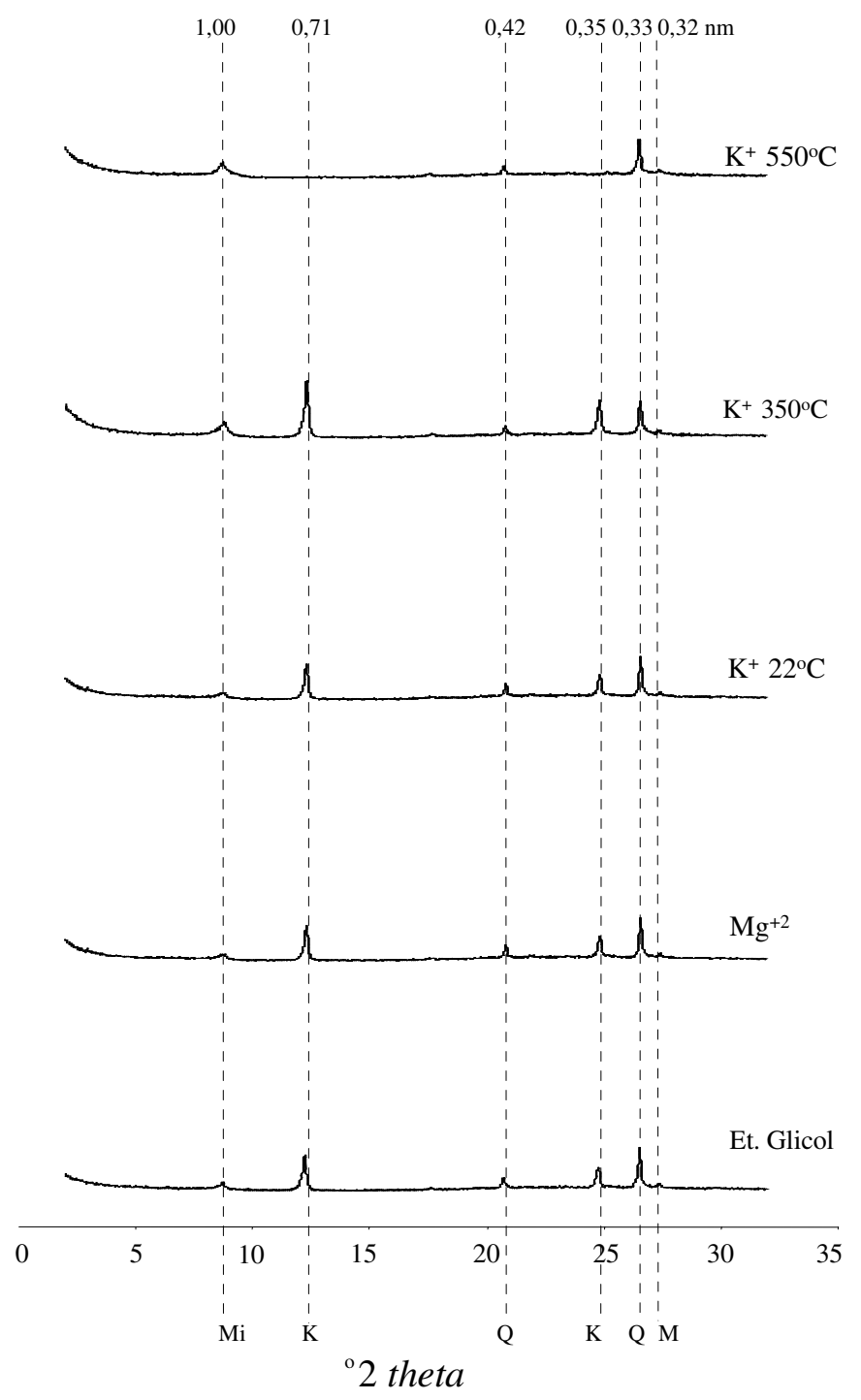

Silte Fino

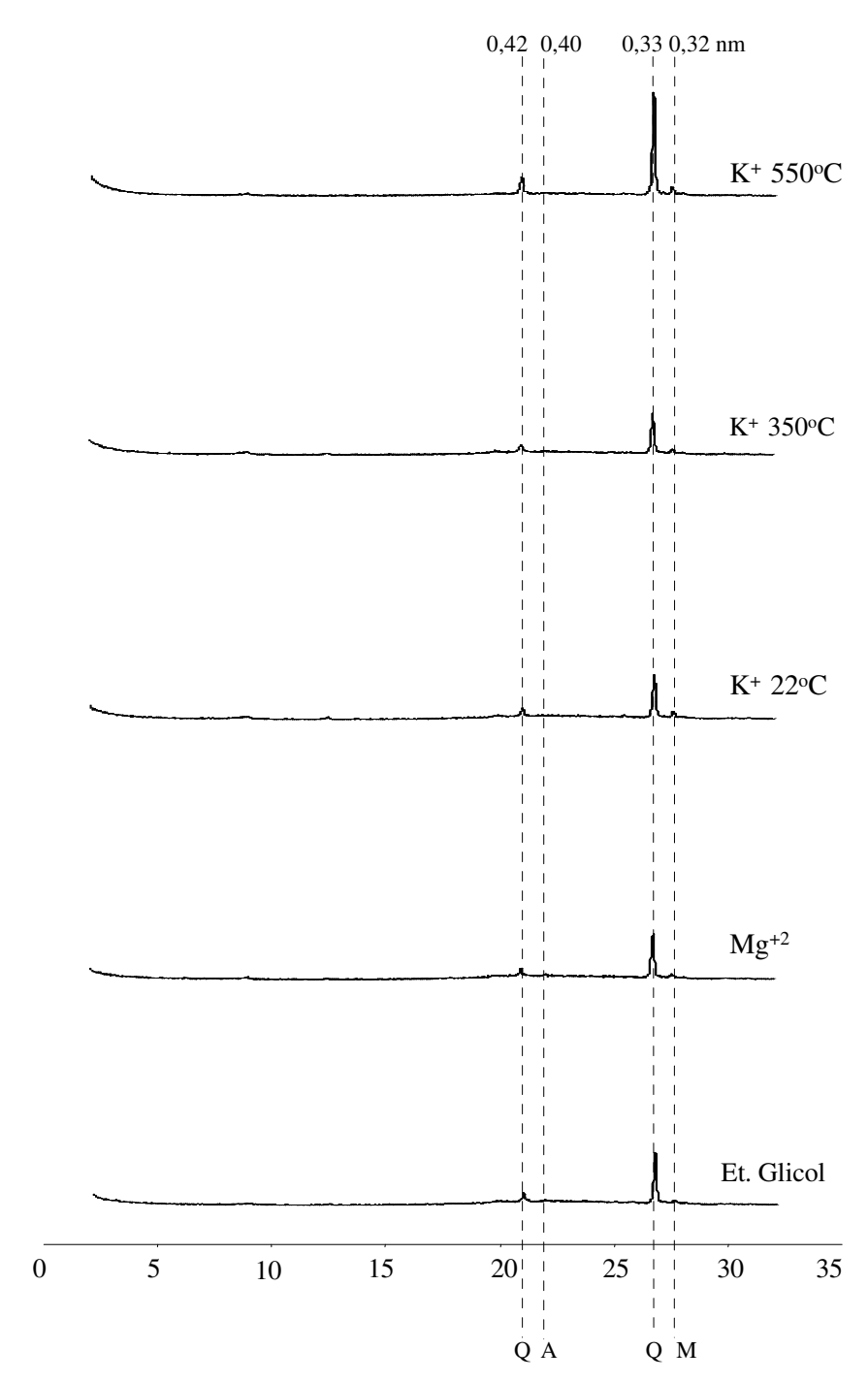




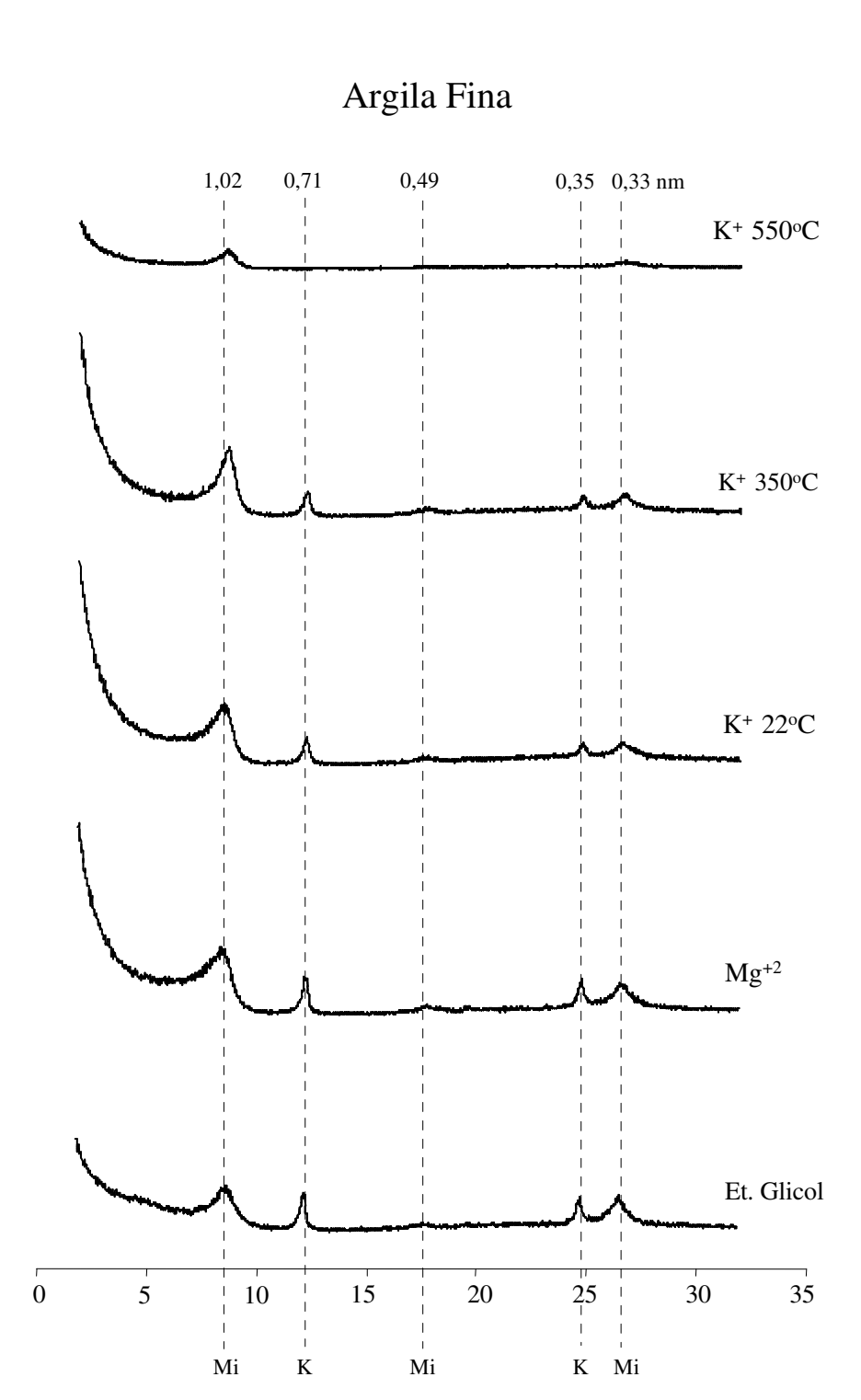

P5 - horizonte 6

\section{Argila Grossa}

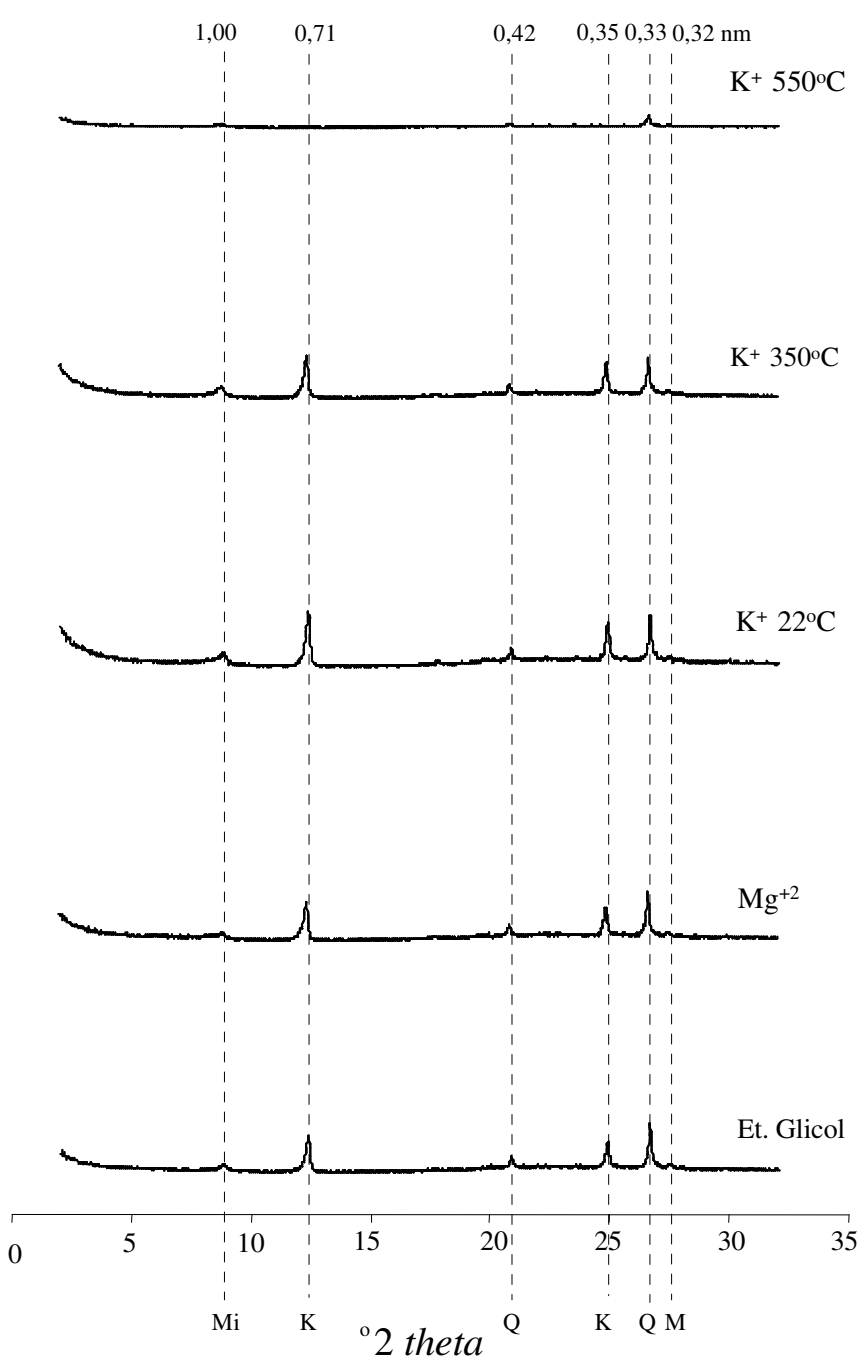

Silte Fino

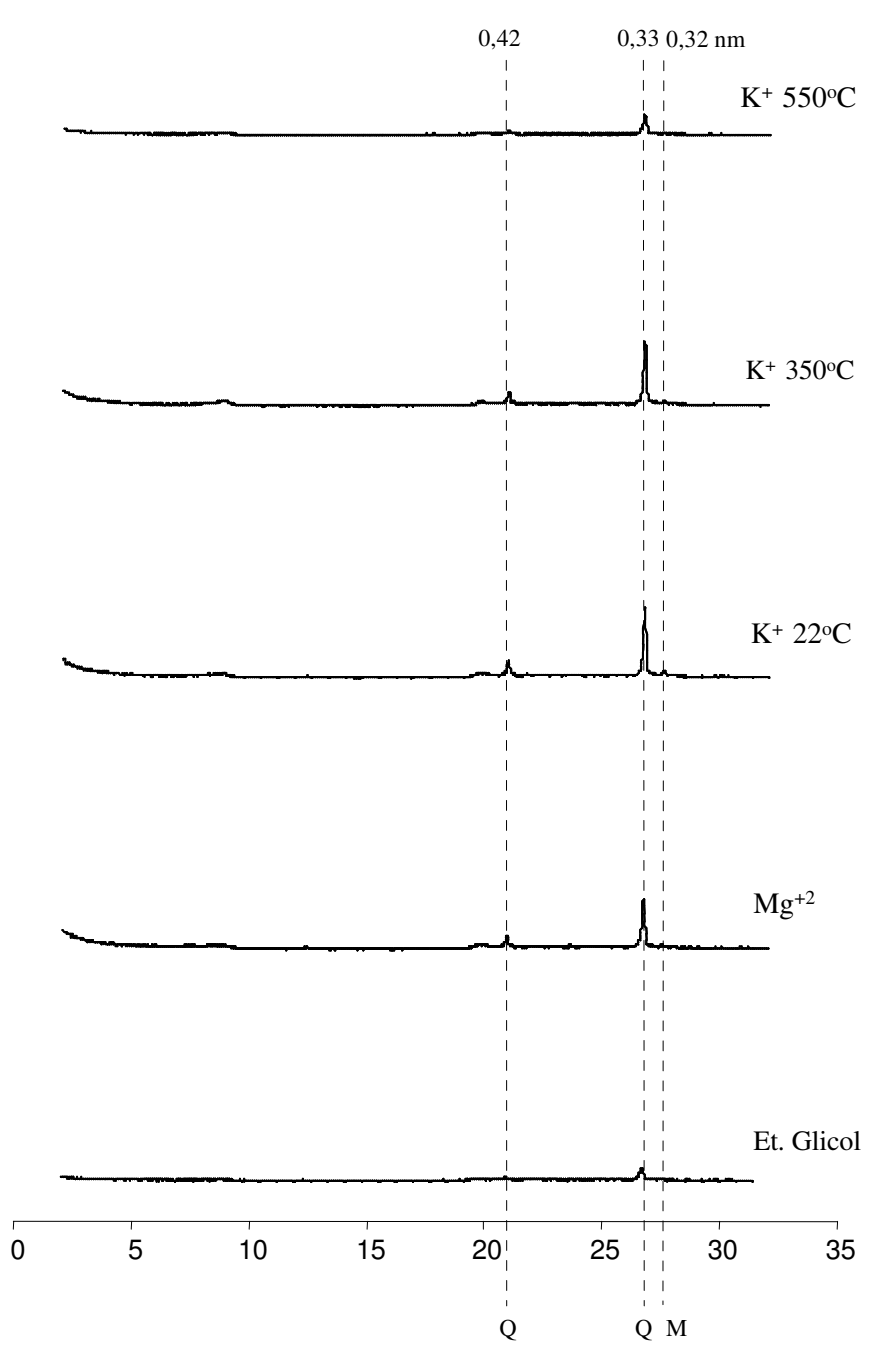

